\title{
MOMENTOS FLETORES NEGATIVOS NOS APOIOS DE LAJES FORMADAS POR VIGOTAS DE CONCRETO PROTENDIDO
}

\section{Eng. Andrei José Merlin}

Dissertação apresentada à Escola de Engenharia de São Carlos da Universidade de São Paulo, como parte dos requisitos para obtenção do título de Mestre em Engenharia de Estruturas.

ORIENTADOR: Mounir Khalil El Debs 
Aos meus pais Natalino e Filomena 


\section{AGRADECIMENTOS}

Ao professor Mounir Khalil El Debs pela dedicação, compressão e orientação prestadas na elaboração deste trabalho.

Aos professores João Bento de Hanai e Roberto Chust Carvalho pelas sugestões dadas ao trabalho.

À bibliotecária Nadir e à secretária Rosi.

Aos demais professores e funcionários e colegas do Departamento de Estruturas da EESC/USP pela colaboração.

À Coordenadoria de Aperfeiçoamento de Pessoal de Nível Superior CAPES, pela bolsa de estudo concedida. 


\section{SUMÁRIO}

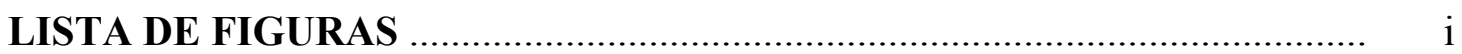

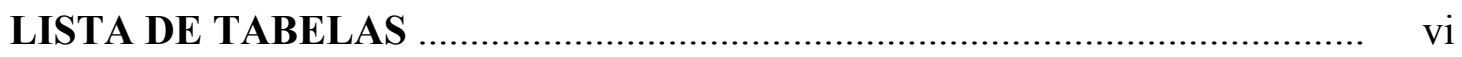

LISTA DE SÍMBOLOS E SIGLAS …...................................................... viii

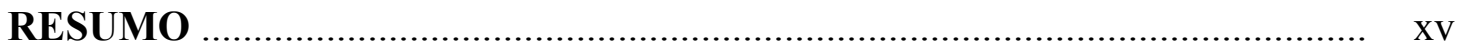

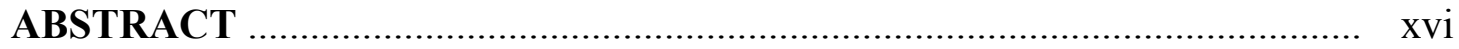

\section{CAPÍTULO 1: INTRODUÇÃO}

1.1 Considerações iniciais ...................................................................... 1

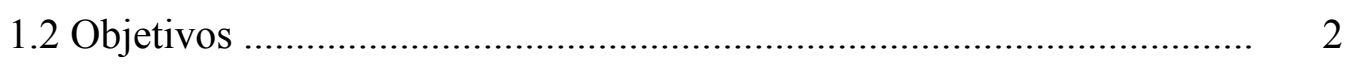

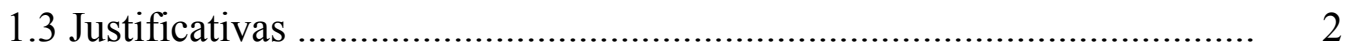

1.4 Metodologia ...................................................................................... 3

1.5 Apresentação do trabalho ......................................................................... 3

\section{CAPÍTULO 2: LAJES FORMADAS POR VIGOTAS PRÉ-MOLDADAS}

2.1 Considerações iniciais ....................................................................... 5

2.2 Lajes nervuradas formadas por vigotas pré-moldadas protendidas ........ 8

2.3 Indicações para o projeto .................................................................... 9

2.3.1 Características geométricas ....................................................... 9

2.3.2 Armadura de distribuiç̧ão .................................................... 12

2.4 Diretrizes para o cálculo .................................................................. 13

2.4.1 Verificação da vigota isolada .................................................... 13

2.4.2 Verificação da vigota na fase de construção ................................ 16

2.4.3 Estado limite de fissuração ......................................................... 19

2.4.4 Estado limite de deformação excessiva ...................................... 23

2.4.5 Estado limite para solicitações tangenciais .................................. 25

2.4.6 Estado limite para solicitações normais ..................................... 28

2.5 Redistribuição dos esforços .................................................................. 29

2.5.1 Prescrições da EF-96 (1997) ..................................................... 30 


\section{CAPÍTULO 3: ESFORÇO DE FLEXÃO DEVIDO AO CARREGAMENTO EXTERNO INCREMENTAL}

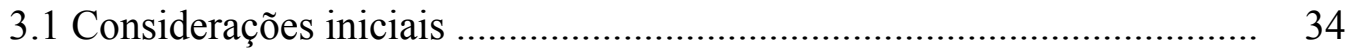

3.2 Consideração da não linearidade física do concreto .............................. 34

3.2.1 Diagrama momento x curvatura segundo CEB-90 (1991) ............ 35

3.2.2 Carregamento incremental .................................................... 45

3.3 Determinação da força última no modelo teórico ................................... 46

3.3.1 Critério da capacidade de rotação das rótulas plásticas ............... 46

3.3.2 Critério da formação de mecanismo de colapso ............................ 48

3.4 Descrição do programa computacional ................................................ 49

3.5 Avaliação do procedimento empregado ................................................ 52

3.5.1 Avaliação 1 - ensaio realizado por GASTAL et al. (1999) ............. 52

3.5.2 Avaliação 2 - ensaio realizado por MARCELLINO (2001) .......... 58

\section{CAPÍTULO 4: ANÁliSE DE SITUAÇÕES REPRESENTATIVAS DE PROJETO}

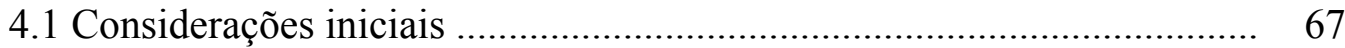

4.2 Definições gerais dos casos analisados ................................................ 67

4.2.1 Definição das dimensões ................................................................ 67

4.2.2 Definição da armadura de continuidade .................................... $\quad 70$

4.3 Descrição das modelagens numéricas ................................................. 74

4.4 Resultados obtidos nas simulações ..................................................... 79

4.4.1 Casos com vãos duplos de 4,0 m ............................................... 79

4.4.2 Casos com vãos duplos de 6,0 m ................................................ 82

4.4.3 Casos com vãos duplos de $8,0 \mathrm{~cm}$............................................ 85

4.4.4 Casos com vãos triplos .............................................................. 88

4.5 Análise dos resultados e comentários .................................................. 92

\section{CAPÍTULO 5: EXEMPLO DE CÁLCULO}

5.1 Considerações iniciais ....................................................................... 100 
5.2 Cálculos iniciais 101

5.3 Parte 1: laje simplesmente apoiada ................................................... 109

5.4 Parte 2: laje contínua ..................................................................... 118

CAPÍTULO 6: CONSIDERAÇÕES FINAIS E CONCLUSÕES 127

\section{BIBLIOGRAFIA}

Referências bibliográficas 130

Bibliografia complementar 132 


\section{LISTA DE FIGURAS}

FIGURA 2.1 Laje formada por nervuras pré-moldadas [EL DEBS (2000)] 6

FIGURA 2.2 Vigotas pré-moldadas disponíveis no mercado brasileiro ..... 7

FIGURA 2.3 Equipamento para a produção das vigotas protendidas ......... 8

FIGURA 2.4 Condições geométricas das lajes, cotas em centímetros

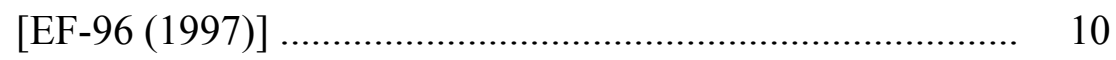

FIGURA 2.5 Tensões na vigota após a transferência da força de protensão

FIGURA 2.6 Solicitações da vigota durante a concretagem [EF-96 (1997)]

FIGURA 2.7 Cuidados durante a fase de construção [CALAVERA (1989)]

FIGURA 2.8 Seqüência de escoramento [CALAVERA (1989)] .... 18

FIGURA 2.9 Homogeneização da seção da laje ....................................... 19

FIGURA 2.10 Estados limites de fissuração [EF-96 (1997)] ....................... 20

FIGURA 2.11 Larguras para a verificação da força cortante [EF-96 (1997)] .

FIGURA 2.12 Perímetro para a verificação do cisalhamento da interface [EF-96 (1997)]

FIGURA 2.13 Consideração da diferença de resistência dos concretos para determinação de $\mathrm{M}_{\mathrm{u}}$ 28

FIGURA 2.14 Determinação do momento negativo resistente 29

FIGURA 2.15 Diagrama de momentos fletores de acordo com a EF-96 (1997)

FIGURA 2.16 Método para a consideração da redistribuição de momentos de acordo com a CPT Planchers (1980) 33

FIGURA 3.1 Curvatura de um incremento de barra de comprimento $\Delta \mathrm{x} \ldots$

FIGURA 3.2 Estágios básicos no diagrama momento-curvatura, adaptado de FIB (1999) ..... 
FIGURA 3.3 Diagrama momento-curvatura segundo CEB-90 (1991) ....... 38

FIGURA 3.4 Trechos do painel contínuo com seções distintas ................ 40

FIGURA 3.5 Forças internas na laje formada por vigotas protendidas ...... 43

FIGURA 3.6 Diagrama tensão-deformação dos materiais .......................... 44

FIGURA 3.7 Diagrama genérico de carga $x$ deslocamento: 1) desenvolvimento real 2) desenvolvimento por etapas lineares [CARVALHO (1994)] ......................................... 45

FIGURA 3.8 Determinação da curvatura média a partir dos deslocamentos ................................................................. 47

FIGURA 3.9 Viga equivalente na região do apoio central ....................... 48

FIGURA 3.10 Critério da formação de um mecanismo de colapso .............. 49

FIGURA 3.11 Fluxograma simplificado para a análise não linear utilizando o programa ANSYS ${ }^{\circledR}$........................................ 50

FIGURA 3.12 Diferenciação com relação ao número de elementos discretizados

FIGURA 3.13 Seção transversal da laje alveolar (dimensões em cm) .......... 53

FIGURA 3.14 Vista longitudinal do ensaio (dimensões em $\mathrm{cm}$ ) ................. 53

FIGURA 3.15 Seção transversal teórica utilizada na análise numérica (dimensões em cm) ....................................................... 54

FIGURA 3.16 Discretização do painel da laje em elementos ...................... 54

FIGURA 3.17 Deslocamentos máximos experimentais e teóricos no vão .... 56

FIGURA 3.18 Resultados experimentais e teóricos para a seção do apoio central .......................................................................... 56

FIGURA 3.19 Diagrama teórico momento $x$ curvatura para a seção do

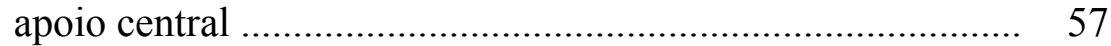

FIGURA 3.20 Evolução dos deslocamentos - análise teórica ..................... 57

FIGURA 3.21 Plano de montagem dos elementos - dimensões em cm ...... 59

FIGURA 3.22 Pórtico de reação - dimensões em cm ................................... 60

FIGURA 3.23 Foto do modelo preparado para o ensaio .............................. 60

FIGURA 3.24 Valores de força e deslocamento utilizados na análise .......... 61

FIGURA 3.25 Foto do início da fissuração ................................................. 62

FIGURA 3.26 Foto do ponto de apoio da laje na ruptura ............................ 62 
FIGURA 3.27 Discretização utilizada para o modelo (dimensões em cm) ... 63

FIGURA 3.28 Deslocamentos na extremidade da laje ............................... 64

FIGURA 3.29 Esquema do ensaio ......................................................... 66

FIGURA 3.30 Deslocamentos na extremidade da laje ajustados ................. 66

FIGURA 4.1 Vigotas utilizadas para os casos analisados (dimensões em

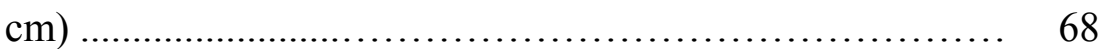

FIGURA 4.2 Seções finais das lajes para os casos analisados (dimensões $\mathrm{em} \mathrm{cm})$

FIGURA 4.3 Distinção entre o momento fletor considerando material elástico-linear e o momento fletor após redistribuição .

FIGURA 4.4 Esquema estático e diagrama de momento fletor utilizados no dimensionamento

FIGURA 4.5 Discretização dos casos analisados 74

FIGURA 4.6 Máximos momentos fletores - casos com vãos de 4,0 m ...... 80

FIGURA 4.7 Deslocamentos máximos - casos com vãos de 4,0 m .......... 81

FIGURA 4.8 Diagrama de momento fletor para carga última - casos com vãos de 4,0 m

FIGURA 4.9 Máximos momentos fletores - casos com vãos de 6,0 m ...... 83

FIGURA 4.10 Deslocamentos máximos - casos com vãos de 6,0 m .......... 84

FIGURA 4.11 Diagrama de momento fletor para carga última - casos com vãos de $6,0 \mathrm{~m}$................................................................... 85

FIGURA 4.12 Máximos momentos fletores - casos com vãos de 8,0 m ...... 86

FIGURA 4.13 Deslocamentos máximos - casos com vãos de 8,0 m .......... 87

FIGURA 4.14 Diagrama de momento fletor para carga última - casos com vãos de $8,0 \mathrm{~m}$............................................................ 88

FIGURA 4.15 Máximos momentos fletores - caso C3/6,0-20-20 .............. 89

FIGURA 4.16 Máximos momentos fletores - caso C2/6,0/8,0-20-20 ....... 89

FIGURA 4.17 Deslocamentos máximos - casos com vãos triplos .............. 90

FIGURA 4.18 Evolução dos momentos fletores - casos com vãos triplos ... 91

FIGURA 4.19 Comparação entre os deslocamentos máximos para carga de serviço ...................................................................... 93 
FIGURA 4.20 Gráfico esquemático da evolução do máximo momento fletor

FIGURA 4.21 Esquema do ensaio realizado por MAGALHÃES (2001) ..... 95

FIGURA 4.22 Máximos momentos fletores para o caso com $\eta=15 \%$ [MAGALHÃES (2001)] 96

FIGURA 4.23 Máximos momentos fletores para o caso com $\eta=40 \%$ [MAGALHÃES (2001)]

FIGURA 4.24 Máximos momentos fletores para o caso com armadura construtiva sobre o apoio [MAGALHÃES (2001)]

FIGURA 4.25 Gráfico esquemático da evolução do máximo momento fletor para lajes formadas por vigotas com armação treliçada

FIGURA 4.26 Grau de redistribuição

FIGURA 5.1 Esquema da laje com vão duplo 100

$\begin{array}{lll}\text { FIGURA 5.2 Seção transversal da vigota protendida (dimensões em cm) } & 101\end{array}$

FIGURA 5.3 Seção transversal final da laje (dimensões em cm) .............. 101

FIGURA 5.4 Características geométricas da vigota (dimensões em cm) ... 102

FIGURA 5.5 Seção da laje homogeneizada (dimensões em cm) ............... 104

FIGURA 5.6 Tensões iniciais na seção de concreto líquida ...................... 106

FIGURA 5.7 Diagrama de momento fletor não utilizando escoras (valores em kN.cm) ........................................................... 108

FIGURA 5.8 Diagrama de momento fletor para a utilização de uma linha de escoras (valores em kN.cm) ...................................... 109

FIGURA 5.9 Diagramas de momento fletor atuantes na laje (valores em kN.cm)

FIGURA 5.10 Equilíbrio das forças na seção da laje para momento fletor positivo

FIGURA 5.11 Deformações da seção composta ......................................... 113

FIGURA 5.12 Regiões para a verificação da força cortante ........................ 114

FIGURA 5.13 Deslocamentos para a situação de serviço ........................... 117

FIGURA 5.14 Deslocamentos máximos - laje biapoiada ......................... 117 
FIGURA 5.15 Diagramas de momento fletor atuantes na laje (valores em kN.cm)

FIGURA 5.16 Diagramas de força cortante atuantes na laje (valores em $\mathrm{kN})$

FIGURA 5.17 Seção de verificação da laje (apoio)

FIGURA 5.18 Equilíbrio das forças na seção da laje para momento fletor negativo 122

FIGURA 5.19 Deslocamentos para a situação de serviço 126

FIGURA 5.20 Deslocamentos máximos - laje contínua 126 


\section{LISTA DE TABELAS}

TABELA 2.1 Capa mínima resistente para as alturas totais padronizadas [Projeto de norma para Laje pré-fabricada] ........................ 11

TABELA 2.2 Escolha do tipo de protensão, segundo NBR-7197 (1989) .... 21

TABELA 2.3 Estados limites a verificar para cada tipo de protensão, segundo NBR-7197 (1989) ................................................ 22

TABELA 2.4 Valor do coeficiente C definido pela EF-96 (1997) .............. 24

TABELA 2.5 Limites para deslocamentos segundo o projeto de revisão da NBR-6118:2000 25

TABELA 3.1 Armaduras utilizadas no modelo em cada seção .................. 55

TABELA 3.2 Características geométricas e mecânicas de cada seção ........ 55

TABELA 3.3 Características geométricas e mecânicas das seções do modelo 64

TABELA 4.1 Valores das cargas para as lajes utilizadas 71

TABELA 4.2 Casos analisados

TABELA 4.3 Número de elementos de cada seção para os casos analisados

TABELA 4.4 Características geométricas e mecânicas das seções para os casos com vãos de $4,0 \mathrm{~m}$

TABELA 4.5 Características geométricas e mecânicas das seções para os casos com vãos de $6,0 \mathrm{~m}$

TABELA 4.6 Características geométricas e mecânicas das seções para os casos com vãos de $8,0 \mathrm{~m}$

TABELA 4.7 Características geométricas e mecânicas das seções para os casos com vãos triplos 78

TABELA 4.8 Comportamento estrutural para os casos com vãos de 4,0 m 79

TABELA 4.9 Comportamento estrutural para os casos com vãos de $6,0 \mathrm{~m} \quad 82$

TABELA 4.10 Comportamento estrutural para os casos com vãos de $8,0 \mathrm{~m} \quad 86$

TABELA 4.11 Comportamento estrutural para os casos com vãos triplos .... 88 
TABELA 4.12 Comparação entre vãos com continuidade e vãos biapoiados 92

TABELA 4.13 Valores do grau de redistribuição 


\section{LISTA DE SÍMBOLOS E SIGLAS}

\section{LETRAS MINÚSCULAS}

$\mathrm{a}_{\mathrm{q}} \quad$ distância entre dois pontos sucessivos de momentos fletores nulos

$1 / \mathrm{r} \quad$ curvatura genérica da seção

$1 / r_{u} \quad$ curvatura correspondente ao momento último

$1 / \mathrm{r}_{\mathrm{y}} \quad$ curvatura correspondente ao momento de escoamento

$1 / r_{1 \mathrm{r}} \quad$ curvatura correspondente ao estádio I com atuação do momento de fissuração

$1 / r_{2 r}$ curvatura correspondente ao estádio II com atuação do momento de fissuração

$1 / r_{t s} \quad$ valor que considera a contribuição do concreto tracionado entre fissuras

b largura genérica da seção

$b_{\mathrm{i}} \quad$ largura da seção no ponto i

$\mathrm{b}_{\mathrm{w}} \quad$ largura mínima da nervura

c distância do eixo vertical médio do material de enchimento até um ponto genérico

d altura útil da laje

$e_{p} \quad$ excentricidade da armadura protendida em relação ao centróide da seção transversal líquida de concreto da vigota

$\mathrm{f}_{\mathrm{cd}} \quad$ resistência de cálculo do concreto à compressão

$\mathrm{f}_{\mathrm{cd}, 1}$ resistência de cálculo do concreto pré-moldado da vigota à compressão

$\mathrm{f}_{\mathrm{cd}, 2}$ resistência de cálculo do concreto moldado no local à compressão

$\mathrm{f}_{\mathrm{ck}} \quad$ resistência característica à compressão do concreto

$\mathrm{f}_{\mathrm{ck}, 1}$ resistência característica à compressão do concreto pré-moldado da vigota

$\mathrm{f}_{\mathrm{ck}, 2}$ resistência característica à compressão do concreto moldado no local

$\mathrm{f}_{\mathrm{ckj}}$ resistência característica à compressão do concreto $\mathrm{a} \mathrm{j}$ dias de idade 
$\mathrm{f}_{\mathrm{cm}} \quad$ resistência média à compressão do concreto

$\mathrm{f}_{\mathrm{ct}, \mathrm{f}}$ resistência do concreto à tração na flexão

$\mathrm{f}_{\text {ctkj }}$ resistência característica à tração do concreto a j dias de idade

$\mathrm{f}_{\mathrm{ctm}}$ resistência média à tração axial do concreto

$\mathrm{f}_{\mathrm{ctm}, \mathrm{f}}$ resistência média à tração por flexão do concreto

$\mathrm{f}_{\mathrm{cv}}$ resistência virtual de cálculo do concreto ao esforço cortante

$\mathrm{f}_{\text {ptk }}$ resistência característica à tração do aço de protensão

$\mathrm{f}_{\text {pyd }}$ resistência de cálculo do aço de protensão ao escoamento

$\mathrm{f}_{\text {pyk }}$ resistência característica de escoamento do aço de protensão

$\mathrm{f}_{\text {pym }}$ resistência média de escoamento do aço de protensão

$\mathrm{f}_{\mathrm{yd}} \quad$ tensão de escoamento da armadura passiva

$\mathrm{f}_{\mathrm{ym}} \quad$ tensão média de escoamento da armadura passiva

g carga permanente

$\mathrm{g}_{1} \quad$ peso próprio da vigota protendida

$\mathrm{g}_{2} \quad$ peso próprio do concreto moldado no local e peso do material de enchimento

$\mathrm{g}_{3} \quad$ carga permanente relativa ao revestimento

h altura total da laje

$\mathrm{h}_{\mathrm{c}} \quad$ altura da capa de concreto

l Vão de cálculo

$\mathrm{m}$ relação entre $\mathrm{E}_{\mathrm{c}, 2}$ e $\mathrm{E}_{\mathrm{c}, 1}$

$\mathrm{p} \quad$ carga total atuante sobre a laje

q carga acidental

$\mathrm{q}_{\mathrm{exe}} \quad$ sobrecarga de execução

$\mathrm{u} \quad$ perímetro crítico ao cisalhamento

x altura da linha neutra da seção

$\mathrm{z}_{\mathrm{p}} \quad$ braço de alavanca entre a força na armadura protendida e no concreto

$\mathrm{z}_{\mathrm{S}} \quad$ braço de alavanca entre a força na armadura passiva e no concreto 


\section{LETRAS MAIÚSCULAS}

$\mathrm{A}_{\mathrm{c}} \quad$ área de concreto

$\mathrm{A}_{\mathrm{ch}}$ área da seção transversal homogeneizada da vigota

$\mathrm{A}_{\mathrm{ch}}{ }^{\prime} \quad$ área da seção transversal homogeneizada da laje

$\mathrm{A}_{\mathrm{CML}}$ área da seção transversal do concreto moldado no local

$\mathrm{A}_{\mathrm{ME}}$ área da seção transversal do material de enchimento

$\mathrm{A}_{\mathrm{p}}$ área da seção transversal de armadura de protensão

$\mathrm{A}_{\mathrm{s}} \quad$ área da seção transversal de armadura passiva

$\mathrm{A}_{\mathrm{v}} \quad$ área da seção transversal da vigota

C coeficiente

E módulo de elasticidade genérico

$\mathrm{E}_{\mathrm{c}} \quad$ módulo de elasticidade do concreto

$\mathrm{E}_{\mathrm{c}, 1} \quad$ módulo de elasticidade do concreto pré-moldado da vigota

$\mathrm{E}_{\mathrm{c}, 2}$ módulo de elasticidade do concreto moldado no local

$\mathrm{E}_{\mathrm{cs}} \quad$ módulo de elasticidade secante do concreto

$\mathrm{E}_{\mathrm{p}} \quad$ módulo de elasticidade da armadura de protensão

$F_{d, u t i}$ ações utilizadas na verificação dos estados limites de utilização

$\mathrm{F}_{\mathrm{Gi}, \mathrm{k}} \quad$ ações permanentes

$\mathrm{F}_{\mathrm{Qj}, \mathrm{k}} \quad$ ações principais acidentais

$\mathrm{F}_{\mathrm{S}} \quad$ Força aplicada na seção $\mathrm{s}$

I momento de inércia genérico

I momento de inércia da seção para o Estádio I

II momento de inércia da seção para o Estádio II

$\mathrm{I}_{\mathrm{c}} \quad$ momento de inércia da seção de concreto

$\mathrm{I}_{\mathrm{ch}} \quad$ momento de inércia da seção transversal homogeneizada da vigota

$\mathrm{I}_{\mathrm{ch}}{ }^{\prime} \quad$ momento de inércia da seção transversal homogeneizada da laje 
$\mathrm{I}_{\mathrm{v}} \quad$ momento de inércia da seção da vigota

$\mathrm{I}_{\mathrm{p}} \quad$ momento de inércia da seção da armadura protendida

M momento fletor genérico

$\mathrm{M}_{\mathrm{i}} \quad$ esforço de flexão na seção i

$\mathrm{M}_{\mathrm{r}} \quad$ momento de fissuração da seção

$\mathrm{M}_{\mathrm{u}} \quad$ momento último da seção

$\mathrm{M}_{\mathrm{y}} \quad$ momento de escoamento da seção

$\mathrm{P}_{\mathrm{a}}$ força na armadura de protensão antes da liberação dos cabos

$\mathrm{P}_{\mathrm{o}} \quad$ força inicial na armadura de protensão considerando as perdas imediatas

$\mathrm{P}_{\mathrm{i}}$ força da armadura de protensão na saída do aparelho de tração na ocasião da aplicação da força de protensão

$\mathrm{P}_{\infty} \quad$ força na armadura de protensão considerando as perdas totais

$\mathrm{R}_{\mathrm{ccl}}$ resultante da força de compressão do concreto pré-moldado

$\mathrm{R}_{\mathrm{cc} 2}$ resultante da força de compressão do concreto moldado no local

$\mathrm{R}_{\mathrm{ct}}$ resultante da força de tração do concreto

$\mathrm{R}_{\mathrm{pt}} \quad$ resultante da força na armadura protendida

$\mathrm{R}_{\mathrm{S}} \quad$ resultante da força na armadura passiva

$\mathrm{V}_{\mathrm{d}} \quad$ força cortante de cálculo

$\mathrm{V}_{\mathrm{u}} \quad$ força cortante última resistida pela seção

$\mathrm{W}_{1}$ módulo de resistência da seção transversal líquida de concreto da vigota, correspondente à fibra inferior

$\mathrm{W}_{2}$ módulo de resistência da seção transversal líquida de concreto da vigota, correspondente à fibra superior

$\mathrm{W}_{1 \mathrm{~h}}$ módulo de resistência da seção homogeneizada da vigota, correspondente à fibra inferior

$\mathrm{W}_{2 \mathrm{~h}}$ módulo de resistência da seção homogeneizada da vigota, correspondente à fibra superior

$\mathrm{W}_{1 \mathrm{~h}}{ }^{\prime} \quad$ módulo de resistência da seção composta homogeneizada para posição 1 
$\mathrm{W}_{\mathrm{I}} \quad$ módulo de resistência no estádio I

$\mathrm{Y}_{1 \mathrm{c}} \quad$ Centro de gravidade da seção de concreto em relação à borda inferior

$\mathrm{Y}_{1 \mathrm{ch}}$ Centro de gravidade da seção transversal homogeneizada da vigota em relação à borda inferior

$\mathrm{Y}_{1 \mathrm{~h}}{ }^{\prime} \quad$ Centro de gravidade da seção transversal homogeneizada da laje em relação à borda inferior

$\mathrm{Y}_{1 \mathrm{p}} \quad$ Centro de gravidade da seção transversal de armadura de protensão em relação à borda inferior da vigota

$\mathrm{Y}_{1 \mathrm{v}} \quad$ Centro de gravidade da seção transversal da vigota em relação à borda inferior

\section{LETRAS GREGAS}

$\alpha \quad$ coeficiente

$\alpha_{p} \quad$ relação entre $E_{p}$ e $E_{c}$

$\beta \quad$ coeficiente de rugosidade da superfície de contato

$\beta_{1} \quad$ coeficiente correspondente à aderência da armadura

$\beta_{2} \quad$ coeficiente correspondente à forma de carregamento

$\beta_{\mathrm{b}} \quad$ coeficiente correspondente a multiplicação de $\beta_{1}$ e $\beta_{2}$

$\delta \quad$ coeficiente

$\delta_{1} \quad$ coeficiente

$\delta_{2} \quad$ coeficiente

$\varepsilon_{\mathrm{c}} \quad$ deformação genérica no concreto

$\varepsilon_{\mathrm{cc}}$ deformação no concreto submetido à compressão

$\varepsilon_{\mathrm{ct}}$ deformação no concreto submetido à tração

$\varepsilon_{\mathrm{p}}$ deformação genérica na armadura de protensão

$\varepsilon_{\mathrm{pi}} \quad$ pré-alongamento da armadura de protensão

$\varepsilon_{\mathrm{S}} \quad$ deformação genérica na armadura passiva

$\varepsilon_{\mathrm{sc}}$ deformação na armadura passiva submetida à compressão

$\gamma_{\text {conc }}$ massa específica do concreto 
$\gamma_{\mathrm{f}} \quad$ coeficiente de majoração das cargas

$\gamma_{\mathrm{ME}} \quad$ massa específica do material de enchimento

$\eta \quad$ grau de redistribuição no apoio

$\theta_{\mathrm{pl}} \quad$ capacidade de rotação da rótula plástica

$\theta_{\mathrm{pl}, \text { cort }}$ parcela da rotação plástica decorrente do esforço cortante

$\theta_{\text {pl,fle }}$ parcela da rotação plástica decorrente do esforço de flexão

$\rho \quad$ taxa geométrica da armadura

$\sigma_{1 \mathrm{p}}$ tensão no concreto na fibra inferior da vigota devida à força de protensão

$\sigma_{2 p}$ tensão no concreto na fibra superior da vigota devida à força de protensão

$\sigma_{\mathrm{c}}$ tensão genérica na seção transversal de concreto

$\sigma_{\mathrm{CML}}$ tensões na seção de concreto moldado no local

$\sigma_{\mathrm{CPM}}$ tensões na seção de concreto pré-moldado da vigota

$\sigma_{\mathrm{cp}}$ tensão no concreto ao nível do baricentro da armadura de protensão, devida a força $\mathrm{P}_{\mathrm{a}}$

$\sigma_{\mathrm{pa}} \quad$ tensão na armadura de protensão devida a força $\mathrm{P}_{\mathrm{a}}$

$\sigma_{\mathrm{p}} \quad$ tensão genérica na armadura de protensão

$\sigma_{\text {po }}$ tensão inicial na armadura de protensão considerando as perdas imediatas

$\sigma_{\mathrm{pi}}$ tensão da armadura de protensão na saída do aparelho de tração na ocasião da aplicação da força de protensão

$\sigma_{\mathrm{p} \infty} \quad$ tensão na armadura de protensão considerando as perdas totais

$\sigma_{\mathrm{s}} \quad$ tensão genérica na armadura passiva

$\Psi_{1} \quad$ fatores de utilização para combinação de ações freqüentes

$\Psi_{2}$ fatores de utilização para combinação de ações quase-permanentes

\section{SIGLAS MAIS UTILIZADAS}

CEB Comite Euro-internacional du Beton

CML Concreto moldado no local

CPM Concreto pré-moldado 
CPT Cahiers des Prescriptions Techniques

FIB Fédération Internacionale du Beton

NBR Norma Brasileira Registrada 


\section{RESUMO}

MERLIN, A. J. (2002). Momentos fletores negativos nos apoios de lajes formadas por vigotas de concreto protendido. São Carlos, 2002. 134p. Dissertação (Mestrado) - Escola de Engenharia de São Carlos, Universidade de São Paulo.

Este trabalho enfoca a análise estrutural de um dos tipos de laje que vem ganhando espaço no mercado brasileiro, que é a laje formada por vigotas de concreto protendido. O objetivo principal do trabalho é contribuir na avaliação do comportamento desse tipo de laje com relação aos momentos fletores negativos no apoio, mediante análise teórica.

Esta análise foi realizada a partir da relação momento $x$ curvatura proposta pelo CEB-90 em conjunto com a técnica do carregamento incremental para a consideração da não-linearidade física do concreto. Esse método foi avaliado através da comparação com resultados experimentais de painéis alveolares encontrados na literatura, verificando que o modelo teórico representa satisfatoriamente o comportamento estrutural de lajes formadas por elementos prémoldados protendidos.

A partir disto, fez-se análises em situações representativas de projeto de lajes formadas por vigotas protendidas, chegando-se as seguintes conclusões: a) a utilização da continuidade favorece fortemente a redução dos deslocamentos; b) os deslocamentos praticamente independem da taxa de armadura de continuidade; c) a evolução do momento fletor negativo no apoio e momento fletor positivo máximo no vão apresentou um comportamento padrão para os casos analisados; d) esse comportamento foi independente da taxa de armadura de continuidade e e) a taxa de armadura de continuidade afetou praticamente o valor da carga última.

Palavras-chaves: Laje pré-moldada, vigota protendida, comportamento não-linear, redistribuição de esforços. 


\begin{abstract}
MERLIN, A. J. (2002). Bending moments in the support of slabs made by precast prestressed concrete joist. São Carlos, 2002. 134p. Dissertation (Master's degree) - Escola de Engenharia de São Carlos, Universidade de São Paulo.
\end{abstract}

This work aims the structural analysis in a type of slabs that is increasing its utilization in Brazil. These slabs are made by precast prestressed joists. The main objective of this work is the evaluation of the behavior of this type of slabs by theoretical analysis of the bending moments on the supports of continuous slabs.

In the theoretical analysis was carried out the consideration of the nonlinear of the concrete behavior through the moment $x$ curvature relationship of Model Code CEB-90 add incremental load technique. This methodology was appraised with experimental results of panels of hollow core slabs and this methodology was able to represent satisfactorily the behavior of slabs made by precast prestressed elements.

Analysis of representative cases of slabs with precast prestressed joists was carried out and the main conclusions were: a) the use of continuity aids highly to decrease the displacements; b) displacements were practically independent of reinforcement ratio on the support; c) the development profiles of the bending moments had a standard behavior to the analysed cases; d) this behavior was independent of reinforcement ratio on the support and e) the reinforcement ratio on the support affected practically the ultimate load value.

Keywords: Precast slabs, precast prestressed joist, non-linear behavior, bending redistribution. 


\section{INTRODUÇÃO}

\subsection{Considerações Iniciais}

As lajes formadas por vigotas pré-moldadas, elementos de enchimento e concreto moldado no local se enquadram em uma das soluções construtivas que levam em conta a racionalização da construção. Isso porque essas lajes necessitam de pouco escoramento, dispensam o uso de fôrmas, são de fácil manuseio e montagem, não necessitando de equipamentos especiais. Além disso, elas viabilizam o aumento da produtividade e a redução do desperdício de materiais.

Um dos tipos de vigota que vem ganhando mercado atualmente no Brasil é a vigota de concreto protendido, com seção transversal com a forma aproximada de um $\mathrm{T}$ invertido. Entretanto, existem poucos fabricantes no Brasil desse tipo de vigota e não há praticamente nenhum estudo acadêmico a respeito do comportamento desses elementos, sendo que o pouco conhecimento técnico é obtido recorrendo-se às normas estrangeiras ou através do cotidiano em canteiro de obras. Muitas vezes esses fatos comprometem a utilização desse tipo de laje.

Nesse contexto, sente-se a necessidade de aprofundar o conhecimento sobre esse tipo de laje, de modo a regulamentar e orientar projetistas e construtores. 


\subsection{Objetivos}

\section{Objetivo geral:}

Contribuir na avaliação do comportamento de lajes formadas por elementos pré-moldados tipo nervuras protendidas, mediante estudo teórico dos momentos fletores negativos junto aos apoios de lajes unidirecionais contínuas para carregamento externo incremental.

\section{Objetivos específicos:}

- Avaliação da redistribuição de momentos fletores mediante simulações numéricas em programas de computador, sendo o estudo dirigido para o caso de lajes unidirecionais formadas por vigotas protendidas;

- Fornecer recomendações de projeto para a consideração da continuidade em relação aos momentos fletores negativos.

\subsection{Justificativas}

A importância e relevância deste trabalho de pesquisa estão calcadas nos seguintes aspectos:

a) o projeto corresponde uma continuidade de pesquisa no assunto, objetivando completar o entendimento deste tipo de laje;

b) na literatura técnica internacional existem poucos trabalhos de pesquisa sobre as lajes formadas por nervuras pré-moldadas; este panorama se repete em nível nacional;

c) não existe um critério consagrado para adotar o momento fletor de continuidade; 


\subsection{Metodologia}

Inicialmente foi realizada uma revisão bibliográfica, de modo a se obter informações disponíveis na literatura técnica sobre o tema.

As análises teóricas dos momentos fletores devidos ao carregamento externo incremental foram realizadas a partir de modelagens numéricas em computador utilizando o programa ANSYS $^{\circledR}$, disponível no Departamento de Engenharia de Estruturas da EESC-USP. O programa ANSYS ${ }^{\circledR}$ utiliza o método dos elementos finitos para a obtenção de esforços e deslocamentos provocados pela ação do carregamento na estrutura.

Para considerar a não-linearidade física do concreto, foram utilizadas a técnica do carregamento incremental e a relação momento $x$ curvatura proposta pelo CEB-90 (1991), através de sub-rotinas acopladas ao ANSYS ${ }^{\circledR}$. Tais procedimentos foram inicialmente desenvolvidos por DROPPA JÚNIOR (1999) e já foram utilizados por MAGALHÃES (2001), para análises de lajes pré-moldadas tipo armação treliçada.

Para a avaliação do procedimento empregado, foi realizada a comparação da análise teórica com resultados experimentais disponíveis na literatura.

A partir dos resultados obtidos em simulações numéricas de situações representativas de projeto, foram fornecidas recomendações de projeto para a consideração da continuidade com relação aos momentos fletores negativos.

\subsection{Apresentação do trabalho}

Este trabalho está dividido em 6 capítulos, apresentando-se a seguir, sucintamente, o conteúdo de cada um deles.

O capítulo 1 apresenta os objetivos, as justificativas e a metodologia do trabalho.

No capítulo 2 são apresentadas as lajes formadas por vigotas prémoldadas protendidas, enfatizando questões relacionadas ao projeto, 
dimensionamento e as formas para a consideração da redistribuição dos esforços durante a fase de dimensionamento.

No capítulo 3 são mostrados os fundamentos para a consideração da nãolinearidade física do concreto. Inicialmente são apresentadas as relações momento $x$ curvatura propostas pelo CEB-90 (1991) e a técnica do carregamento incremental. Em seguida foram realizadas comparações entre ensaios encontrados na literatura com os resultados obtidos em simulações numéricas.

No capítulo 4 são apresentados os resultados obtidos nas simulações numéricas das situações representativas de projeto e a análise desses resultados.

No capítulo 5 é realizado o dimensionamento de uma laje formada por vigotas pré-moldadas protendidas, com o intuito de ilustrar o processo de cálculo desse tipo de laje.

As conclusões e dos comentários finais deste trabalho são apresentadas no capítulo 6, assim como as sugestões para o desenvolvimento de futuras pesquisas. 


\section{LAJES FORMADAS POR VIGOTAS PRÉ - MOLDADOS}

\subsection{Considerações iniciais}

Uma das aplicações mais comuns de elementos de concreto pré-moldado é nas lajes de edifícios. As principais variações mais utilizadas são:

a) painéis TT;

b) painéis alveolares;

c) elementos de pré-laje;

d) lajes formadas por nervuras pré-moldadas, comumente chamadas de "lajes pré-moldadas" ou "lajes pré-fabricadas".

As lajes formadas por nervuras pré-moldadas são, conforme ilustradas na figura 2.1, constituídas basicamente de:

a) elementos lineares pré-moldados, que são as nervuras, dispostas espaçadamente em uma direção;

b) elementos de enchimento, intercalados entre os elementos prémoldados;

c) capa de concreto moldado no local. 


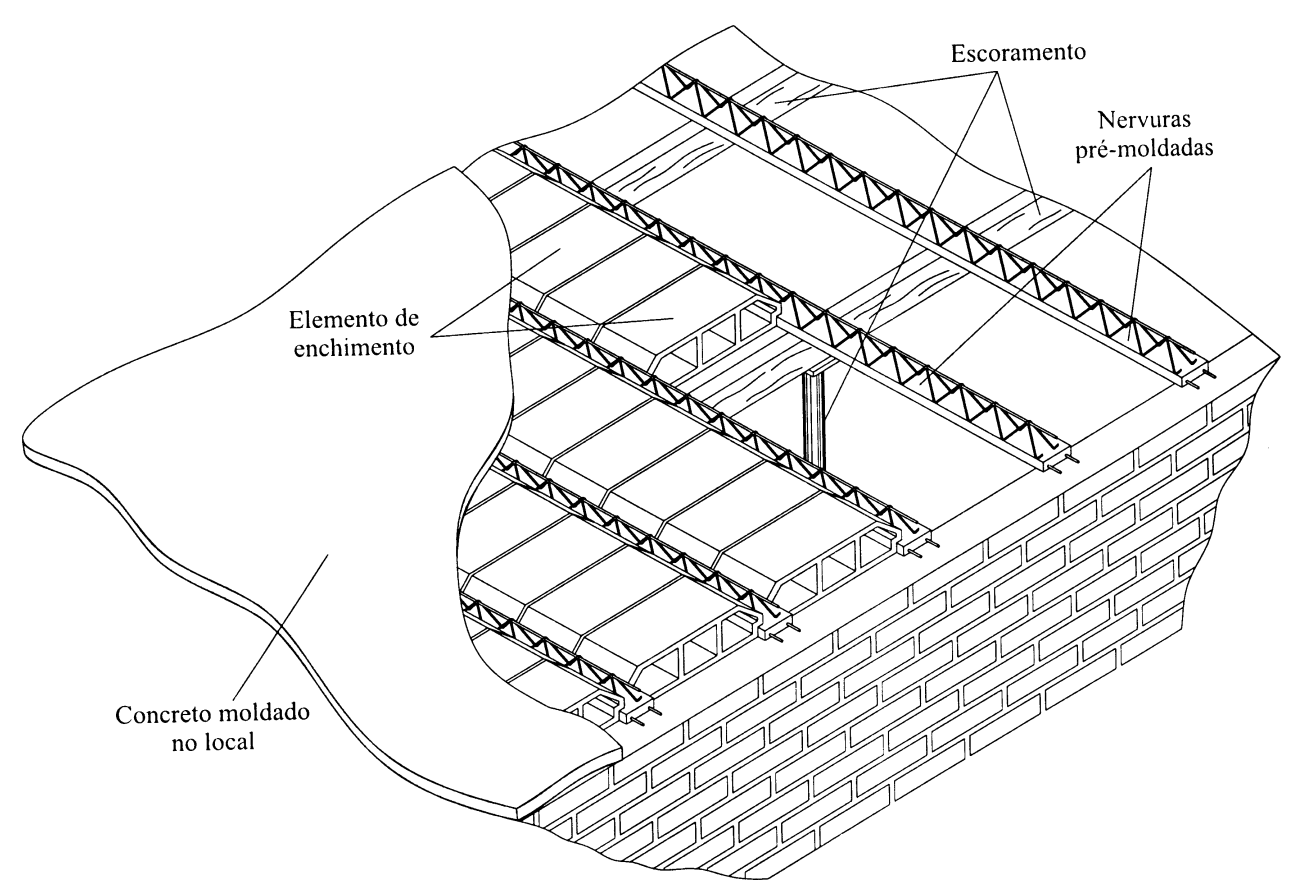

FIGURA 2.1 - Laje formada por nervuras pré-moldadas [EL DEBS (2000)]

Com relação às seções transversais, os elementos pré-moldados podem ser com ou sem armadura saliente, em forma de $\mathrm{T}$ invertido ou I. Os materiais de enchimento normalmente utilizados são blocos vazados de concreto ou material cerâmico, ou ainda blocos de poliestireno expandido, conhecidos pela sigla EPS.

A utilização de elementos de material leve está ligada à idéia de substituir parte do concreto da região tracionada das lajes, bem como servir de sustentação à camada de concreto fresco que é aplicada sobre os painéis das lajes pré-fabricadas.

Os tipos de vigotas utilizadas atualmente são os seguintes (figura 2.2):

a) vigotas de concreto armado comum, não protendido, com seção transversal com a forma aproximada de um $\mathrm{T}$ invertido, com armadura passiva totalmente envolvida pelo concreto;

b) vigotas de concreto protendido, com seção transversal com a forma aproximada de um $\mathrm{T}$ invertido, com armadura de protensão prétracionada e totalmente envolvida pelo concreto;

c) vigotas treliçadas, formadas por uma armadura treliçada de aço e por uma placa de concreto envolvendo as barras inferiores da treliça que irão compor a armadura da face tracionada da laje. 
Além da aplicação destes elementos em obras residenciais, em prédios de poucos pavimentos, deve-se destacar, no entanto, que recentemente estes tipos de laje tem avançado rumo aos edifícios de mais pavimentos, utilizando-se vigotas com armadura protendida e vigotas com armação em forma de treliça.

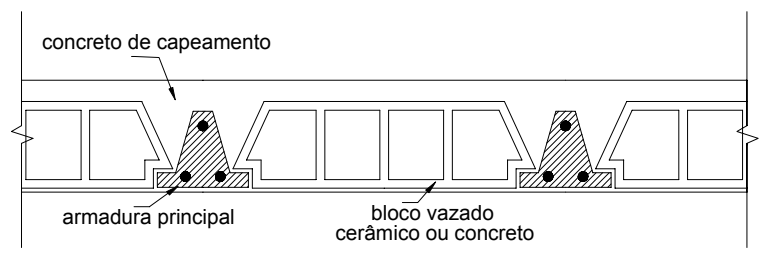

vigota de concreto armado comum

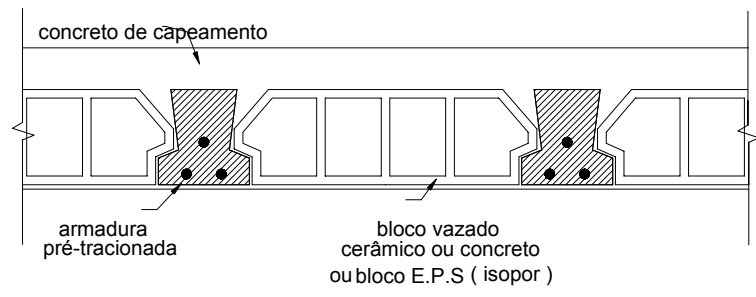

vigota de concreto armado protendido

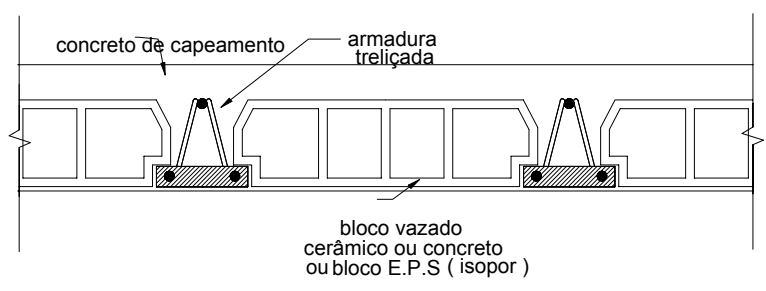

vigota treliçada

FIGURA 2.2 - Vigotas pré-moldadas disponíveis no mercado brasileiro 


\subsection{Lajes nervuradas formadas por vigotas pré-moldadas protendidas}

As vigotas protendidas são produzidas em fábricas com sistema de prétração. Tais fábricas utilizam pistas de protensão de grande extensão (100 a 200 m), na qual os cabos são tensionados por sistema hidráulico.

Normalmente a produção das vigotas é mecanizada, sendo realizada por um sistema similar ao dos painéis alveolares. Utilizando fôrma deslizante, o equipamento (figura 2.3) lança, conforma e adensa o concreto a medida que vai se movendo ao longo da pista de protensão, deixando o produto acabado.

Com este tipo de elemento pré-moldado podem ser atingidos vãos bastante elevados, mas por questões de manuseio, em geral, os vãos não ultrapassam a casa $\operatorname{dos} 10 \mathrm{~m}$.

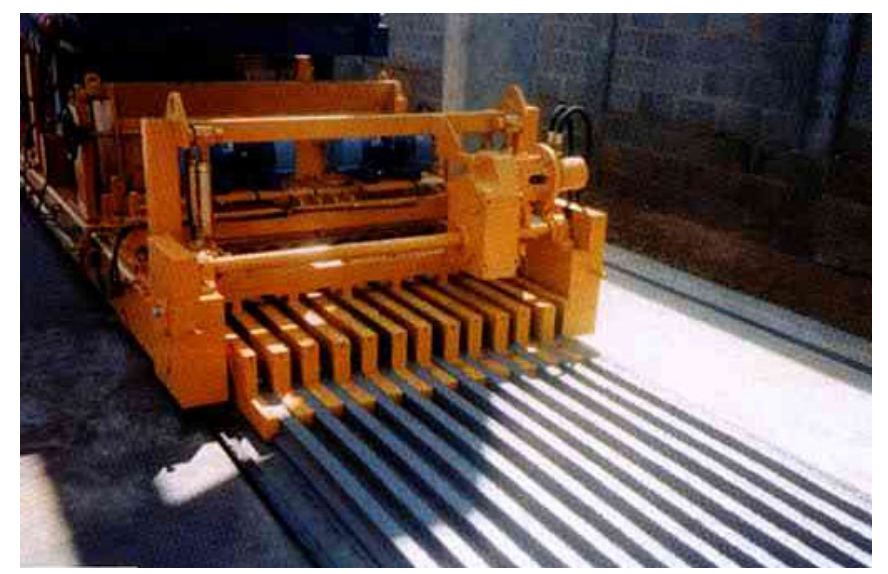

FIGURA 2.3 - Equipamento para a produção das vigotas protendidas

As principais vantagens que podem ser apontadas na utilização dos pavimentos formados por vigotas pré-moldadas em relação aos pavimentos tradicionais de lajes maciças de concreto armado são:

- considerando igualdade de vãos e sobrecargas, possuem menor peso próprio, com conseqüente alívio sobre as fundações;

- dispensam o uso de fôrmas, pois os elementos pré-moldados e os elementos de enchimento fazem esse papel;

- proporcionam a diminuição da mão-de-obra de execução. 
Especificamente com relação às lajes formadas por vigotas pré-moldadas protendidas, podem ser indicadas as seguintes vantagens:

- proporcionam sensível redução do escoramento das lajes, pois o elemento pré-moldado possui capacidade portante capaz de reduzir as linhas de escoras;

- apresentam melhores condições de atender ao estado limite de deformação excessiva, devido a protensão de parte da seção.

Enquanto que as principais desvantagens desse sistema, como apontados por DROPPA Jr. (1999), são:

- em geral, não possui um comportamento monolítico com o restante da estrutura, o que pode ser inconveniente sob o ponto de vista do contraventamento da edificação;

- as vigotas protendidas, dependendo do vão final da laje, podem resultar em elementos relativamente pesados, dificultando seu manuseio durante o transporte e montagem.

\subsection{Indicações para o projeto}

\subsubsection{Características geométricas}

A norma espanhola EF-96 (1997) se aplica às lajes de vigotas que apresentem as seguintes condições:

- a altura total da laje não deve ultrapassar $50 \mathrm{~cm}$;

- o vão de cada tramo deve ser menor que $10 \mathrm{~m}$;

- a distância livre entre nervuras não deve ultrapassar $100 \mathrm{~cm}$; 
Além disso, a EF-96 (1997) prescreve que a laje deve cumprir aos seguintes requisitos:

- a espessura da mesa não deve ser menor que (figura 2.4):

- $\quad 3 \mathrm{~cm}$ sobre as vigotas

- $4 \mathrm{~cm}$ sobre os elementos de enchimento cerâmico ou de concreto

- $5 \mathrm{~cm}$ os elementos de enchimento de outro tipo ou recuperáveis

- o elemento de enchimento deve permitir, a qualquer distância c de seu eixo vertical de simetria, uma espessura de concreto maior que c/8 para peças com elemento de enchimento resistente e c/6 para os demais casos (c - medida mostrada na figura 2.4);

- o elemento de enchimento, conforme figura 2.4, deve manter uma distância de $3 \mathrm{~cm}$ da face superior da vigota, no mínimo;

- as vigotas protendidas deverão apresentar armadura ativa na zona inferior constituída pelo menos por dois cabos na posição simétrica em relação ao plano vertical médio;

- a taxa geométrica $\rho$ da armadura protendida não deve ser menor que $0,15 \%$ da área da seção total da vigota.

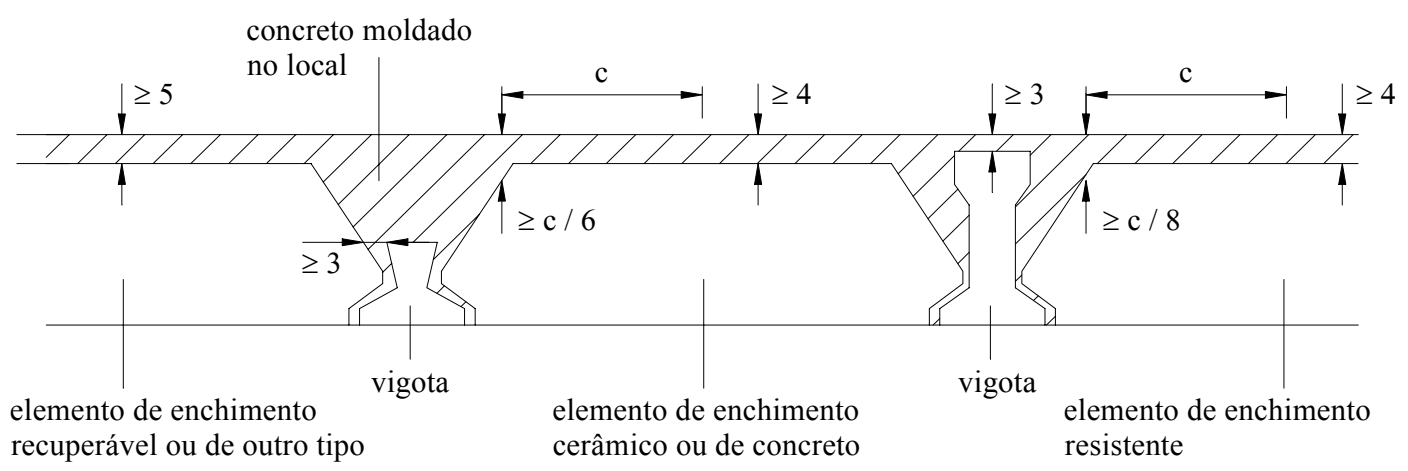

FIGURA 2.4 - Condições geométricas das lajes, cotas em centímetros [EF-96 (1997)] 
O projeto de revisão da NBR-6118:2000 especifica, para o cálculo de lajes nervuradas, os seguintes pontos:

- a espessura da mesa, quando não houver tubulações horizontais embutidas, não deve ser menor que $3 \mathrm{~cm}$ ou 1/15 da distância entre nervuras;

- a espessura da mesa deve ser no mínimo de $4 \mathrm{~cm}$, quando existirem tubulações embutidas de diâmetro máximo de $12,5 \mathrm{~mm}$;

- a espessura das nervuras não deve ser inferior a $5 \mathrm{~cm}$;

- não é permitido o uso de armadura de compressão em nervuras de espessura inferior a $8 \mathrm{~cm}$;

- a resistência à flexão da mesa deverá ser verificada sempre que a distância entre eixos de nervuras superar $60 \mathrm{~cm}$;

- as nervuras deverão ser verificadas ao cisalhamento, como vigas, se a distância entre eixos for maior que $60 \mathrm{~cm}$ e como laje, caso contrário.

De acordo com o projeto de norma para Laje pré-fabricada CE - 18:314.01 [ABNT (2001)], a mesa de compressão só pode ser considerada como parte resistente se sua espessura for no mínimo igual a $3 \mathrm{~cm}$. Existindo tubulações, a espessura mínima da capa de concreto acima da tubulação deve ser no mínimo de $2 \mathrm{~cm}$, observando os limites estabelecidos na tabela 2.1.

TABELA 2.1 - Capa mínima resistente para as alturas totais padronizadas

[Projeto de norma para Laje pré-fabricada]

\begin{tabular}{|c|c|c|c|c|c|c|c|c|c|c|c|c|}
\hline Altura total da laje $(\mathrm{cm})$ & 10,0 & 11,0 & 12,0 & 13,0 & 14,0 & 16,0 & 17,0 & 20,0 & 21,0 & 24,0 & 25,0 & 30,0 \\
\hline $\begin{array}{c}\text { Espessura mínima da } \\
\text { capa resistente }(\mathrm{cm})\end{array}$ & 3,0 & 4,0 & 4,0 & 4,0 & 4,0 & 4,0 & 4,0 & 4,0 & 4,0 & 4,0 & 5,0 & 5,0 \\
\hline
\end{tabular}




\subsubsection{Armadura de distribuição}

Como apresentada por EL DEBS (2000), a armadura de distribuição disposta na capa de concreto possui as seguintes finalidades:

a) promover um comportamento conjunto mais efetivo da laje com a estrutura;

b) reduzir os efeitos da retração diferencial entre o concreto moldado no local e o concreto pré-moldado;

c) reduzir a abertura de fissuras devido à retração e aos efeitos térmicos;

d) propiciar melhor distribuição transversal de cargas localizadas;

e) propiciar um comportamento de diafragma mais efetivo;

f) auxiliar no combate ao colapso progressivo.

Tal armadura de distribuição, segundo a EF-96 (1997), não deve ter diâmetro inferior a $4 \mathrm{~mm}$, com espaçamento nas duas direções não superior $35 \mathrm{~cm}$ e área da seção transversal satisfazendo aos seguintes valores:

- direção perpendicular às nervuras:

$$
A_{s} \geq 50 . \frac{h_{c}}{f_{y d}}
$$

- direção paralela às nervuras:

$$
A_{s} \geq 25 \cdot \frac{h_{c}}{f_{y d}}
$$

sendo:

$\mathrm{h}_{\mathrm{c}}$ - espessura mínima da capa em cm;

$\mathrm{f}_{\mathrm{yd}}$ - tensão de escoamento do aço em MPa;

$\mathrm{A}_{\mathrm{s}}$ - área da seção transversal de armadura $\mathrm{em} \mathrm{cm}^{2} / \mathrm{m}$.

Já o projeto de norma para Laje pré-fabricada, citado anteriormente, é mais conservador, especificando a utilização de uma armadura de distribuição, colocada na capa de concreto complementar, com seção de no mínimo $0,9 \mathrm{~cm}^{2} / \mathrm{m}$ 
para aços CA-25 e de $0,6 \mathrm{~cm}^{2} / \mathrm{m}$ para aços CA-50 e CA-60, contendo pelo menos três barras por metro.

\subsection{Diretrizes para o cálculo}

\subsubsection{Verificação da vigota isolada}

Com o intuito de diminuir os riscos de ruptura prematura das armaduras ativas, de corrosão favorecida pela tração e de relaxação excessiva, a tensão $\sigma_{\mathrm{pi}}$ da armadura de protensão na saída do aparelho de tração na ocasião da aplicação da força de protensão $\mathrm{P}_{\mathrm{i}}$ deve respeitar os seguintes limites:

- $\quad$ Segundo EP-80 (1980)

$$
\sigma_{\mathrm{pi}} \leq\left\{\begin{array}{l}
0,75 \cdot \mathrm{f}_{\mathrm{ptk}} \\
0,90 . \mathrm{f}_{\mathrm{pyk}}
\end{array}\right.
$$

- $\quad$ Segundo NBR-7197 (1989)

$$
\begin{aligned}
& \sigma_{\mathrm{pi}} \leq\left\{\begin{array}{l}
0,81 . f_{\mathrm{ptk}} \\
0,95 . f_{\text {pyk }}
\end{array} \quad\right. \text { (para aços da classe RN) } \\
& \sigma_{\mathrm{pi}} \leq\left\{\begin{array}{l}
0,81 . \mathrm{f}_{\mathrm{ptk}} \\
0,90 \cdot \mathrm{f}_{\mathrm{pyk}}
\end{array} \quad \text { (para aços da classe } \mathrm{RB}\right)
\end{aligned}
$$

sendo:

$\mathrm{f}_{\text {ptk }}$ - resistência característica à tração do aço de protensão;

$\mathrm{f}_{\text {pyk }}$ - resistência característica de escoamento do aço de protensão.

A partir do momento que ocorre a liberação dos cabos de protensão, a vigota será submetida a uma força de compressão $\left(\mathrm{P}_{\mathrm{O}}\right)$ igual à força inicial nos cabos menos a soma das perdas imediatas $\left(\Delta \mathrm{P}_{\mathrm{O}}\right)$ originadas pelo:
a) deslizamento da armadura na ancoragem e acomodação da ancoragem;
b) deformação elástica imediata do concreto na transferência;
c) relaxação inicial da armadura;
d) retração inicial do concreto. 
As tensões finais na vigota, que serão utilizadas para a análise das lajes nos estados limites últimos e de utilização, deverão incluir ainda as perdas diferidas $\left(\Delta \mathrm{P}_{\infty}\right)$ devidas:

e) relaxação da armadura e retração do concreto posteriores à transferência;

f) fluência do concreto.

Portanto, os valores característicos da força de protensão no instante da liberação dos cabos e no instante final de serviço em que a estrutura alcançou seu tempo de vida útil prevista (a este efeito pode-se supor $\mathrm{t}=\infty$ ) serão dados por:

$$
\begin{aligned}
& \mathrm{P}_{\mathrm{o}}=\mathrm{P}_{\mathrm{i}}-\Delta \mathrm{P}_{\mathrm{o}} \\
& \mathrm{P}_{\infty}=\mathrm{P}_{\mathrm{i}}-\Delta \mathrm{P}_{\mathrm{i}}-\Delta \mathrm{P}_{\infty}
\end{aligned}
$$

A EP-80 (1980) especifica ainda que a tensão na armadura de protensão no instante $\mathrm{t}=\infty$ deve respeitar o seguinte limite:

$$
\sigma_{\mathrm{p} \infty} \leq 0,6 . f_{\mathrm{ptk}}
$$

A EF-96 (1997) prescreve que no ato da liberação dos cabos, a seção de concreto da vigota não deve apresentar tensões de tração maiores que a resistência à tração do concreto, nem deve atingir tensões de compressão maiores que $62,5 \%$ da resistência à compressão do concreto, capazes de produzir microfissuração longitudinal (figura 2.5-a). Já a NBR-7197 (1989) admite apenas tensões de compressão limitadas a 70\% da resistência à compressão do concreto (figura 2.5-b), de modo a fazer uma verificação simplificada do Estado Limite Último.

Tais tensões são calculadas como mostrado a seguir:

$$
\begin{gathered}
\sigma_{1}=\frac{P_{o}}{A_{c}}-\frac{P_{o} \cdot e_{p}}{W_{1}} \\
\sigma_{2}=\frac{P_{o}}{A_{c}}+\frac{P_{o} \cdot e_{p}}{W_{2}}
\end{gathered}
$$




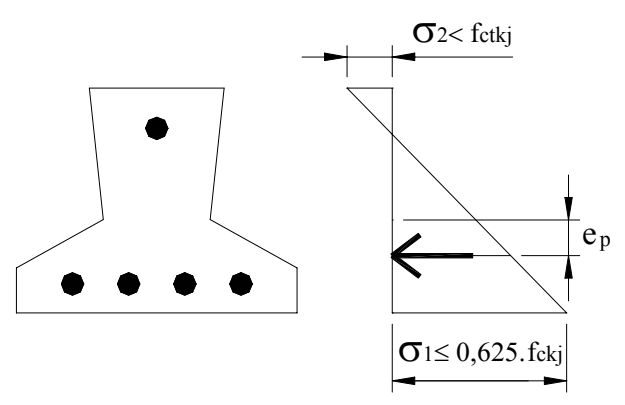

(a) EF-96

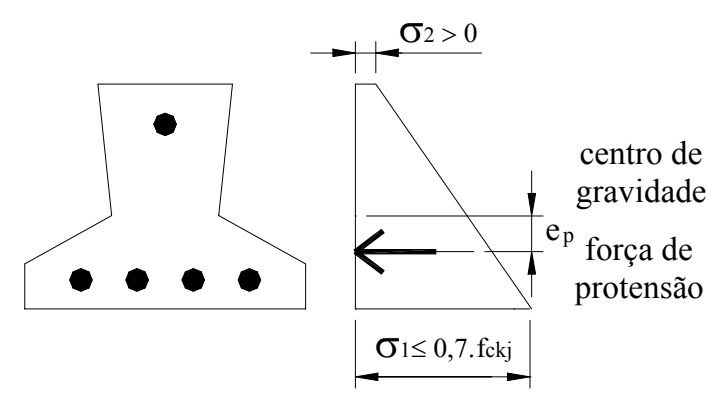

(b) NBR-7197

FIGURA 2.5 - Tensões na vigota após a transferência da força de protensão

onde:

$\sigma_{1}, \sigma_{2}-$ tensões no concreto nas fibras inferior e superior da vigota, com valor positivo para compressão e negativo para tração;

$\mathrm{P}_{\mathrm{o}}$ - força inicial na armadura de protensão considerando as perdas imediatas;

$\mathrm{A}_{\mathrm{c}}$ - área líquida de concreto da seção transversal da vigota;

$e_{p}$ - excentricidade da armadura protendida em relação ao centróide da seção transversal líquida de concreto (considerando negativo quando a armadura protendida estiver abaixo do centróide da seção de concreto);

$\mathrm{W}_{1}, \mathrm{~W}_{2}$ - módulos de resistência da seção transversal líquida de concreto, correspondentes à fibra inferior e superior respectivamente;

$\mathrm{f}_{\text {ckj }}$ - resistência característica à compressão do concreto da vigota no instante da liberação dos cabos protendidos;

$\mathrm{f}_{\text {ctkj }}$ - resistência característica à tração do concreto da vigota no instante da liberação dos cabos protendidos, podendo-se utilizar igual a 0,21. 3 $\sqrt{\mathrm{f}_{\mathrm{ckj}}^{2}}$ segundo a EF-96 (1997), com $\mathrm{f}_{\mathrm{ckj}}$ em MPa. 


\subsubsection{Verificação da vigota na fase de construção}

Em cada tramo, deve-se verificar se as vigotas necessitam ou não de escoramento e, nesse caso, a separação máxima entre as linhas de escoras, que será calculada levando-se em conta:

a) durante a concretagem em obra, a ação característica de execução sobre as vigotas será o peso total da laje e uma sobrecarga de execução não inferior a $1 \mathrm{kN} / \mathrm{m}^{2}$;

b) o vão de cálculo de cada tramo se medirá entre os apoios extremos das vigotas e os eixos das escoras (figura 2.6);

c) as solicitações serão calculadas pelo método linear, na hipótese de rigidez constante da vigota;

d) o coeficiente de majoração $\gamma_{\mathrm{f}}$ sobre as ações de execução, segundo a EF-96 (1997), pode ser tomado igual a 1,25. E com base na NBR-8681 (1984), pode-se utilizar $\gamma_{\mathrm{f}}$ igual a 1,2;

e) em alguns casos é conveniente considerar uma carga concentrada devida ao equipamento (girica) utilizado para o transporte do concreto sobre a laje.

As tensões nas vigotas deverão ser limitadas nos seguintes valores:

- sobre as escoras:

- na fibra inferior:

$$
\sigma_{1 \mathrm{p}}+\gamma_{\mathrm{f}} \cdot \mathrm{M}_{1} / \mathrm{W}_{1 \mathrm{~h}} \leq\left\{\begin{array}{c}
0,625 . \mathrm{f}_{\mathrm{ck}}-\mathrm{EF}-96 \\
0,7 . \mathrm{f}_{\mathrm{ck}}-\mathrm{NBR}-7197
\end{array}\right.
$$

- na fibra superior

$$
\sigma_{2 p}-\gamma_{f} \cdot M_{1} / W_{2 h} \geq\left\{\begin{array}{c}
f_{c t, f}-\text { EF-96 } \\
0-\text { NBR-7197 }
\end{array}\right.
$$


- nos vãos:

- na fibra inferior:

$\sigma_{1 \mathrm{p}}-\gamma_{\mathrm{f}} \cdot \mathrm{M}_{2} / \mathrm{W}_{1 \mathrm{~h}} \geq 0-$ EF-96 e NBR-7197

- na fibra superior

$$
\sigma_{2 p}+\gamma_{f} \cdot M_{2} / W_{2 h} \leq\left\{\begin{array}{c}
0,625 \cdot f_{c k}-\text { EF-96 } \\
0,7 . f_{c k}-\text { NBR-7197 }
\end{array}\right.
$$

sendo:

$\sigma_{1 \mathrm{p}}, \sigma_{2 \mathrm{p}}-$ tensões no concreto nas fibras inferior e superior da vigota devidas à força de protensão, considerando todas as perdas até a fase de execução da laje;

$\mathrm{M}_{1}, \mathrm{M}_{2}$ - esforços de flexão na vigota devidos às ações de execução, respectivamente, nos pontos com presença de escoras e nos vãos (ver figura 2.6);

$\mathrm{W}_{1 \mathrm{~h}}, \mathrm{~W}_{2 \mathrm{~h}}-$ módulos resistentes da seção homogeneizada da vigota, correspondentes à fibra inferior e superior respectivamente;

$\mathrm{f}_{\mathrm{ck}}$ - resistência característica à compressão do concreto da vigota;

$\mathrm{f}_{\mathrm{ct}, \mathrm{f}}$ - resistência do concreto à tração na flexão. Segundo EF-96 (1997) igual a $0,37 \cdot \sqrt[3]{\mathrm{f}_{\mathrm{ck}}^{2}}$ em MPa;

$\gamma_{\mathrm{f}}-$ coeficiente de majoração das cargas.

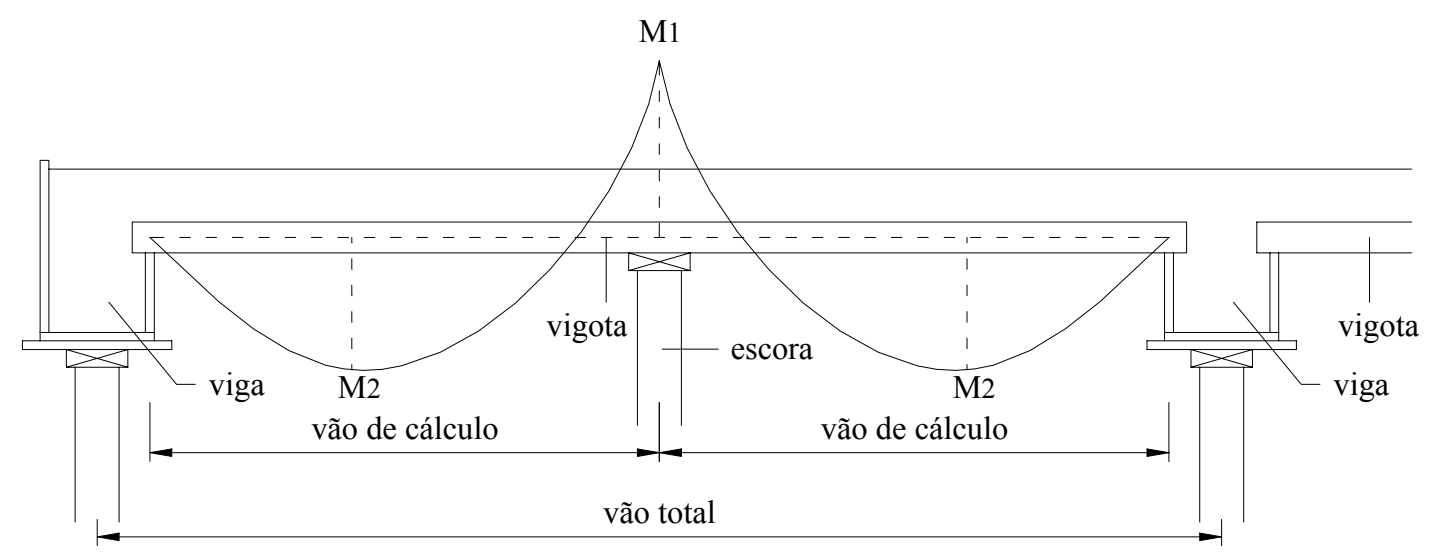

FIGURA 2.6 - Solicitações da vigota durante a concretagem [EF-96 (1997)] 
Para o caso da vigota protendida, CALAVERA (1989) destaca que, quando for necessária a utilização de escoramento, não se deve tentar corrigir, mediante a subida das escoras, a flecha imediata devido ao peso próprio da vigota, pois isso deixaria a vigota com o dobro do vão previsto entre escoras (trecho AC na figura 2.7) ou com um balanço igual a distância entre escoras (trecho CD na figura 2.7).

Portanto, deve-se obedecer as seguintes etapas durante a operação de execução da laje. Na etapa 1 (figura 2.8-a), as escoras são colocadas visivelmente abaixo dos apoios. Na etapa 2 (figura 2.8-b), são colocadas as vigotas pré-moldadas, que apresentarão flecha instantânea devido ao peso próprio trabalhando apoiadas unicamente nos extremos com um vão igual a $\ell$. Na etapa 3 (figura 2.8-c), as escoras sobem até entrar estritamente em contato com as vigotas pré-moldadas, sem forçá-las para cima.

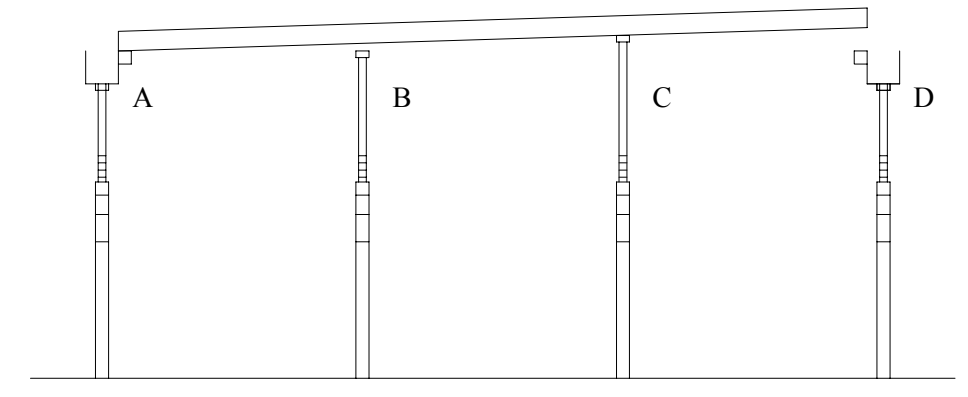

FIGURA 2.7 - Cuidados durante a fase de construção [CALAVERA (1989)]

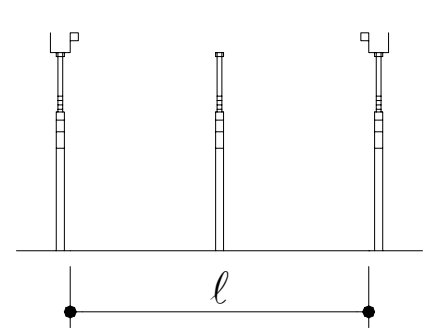

(a)

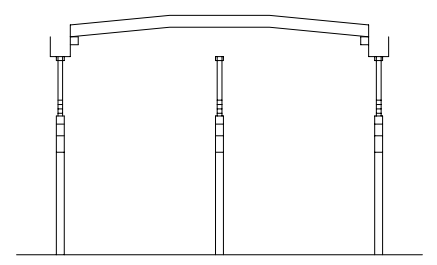

(b)

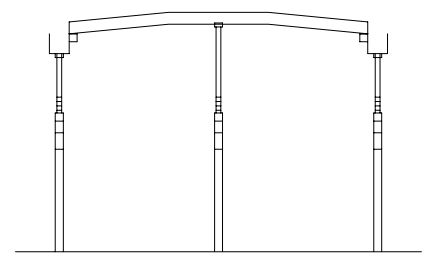

(c)

FIGURA 2.8 - Seqüência de escoramento [CALAVERA (1989)] 


\subsubsection{Estado limite de fissuração}

Para efetuar a verificação do estado limite de fissuração, deve-se inicialmente realizar a homogeneização da seção conforme indicado na figura 2.9. $\mathrm{Na}$ prática a homogeneização da seção é realizada substituindo as larguras $\underline{b}$ do concreto moldado no local por uma largura fictícia $b_{n}=m \cdot b$. Sendo $\underline{m}$ a relação entre os módulos de elasticidade do concreto moldado no local $\left(\mathrm{E}_{\mathrm{c}, 2}\right)$ e o concreto pré-moldado $\left(\mathrm{E}_{\mathrm{c}, 1}\right)$, como mostrado abaixo. Isto equivale substituir o contorno $\mathrm{S}$ do concreto moldado no local por outro $\mathrm{S}^{\prime}$.

$$
\mathrm{m}=\frac{\mathrm{E}_{\mathrm{c}, 2}}{\mathrm{E}_{\mathrm{c}, 1}}=\sqrt{\frac{\mathrm{f}_{\mathrm{ck}, 2}}{\mathrm{f}_{\mathrm{ck}, 1}}}
$$

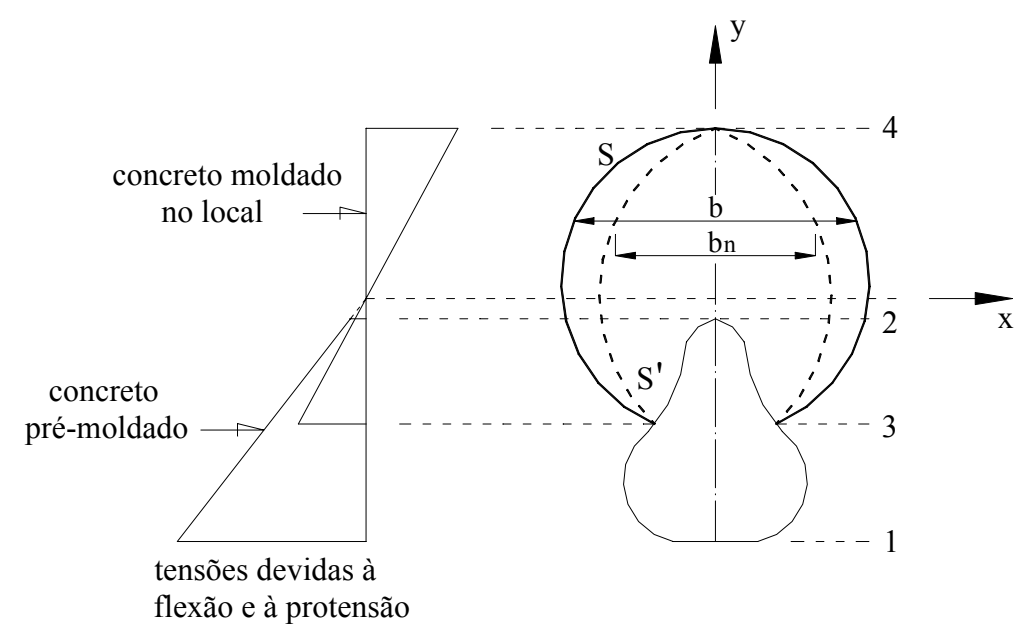

FIGURA 2.9 - Homogeneização da seção da laje

As tensões das fibras extremas da seção composta são:

$$
\begin{aligned}
& \sigma_{\mathrm{CPM} 1}=\frac{\mathrm{P}_{\infty}}{\mathrm{A}_{\mathrm{c}}}-\frac{\mathrm{P}_{\infty} \cdot \mathrm{e}_{\mathrm{p}}}{\mathrm{W}_{1}}-\frac{\mathrm{M}_{1}}{\mathrm{~W}_{1 \mathrm{~h}}}-\frac{\mathrm{M}_{2}}{\mathrm{~W}_{1 \mathrm{~h}}{ }^{\prime}} \\
& \sigma_{\mathrm{CPM} 2}=\frac{\mathrm{P}_{\infty}}{\mathrm{A}_{\mathrm{c}}}+\frac{\mathrm{P}_{\infty} \cdot \mathrm{e}_{\mathrm{p}}}{\mathrm{W}_{2}}+\frac{\mathrm{M}_{1}}{\mathrm{~W}_{1 \mathrm{~h}}}-\frac{\mathrm{M}_{2}}{\mathrm{~W}_{2 \mathrm{~h}^{\prime}}} \\
& \sigma_{\mathrm{CML} 3}=-\mathrm{m} \cdot \frac{\mathrm{M}_{2}}{\mathrm{~W}_{3 \mathrm{~h}^{\prime}}{ }^{\prime}} \\
& \sigma_{\mathrm{CML} 4}=\mathrm{m} \cdot \frac{\mathrm{M}_{2}}{\mathrm{~W}_{4 \mathrm{~h}^{\prime}}}
\end{aligned}
$$


sendo:

$\sigma_{\mathrm{CPM}}, \sigma_{\mathrm{CML}}-$ tensões na seção de concreto pré-moldado e moldado no local, respectivamente;

$\mathrm{P}_{\infty}$ - força na armadura de protensão considerando as perdas totais;

$\mathrm{A}_{\mathrm{c}}$ - área líquida de concreto da seção transversal da vigota;

$e_{p}$ - excentricidade da armadura protendida em relação ao centróide da seção transversal líquida de concreto;

$\mathrm{W}_{1}, \mathrm{~W}_{2}-$ módulos de resistência da seção transversal líquida de concreto, correspondentes à fibra inferior e superior respectivamente;

$\mathrm{W}_{1 \mathrm{~h}}, \mathrm{~W}_{2 \mathrm{~h}}$ - módulos de resistência da seção homogeneizada da vigota, correspondentes à fibra inferior e superior respectivamente;

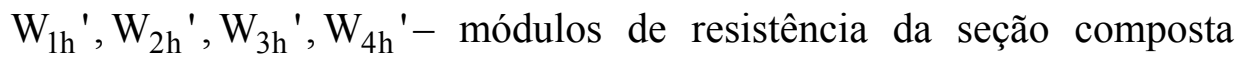
homogeneizada, obtidos dividindo o momento de inércia da seção composta homogeneizada pela distância y;

$M_{1}$ - esforços de flexão na seção antes da solidarização dos concretos;

$\mathrm{M}_{2}$ - esforços de flexão na seção após a solidarização dos concretos;

Para prevenir os efeitos da fissuração, segundo a EF-96 (1997), as lajes formadas por vigotas protendidas devem ser projetadas de tal forma que, quando submetida à carga total, se verifiquem as seguintes condições (figura 2.10):

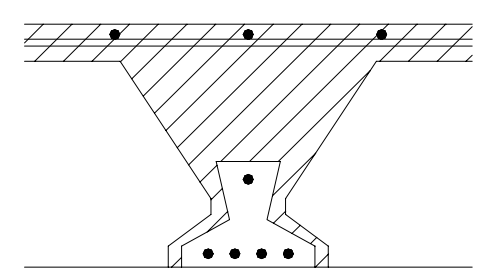

\section{Estado limite de} descompressão

Classe I

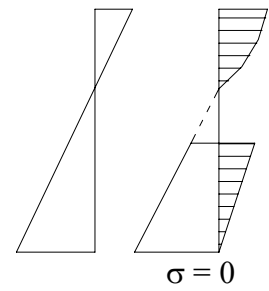

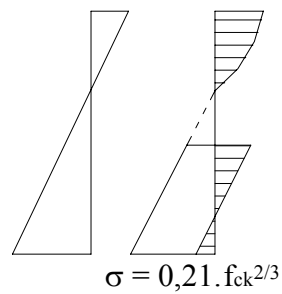

Estado limite de formação de fissuras Classe II

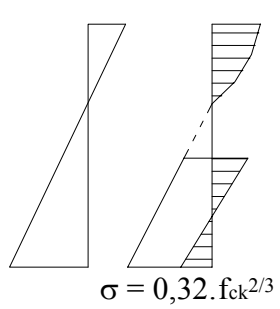

Estado limite de abertura das fissuras Classe III

FIGURA 2.10 - Estados limites de fissuração [EF-96 (1997)] 
a) Para a Classe I, não ultrapasse o estado limite de descompressão, caracterizado pela existência de tensão nula na fibra menos comprimida da seção;

b) Para a Classe II, não ultrapasse o estado limite de aparecimento de fissuras, caracterizado pelo aparecimento de uma tensão tração de valor $0,21 \cdot \sqrt[3]{\mathrm{f}_{\mathrm{ck}}^{2}}$ na fibra mais tracionada da seção, com $\mathrm{f}_{\mathrm{ck}}$ em MPa;

c) Para Classe III, não atinja o estado limite de fissuração controlada, caracterizado pelo aparecimento de uma tensão de tração de valor $0,32 \cdot \sqrt[3]{\mathrm{f}_{\mathrm{ck}}^{2}}$ na fibra mais tracionada da seção, com $\mathrm{f}_{\mathrm{ck}}$ em MPa;

As classes indicadas acima dependem das condições ambientais que se encontrará a estrutura que está sendo projetada, e estão indicadas a seguir:

a) Classe I: estruturas situadas em ambientes muito agressivos, tal como atmosfera marinha ou industrial, contato com o terreno, contato com águas salinas ou ligeiramente ácidas;

b) Classe II: estruturas expostas a intempérie;

c) Classe III: estruturas não submetidas a ambientes agressivos, tal como no interior de edifícios ou no exterior com baixa umidade.

A NBR-7197 (1989) especifica três tipos de protensão, que podem ser encarados como graus de protensão (completa, limitada e parcial) e dependem do nível de agressividade que a estrutura será submetida (ver tabela 2.2). Em função do tipo de protensão são definidos quais estados limites devem ser respeitados, com as respectivas combinações de ações a serem utilizadas (ver tabela 2.3).

TABELA 2.2 - Escolha do tipo de protensão, segundo NBR-7197 (1989)

\begin{tabular}{|c|c|}
\hline $\begin{array}{c}\text { Nível de agressividade do } \\
\text { ambiente }\end{array}$ & $\begin{array}{c}\text { Exigências mínimas quanto ao } \\
\text { tipo de protensão }\end{array}$ \\
\hline muito agressivo & protensão completa \\
\hline pouco agressivo & protensão limitada \\
\hline não agressivo & protensão parcial \\
\hline
\end{tabular}


TABELA 2.3 - Estados limites a verificar para cada tipo de protensão, segundo NBR-7197 (1989)

\begin{tabular}{|c|c|c|c|}
\hline \multirow{2}{*}{ Tipos de protensão } & \multicolumn{3}{|c|}{ Combinação de ações } \\
\cline { 2 - 4 } & Quase-permanente & Freqüente & Rara \\
\hline completa & - & descompressão & $\begin{array}{c}\text { formação de } \\
\text { fissuras }\end{array}$ \\
\hline limitada & descompressão & $\begin{array}{c}\text { formação de } \\
\text { fissuras }\end{array}$ & - \\
\hline parcial & descompressão & abertura de fissuras & - \\
\hline
\end{tabular}

As combinações de ações indicadas acima podem ser representadas da seguinte forma:

- Combinação quase-permanente de utilização:

$$
\mathrm{F}_{\mathrm{d}, \mathrm{uti}}=\sum_{\mathrm{i}=1}^{\mathrm{m}} \mathrm{F}_{\mathrm{Gi}, \mathrm{k}}+\sum_{\mathrm{j}=1}^{\mathrm{n}} \Psi_{2 \mathrm{j}} \cdot \mathrm{F}_{\mathrm{Qj}, \mathrm{k}}
$$

- Combinação freqüente de utilização:

$$
\mathrm{F}_{\mathrm{d}, \mathrm{uti}}=\sum_{\mathrm{i}=1}^{\mathrm{m}} \mathrm{F}_{\mathrm{Gi}, \mathrm{k}}+\Psi_{1} \cdot \mathrm{F}_{\mathrm{q} 1, \mathrm{k}}+\sum_{\mathrm{j}=1}^{\mathrm{n}} \Psi_{2 \mathrm{j}} \cdot \mathrm{F}_{\mathrm{Qj}, \mathrm{k}}
$$

- Combinação rara de utilização:

$$
\mathrm{F}_{\mathrm{d}, \text { uti }}=\sum_{\mathrm{i}=1}^{\mathrm{m}} \mathrm{F}_{\mathrm{Gi}, \mathrm{k}}+\mathrm{F}_{\mathrm{Q} 1, \mathrm{k}}+\sum_{\mathrm{j}=1}^{\mathrm{n}} \Psi_{1 \mathrm{j}} \cdot \mathrm{F}_{\mathrm{Qj}, \mathrm{k}}
$$

onde:

$\mathrm{F}_{\mathrm{d} \text {,uti }}$ - ações utilizadas na verificação dos estados limites de utilização;

$\mathrm{F}_{\mathrm{Gi}, \mathrm{k}}$ - ações permanentes, podendo ser peso próprio da laje, peso de alvenarias e revestimentos, etc;

$\mathrm{F}_{\mathrm{Qj}, \mathrm{k}}$ - ações principais acidentais, podendo ser cargas variáveis, sobrecarga de utilização, etc;

$\Psi_{1}, \Psi_{2}$ - fatores de utilização para combinação de ações freqüentes e quase-permanentes, respectivamente, cujos valores estão definidos na NBR-8681 (1984) 


\subsubsection{Estado limite de deformação excessiva}

Segundo a EF-96 (1997), o cálculo das deformações das lajes deve ser feito levando-se em conta tanto os efeitos instantâneos como os diferidos, de acordo com as características dos materiais e das seções, e os efeitos de retração e fluência correspondentes.

No cálculo da flecha, deve-se distinguir:

- flecha total no tempo infinito, produzida pela totalidade das cargas atuantes, tanto as permanentes como as sobrecargas. Essa flecha é formada pela flecha instantânea produzida por todas as cargas, mais a flecha diferida produzida pelas cargas permanentes a partir da sua atuação;

- flecha ativa relativa a um elemento não estrutural, produzida a partir do instante em que se constrói tal elemento. Portanto, seu valor é igual a flecha total no tempo infinito menos aquela que já existia antes da construção de tal elemento.

A EF-96 (1997) limita tais flechas nos seguintes valores:

a) a flecha total no tempo infinito não deve exceder o menor dos valores $\ell / 250$ e $\ell / 500+1 \mathrm{~cm}$;

b) para lajes que irão suportar paredes: a flecha ativa não deve exceder o menor dos valores $\ell / 400$ e $\ell / 800+0,6 \mathrm{~cm}$;

c) para lajes que irão suportar paredes muito rígidas: a flecha ativa não deve exceder o menor dos valores $\ell / 500$ e $\ell / 1000+0,5 \mathrm{~cm}$;

Nas expressões anteriores $\ell$ é o valor do vão e, no caso de balanço, 1,6 vezes o valor.

Nas lajes com vãos menores que 7 metros e sobrecargas não maiores que $4 \mathrm{kN} / \mathrm{m}^{2}$, a EF-96 (1997) indica que não é necessário verificar a flecha caso a altura total da laje for maior que h:

$$
\mathrm{h}=\delta_{1} \cdot \delta_{2} \cdot \ell / \mathrm{C} \quad(\mathrm{em} \text { metros })
$$


onde:

$\delta_{1}-$ fator que depende da carga total $(\mathrm{p}=\mathrm{g}+\mathrm{q})$, tendo valor igual a $\sqrt{\mathrm{p} / 7}$, com $\mathrm{p}$ em $\mathrm{kN} / \mathrm{m}^{2}$;

$\delta_{2}$ - fator com valor igual a $\sqrt[4]{\ell / 6}$;

$\ell$ - vão de cálculo da laje em metros;

$\mathrm{C}$ - coeficiente cujo valor pode ser encontrado na tabela 2.4.

TABELA 2.4 - Valor do coeficiente C definido pela EF-96 (1997)

\begin{tabular}{|c|c|c|c|}
\hline \multirow{2}{*}{} & \multicolumn{3}{|c|}{ tipo de tramo } \\
\cline { 2 - 4 } & isolado & extremo & interior \\
\hline com divisórias & 20 & 24 & 27 \\
\hline com paredes & 19 & 23 & 26 \\
\hline Cobertura & 22 & 26 & 29 \\
\hline
\end{tabular}

No que diz respeito ao estado limite de deformações excessivas, a NBR-7197 (1989) prescreve em seu anexo que essa verificação deve ser feita utilizando a combinação quase-permanente de ações.

O projeto de revisão da NBR-6118:2000 apresentada os deslocamentos limites, considerando não apenas os deslocamentos que impeçam a utilização adequada da construção (estrutura em serviço), mas os deslocamentos capazes de produzir sensações desagradáveis para o usuário (aceitabilidade sensorial) e os deslocamentos que ocasionem o mau funcionamento de elementos não estruturais ligados à estrutura. Tais limites para os deslocamentos estão apresentados na tabela 2.5 . 
TABELA 2.5 - Limites para deslocamentos segundo o projeto de revisão da NBR-61 18:2000

\begin{tabular}{|c|c|c|c|}
\hline \multicolumn{4}{|c|}{ Estrutura em serviço } \\
\hline $\begin{array}{l}\text { Razão da } \\
\text { limitação }\end{array}$ & Exemplos & $\begin{array}{c}\text { Deslocamento } \\
\text { limite }\end{array}$ & Deslocamento a considerar \\
\hline $\begin{array}{c}\text { Superfícies que } \\
\text { devem drenar água }\end{array}$ & Coberturas e varandas & $\ell / 250$ & Deslocamento total \\
\hline \multirow{2}{*}{$\begin{array}{c}\text { Pavimentos que } \\
\text { devem permanecer } \\
\text { planos }\end{array}$} & \multirow{2}{*}{$\begin{array}{l}\text { Ginásios e pistas de } \\
\text { boliche }\end{array}$} & $\begin{array}{l}\ell / 350+\text { contra- } \\
\text { flecha }\end{array}$ & Deslocamento total \\
\hline & & $\ell / 600$ & $\begin{array}{l}\text { Deslocamento incremental } \\
\text { após a construção do piso }\end{array}$ \\
\hline $\begin{array}{l}\text { Elementos que } \\
\text { suportam } \\
\text { equipamentos } \\
\text { sensíveis }\end{array}$ & $\begin{array}{l}\text { Laboratórios de medidas } \\
\text { de grande precisão }\end{array}$ & $\begin{array}{l}\text { De acordo com } \\
\text { recomendações } \\
\text { do fabricante }\end{array}$ & $\begin{array}{c}\text { Deslocamento que ocorram } \\
\text { após nivelamento do } \\
\text { aparelho }\end{array}$ \\
\hline \multicolumn{4}{|c|}{ Aceitabilidade sensorial } \\
\hline $\begin{array}{l}\text { Razão da } \\
\text { limitação }\end{array}$ & Exemplos & $\begin{array}{c}\text { Deslocamento } \\
\text { limite }\end{array}$ & Deslocamento a considerar \\
\hline Visual & $\begin{array}{c}\text { Deslocamentos em } \\
\text { elementos estruturais } \\
\text { visíveis }\end{array}$ & $\ell / 250$ & Deslocamento total \\
\hline Outros & $\begin{array}{c}\text { Vibrações que podem ser } \\
\text { sentidas no piso }\end{array}$ & $\ell / 350$ & $\begin{array}{c}\text { Deslocamentos devidos à } \\
\text { carga acidental }\end{array}$ \\
\hline \multicolumn{4}{|c|}{ Efeitos em elementos não estruturais } \\
\hline $\begin{array}{l}\text { Razão da } \\
\text { limitação }\end{array}$ & Exemplos & $\begin{array}{c}\text { Deslocamento } \\
\text { limite } \\
\end{array}$ & Deslocamento a considerar \\
\hline \multirow{2}{*}{ Paredes } & $\begin{array}{l}\text { Alvenaria, caixilhos e } \\
\text { revestimento }\end{array}$ & $\ell / 500$ ou $10 \mathrm{~mm}$ & $\begin{array}{c}\text { Deslocamento ocorrido após } \\
\text { a construção da parede }\end{array}$ \\
\hline & $\begin{array}{c}\text { Divisórias leves e } \\
\text { caixilhos telescópicos }\end{array}$ & $\ell / 250$ ou $25 \mathrm{~mm}$ & $\begin{array}{c}\text { Deslocamento ocorrido após } \\
\text { a instalação da divisória }\end{array}$ \\
\hline \multirow{2}{*}{ Forros } & Revestimentos colados & $\ell / 350$ & $\begin{array}{c}\text { Deslocamento ocorrido após } \\
\text { a construção do forro }\end{array}$ \\
\hline & $\begin{array}{c}\text { Revestimentos } \\
\text { pendurados ou com juntas } \\
\end{array}$ & $\ell / 175$ & $\begin{array}{c}\text { Deslocamento ocorrido após } \\
\text { a construção do forro }\end{array}$ \\
\hline \multicolumn{4}{|c|}{$\begin{array}{l}\text { Observações: } \\
\text { 1) Quando se tratar de balanços, o vão equivalente a ser considerado deve ser o dobro do } \\
\text { comprimento do balanço; } \\
\text { 2) Para o caso de elementos de superfície, os limites prescritos consideram que o valor de } \ell \text { é o } \\
\text { menor vão, exceto em casos de verificação de paredes e divisórias, onde interessa a direção } \\
\text { na qual a parede ou divisória se desenvolve. }\end{array}$} \\
\hline
\end{tabular}

\subsubsection{Estado limite último para as solicitações tangenciais}

A resistência à força cortante da laje com vigotas protendidas é determinada com as recomendações de resistência à força cortante de elementos sem armadura transversal. 
Segundo a EF-96 o esforço cortante de cálculo $V_{d}$ por nervura deve respeitar as seguintes expressões:

- $\quad$ esgotamento conjunto com a compressão da nervura

$$
\mathrm{V}_{\mathrm{d}} \leq \mathrm{V}_{\mathrm{u} 1}=0,3 \cdot \mathrm{f}_{\mathrm{cd}} \cdot \mathrm{b}_{\mathrm{w}} \cdot \mathrm{d}
$$

- esgotamento conjunto com a tração da nervura

$$
\mathrm{V}_{\mathrm{d}} \leq \mathrm{V}_{\mathrm{u} 2}=2 \cdot \mathrm{f}_{\mathrm{cv}} \cdot \mathrm{b}_{\mathrm{w}} \cdot \mathrm{d}
$$

sendo:

$\mathrm{b}_{\mathrm{w}}$ - largura mínima da nervura;

$\mathrm{d}$ - altura útil da laje;

$\mathrm{f}_{\mathrm{cd}}$ - resistência de cálculo do concreto à compressão;

$\mathrm{f}_{\mathrm{cv}}$ - resistência virtual de cálculo do concreto ao esforço cortante. Igual a $0,16 \cdot \sqrt{f_{c d}}$, com $f_{c d}$ expresso em MPa;

As equações anteriores devem ser verificadas utilizando diversas larguras $b_{i}$, considerando a resistência do concreto que é cortado pelas superfícies de referência (figura 2.11). E quando a superfície de referência cortar os dois concretos, deve-se fazer a verificação para a largura do concreto pré-moldado com sua resistência e para a largura total com a resistência do concreto moldado no local.

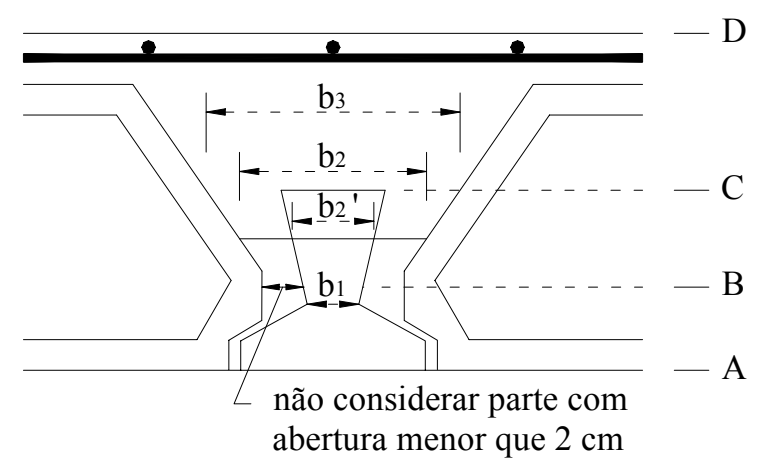

FIGURA 2.11 - Larguras para a verificação da força cortante [EF-96 (1997)]

Assim, distinguem-se três zonas de verificação do esforço cortante:

Zona $A-B$

Zona constituída somente por concreto da vigota pré-moldada, pois como mostrado na figura 2.11, não se considera o concreto moldado no local 
abaixo de aberturas menores que $2 \mathrm{~cm}$. O valor mínimo de $b_{\mathrm{i}}$ é, portanto, a dimensão $b_{1}$, logo:

$$
\begin{aligned}
& V_{d} \leq V_{u}\left(b_{1}\right) \\
& \text { em que } V_{u} \text { é particularizada para a largura } b_{1} .
\end{aligned}
$$

Zona $B-C$

Nesta zona há a presença tanto de concreto pré-fabricado como moldado no local. $\mathrm{O}$ esforço cortante $\mathrm{V}_{\mathrm{d}}$ mínimo é definido por:

$$
V_{d} \leq\left\{\begin{array}{l}
V_{u}\left(b_{2}\right)-\text { com a resistência do concreto moldado no local } \\
V_{u}\left(b_{2}{ }^{\prime}\right)-\text { com a resistência do concreto pré-moldado }
\end{array}\right.
$$

Zona $C-D$

Existe somente concreto moldado no local. $\mathrm{O}$ menor valor de $\mathrm{V}_{\mathrm{d}}$ nesta zona será:

$$
\mathrm{V}_{\mathrm{d}} \leq \mathrm{V}_{\mathrm{u}}\left(\mathrm{b}_{3}\right)
$$

Além disso, para as lajes com vigotas protendidas, cujas seções se completam com concreto moldado na obra (figura 2.12), a EF-96 (1997) especifica que, não haverá problema com o cisalhamento na interface entre os dois concretos, se for verificado:

$$
\mathrm{V}_{\mathrm{d}} \leq \beta . \text { u.d.f } \mathrm{fv}_{\mathrm{cv}}
$$

sendo:

$\mathrm{f}_{\mathrm{cv}}$ - resistência virtual de cálculo do concreto moldado na obra ao esforço cortante. Igual a $0,16 \cdot \sqrt{\mathrm{f}_{\mathrm{cd}}}$, com $\mathrm{f}_{\mathrm{cd}}$ expresso em MPa;

$\mathrm{u}$ - perímetro crítico ao cisalhamento (figura 2.12), incluindo, se for necessário, zonas de concreto moldado no local;

$\beta$ - coeficiente de rugosidade da superfície de contato, de valor 1,2 para superfícies rugosas e 0,6 para superfície lisa;

$\mathrm{d}$ - altura útil da seção. 

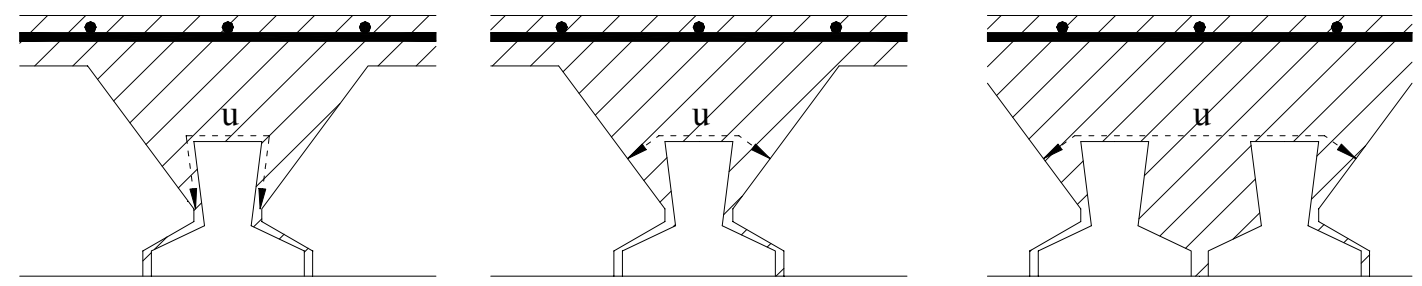

FIGURA 2.12 - Perímetro para a verificação do cisalhamento da interface [EF-96 (1997)]

\subsubsection{Estado limite último para as solicitações normais}

$\mathrm{Na}$ determinação do momento último $\left(\mathrm{M}_{\mathrm{u}}\right)$ da seção composta, deve-se levar em conta os diferentes valores de resistência de cálculo $f_{c d}$ apresentado pelos distintos concretos que formam a seção (figura 2.13). Naturalmente, quando a zona comprimida afeta unicamente a um dos dois concretos, o valor de $f_{c d}$ do concreto que não estiver comprimido não intervém nos cálculos. Para a determinação da tensão na armadura de protensão $\sigma_{\mathrm{p}}$ deve levar em consideração o alongamento prévio da armadura, existente antes de se considerar as ações externas, denominado de préalongamento.

Para a determinação do momento último da seção a armadura é normalmente considerada estando no centro de gravidade das barras, como pode ser visto na figura 2.13. Essa simplificação pode conduzir a erros significativos se a vigota apresentar várias camadas de armadura, necessitando fazer um cálculo mais apurado com a consideração de cada uma das camadas separadamente.

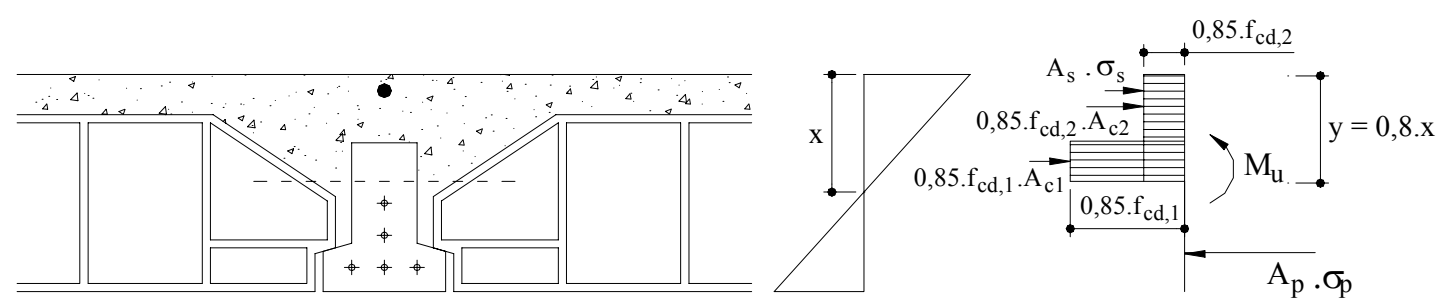

FIGURA 2.13 - Consideração da diferença de resistência dos concretos para determinação de $\mathrm{M}_{\mathrm{u}}$ 
Para momentos negativos a EF-96 (1997) indica que se pode calcular as lajes como vigotas armadas (figura 2.14).

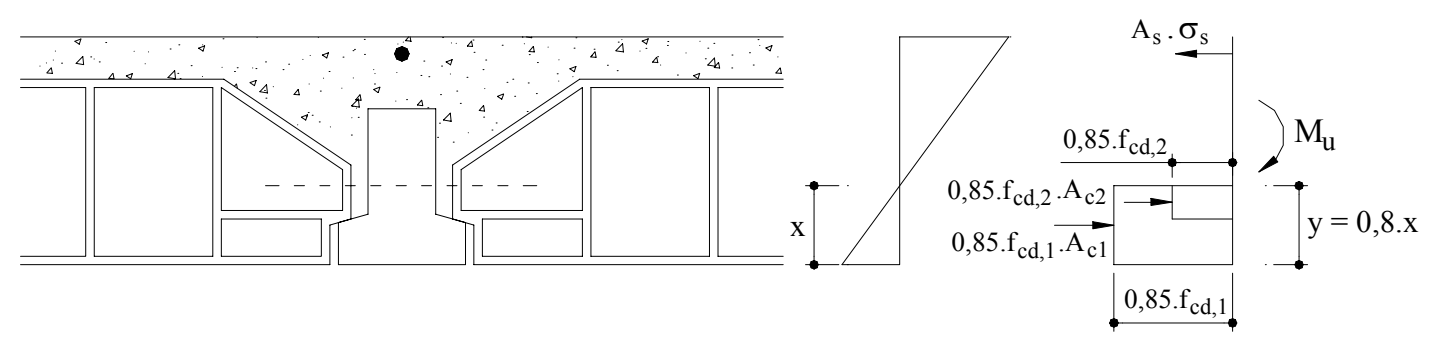

FIGURA 2.14 - Determinação do momento negativo resistente

\subsection{Redistribuição dos esforços}

"Os momentos fletores podem ser avaliados utilizando a análise linear, desde que o carregamento atuante tenha um valor tal que o limite elástico não seja excedido para os materiais constituintes. Quando esse limite elástico for excedido, para um determinado carregamento, os momentos fletores diferenciarão daqueles obtidos pela análise linear. A diferença entre o momento fletor real para uma seção e aquele determinado pela análise linear é referida como redistribuição de momento" (KODUR \& CAMPBELL, 1996).

A utilização de uma análise linear seguida por uma limitação na redistribuição de momentos já é normalmente utilizada em projetos. A utilização da redistribuição de momentos apresenta vários benefícios, como os apontados pelo CEB (1998) e listados a seguir:

- a transferência de esforços solicitantes para as áreas com tensões mais baixas;

- menor taxa de armadura localizada nas áreas de momentos negativos, portanto, tensões reduzidas na região comprimida da seção;

- redução do congestionamento de barras de aço sobre os apoios de lajes contínuas, ocasionando melhoria das condições de concretagem nestas áreas críticas;

- maior liberdade no detalhamento da armadura. 


\subsubsection{Prescrições da EF-96 (1997)}

Para a consideração da redistribuição de momentos fletores, a EF-96 (1997) faz as mesmas prescrições para todo tipo de laje formada por elementos prémoldados unidirecionais.

Pode-se considerar a redistribuição plástica de momentos com valor de $15 \%$, ou no máximo, a redistribuição que resulte de igualar os momentos nos apoios e nos vãos.

Nos apoios sem continuidade deve ser considerado um momento fletor negativo resultante do engastamento parcial com a viga de borda, com valor não menor que $1 / 4$ do momento fletor máximo positivo do tramo adjacente.

Todos vãos deverão resistir, no mínimo, um momento positivo igual a $1 / 2$ de seu momento isostático.

As solicitações com a redistribuição máxima admitida para as lajes podem ser obtidas pelo seguinte método simplificado:

a) Momento fletor máximo positivo em cada tramo (figura 2.15-a) - serão calculados os momentos para a carga total de acordo com o seguinte critério; nos tramos externos se utilizará um momento igual ao de seu apoio interno $\left(\mathrm{M}_{1}\right.$ ou $\left.\mathrm{M}_{3}\right)$. Nos tramos internos se utilizará um momento igual ao de ambos apoios $\left(\mathrm{M}_{2}\right)$. Nos apoios externos se utilizará zero para o caso em que não haja balanço e, caso contrário, o momento devido às cargas permanentes do mesmo $\left(\mathrm{M}_{\mathrm{bcp}}\right)$;

b) Momento fletor negativo em cada apoio - nos apoios externos se utilizará momento igual a $1 / 4$ do momento positivo do tramo adjacente ou o momento do balanço devido a carga total $\left(\mathrm{M}_{\mathrm{b}}\right)$, se existir e for maior. Nos apoios internos, o maior dos momentos positivos dos tramos adjacentes;

c) A envoltória dos momentos fletores (figura 2.15-b) será obtida superpondo ao diagrama básico os momentos fletores das cargas permanentes de cada tramo, traçada a partir dos momentos negativos considerados nos correspondentes apoios. 


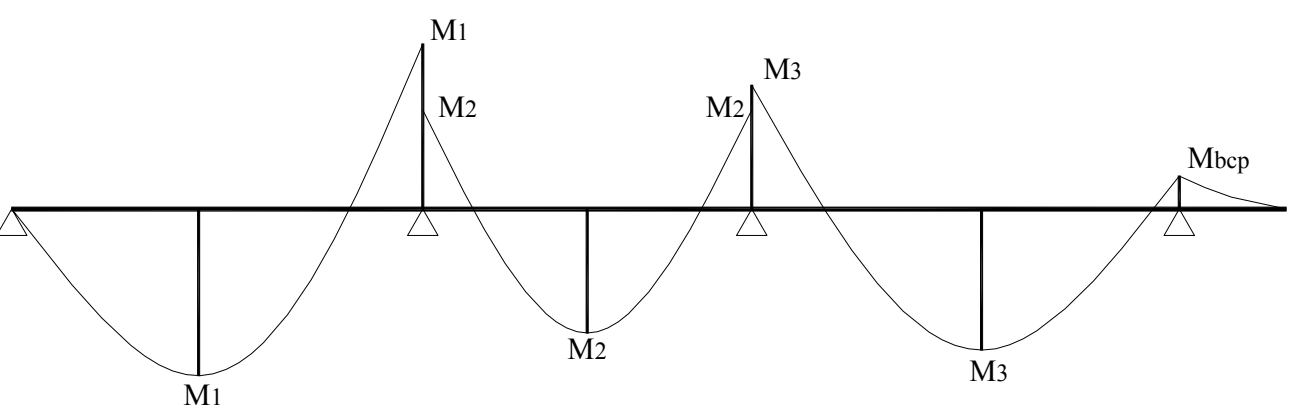

Diagrama básico de momentos fletores

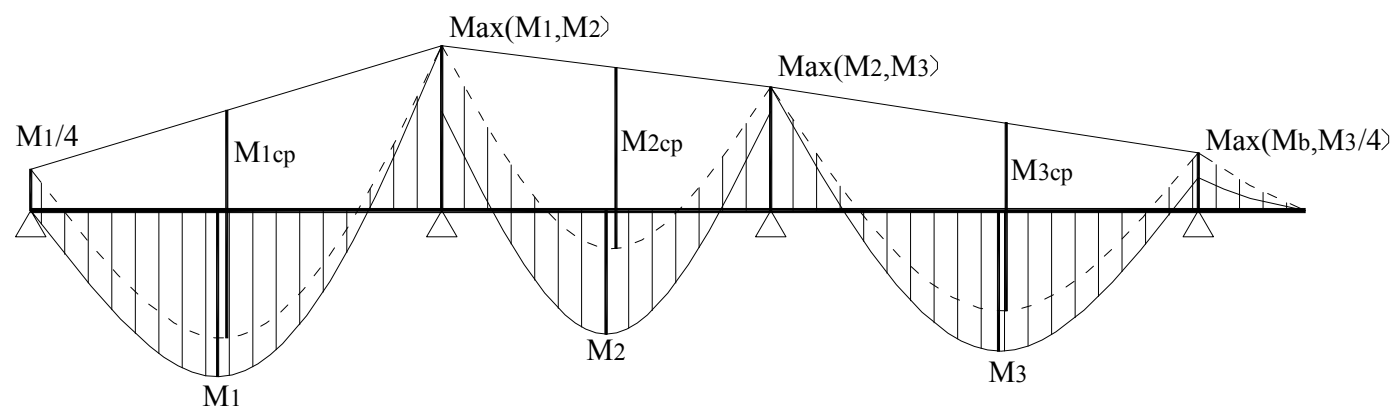

Envoltória de momentos fletores

FIGURA 2.15 - Diagrama de momentos fletores de acordo com a EF-96 (1997)

\subsubsection{Prescrições da CPT Planchers (1980)}

Para o caso das lajes formadas por vigotas protendidas, o método da CPT Planchers para a consideração da redistribuição de momentos fletores consiste em fixar, para cada tramo, os valores máximos dos momentos no vão e nos apoios em frações de $\mathrm{M}_{\mathrm{o}}$. $\mathrm{O}$ valor de $\mathrm{M}_{\mathrm{o}}$ é definido como momento fletor máximo de um tramo isostático de mesmo vão e submetido à mesma carga, como pode ser visto na figura 2.16 .

Este método é limitado às lajes com as seguintes características:

- relação entre vãos sucessivos compreendida entre 0,80 e 1,25;

- carga acidental menor que duas vezes a carga permanente e inferior a $5 \mathrm{kN} / \mathrm{m}^{2}$. 
Os limites para os momentos com a consideração da redistribuição serão:

1) $\mathrm{M}_{\text {vão }}+\frac{\mathrm{M}_{\mathrm{esq}}+\mathrm{M}_{\mathrm{dir}}}{2} \geq(1+0,3 \cdot \alpha) \cdot \mathrm{M}_{\mathrm{o}} \quad \operatorname{com}(1+0,3 \cdot \alpha) \leq 1,05$

sendo:

$\alpha=\frac{\mathrm{q}}{\mathrm{g}+\mathrm{q}}$

$\mathrm{g}$ - carga permanente;

q - carga acidental;

$\mathrm{M}_{\text {esq }}$ e $\mathrm{M}_{\text {dir }}$ - valores absolutos dos momentos, respectivamente, sobre o apoio à esquerda e a direita;

$\mathrm{M}_{\text {vão }}$ - momento máximo no vão.

2) momento máximo no vão $M_{\text {vão }}$ deve ser superior a:

$\frac{1+0,3 \cdot \alpha}{2} \cdot \mathrm{M}_{\mathrm{o}}-$ no caso de tramos internos;

$\frac{1,2+0,3 \cdot \alpha}{2} \cdot \mathrm{M}_{\mathrm{o}}-$ no caso de tramos externos.

3) valor absoluto do momento sobre cada apoio deve ser:

- superior a:

$0,45 \mathrm{M}_{\mathrm{o}}{ }^{\prime}$ - para lajes com dois tramos;

$0,40 \mathrm{M}_{\mathrm{o}}{ }^{\prime}$ - para apoios internos de lajes com mais de dois tramos.

- inferior a:

$0,65 \mathrm{M}_{\mathrm{o}}{ }^{\prime}$ - para lajes com dois tramos;

$0,60 \mathrm{M}_{\mathrm{o}}{ }^{\prime}$ - para apoios vizinhos ao tramo externo de lajes com mais de dois tramos;

0,55 $\mathrm{M}_{\mathrm{o}}{ }^{\prime}$ - para apoios não vizinhos ao tramo externo de lajes com mais de três tramos. 
sendo:

para lajes montadas na obra com escoras $\rightarrow \mathrm{M}_{\mathrm{o}}{ }^{\prime}=\mathrm{M}_{\mathrm{o}}$;

para lajes moldadas na obra sem escoras $\rightarrow \mathrm{M}_{\mathrm{o}}{ }^{\prime}$ é igual a $\mathrm{M}_{\mathrm{o}}$, mas considerando somente $60 \%$ do peso da laje.

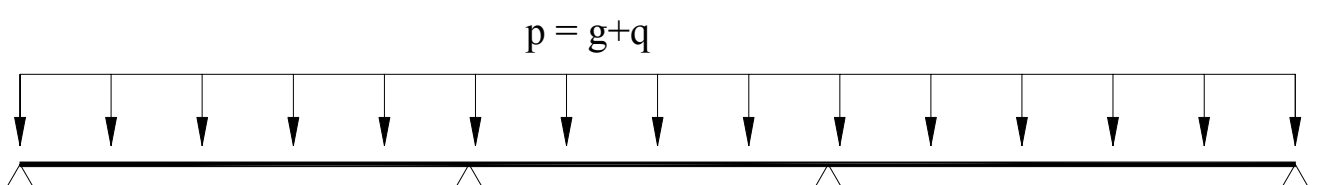

(a) Esquema estático da laje

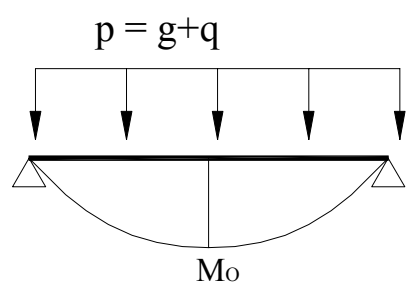

(b) Determinação de Mo para o tramo interno

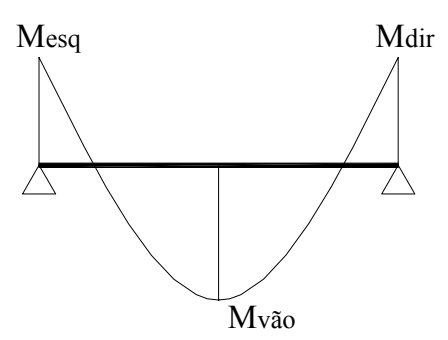

(c) Limites no vão e nos apoios a serem determinados

FIGURA 2.16 - Método para a consideração da redistribuição de momentos de acordo com a CPT Planchers (1980) 


\section{ESFORÇO DE FLEXÃO DEVIDO AO CARREGAMENTO EXTERNO INCREMENTAL}

\subsection{Considerações iniciais}

A análise teórica da continuidade foi realizada através de simulações numéricas em faixas de lajes nervuradas unidirecionais formadas por vigotas protendidas, com a consideração da não linearidade física do concreto a partir do uso da relação momento $x$ curvatura proposta pelo CEB-90 (1991) em conjunto com a técnica do carregamento incremental. Para isso, foi utilizado o programa computacional ANSYS ${ }^{\circledR}$, por apresentar recursos que facilitam a entrada de dados, modificação dos dados e visualização dos resultados.

\subsection{Consideração da não linearidade física do concreto}

Para se avaliar os deslocamentos e esforços solicitantes em uma estrutura é necessário uma estimativa segura dos parâmetros de rigidez dos elementos de concreto. Esta avaliação se torna complexa pelo fato de que parte do elemento trabalhar no Estádio I, parte no Estádio II e alguns trechos poderem estar no Estádio III. A estimativa dos parâmetros de rigidez se torna ainda mais necessária no caso de estruturas hiperestáticas, pois sua mudança irá afetar além dos deslocamentos, os esforços solicitantes. Devido a isso têm sido desenvolvidos vários modelos nãolineares. 
Dentre os diversos modelos para se considerar a não linearidade física do concreto, KODUR \& CAMPBELL (1996) destaca que o método de elementos finitos de análise apresenta as melhores aproximações do comportamento real da estrutura. Baseado no nível de idealização da estrutura, os autores anteriores fazem a distinção do método dos elementos finitos entre macroscópicos e microscópicos. Em um modelo macroscópico, a estrutura é dividida em segmentos de comprimento finitos e o comportamento não linear do material é introduzido através da utilização das relações momento $x$ curvatura dos elementos. No caso de um modelo microscópico, a estrutura é dividida em segmentos, que serão subseqüentemente divididos em camadas e, a não linearidade é introduzida através das relações tensão $x$ deformação dos materiais constituintes em cada camada. Quando comparado com um modelo microscópico, um modelo macroscópico normalmente necessitará de menor esforço computacional para a análise e ao mesmo tempo produz bons resultados.

\subsubsection{Diagrama momento $x$ curvatura segundo CEB-90 (1991)}

A relação momento $x$ curvatura é uma ferramenta básica para o cálculo das deformações em elementos estruturais.

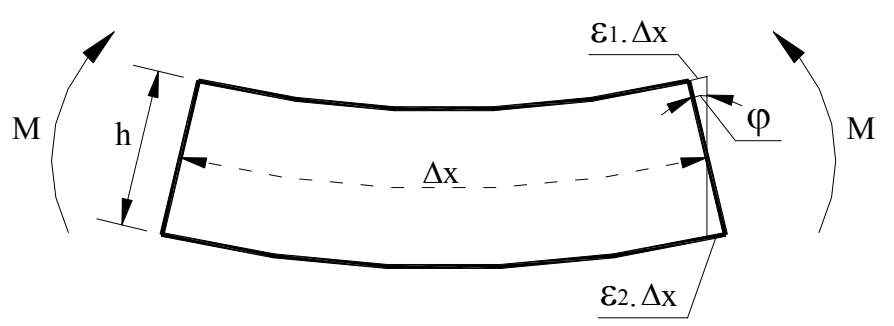

FIGURA 3.1 - Curvatura de um incremento de barra de comprimento $\Delta \mathrm{x}$

Se um incremento de barra de comprimento $\Delta \mathrm{x}$, conforme figura 3.1 , for submetido a um momento fletor $\mathrm{M}$, a deformação nas fibras superior e inferior serão respectivamente:

$$
\varepsilon_{1}=\frac{- \text { M.0,5.h }}{\text { E.I }}
$$




$$
\varepsilon_{2}=\frac{+ \text { M.0,5.h }}{\text { E.I }}
$$

onde: $\mathrm{E}$ - módulo de elasticidade do elemento;

I - momento de inércia da seção.

E a rotação angular será:

$$
\Delta \theta=\frac{\left(\left|\varepsilon_{1}\right|+\varepsilon_{2}\right) \cdot \Delta \mathrm{x}}{\mathrm{h}}
$$

E a curvatura, definida como a rotação angular por unidade de comprimento do elemento será:

$$
\frac{1}{\mathrm{r}}=\frac{\Delta \theta}{\Delta \mathrm{x}}=\frac{\left|\varepsilon_{1}\right|+\varepsilon_{2}}{\mathrm{~h}}
$$

Com a substituição dos valores de $\varepsilon_{1}$ e $\varepsilon_{2}$ na equação da curvatura, temos:

$$
\frac{1}{\mathrm{r}}=\frac{\mathrm{M}}{\mathrm{E} . \mathrm{I}}
$$

Tal expressão é uma maneira possível de se relacionar o momento atuante $(\mathrm{M})$ com a curvatura (1/r) a partir de um modelo que considera a flexão simples pura em um trecho de peça em que a seção está contida.

Para o caso de elementos de concreto, existem várias expressões que definem o módulo de elasticidade em função da resistência característica à compressão do material. Para este trabalho foi utilizado o valor definido pelo CEB90 (1991), que admite uma redução $\left(\mathrm{E}_{\mathrm{cs}}\right)$ de $15 \%$ do módulo de elasticidade $\left(\mathrm{E}_{\mathrm{c}}\right)$ devido ao início de plastificação do concreto.

$$
\mathrm{E}_{\mathrm{c}}=21500 \cdot \sqrt[3]{\frac{\mathrm{f}_{\mathrm{cm}}}{10}}[\mathrm{MPa}] ; \quad \mathrm{E}_{\mathrm{cs}}=0,85 \cdot \mathrm{E}_{\mathrm{c}}
$$

onde:

$\mathrm{f}_{\mathrm{cm}}=\mathrm{f}_{\mathrm{ck}}+8-$ resistência média à compressão;

$\mathrm{f}_{\mathrm{ck}}-$ resistência característica à compressão do concreto aos 28 dias. 
No caso de um elemento de concreto armado ou para o caso da laje formada por nervuras pré-moldadas de concreto protendido submetido a um momento fletor, os seguintes estágios básicos (figura 3.2) serão observados:

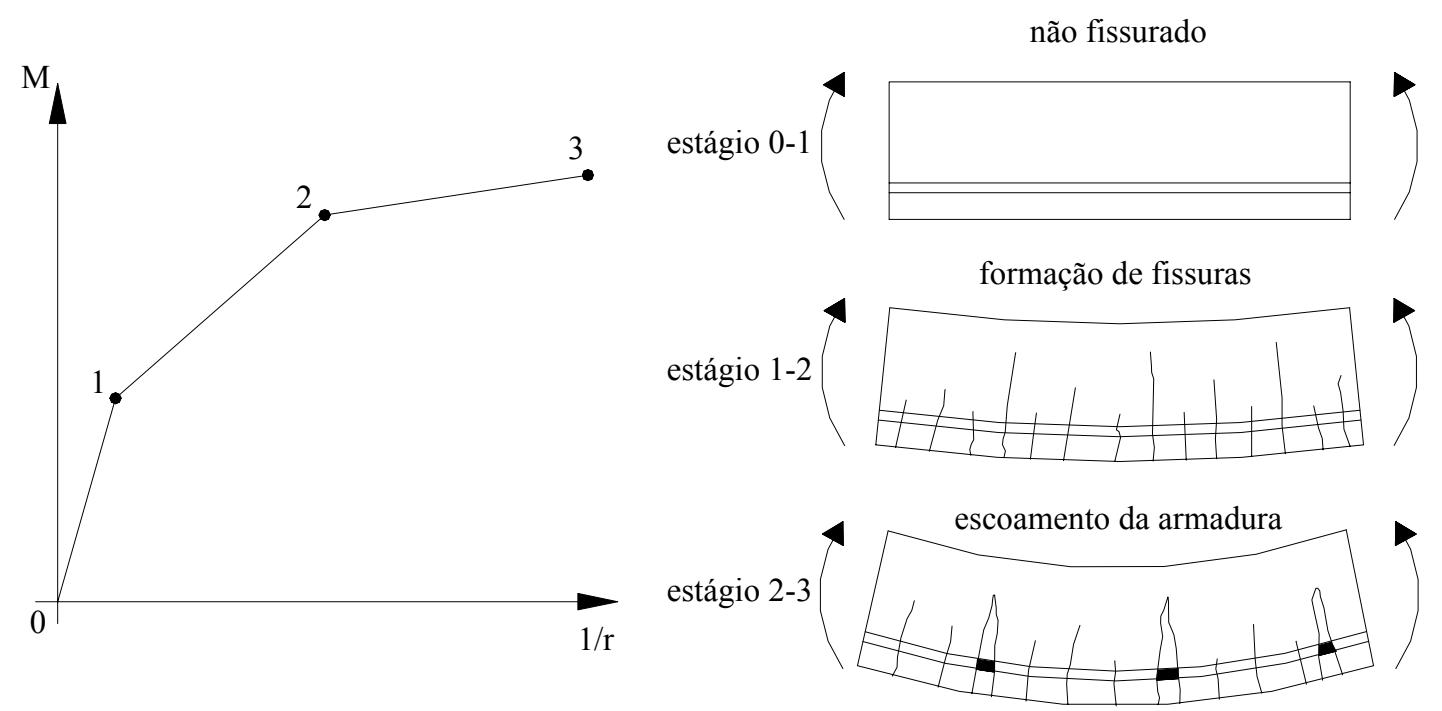

FIGURA 3.2 - Estágios básicos no diagrama momento-curvatura, adaptado de FIB (1999)

- Estágio 0-1: estágio não fissurado

Neste estágio não há a ocorrência de fissuras.

- Estágio 1-2: estágio de formação de fissuras

Neste estágio, formam-se fissuras que se propagam em direção da zona de compressão. As fissuras subseqüentes terão menor comprimento, porque a seção transversal não estará inteiramente tensionada, devido à influência das primeiras fissuras. Logo em seguida aparecerão novas fissuras, que serão limitadas às regiões da armadura.

- Estágio 2-3: estágio de escoamento

A armadura escoa. A curvatura aumenta drasticamente, no entanto o aumento do momento fletor é relativamente pequeno.

Na figura 3.3 é representada a relação momento $x$ curvatura apresentada pelo CEB-90 (1991), que considera a curvatura média influenciada pela fissuração antes da atuação do momento de fissuração $\left(M_{r}\right)$, isto é, para o valor de $\sqrt{\beta_{b}} \cdot M_{r}$, em 
que $\beta_{\mathrm{b}}$ é um coeficiente que considera a aderência da armadura e a forma de carregamento.

Para um momento superior a $\sqrt{\beta_{\mathrm{b}}} \cdot \mathrm{M}_{\mathrm{r}}$ ocorre uma sensível diminuição na rigidez à flexão, embora não exista, a princípio, sinal de escoamento do aço ou plastificação do concreto comprimido. Este trecho corresponde ao estádio II.

O terceiro trecho ocorre quando o aço tracionado escoa ou o concreto comprimido plastifica, provocando uma sensível variação do trecho. Nesta situação as deformações começam a ser grandes, pelo menos na região próxima a esta seção. $\mathrm{O}$ momento de escoamento $\left(\mathrm{M}_{\mathrm{y}}\right)$ e o momento último $\left(\mathrm{M}_{\mathrm{u}}\right)$ limitam este trecho do diagrama.

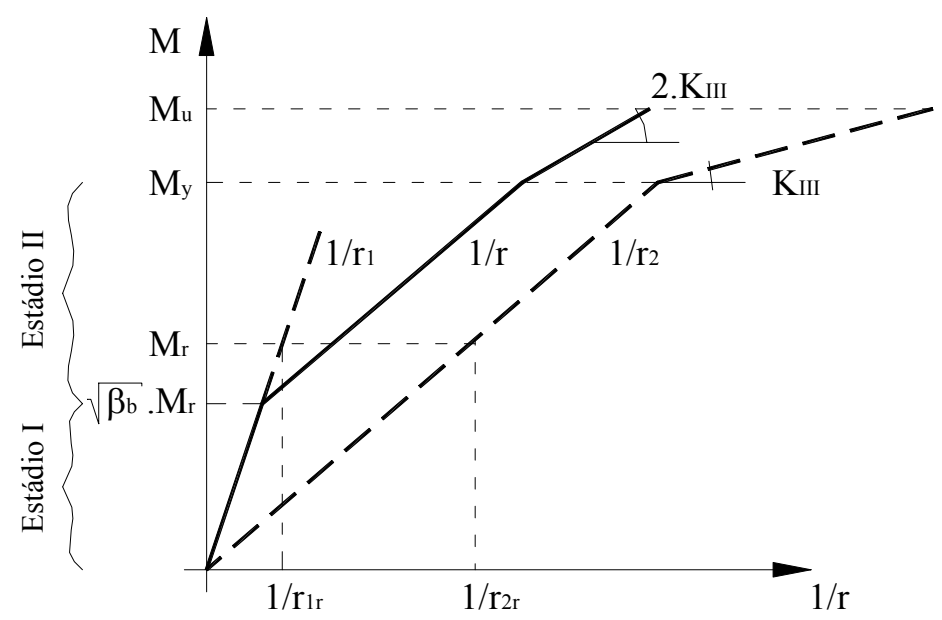

FIGURA 3.3 - Diagrama momento-curvatura segundo CEB-90 (1991)

O CEB-90 (1991) fornece as seguintes indicações para a função momento - curvatura:

$$
\begin{aligned}
& \text { Estádio I }-\mathrm{M}<\sqrt{\beta_{\mathrm{b}}} \cdot \mathrm{M}_{\mathrm{r}} \\
& \qquad \begin{aligned}
\frac{1}{\mathrm{r}}=\frac{1}{\mathrm{r}_{1}}=\frac{\sqrt{\beta_{\mathrm{b}}} \cdot \mathrm{M}_{\mathrm{r}}}{\mathrm{E}_{\mathrm{c}} \cdot \mathrm{I}_{\mathrm{I}}} \\
\operatorname{com} \beta_{\mathrm{b}}>\beta_{1} \cdot \beta_{2}
\end{aligned}
\end{aligned}
$$

Estádio II $-\sqrt{\beta_{\mathrm{b}}} \cdot \mathrm{M}_{\mathrm{r}}<\mathrm{M}<\mathrm{M}_{\mathrm{y}}$

$$
\frac{1}{\mathrm{r}}=\frac{1}{\mathrm{r}_{2}}-\frac{1}{\mathrm{r}_{\mathrm{ts}}}=\frac{1}{\mathrm{r}_{2}}-\left(\frac{1}{\mathrm{r}_{2 \mathrm{r}}}-\frac{1}{\mathrm{r}_{1 \mathrm{r}}}\right) \cdot \beta_{\mathrm{b}} \cdot\left(\frac{\mathrm{Mr}}{\mathrm{M}}\right)
$$




$$
\operatorname{com} \frac{1}{r_{2}}=\frac{M}{E_{c s} \cdot I_{I I}} ; \frac{1}{r_{1 r}}=\frac{M_{r}}{E_{c} \cdot I_{I}} ; \frac{1}{r_{2 r}}=\frac{M_{r}}{E_{c s} \cdot I_{I I}}
$$

Para $\mathrm{M}>\mathrm{M}_{\mathrm{y}}$

$$
\begin{aligned}
& \frac{1}{\mathrm{r}}=\frac{1}{\mathrm{r}_{\mathrm{y}}}-\left(\frac{1}{\mathrm{r}_{2 \mathrm{r}}}-\frac{1}{\mathrm{r}_{1 \mathrm{r}}}\right) \cdot \beta_{\mathrm{b}} \cdot\left(\frac{\mathrm{Mr}}{\mathrm{M}_{\mathrm{y}}}\right)+\frac{\left(\mathrm{M}-\mathrm{M}_{\mathrm{y}}\right)}{2 \cdot \mathrm{K}_{\mathrm{III}}} \\
& \operatorname{com} \mathrm{K}_{\mathrm{III}}=\frac{\mathrm{M}_{\mathrm{u}}-\mathrm{M}_{\mathrm{y}}}{\frac{1}{\mathrm{r}_{\mathrm{u}}}-\frac{1}{\mathrm{r}_{\mathrm{y}}}}
\end{aligned}
$$

onde:

M - momento fletor na seção ou trecho analisado;

$\mathrm{M}_{\mathrm{y}}$ - momento que inicia o escoamento da armadura tracionada ou plastificação do concreto comprimido;

$\mathrm{M}_{\mathrm{r}}$ - momento de fissuração da seção ou trecho analisado;

$\mathrm{M}_{\mathrm{u}}$ - momento último da seção;

$1 / \mathrm{r}_{\mathrm{y}}$ - curvatura correspondente ao momento $\mathrm{M}_{\mathrm{y}}$;

$1 / r_{u}-$ curvatura correspondente ao momento $\mathrm{M}_{\mathrm{u}}$;

$1 / r_{2}$ - curvatura correspondente ao estádio II puro com atuação do momento $\mathrm{M}$;

$1 / \mathrm{r}_{1 \mathrm{r}}$ - curvatura correspondente ao estádio I com atuação do momento $\mathrm{M}_{\mathrm{r}}$

$1 / r_{2 r}$ - curvatura correspondente ao estádio II com atuação do momento $\mathrm{M}_{\mathrm{r}}$;

$1 / \mathrm{r}_{\mathrm{ts}}$ - contribuição do concreto tracionado entre fissuras ("tension stiffening");

$\beta_{b}$ - coeficiente que considera a aderência da armadura e a forma de carregamento;

$\beta_{1}-0,5$ para barras de má aderência e 1,0 caso contrário;

$\beta_{2}-0,5$ para cargas de longa duração e 0,8 para o primeiro carregamento. 
Para determinar cada trecho do diagrama momento $x$ curvatura, deve-se definir o momento de fissuração $\left(\mathrm{M}_{\mathrm{r}}\right)$, o momento de escoamento do aço ou plastificação do concreto $\left(\mathrm{M}_{\mathrm{y}}\right)$ e o momento último $\left(\mathrm{M}_{\mathrm{u}}\right)$, para isso, deve-se fazer a distinção entre três partes do painel, conforme figura 3.4:

- trecho A: seção de concreto armado submetida a momentos negativos;

- trecho B: seção composta de vigota protendida com capa de concreto, submetida a momentos negativos;

- trecho C: seção composta de vigota protendida com capa de concreto, submetida a momentos positivos;

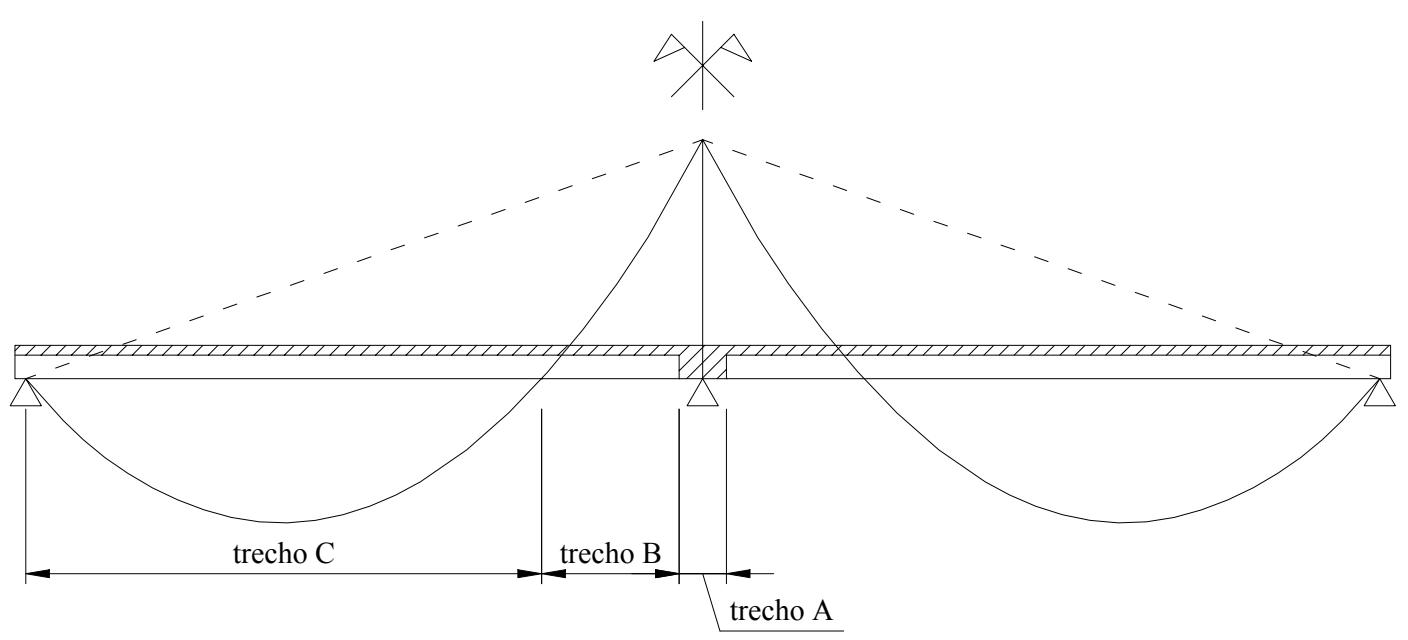

FIGURA 3.4 - Trechos do painel contínuo com seções distintas

\section{a) Determinação do momento de fissuração}

$\mathrm{O}$ valor do momento de fissuração, para a região de concreto armado (trecho A), pode ser determinado conforme LEONHARDT (1982), NBR-7197 (1989) e CEB-90 (1991) pela expressão:

$$
\mathrm{M}_{\mathrm{r}}=\mathrm{W}_{\mathrm{I}} \cdot \mathrm{f}_{\mathrm{ctm}, \mathrm{f}}
$$

com:

$\mathrm{W}_{\mathrm{I}}$ - módulo resistente no estádio I considerando a armadura;

$\mathrm{f}_{\mathrm{ctm}, \mathrm{f}}$ - resistência média à tração por flexão do concreto. 
A NBR-7197 (1989) define que para a verificação do estado limite de formação de fissuras, a resistência à tração na flexão deve ser considerada igual a 1,2 vez o valor da sua resistência à tração axial para vigas de seção $T$ e 1,5 vez a resistência à tração para vigas de seção retangular. E o CEB-90 (1991) permite, para o caso de não se ter resultados experimentais, usar a seguinte expressão para a resistência à tração axial do concreto:

$$
\begin{aligned}
& \mathrm{f}_{\mathrm{ctm}}=1,4 \cdot\left(\frac{\mathrm{f}_{\mathrm{ck}}}{10}\right)^{\frac{2}{3}}[\mathrm{MPa}] \\
& \text { onde: } \mathrm{f}_{\mathrm{ctm}}-\text { resistência média à tração axial do concreto }
\end{aligned}
$$

Portanto, serão empregadas as seguintes expressões para a determinação da resistência à tração na flexão:

$$
\begin{array}{ll}
\mathrm{f}_{\mathrm{ctm}, \mathrm{f}}=1,2 . \mathrm{f}_{\mathrm{ctm}} & \text { para vigas com seção } \mathrm{T} ; \\
\mathrm{f}_{\mathrm{ctm}, \mathrm{f}}=1,5 . \mathrm{f}_{\mathrm{ctm}} & \text { para vigas com seção retangular. }
\end{array}
$$

Para a região da laje em que há a presença da vigota protendida (trechos B e C), o momento de fissuração foi determinado, como apresentado por PRIESTLEY et al. (1971), fazendo-se o equilíbrio das forças internas na seção. Considerando a contribuição do concreto tracionado e lembrando que a amadura de protensão possui um pré-alongamento $\left(\varepsilon_{\mathrm{pi}}\right)$, conforme indicado na figura 3.5.

A condição de equilíbrio estabelece:

- para o caso de momento positivo - trecho C $(\mathrm{M}>0)$

$$
\mathrm{R}_{\mathrm{ccl}}+\mathrm{R}_{\mathrm{cc} 2}+\mathrm{R}_{\mathrm{s}}=\mathrm{R}_{\mathrm{pt}}+\mathrm{R}_{\mathrm{ct}}
$$

- para o caso de momento negativo - trecho $\mathrm{B}(\mathrm{M}<0)$

$$
\mathrm{R}_{\mathrm{ccl}}+\mathrm{R}_{\mathrm{cc} 2}=\mathrm{R}_{\mathrm{pt}}+\mathrm{R}_{\mathrm{s}}+\mathrm{R}_{\mathrm{ct}}
$$

sendo:

$\mathrm{R}_{\mathrm{ccl}}$ - resultante de compressão do concreto pré-moldado;

$\mathrm{R}_{\mathrm{cc} 2}$ - resultante de compressão do concreto moldado no local;

$\mathrm{R}_{\mathrm{ct}}$ - resultante de tração do concreto; 
$\mathrm{R}_{\mathrm{pt}}$ - resultante da armadura protendida;

$\mathrm{R}_{\mathrm{S}}$ - resultante da armadura passiva;

com:

$\mathrm{R}_{\mathrm{ccl}}=\int_{0}^{\mathrm{x}_{1}} \sigma_{\mathrm{cl}}(\mathrm{y}) \cdot \mathrm{b}_{\mathrm{y}} \cdot \mathrm{dy}$ para $\mathrm{M}>0$

$\mathrm{R}_{\mathrm{ccl}}=\int_{\mathrm{x} 1}^{\mathrm{x}} \sigma_{\mathrm{cl}}(\mathrm{y}) \cdot \mathrm{b}_{\mathrm{y}} \cdot \mathrm{dy}$ para $\mathrm{M}<0 \quad$ e $\sigma_{\mathrm{cl}}(\mathrm{y})=\mathrm{f}\left[\varepsilon_{\mathrm{cl}}(\mathrm{y})\right]$

$\mathrm{R}_{\mathrm{cc} 2}=\int_{\mathrm{x} 1}^{\mathrm{x}} \sigma_{\mathrm{c} 2}(\mathrm{y}) \cdot \mathrm{b}_{\mathrm{y}} \cdot \mathrm{dy}$ para $\mathrm{M}>0$

$\mathrm{R}_{\mathrm{cc} 2}=\int_{0}^{\mathrm{x}_{1}} \sigma_{\mathrm{c} 2}(\mathrm{y}) \cdot \mathrm{b}_{\mathrm{y}} \cdot \mathrm{dy}$ para $\mathrm{M}<0$

e $\quad \sigma_{\mathrm{c} 2}(\mathrm{y})=\mathrm{f}\left[\varepsilon_{\mathrm{c} 2}(\mathrm{y})\right]$

$$
\begin{array}{ll}
\mathrm{R}_{\mathrm{ct}}=\int_{\mathrm{x}-\mathrm{h}}^{0} \sigma_{\mathrm{c}}(\mathrm{y}) \cdot \mathrm{b}_{\mathrm{y}} \cdot \mathrm{dy} & \text { e } \begin{array}{l}
\sigma_{\mathrm{c}}(\mathrm{y})=\mathrm{f}\left[\varepsilon_{\mathrm{c}}(\mathrm{y})\right] \text { com } \\
\sigma_{\mathrm{c}}(\mathrm{x}-\mathrm{h})=\mathrm{f}_{\mathrm{ct}}
\end{array} \\
\mathrm{R}_{\mathrm{pt}}=\mathrm{A}_{\mathrm{p}} \cdot \mathrm{f}_{\mathrm{d}} & \text { e } \mathrm{f}_{\mathrm{d}}=\mathrm{f}\left(\varepsilon_{\mathrm{pd}}\right) \operatorname{com} \varepsilon_{\mathrm{pd}}=\varepsilon_{\mathrm{p}}+\varepsilon_{\mathrm{pi}} \\
\mathrm{R}_{\mathrm{s}}=\mathrm{A}_{\mathrm{s}} \cdot \mathrm{f}_{\mathrm{s}} & \text { e } \mathrm{f}_{\mathrm{s}}=\mathrm{f}\left(\varepsilon_{\mathrm{s}}\right)
\end{array}
$$

O equacionamento acima foi otimizado, utilizando Mathcad ${ }^{\circledR}$, para o caso da região da laje em que há a presença da vigota protendida (trechos B e C).

Por se tratar do estudo do comportamento de elementos, os valores da resistência considerado nos diagramas tensão $x$ deformação do concreto e do aço serão valores médios indicados por $\mathrm{f}_{\mathrm{cm}}$ (resistência média à compressão do concreto), $\mathrm{f}_{\mathrm{ctm}}$ (resistência média à tração do concreto), $\mathrm{f}_{\mathrm{ym}}$ (resistência média à tração do aço para armadura passiva), $\mathrm{f}_{\text {pym }}$ (resistência média à tração do aço de protensão). Tais diagramas estão apresentados na figura 3.6 e foram obtidos a partir da NBR-6118 (1978) para o caso do concreto comprimido e aços tipo A e B. Para o concreto na tração a curva assumida foi linear com declividade igual a tangente da curva de compressão no ponto zero, enquanto que para o aço de protensão o diagrama assumido foi análogo ao diagrama correspondente ao aço tipo B. 

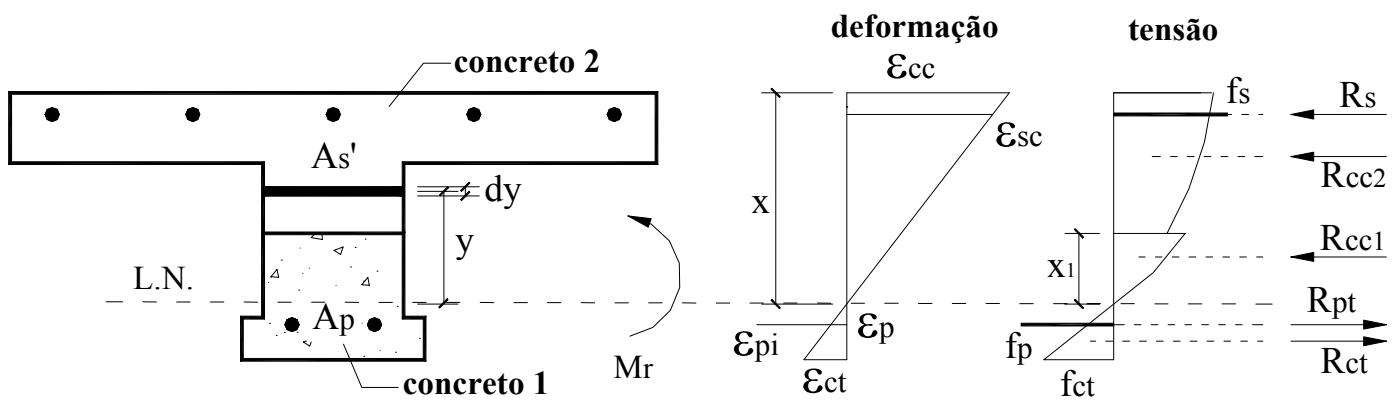

(a) Para o caso de momento positivo
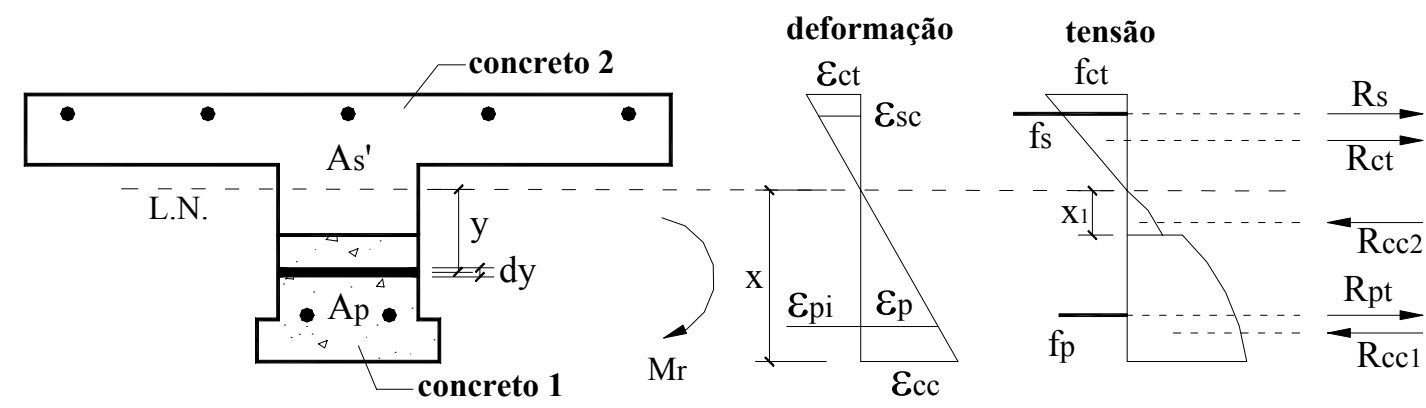

(b) Para o caso de momento negativo

FIGURA 3.5 - Forças internas na laje formada por vigotas protendidas

\section{b) Determinação do momento último}

O momento último, tanto para seções de concreto armado quanto para seções de concreto protendido (trechos A, B e C), pode ser encontrado fazendo-se o equilíbrio das forças internas como mostrado anteriormente. Escolhendo os valores limites de deformação para o concreto e aço.

\section{c) Determinação do momento fletor correspondente ao escoamento}

O momento que equivale ao início do escoamento da armadura tracionada ou o momento para que ocorra a plastificação do concreto comprimido é difícil ser definido e o CEB-90 (1991) evita fazê-lo. O valor que será considerado para a deformação que corresponde ao início de plastificação do concreto será de $1,5 \%$ e a tensão que corresponde ao escoamento da armadura tracionada do aço tipo B e para o aço de protensão será de $0,85 . f_{y m}$ e $0,85 . f_{\text {pym }}$, respectivamente. Tais valores foram analisados por DROPPA Jr. (1999), comparando-os com valores obtidos em ensaios experimentais. 


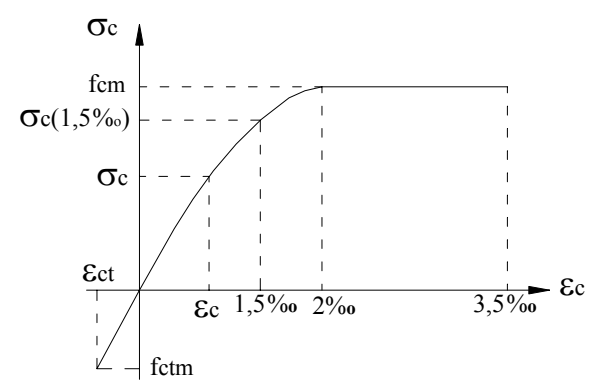

(a) - Concreto



(c) - Aço tipo A

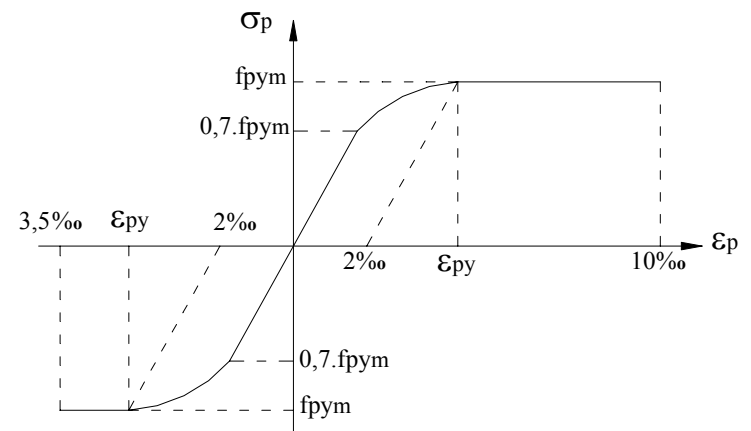

(b) - Aço de protensão

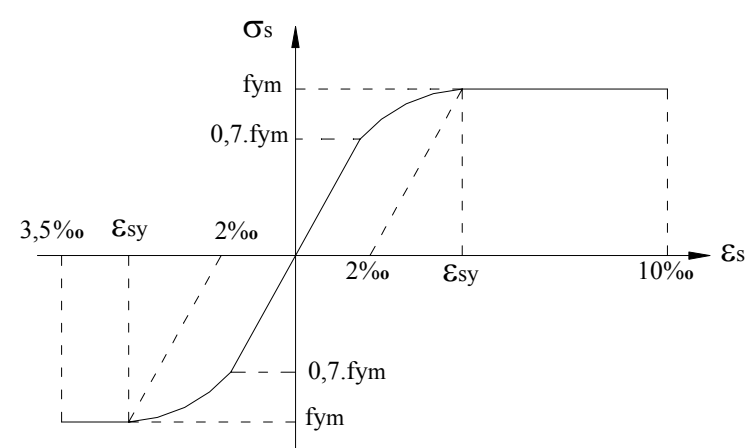

(d) - Aço tipo B

Figura 3.6 - Diagrama tensão-deformação dos materiais 


\subsubsection{Carregamento incremental}

A técnica do carregamento incremental é uma das técnicas utilizadas para se considerar a não-linearidade física do concreto. Esta técnica consiste em obter o carregamento atuante na estrutura a partir da soma de $\mathrm{n}$ etapas de carga ou incrementos de carga (figura 3.7). A técnica do carregamento incremental possibilita trabalhar com a rigidez da estrutura atualizada a cada etapa de carga.

Considera-se que, em cada etapa de carga, há linearidade entre esforços e deslocamentos, bastando para tanto considerar um certo número mínimo de etapas. Portanto, o problema não-linear passa a ser resolvido de forma linear, ou seja, através de uma soma de parcelas lineares.

Para se utilizar a rigidez de cada elemento em cada etapa, considera-se o nível de solicitação da etapa anterior. Tem-se portanto uma aproximação que pode ser pequena, na medida em que se aumenta o número de etapas.

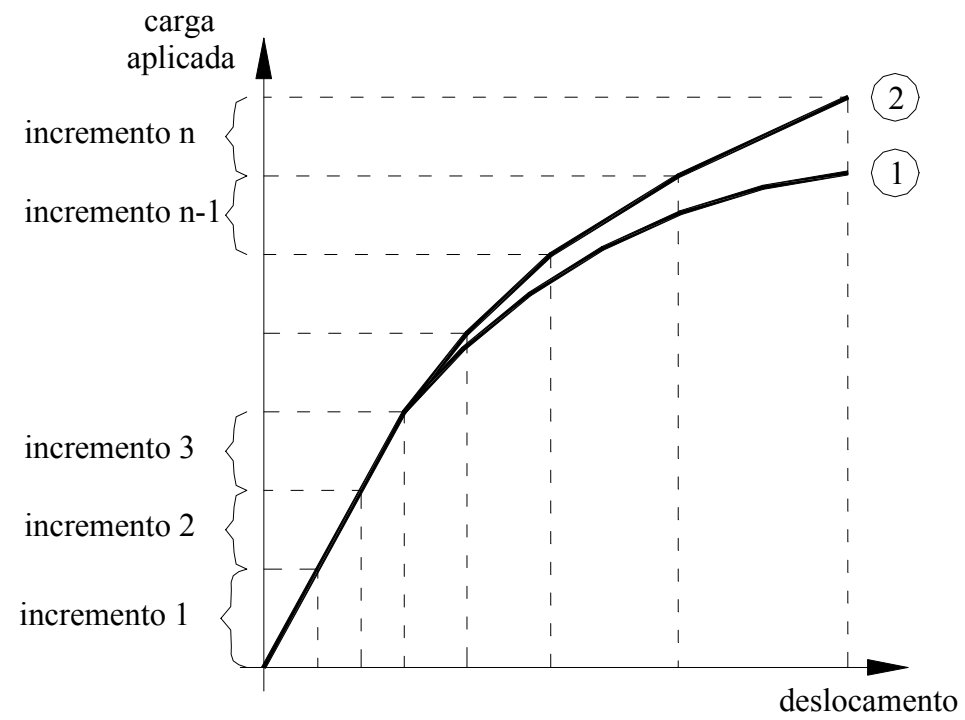

FIGURA 3.7 - Diagrama genérico de carga $x$ deslocamento:1) desenvolvimento real 2) desenvolvimento por etapas lineares [CARVALHO (1994)] 


\subsection{Determinação da força última no modelo teórico}

Os critérios adotados para a determinação da força última são os mesmos presentes em MAGALHÃES (2001):

I. Capacidade de rotação das rótulas plásticas

II. Formação de mecanismo de colapso

\subsubsection{Critério da capacidade de rotação das rótulas plásticas}

Este critério verifica se não foi excedida a capacidade de rotação plástica das rótulas nas regiões críticas.

Quando no carregamento incremental do modelo teórico o momento fletor de uma seção atinge $\mathrm{M}_{\mathrm{u}}$, é criada uma rótula plástica, e com isso não é possível obter a curvatura desta seção utilizando a relação momento $x$ curvatura do CEB-90 (1991). A curvatura desta seção será determinada a partir da hipótese que nas suas proximidades a deformada será aproximada por um arco de círculo (figura 3.8). Portanto, a curvatura fica determinada por:

$$
\begin{aligned}
& \frac{1}{\mathrm{r}}=\frac{2 . \mathrm{a}}{\left(\ell_{\mathrm{e}}\right)^{2}+\mathrm{a}^{2}} \\
& \text { onde: } \mathrm{a}=\mathrm{d}_{2}-\left(\frac{\mathrm{d}_{1}+\mathrm{d}_{3}}{2}\right) \\
& \quad \ell_{\mathrm{e}}-\text { tamanho do elemento } \\
& \mathrm{d}_{1}, \mathrm{~d}_{2}, \mathrm{~d}_{3}-\text { deslocamentos respectivamente dos nós } 1,2 \text { e } 3 \text { (ver } \\
& \quad \text { figura } 3.8)
\end{aligned}
$$

Com a criação da rótula plástica, a consideração da capacidade de rotação plástica será realizada considerando o modelo de Darmstadt-Leipizig apresentado no CEB (1998). Tal modelo foi utilizado por MAGALHÃES (2001) para a análise de lajes contínuas formadas por vigotas treliçadas, obtendo bons resultados. 


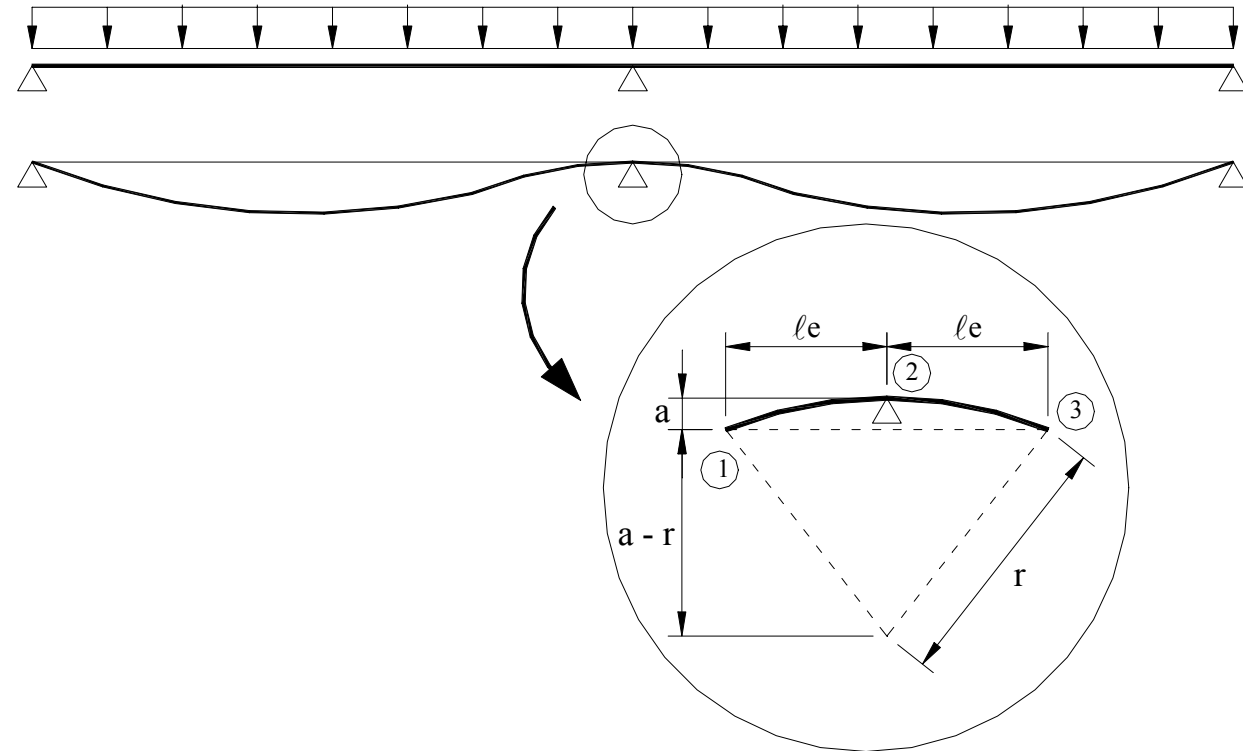

Figura 3.8 - Determinação da curvatura média a partir dos deslocamentos

De acordo com o modelo de Darmstadt-Leipizig, a capacidade de rotação plástica está dividida em duas partes que são determinadas separadamente, conforme a seguinte expressão:

$\theta_{\mathrm{pl}}=\theta_{\mathrm{pl}, \mathrm{fle}}+\theta_{\mathrm{pl}, \mathrm{cort}}$

onde:

$\theta_{\mathrm{pl}}$ - capacidade de rotação da rótula plástica;

$\theta_{\mathrm{pl}, \mathrm{fle}}$ - parcela da rotação plástica decorrente do esforço de flexão;

$\theta_{\mathrm{pl}, \mathrm{cort}}$ - parcela da rotação plástica decorrente do esforço cortante;

Sabendo que o esforço de flexão é o esforço predominante em laje, será considerado nas verificações da capacidade de rotação das rótulas plásticas somente a parcela de deformações plásticas decorrentes dos esforços de flexão $\left(\theta_{\mathrm{pl}}=\theta_{\mathrm{pl} \text {,fle }}\right)$. Com isso a capacidade de rotação das rótulas plásticas, segundo o modelo de Darmstadt-Leipizig é dada pela expressão:

$$
\theta_{\mathrm{pl}}=\frac{\mathrm{a}_{\mathrm{q}}}{\mathrm{d}} \cdot\left[\frac{1}{\mathrm{r}_{1 \mathrm{r}}} \cdot \mathrm{d} \cdot\left(\frac{\mathrm{M}_{\mathrm{y}}}{\mathrm{M}_{\mathrm{u}}}-1\right)+\frac{1}{\mathrm{r}_{\mathrm{y}}} \cdot \mathrm{d} \cdot\left(\frac{\mathrm{M}_{\mathrm{r}}}{\mathrm{M}_{\mathrm{y}}}-\frac{\mathrm{M}_{\mathrm{r}}}{\mathrm{M}_{\mathrm{u}}}\right)+\frac{1}{\mathrm{r}_{\mathrm{u}}} \cdot \mathrm{d} \cdot\left(1-\frac{\mathrm{M}_{\mathrm{y}}}{\mathrm{M}_{\mathrm{u}}}\right)\right]
$$

onde: $\mathrm{a}_{\mathrm{q}}$ - distância entre os pontos de momento fletor nulo 
Como o estudo experimental para a avaliação da capacidade de rotação das rótulas plásticas utilizou ensaios de elementos unidirecionais simplesmente apoiados com uma força concentrada aplicada no meio do vão, é necessário utilizar o conceito de "viga equivalente" (figura 3.9) para a análise de estruturas estaticamente indeterminadas.
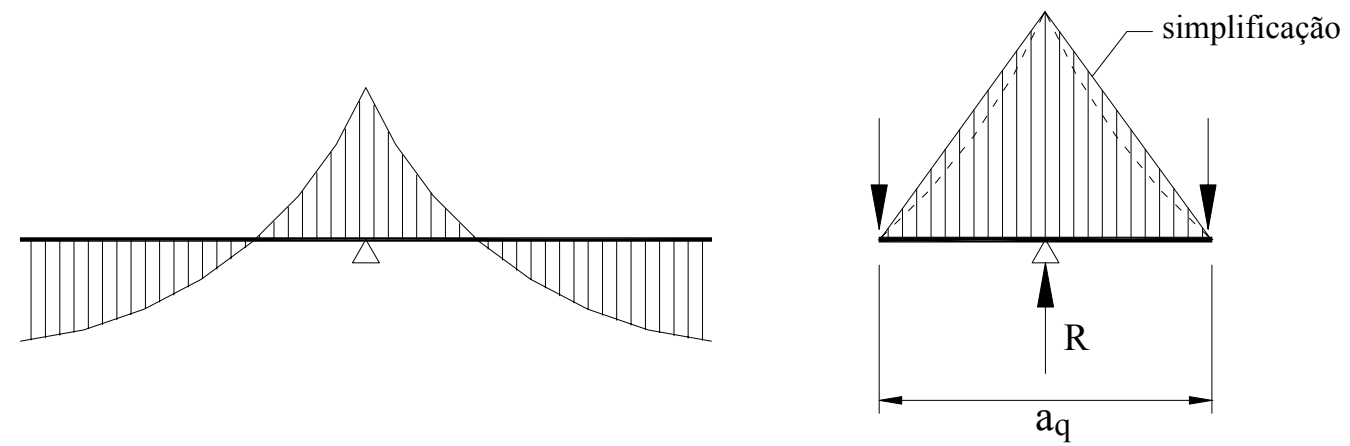

Figura 3.9 - Viga equivalente na região do apoio central

\subsubsection{Critério da formação de mecanismo de colapso}

O segundo critério na determinação da força última será o critério da formação de mecanismo de colapso. Neste critério, determina-se a força necessária para que o elemento estrutural se transforme em um mecanismo contendo deslocamentos que crescem infinitamente. Para ilustrar esse critério, toma-se uma viga engastada em uma extremidade e simplesmente apoiada em outra, com uma carga concentrada, F, no centro (figura 3.10-a). O diagrama de momentos fletores tem a forma apresentada na figura 3.10-b e o momento máximo ocorre na extremidade B, com valor igual a 3.F. $\ell / 16$.

Com um incremento de carga, a seção B começará a escoar. Após um novo acréscimo de carga, começará a ocorrer o escoamento da seção $\mathrm{C}$, onde há um pico no diagrama de momentos fletores.

Se a carga continuar a crescer, forma-se uma articulação plástica na extremidade B. No entanto isso não provocará a ruína do elemento estrutural, pois este se comporta como uma estrutura estaticamente determinada, suportando uma carga $\mathrm{F}$ na seção $\mathrm{C}$ e o momento último em $\mathrm{B}$. Com este esquema estático, a estrutura suportará um acréscimo de carga até que o momento fletor em $\mathrm{C}$ também 
atinja o momento último (figura 3.10-d). Nesta ocasião, existirão articulações nas seções B e C (figura 3.10-c) e a estrutura formará um mecanismo. Então, pode ocorrer deslocamentos que crescem infinitamente e a força última é atingida, pois o elemento estrutural não consegue suportar mais nenhum acréscimo de carga.

(a)

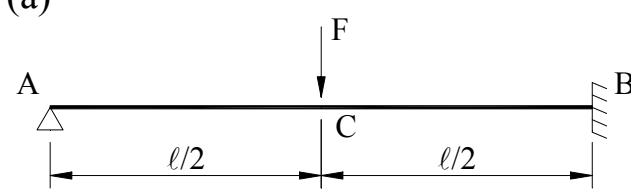

(b)

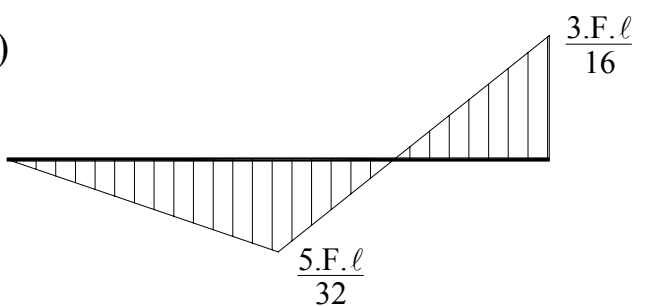

(c)

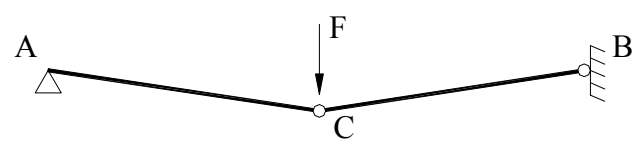

(d)

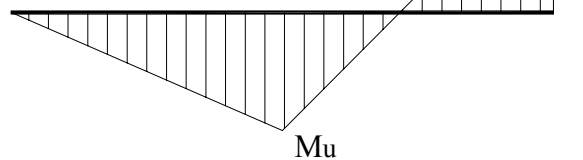

Figura 3.10 - Critério da formação de um mecanismo de colapso

\subsection{Descrição do programa computacional}

Como já foi comentado, foi utilizado o programa computacional ANSYS $^{\circledR}$ para auxiliar na análise estrutural da laje.

O elemento adotado para as análises será um elemento de barra uniaxial contendo 6 graus de liberdade em cada nó, ou seja, translação e rotação nas três direções. Tal elemento faz parte da biblioteca de elementos do ANSYS $^{\circledR}$ e é denominado BEAM-3D Elastic Beam.

Para a realização da análise não-linear, utilizando o programa ANSYS ${ }^{\circledR}$, implementou-se as equações de momento $x$ curvatura e o processo para o carregamento incremental. Esta implementação, que modifica o esquema habitual de processamento linear do programa é possível mediante a introdução de "macros" ou sub-rotinas inicialmente desenvolvidas por DROPPA Jr (1999).

A análise não-linear é realizada, após o dimensionamento dos elementos constituintes. Para o dimensionamento, consideram-se os esforços solicitantes obtidos mediante o emprego da análise linear. 
Na figura 3.11 mostra-se o fluxograma simplificado, para a consideração da análise não-linear.

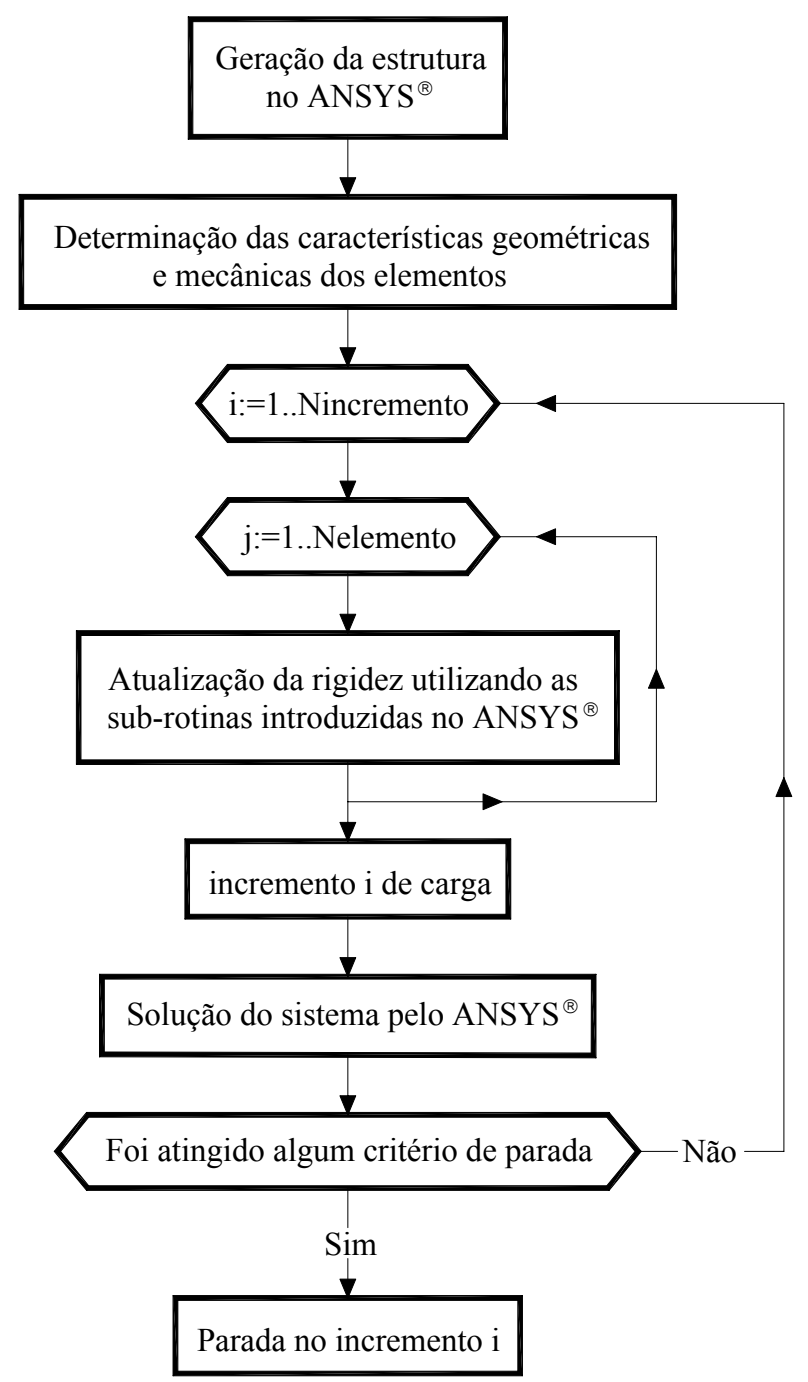

FIGURA 3.11 - Fluxograma simplificado para a análise não linear utilizando o programa ANSYS ${ }^{\circledR}$

Portanto, para realizar a análise não-linear, como ilustrado na figura 3.11, deve-se inicialmente fazer a geração da estrutura no programa ANSYS $^{\circledR}$, que consiste em definir a geometria da estrutura, vinculações e o carregamento para o incremento $\mathrm{i}=1$.

Em seguida, calcula-se as características mecânicas e geométricas de cada tipo de elemento $\left(I_{1}, I_{2}, M_{r}, M_{y}, 1 / r_{y}, M_{u}\right.$ e $\left.1 / r_{u}\right)$, que são os parâmetros necessários para definir o diagrama momento $x$ curvatura de cada elemento segundo CEB-90 (1991). 
Após isso, segue-se com a análise incremental, ou seja, a resolução da estrutura $\mathrm{n}$ vezes, sendo $\mathrm{n}$ igual ao número de incrementos de carga. No esquema isto é visto na variação de i de 1 até NIncremento (número de incrementos).

Para cada incremento, a rigidez de cada elemento é atualizada pelas subrotinas. Para isso, as sub-rotinas utilizam a relação momento $x$ curvatura dos elementos definida pelo CEB-90 (1991) e o esforço de flexão obtido no incremento $(\mathrm{i}-1)$.

O programa segue o processamento até um incremento de carga i genérico, em que se atinge um dos critérios de parada (critério da capacidade de rotação das rótulas plásticas ou critério da formação de mecanismo de colapso).

Vale ressaltar que os valores que são considerados para os esforços na estrutura serão aqueles obtidos no ponto central dos elementos. Portanto, quanto maior for o número de elementos ou divisões da estrutura, melhor será a aproximação ao diagrama real. Isso pode ser visto na figura 3.12, onde está apresentada uma viga bi-apoiada, com carregamento distribuído e discretizada em 3 e 5 elementos.

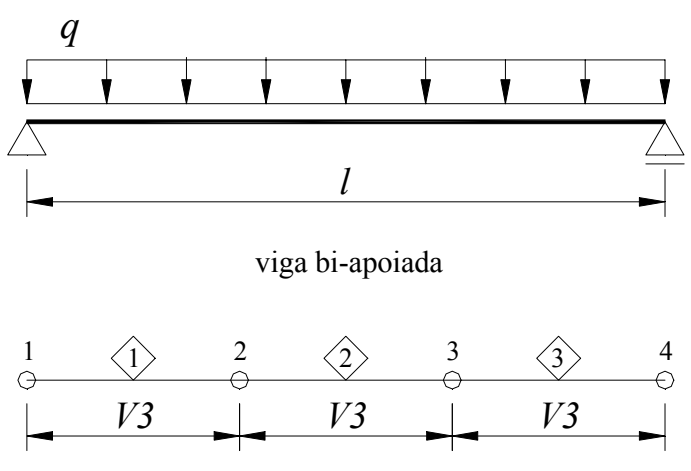

representação da viga bi-apoiada com 3 elementos

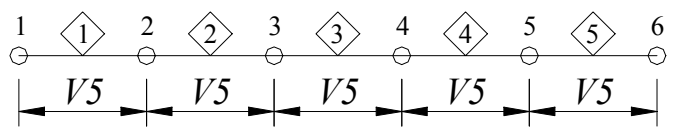

representação da viga bi-apoiada com 5 elementos n - nó 'n'

n - elemento ' $n$ '

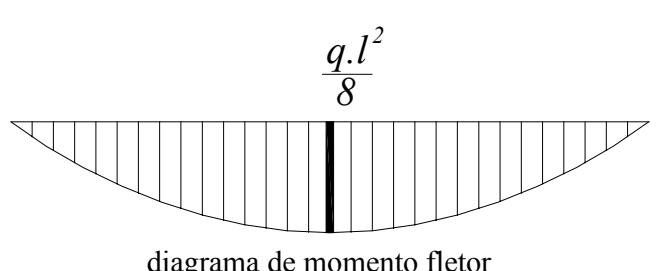

diagrama de momento fletor

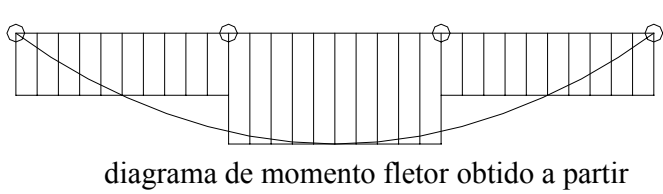
da discretização da viga em 3 elementos

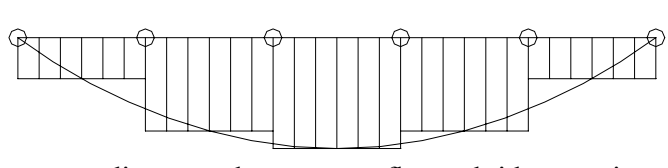

diagrama de momento fletor obtido a partir da discretização da viga em 5 elementos

FIGURA 3.12 - Diferenciação com relação ao número de elementos discretizados 


\subsection{Avaliação do procedimento empregado}

Para se avaliar o procedimento empregado para a análise da continuidade de lajes, utilizou-se os resultados do ensaio realizado por GASTAL et al. (1999) e MARCELLINO (2001), que apresentam o estudo sobre a continuidade de lajes alveolares. Foram utilizados estes ensaios por não encontrar na literatura valores experimentais para o caso de lajes formadas por vigotas pré-moldadas de concreto protendido.

\subsubsection{Avaliação 1 - ensaio realizado por GASTAL et al. (1999)}

\section{a) Descrição do ensaio}

No ensaio realizado por GASTAL et al. (1999) foram utilizados 2 painéis de lajes alveolares de 5 metros de comprimento e seção transversal de $60 \mathrm{~cm}$ de largura e $12 \mathrm{~cm}$ de altura.

As armaduras de protensão eram compostas por 6 cordoalhas de protensão, cada uma com 3 fios de $3 \mathrm{~mm}$ de diâmetro, aço CP-190 RB, sendo que duas das cordoalhas localizavam-se a $1,7 \mathrm{~cm}$ da face superior da laje, enquanto que as outras quatro estavam posicionadas a $1,7 \mathrm{~cm}$ da face inferior, como ilustrada na figura 3.13 .

As lajes alveolares foram posicionadas sobre o sistema de apoios, recebendo em seguida uma capa estrutural de $4 \mathrm{~cm}$ de concreto, passando a apresentar $16 \mathrm{~cm}$ de altura na seção transversal composta. Juntamente com a capa estrutural foi concretado um diafragma de $25 \mathrm{~cm}$ de comprimento, ligando uma laje alveolar à outra (figura 3.14). No apoio central, envolvidas pela capa, foram posicionada 2 barras de aço CA-50 de $20 \mathrm{~mm}$ de diâmetro e 4 metros de comprimento para atuarem com armadura de continuidade. Além destas barras, colocou-se ao longo de toda a capa de concreto uma tela soldada $10 \times 10 \mathrm{~cm}$ de aço CA-60 de 5,0 mm de diâmetro. 


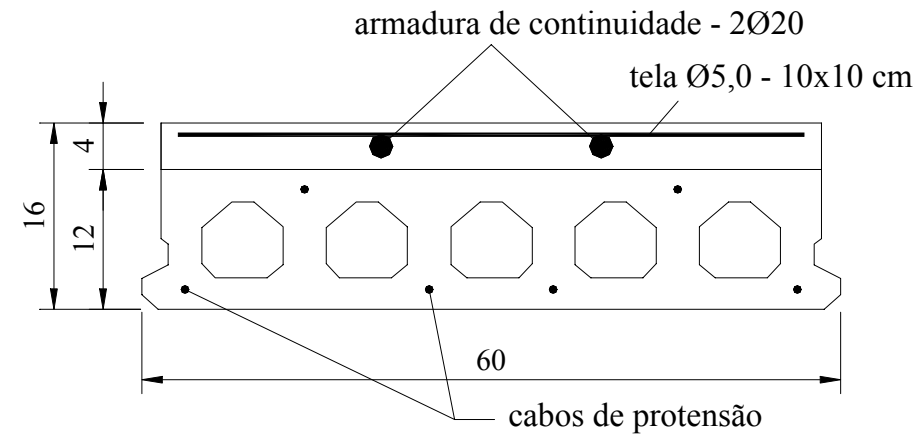

FIGURA 3.13 - Seção transversal da laje alveolar (dimensões em cm)

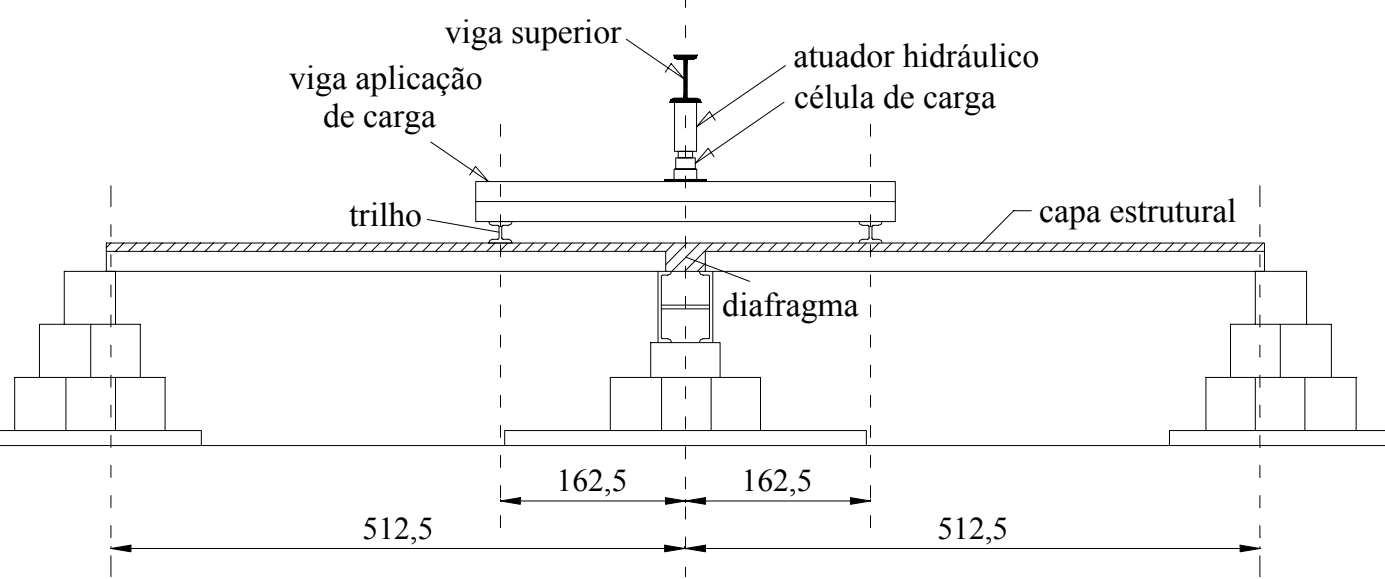

FIGURA 3.14 - Vista longitudinal do ensaio (dimensões em cm)

O carregamento aplicado sobre o protótipo iniciou-se em etapas de carga de 2,5 kN, verificando-se o aparecimento da primeira fissura aos $10 \mathrm{kN}$, no vão direito. A partir dos $30 \mathrm{kN}$, foram adotados passos de carga de $5 \mathrm{kN}$ até a ruptura, que ocorreu por esmagamento do concreto na seção sob o ponto de aplicação de carga no vão direito, aos $75 \mathrm{kN}$.

\section{b) Análise teórica}

Para a representação da seção transversal da laje alveolar foi utilizada uma seção teórica com área e inércia equivalentes às seções reais, conforme figura 3.15 . 


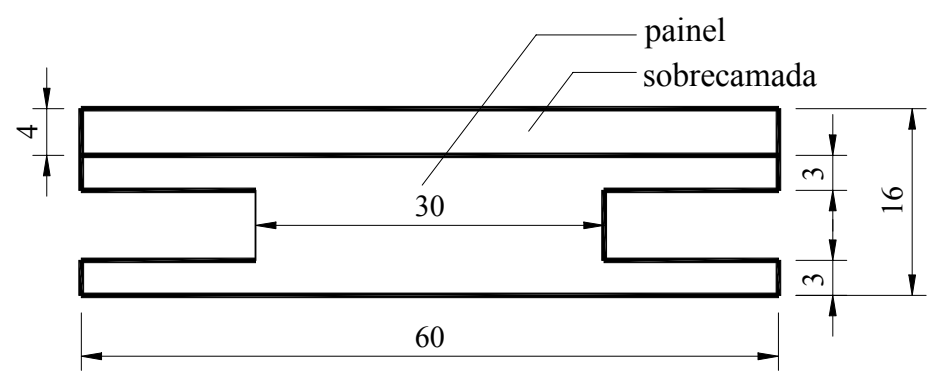

FIGURA 3.15 - Seção transversal teórica utilizada na análise numérica (dimensões em cm)

As simulações numéricas foram realizadas tirando proveito da simetria em relação ao apoio central. Com isso, o painel foi discretizado utilizando três tipos diferentes de seção (figura 3.16):

- $\quad$ seção 1: seção de concreto armado do diafragma

1 elemento de $12,5 \mathrm{~cm}$;

- Seção 2: seção composta, com armadura de continuidade

1 elemento de $7,5 \mathrm{~cm}$ e 18 elementos de $10 \mathrm{~cm}$;

- $\quad$ seção 3: seção composta, sem armadura de continuidade

15 elementos de $20 \mathrm{~cm}$ e 1 elemento de $12,5 \mathrm{~cm}$;

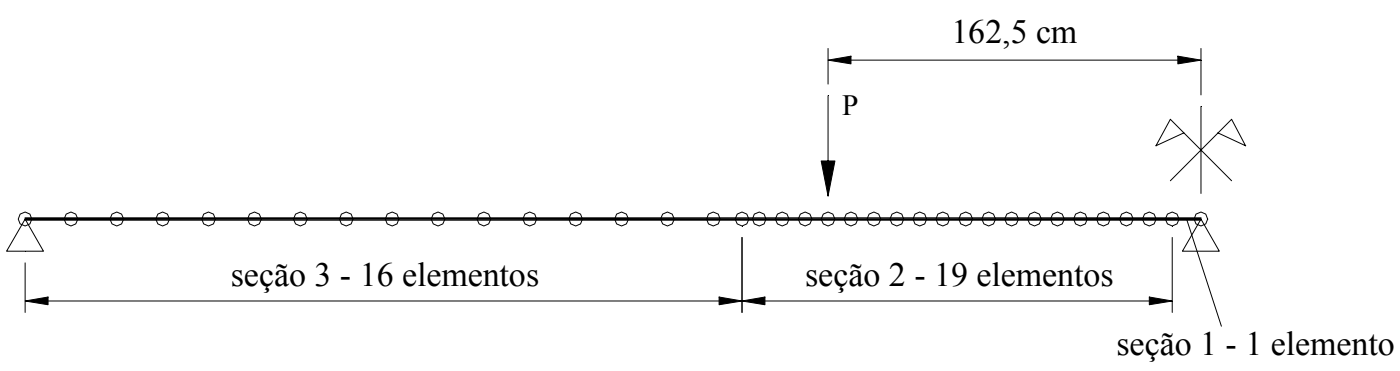

FIGURA 3.16 - Discretização do painel da laje em elementos

Nas simulações numéricas foi considerado que as barras utilizadas eram de boa aderência $\left(\beta_{1}=1,0\right)$ e o painel recebia a atuação do primeiro carregamento $\left(\beta_{2}=0,8\right)$, conduzindo a um $\beta_{\mathrm{b}}$ igual a 0,8 .

Também foram considerados os seguintes valores médios para a resistência dos materiais: $\mathrm{f}_{\mathrm{cm}}=35 \mathrm{MPa}$ e $\mathrm{f}_{\mathrm{ym}}=500 \mathrm{MPa}$. Para o caso da resistência à tração da armadura de protensão, foi utilizado o mesmo valor empregado pelo autor do ensaio, com valor de $\mathrm{f}_{\mathrm{pm}}=2020 \mathrm{MPa}$.

As seções de armadura utilizadas no modelo estão mostradas na tabela 3.1. 
TABELA 3.1 - Armaduras utilizadas no modelo em cada seção

\begin{tabular}{|c|c|c|c|}
\hline & Seção 1 & Seção 2 & Seção 3 \\
\hline armadura de protensão $\left(\mathbf{c m}^{\mathbf{2}}\right)$ & - & 1,27 & 1,27 \\
\hline armadura passiva $\left(\mathbf{c m}^{\mathbf{2}}\right)$ & 6,30 & 6,30 & - \\
\hline armadura de distribuição $\left(\mathbf{c m}^{\mathbf{2}}\right)$ & 1,20 & 1,20 & 1,20 \\
\hline
\end{tabular}

$\mathrm{Na}$ tabela 3.2 estão apresentadas as características mecânicas e geométricas obtidas para os diversos trechos.

TABELA 3.2 - Características geométricas e mecânicas de cada seção

\begin{tabular}{|c|c|c|c|c|}
\hline & \multirow{2}{*}{ Seção 1} & \multicolumn{2}{|c|}{ Seção 2} & \multirow{2}{*}{ Seção 3} \\
\hline & & $\begin{array}{c}\text { para } \\
M>0\end{array}$ & $\begin{array}{c}\text { para } \\
M<0\end{array}$ & \\
\hline$I_{1}\left(\mathrm{~cm}^{4}\right)$ & 21662,46 & 20147,75 & 20147,75 & 19522,25 \\
\hline$I_{2}\left(\mathrm{~cm}^{4}\right)$ & 5632,82 & 933,71 & 13470,47 & 974,83 \\
\hline$M_{r}(k N . c m)$ & 1528,40 & 2469,57 & 1369,25 & 2413,59 \\
\hline$M_{y}(\mathbf{k N . c m})$ & 6058,01 & 2569,97 & 2649,48 & 2570,16 \\
\hline $1 / r_{y}\left(\mathrm{~cm}^{-1}\right)$ & $3,495 \cdot 10^{-4}$ & $4,575 \cdot 10^{-4}$ & $5,272.10^{-4}$ & $4,575.10^{-4}$ \\
\hline$M_{u}(k N . c m)$ & 4699,54 & 2825,29 & 5139,86 & 2773,35 \\
\hline $1 / r_{u}\left(\mathrm{~cm}^{-1}\right)$ & $9,016 \cdot 10^{-4}$ & $1,818.10^{-3}$ & $7,191 \cdot 10^{-4}$ & $1,778.10^{-3}$ \\
\hline
\end{tabular}

\section{c) Comparação entre os resultados experimentais e a análise teórica}

Na figura 3.17 estão mostrados os deslocamentos experimentais máximos em cada vão do protótipo (direito e esquerdo) encontrados em GASTAL et al. (1999) e os deslocamentos máximos da simulação numérica utilizando a relação momento $x$ curvatura do CEB-90 (1991) em conjunto com a técnica do carregamento incremental.

$\mathrm{Na}$ figura 3.18 pode ser visto os resultados experimentais e teóricos para a seção do apoio central. Os valores experimentais foram determinados a partir dos resultados experimentais das deformações da armadura e do concreto na região do apoio central, medidos com extensômetros elétricos.

$\mathrm{Na}$ figura 3.19 é mostrado o aspecto do diagrama teórico momentocurvatura para a seção do apoio central. Esta seção é a que forma a rótula plástica (seção crítica). 
A figura 3.20 ilustra a evolução teórica dos deslocamentos ao longo do elemento estrutural à medida que o carregamento vai atuando.

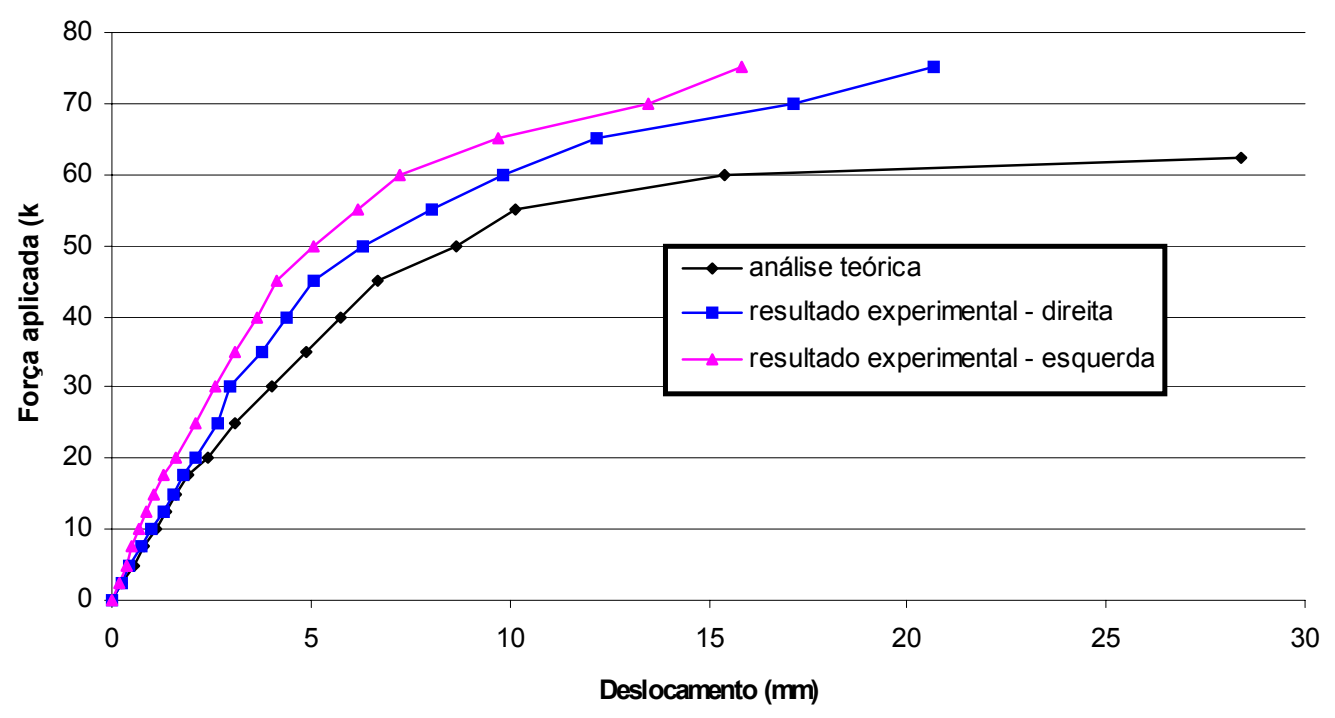

FIGURA 3.17 - Deslocamentos máximos experimentais e teóricos no vão

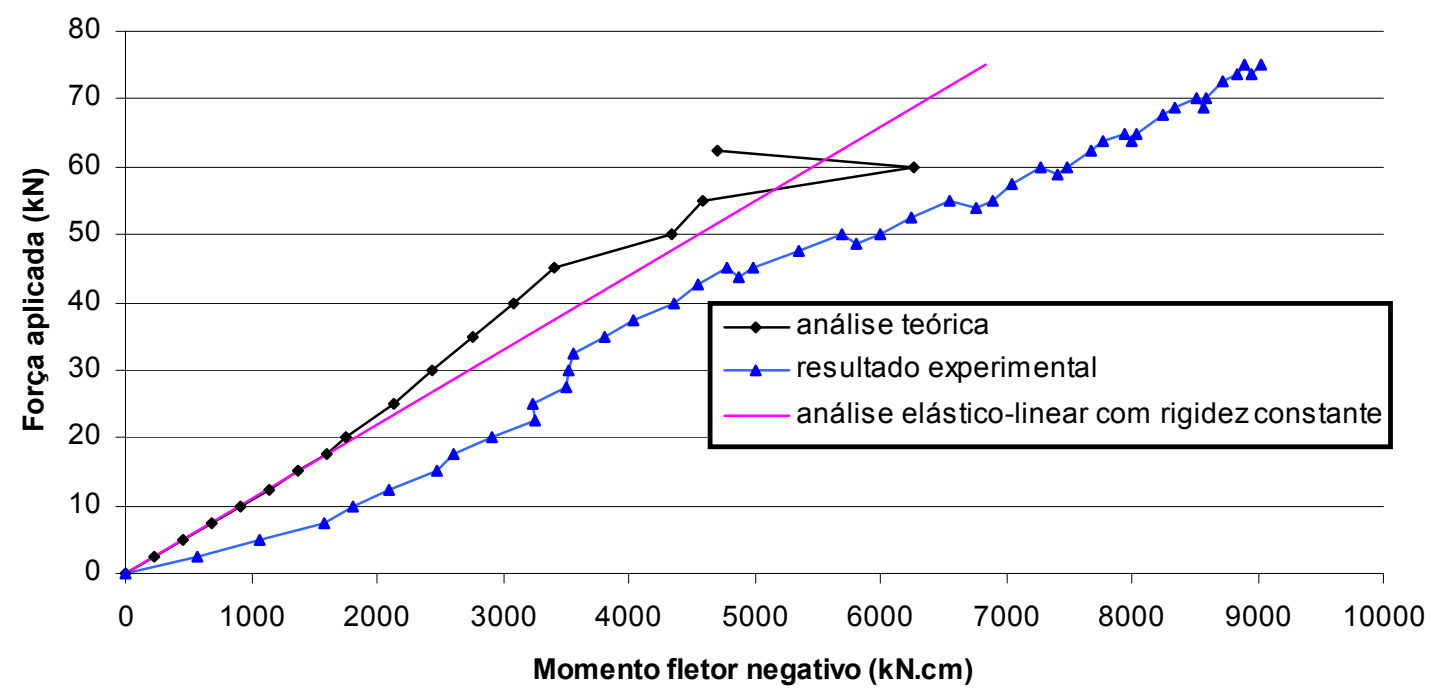

FIGURA 3.18 - Resultados experimentais e teóricos para a seção do apoio central

A diferença entre a carga última teórica e experimental pode ser explicada devido ao fato das propriedades relacionadas à resistência dos materiais utilizados no ensaio serem maiores que aquelas consideradas na análise teórica. Cabe destacar que a resistência do aço não foi medida e não foi apresentado o valor de resistência do concreto no instante em que se realizou o ensaio, apenas a sua resistência característica $\left(\mathrm{f}_{\mathrm{ck}}\right)$. 


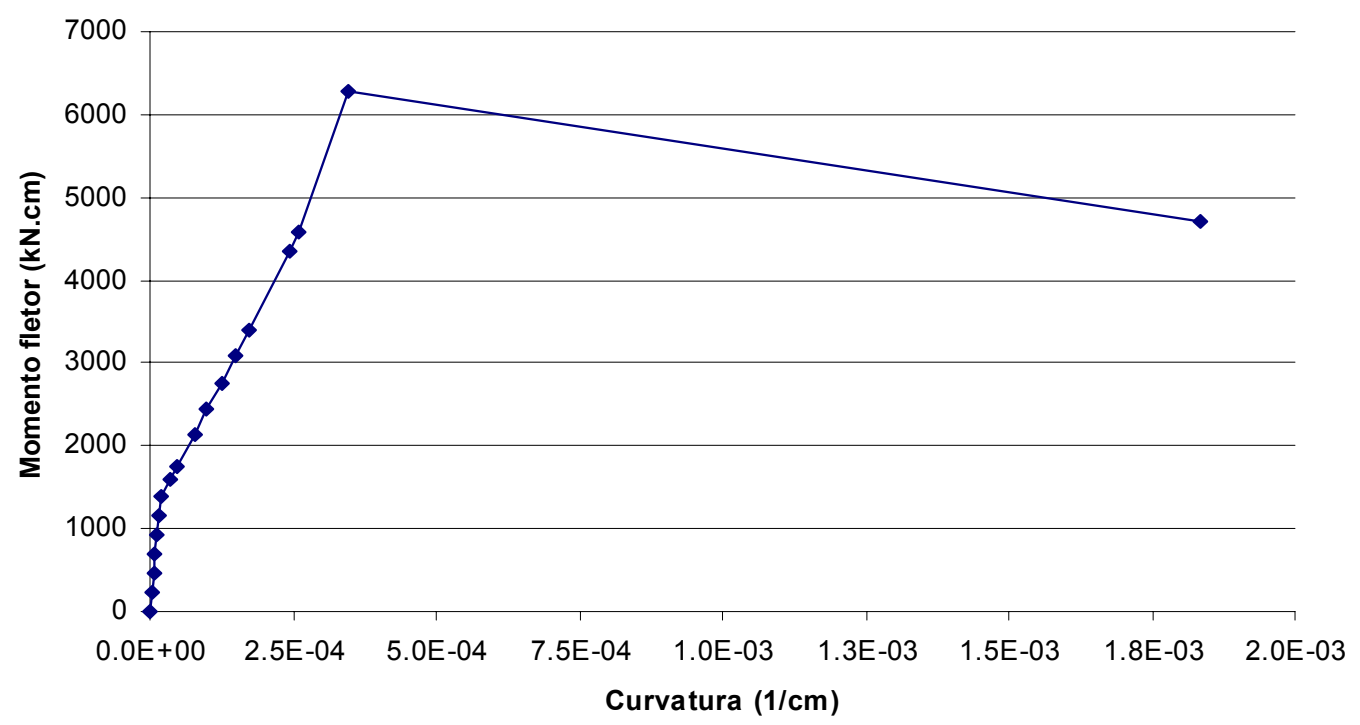

FIGURA 3.19 - Diagrama teórico momento $x$ curvatura para a seção do apoio central

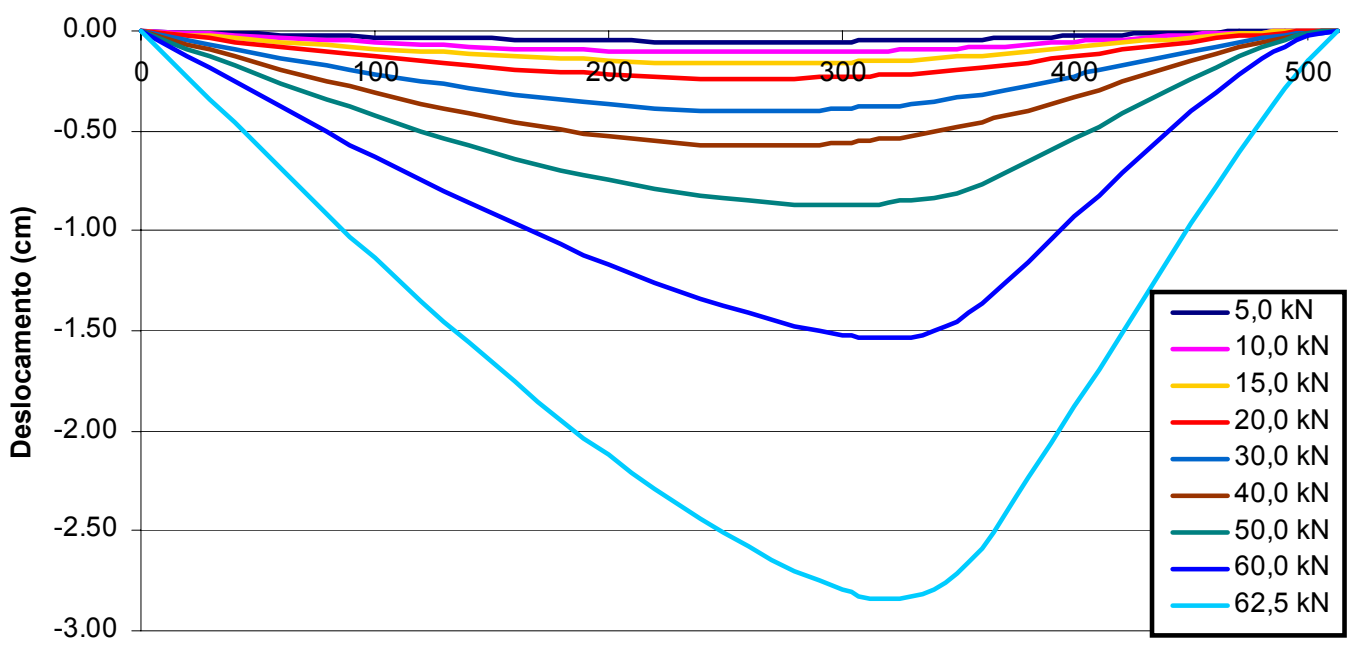

FIGURA 3.20 - Evolução dos deslocamentos - análise teórica

De acordo com a figura 3.17, pode-se verificar que o método numérico utilizado possui grande eficiência para prever o comportamento de lajes contínuas de seção composta, formadas por elementos pré-moldados protendidos e uma capa adicional de concreto.

Na figura 3.18 pode ser visto que a análise teórica não-linear esteve bem próxima da análise supondo material elástico-linear e inércia constante, sendo que para o Estádio I, antes da seção fissurar, os valores dos momentos fletores no apoio central considerando análise não-linear são iguais aos momentos fletores que se obteriam supondo material elástico-linear e inércia constante. 
Para o Estádio II, à medida que o carregamento vai aumentando, vai ocorrendo uma diminuição da velocidade de crescimento do momento negativo teórico não-linear, ficando no máximo $17 \%$ menor que o momento negativo calculado com material elástico linear e rigidez constante para o incremento de carga de $45 \mathrm{kN}$.

$\mathrm{Na}$ simulação numérica foram adotados dois critérios de parada para a definição da carga última: a) quando a curvatura da seção que forma a rótula plástica atingir a curvatura última ou b) quando há formação do mecanismo de colapso (for atingido momento último no vão). Na análise deste modelo, o último incremento de carga ocorreu coincidentemente por ter atingido o momento último no ponto de aplicação da força, além da curvatura no apoio central atingir seu valor último. Isso pode ser constatado pela figura 3.19, em que a curvatura na seção do apoio central ultrapassa o seu valor último $\left(9,016.10^{-4} \mathrm{~cm}^{-1}\right)$ no último incremento de carga.

A figura 3.20 mostra que, à medida que o carregamento vai aumentando, o ponto de deslocamento máximo no vão vai se aproximando do ponto de atuação da força (350 cm do apoio externo), sendo este o ponto que atinge o momento último.

\subsubsection{Avaliação 2-ensaio realizado por MARCELLINO (2001)}

\section{a) Descrição do ensaio}

O ensaio realizado por MARCELLINO (2001), conforme figura 3.21, foi executado com seis partes de dimensões $100 \times 100 \mathrm{~cm}$ de lajes alveolares de $10 \mathrm{~cm}$ de espessura, apoiadas em uma viga pré-fabricada de $20 \times 40 \mathrm{~cm}$ e vão de 3,14 metros. Essa viga por sua vez apoiou-se em consolos moldados em pilares de 20x50 cm de seção transversal.

O contato da viga com o consolo foi feito por aparelho de apoio simples de elastômero de dimensões $11 \times 16 \mathrm{~cm}$.

As lajes alveolares receberam uma capa estrutural de concreto de $4 \mathrm{~cm}$ de concreto, formando uma seção composta de $14 \mathrm{~cm}$ de altura. Envolvida por essa capa foi posicionada uma armadura negativa composta por barras CA-50 de $10 \mathrm{~mm}$ de diâmetro e espaçadas entre si de $10 \mathrm{~cm}$. 

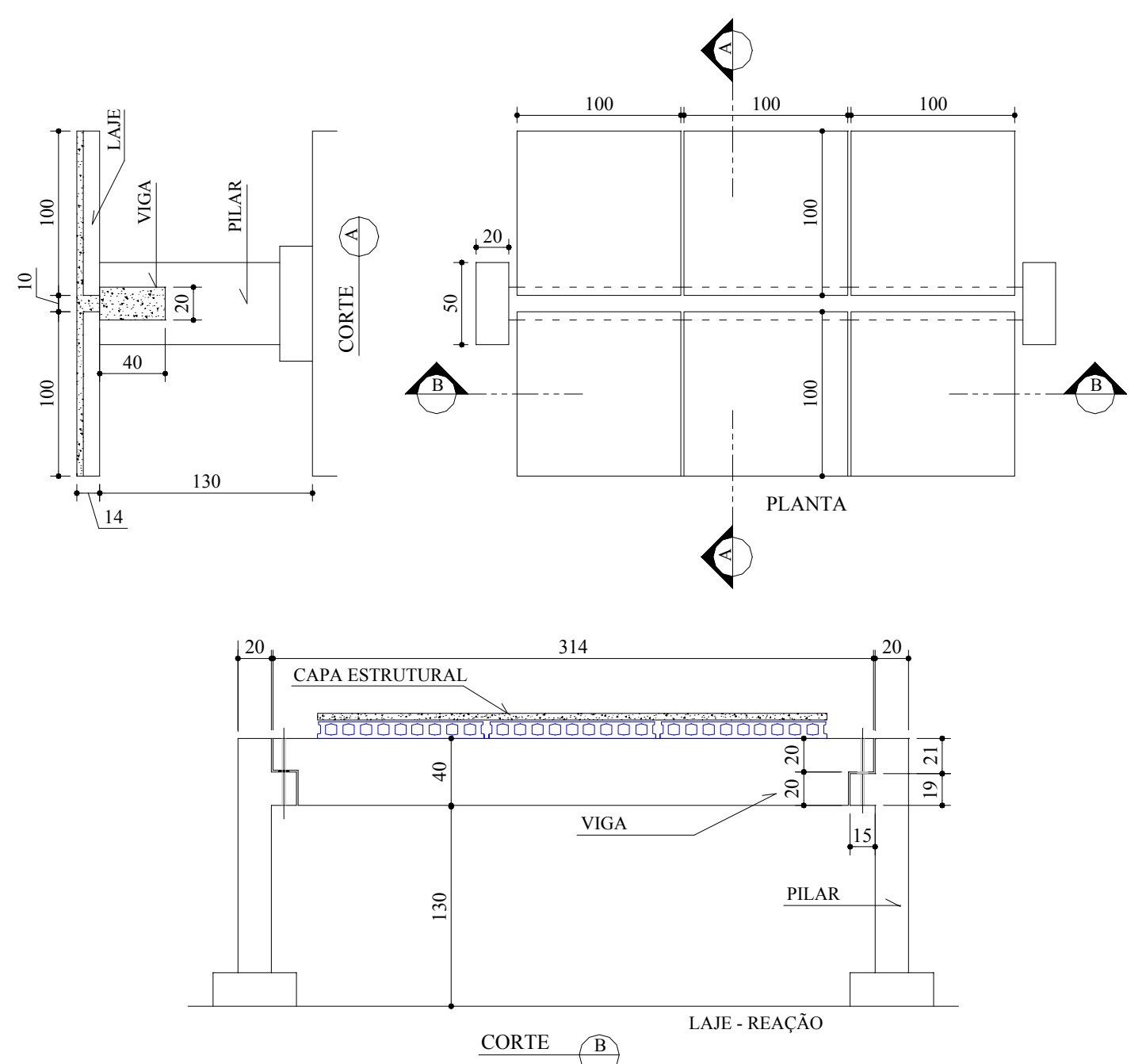

FIGURA 3.21 - Plano de montagem dos elementos (dimensões em cm)

A laje composta tem comportamento de laje em balanço com carga na extremidade, sendo que essa carga foi aplicada por um atuador, de um lado, e do outro lado através da utilização de um macaco hidráulico (figuras 3.22 e 3.23). Para que a carga fosse distribuída uniformemente ao longo da extremidade das lajes em balanço, foi colocado um perfil metálico de $10 \mathrm{~cm}$ de largura por $25 \mathrm{~cm}$ de altura, entre a célula de carga e a extremidade da laje, em cada lado.

Havia ainda a aplicação, através de outro sistema hidráulico, de forças nos terços médios da viga pré-fabricada. $\mathrm{O}$ autor do ensaio utilizou essa carga para analisar o comportamento conjunto laje-viga, que não faz parte do escopo desta pesquisa. 


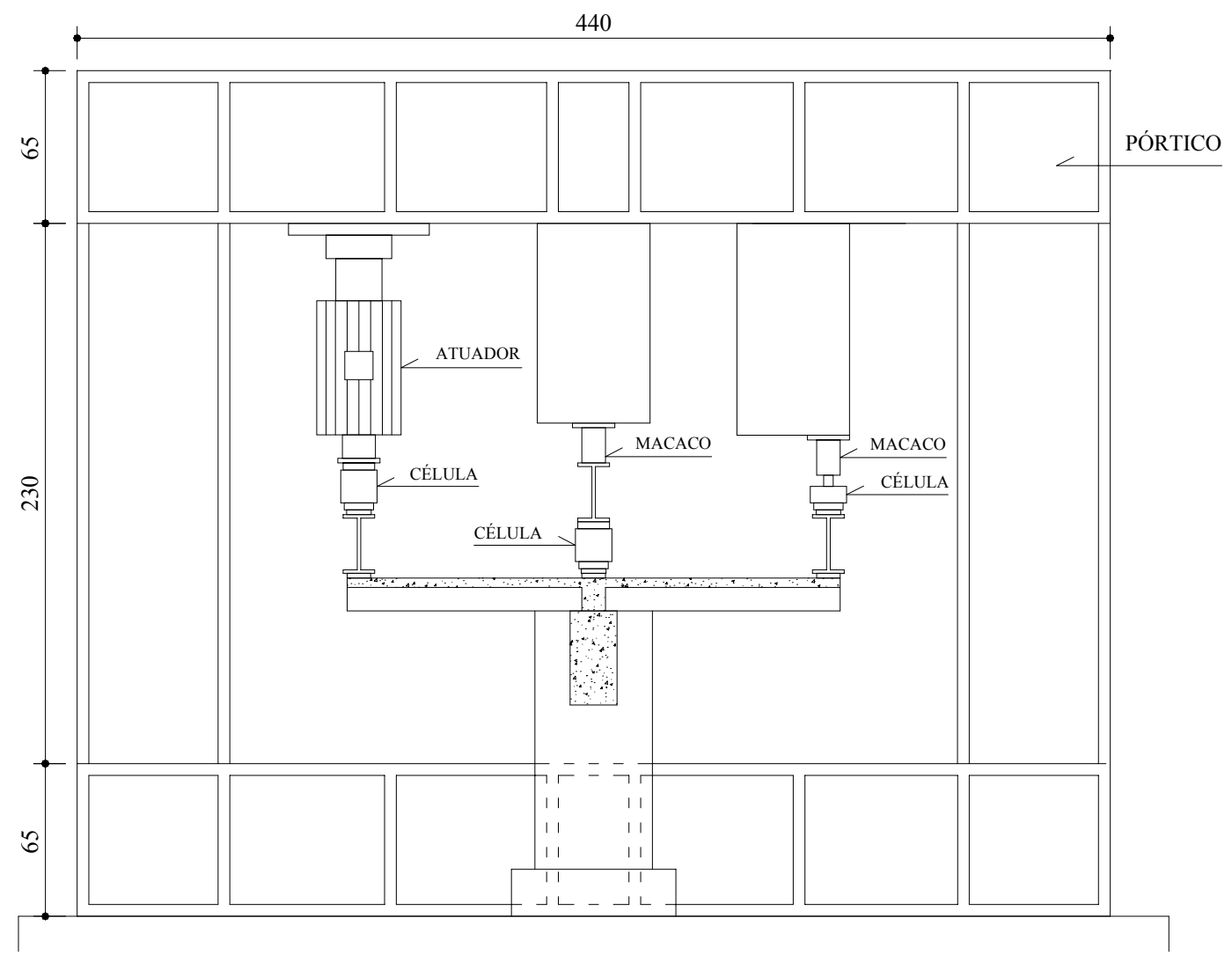

FIGURA 3.22 - Pórtico de reação - dimensões em cm

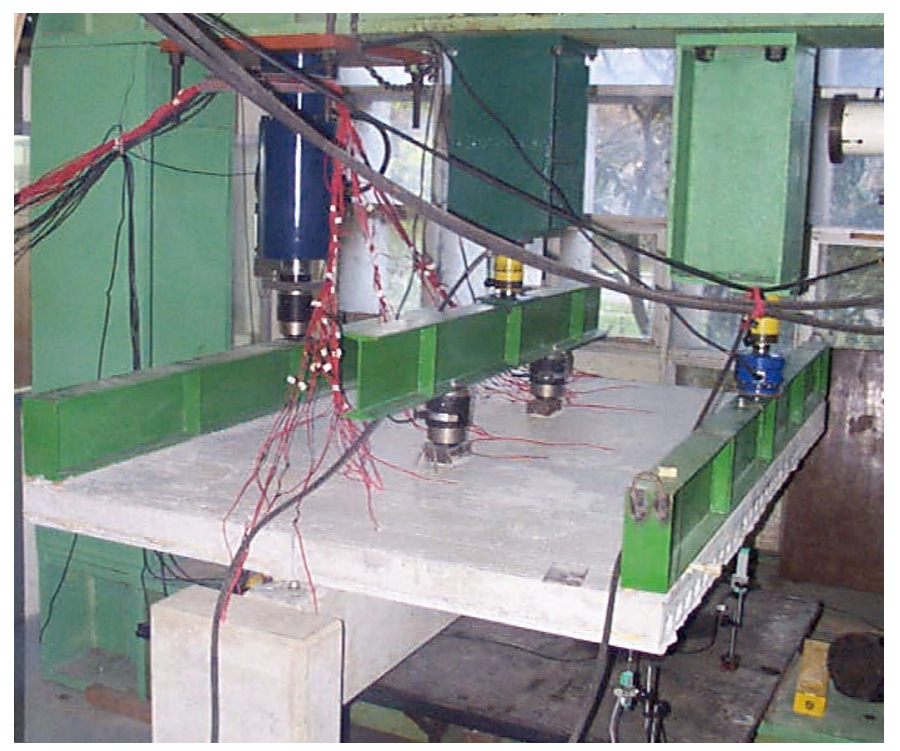

FIGURA 3.23 - Foto do modelo preparado para o ensaio 
Os valores de força e deslocamento da laje, utilizados para a análise, foram aqueles obtidos pela média dos valores medidos (figura 3.24).

Ou seja,

$\mathrm{F}_{\mathrm{M}}=\left(\mathrm{FA}_{\mathrm{A}}+\mathrm{FB}\right) / 2$

$\delta=\mathrm{DM}-\mathrm{DV}$

sendo:

$F_{M}$ - força média;

$F_{A}$ - força aplicada pelo atuador;

FB - força aplicada pelo macaco hidráulico;

$\delta$ - deslocamento médio da laje desconsiderando o movimento conjunto laje-viga;

$\mathrm{DM}_{\mathrm{M}}$ - deslocamento médio da extremidade da laje;

$\mathrm{DM}_{\mathrm{M}}=\left(\mathrm{D}_{1}+\mathrm{D} 2\right) / 2$;

com D1 (macaco hidráulico) e D2 (atuador) sendo os deslocamentos medidos pelos transdutores de deslocamento exatamente sob as cargas;

Dv - deslocamento no meio do vão da viga pré-fabricada.

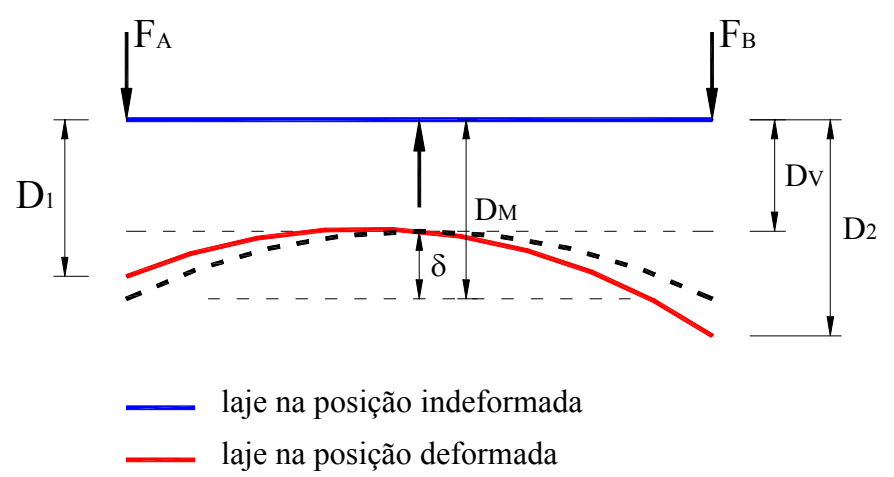

FIGURA 3.24 - Valores de força e deslocamento utilizados na análise

A fissuração da laje só foi visível para a carga de $113 \mathrm{kN}$ e a ruptura ocorreu com o valor de carga correspondente $223 \mathrm{kN}$ e flecha de 2,68 $\mathrm{cm}$ na extremidade da laje (descontando o deslocamento relativo da viga pré-fabricada).

Pôde-se notar claramente a formação de fissura na interface do concreto pré-fabricado da laje alveolar e o concreto do diafragma moldado no local. Isso 
ocorreu em toda extensão longitudinal da laje nos dois lados, como pode ser observado nas figuras 3.25 e 3.26 .

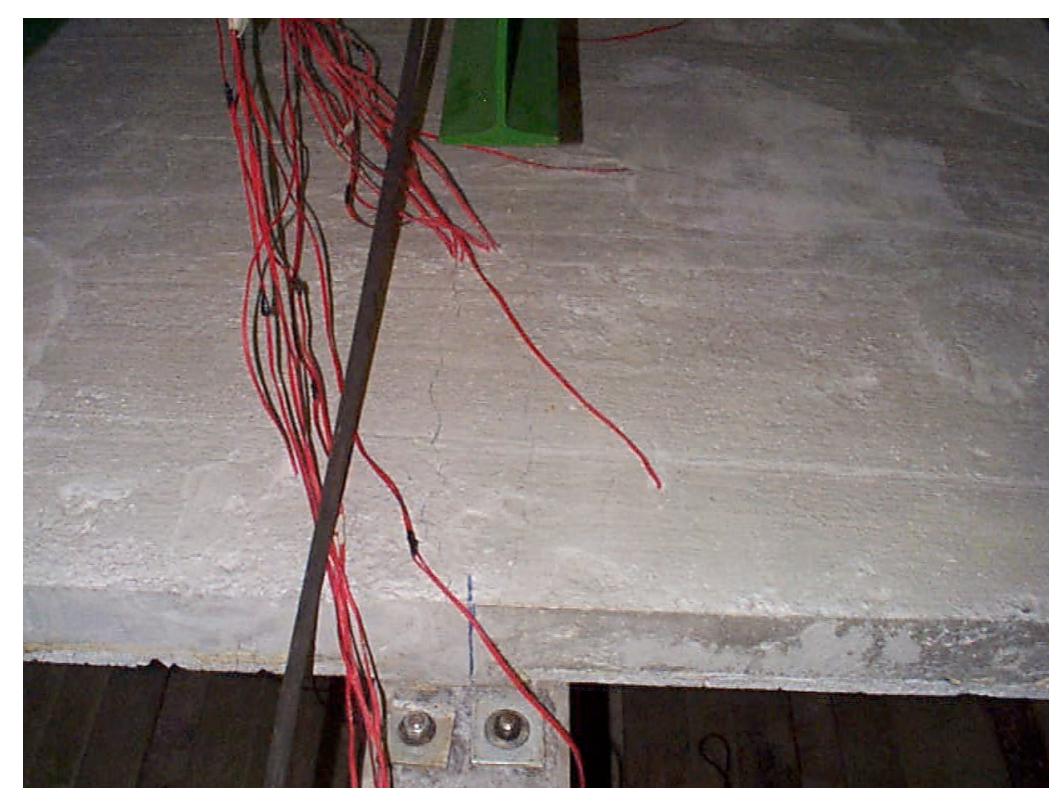

FIGURA 3.25 - Foto do início da fissuração

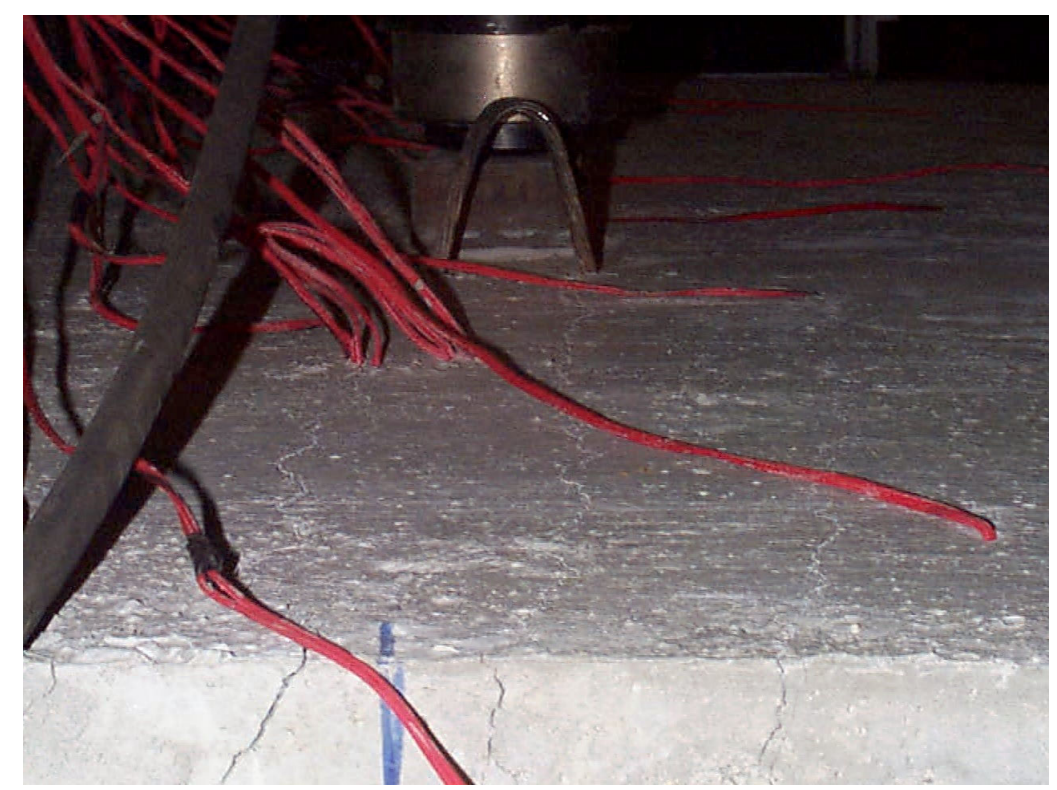

FIGURA 3.26 - Foto do ponto de apoio da laje na ruptura 


\section{b) Análise teórica}

A análise teórica utilizando o programa $\operatorname{ANSYS}^{\circledR}$ foi realizada utilizando dois tipos diferentes de seção (figura 3.27):

- $\quad$ seção 1: seção de concreto armado do diafragma

1 elemento de $10 \mathrm{~cm}$;

- $\quad$ seção 2: seção de laje composta

19 elementos de $5 \mathrm{~cm}$;

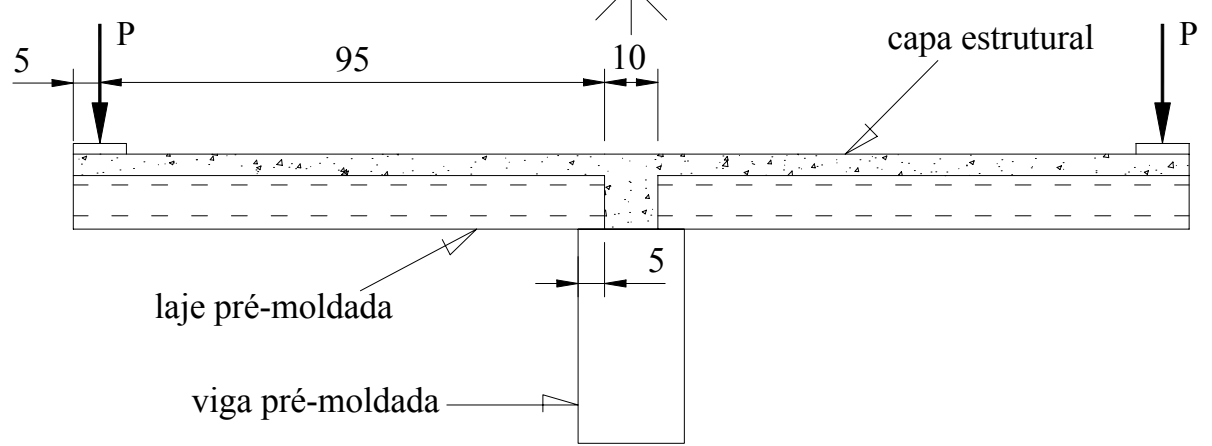

(a) Esquema da laje no ensaio

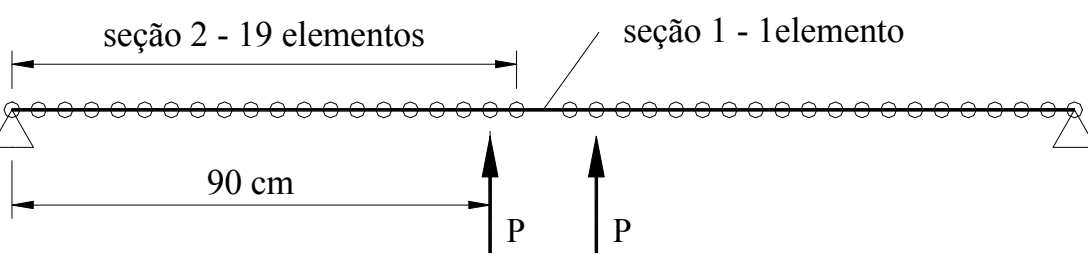

(b) Discretização utilizada no programa

FIGURA 3.27 - Discretização utilizada para o modelo (dimensões em cm)

Na figura 3.27 pode-se observar também o esquema estático utilizado.

Foi utilizado este esquema estático equivalente ao ensaio para evitar eventuais problemas durante o processamento.

As características mecânicas e geométricas das seções descritas anteriormente estão apresentadas na tabela 3.3. Para a seção de concreto armado do diafragma, foram adotados valores elevados para as características mecânicas e geométricas, visto que a viga pré-moldada abaixo desse elemento forma uma região 
de grande rigidez. E para a seção da laje alveolar, os valores foram retirados da tese de MARCELLINO (2001), autor do ensaio.

TABELA 3.3 - Características geométricas e mecânicas das seções do modelo

\begin{tabular}{|c|c|c|}
\hline & Seção 1 & Seção 2 \\
\hline$I_{1}\left(\mathrm{~cm}^{4}\right)$ & 50000 & 21829 \\
\hline$I_{2}\left(\mathrm{~cm}^{4}\right)$ & 10000 & 5635 \\
\hline$M_{r}(k N . c m)$ & 500 & 1148 \\
\hline$M_{y}(k N . c m)$ & 1000 & 4900 \\
\hline $1 / r_{y}\left(\mathrm{~cm}^{-1}\right)$ & $5,0.10^{-2}$ & $2,735.10^{-4}$ \\
\hline$M_{u}(k N . c m)$ & 2000 & 5100 \\
\hline $1 / r_{u}\left(\mathrm{~cm}^{-1}\right)$ & $8,0.10^{-3}$ & $2,971.10^{-4}$ \\
\hline
\end{tabular}

\section{c) Comparação entre o resultado experimental e a análise teórica}

$\mathrm{Na}$ figura 3.28 estão mostrados os deslocamentos experimentais médio na extremidade da laje, desconsiderando o movimento conjunto laje-viga, obtidos por MARCELLINO (2001) e os deslocamentos obtidos na simulação numérica utilizando a relação momento $x$ curvatura do CEB-90 (1991) em conjunto com a técnica do carregamento incremental.

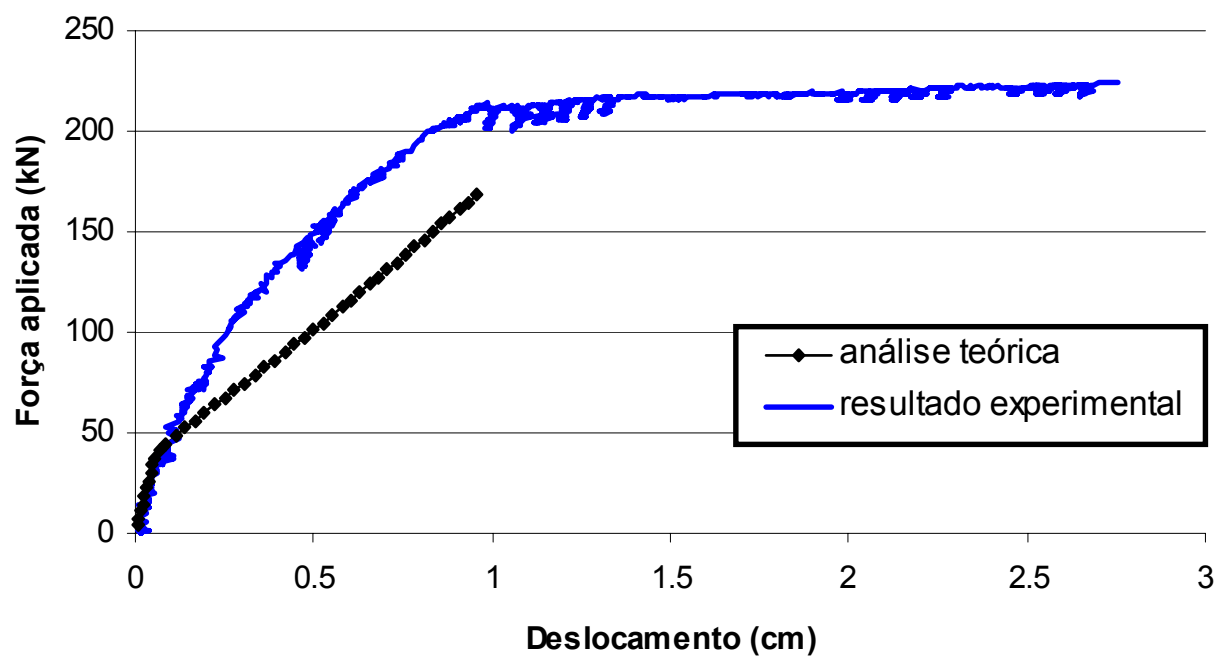

FIGURA 3.28 - Deslocamentos na extremidade da laje 
$\mathrm{Na}$ análise numérica não houve um patamar, pois, como o modelo é isostático, o programa não considera redistribuição de esforços entre suas partes, portanto o processamento é interrompido após a seção crítica atingir o momento último.

Pela figura 3.28 pode ser visto que, até a força de $50 \mathrm{kN}$, a diferença entre os deslocamentos experimentais e os obtidos pela análise numérica praticamente não existiu. Após este nível de carga, a diferença entre os deslocamentos começou a aparecer, atingindo o valor de 64,7\% quando ocorre o término do processamento numérico com uma força de $169 \mathrm{kN}$.

A razão dessa diferença crescente com o acréscimo de carga foi devida ao modo como foi realizado o ensaio e à forma de instrumentação da laje para se obter o deslocamento em sua extremidade.

O modo como foi realizado o ensaio, fez com que a deformação da laje não fosse constante, devido à deformação da viga pré-moldada em que ela se apoiava, como pode ser vista na figura 3.29. Além disso, o transdutor para a medição do deslocamento da viga foi colocado no meio de seu vão, ponto com deslocamento máximo. Assim, os valores dos deslocamentos na extremidade laje $(\delta)$ descontados os deslocamentos relativos da viga pré-moldada (Dv), conforme a fórmula:

$$
\delta=\mathrm{DM}-\mathrm{DV}
$$

conduziram a valores menores aos que seriam obtidos se a laje fosse apoiada sobre uma base indeformável, que é o que se considera na simulação numérica.

Portanto, se o que foi exposto acima fosse considerado, os deslocamentos experimentais e os obtidos pela simulação numérica apresentariam uma melhor concordância entre si. Isso pode ser comprovado pelo gráfico da figura 3.30, em que os deslocamentos na extremidade da laje foram ajustados admitindo como valor de Dv, metade do valor do deslocamento no meio do vão da viga. 
(a) Perspectiva do modelo ensaiado

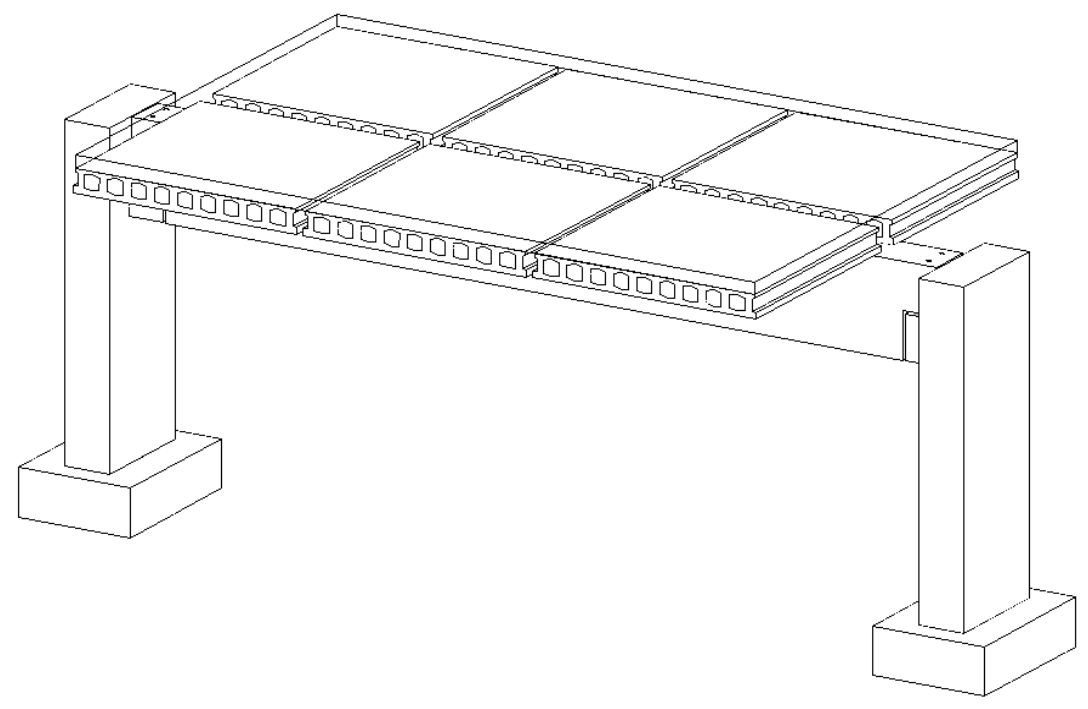

(b) Esquema da laje deformada

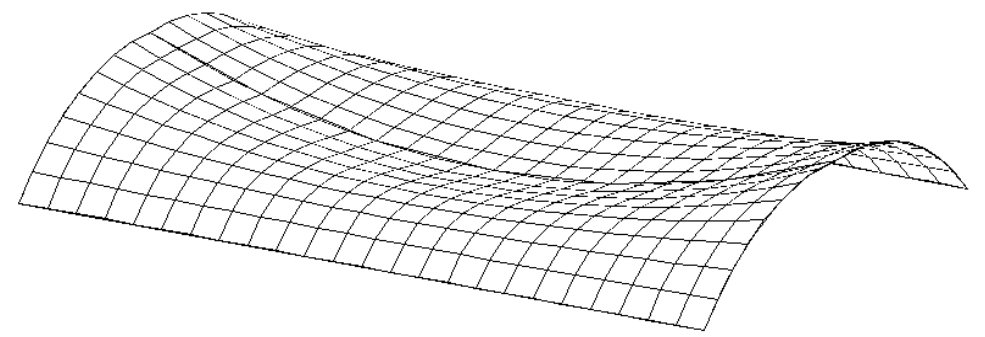

FIGURA 3.29 - Esquema do ensaio

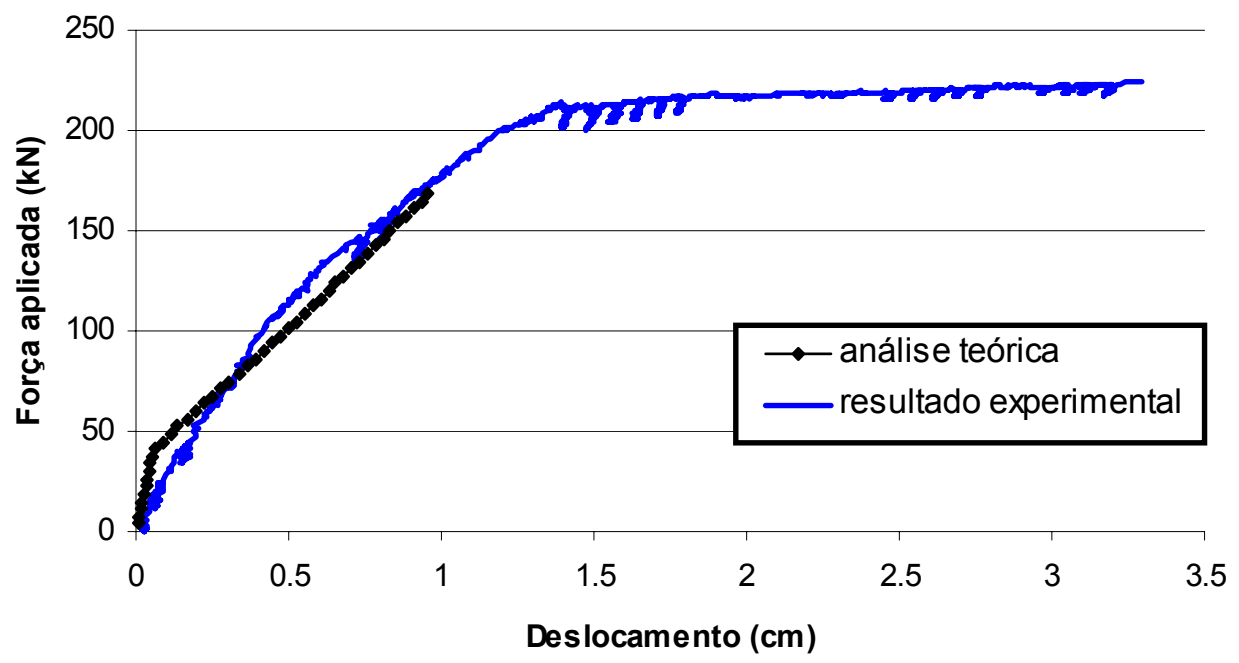

FIGURA 3.30 - Deslocamentos na extremidade da laje ajustados 


\section{ANÁLISE DE SITUAÇÕES REPRESENTATIVAS DE PROJETO}

\subsection{Considerações iniciais}

Este capítulo trata-se da análise de situações representativas de projeto de lajes unidirecionais formadas pelos elementos protendidos descritos nos capítulos anteriores, através de simulações numéricas. Estas simulações foram realizadas visando contribuir na compreensão do comportamento dos momentos fletores negativos junto aos apoios desse tipo de laje.

Para a consideração da não-linearidade física dos materiais, foi utilizada a técnica do carregamento incremental em conjunto com a relação momento $x$ curvatura proposta pelo CEB-90 (1991), como descrito anteriormente.

\subsection{Definições gerais dos casos analisados}

\subsubsection{Definição das dimensões}

As dimensões dos vãos e as larguras entre nervuras empregadas na análise foram aqueles que normalmente são utilizados em situações de projeto.

Para os vãos foram adotados valores de 4,0-6,0-8,0 $\mathrm{m}$ e o valor entre nervuras foi de $50 \mathrm{~cm}$ para todos os casos analisados. 
Os elementos pré-moldados empregados para os casos eram formados por concreto com $35 \mathrm{MPa}$ de resistência característica à compressão e fios de aço CP160-RN possuindo as seguintes características geométricas, conforme figura 4.1:

- casos com vãos de $4,0 \mathrm{~m}$ :

vigota com $12 \mathrm{~cm}$ de largura e $9 \mathrm{~cm}$ de altura, possuindo quatro fios de $5 \mathrm{~mm}$ de diâmetro com $25,2 \mathrm{kN}$ de força inicial $\left(\mathrm{P}_{\mathrm{i}}\right)$ por fio;

- casos com vãos de 6,0 m:

vigota com $12 \mathrm{~cm}$ de largura e $12 \mathrm{~cm}$ de altura, possuindo cinco fios de $6 \mathrm{~mm}$ de diâmetro com 36,6 kN de força inicial $\left(\mathrm{P}_{\mathrm{i}}\right)$ por fio;

- casos com vão de $8,0 \mathrm{~m}$ :

vigota com $12 \mathrm{~cm}$ de largura e $12 \mathrm{~cm}$ de altura, possuindo quatro fios de $7 \mathrm{~mm}$ de diâmetro com 46,2 $\mathrm{kN}$ de força inicial $\left(\mathrm{P}_{\mathrm{i}}\right)$ por fio;

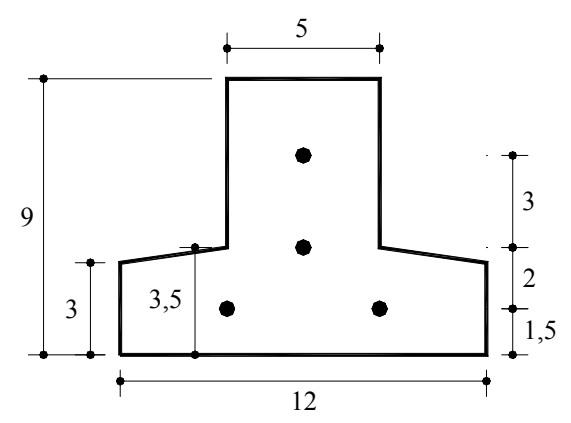

vigota para vãos de $4,0 \mathrm{~m}$

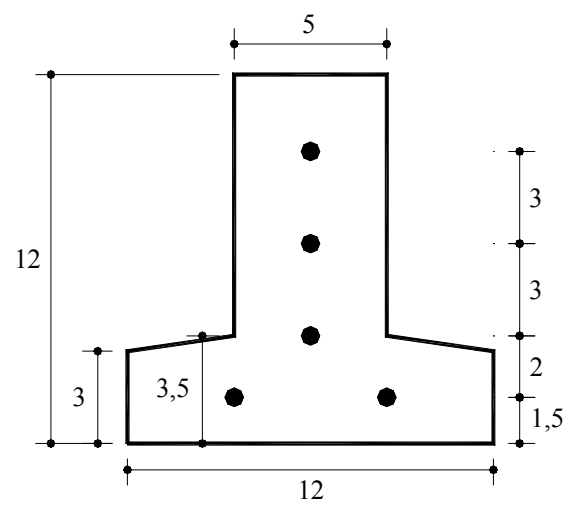

vigota para vãos de $6,0 \mathrm{~m}$

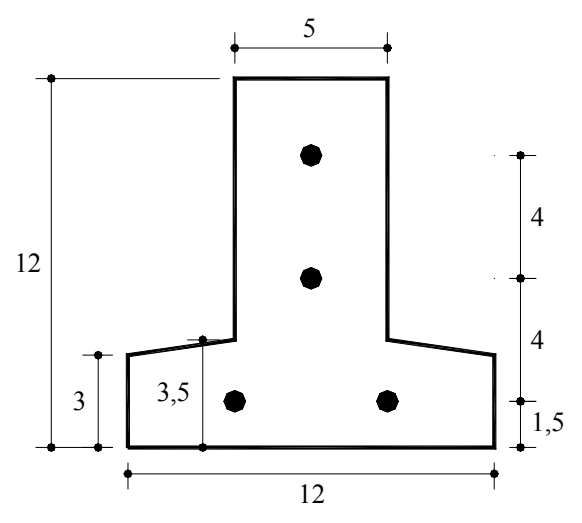

vigota para vãos de $8,0 \mathrm{~m}$

FIGURA 4.1 - Vigotas utilizadas para os casos analisados (dimensões em cm) 
A seção transversal final da laje foi completada com material de enchimento composto por blocos vazados de concreto e uma capa de concreto, levando a altura total da laje para 12,16 e $20 \mathrm{~cm}$, respectivamente para os casos com vãos de 4,0, 6,0 e 8,0 m. Todos os casos possuíam uma espessura de capeamento igual a $4 \mathrm{~cm}$, como pode ser visto na figura 4.2 , respeitando as recomendações do projeto de revisão da NBR-6118:2000, do projeto de norma para Laje pré-fabricada CE - 18:314.01 e a norma espanhola EF-96 (1997), conforme apresentado no capítulo 2.

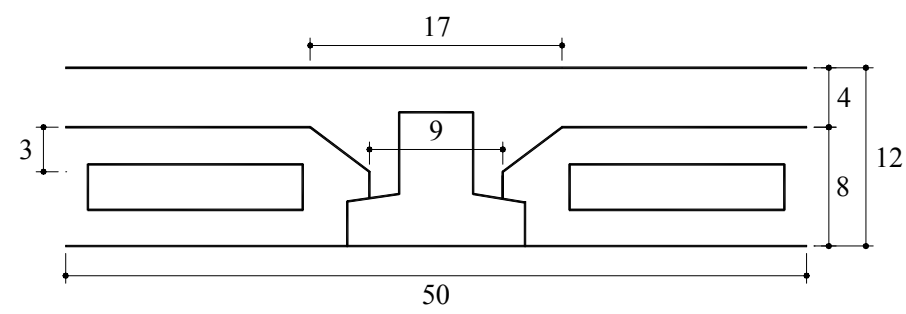

seção de laje para vãos de 4,0 m

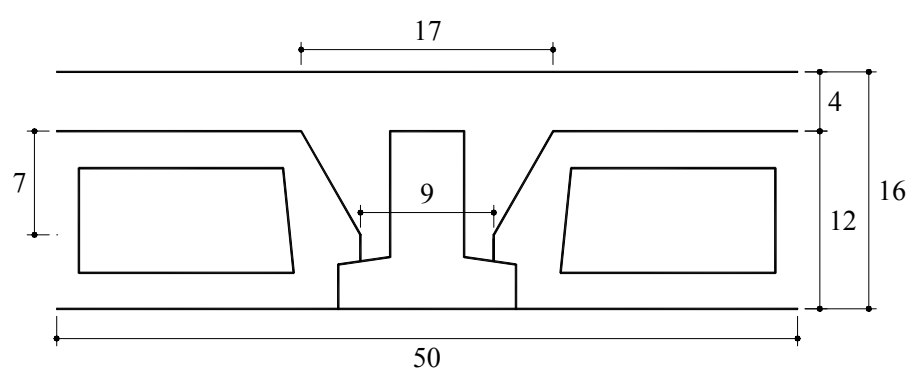

seção de laje para vãos de $6,0 \mathrm{~m}$

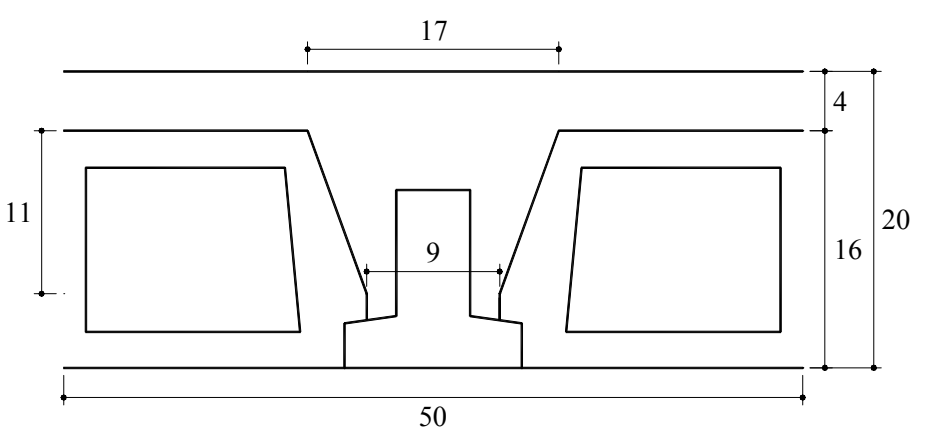

seção de laje para vãos de $8,0 \mathrm{~m}$

FIGURA 4.2 - Seções finais das lajes para os casos analisados (dimensões em cm)

$\mathrm{Na}$ capa de concreto foi colocada armadura de distribuição formada por uma tela soldada constituída por fios de $3,8 \mathrm{~mm}$ de diâmetro de aço CA-60 com $15 \mathrm{~cm}$ de espaçamento entre fios tanto na direção transversal quanto longitudinal à 
nervura, satisfazendo as recomendações do projeto de norma para Laje pré-fabricada CE - 18:314.01 e da EF-96 (1997).

\subsubsection{Definição da armadura de continuidade}

A determinação da armadura de continuidade foi feita admitindo vários graus de redistribuição de momento fletor, mas tendo o cuidado de que não se ultrapassasse a capacidade resistente da laje no vão.

O grau de redistribuição $\eta$, expresso em porcentagem, é definido por:

$\eta=(1-\delta) \cdot 100$

onde: $\delta$ - fator de redistribuição, igual a $\delta=\frac{\mathrm{M}_{\mathrm{ap}}}{\mathrm{M}_{\mathrm{el}}}$ (ver figura 4.3);

$\mathrm{M}_{\mathrm{ap}}$ - momento fletor negativo após a redistribuição;

$\mathrm{M}_{\mathrm{el}}$ - momento fletor negativo considerando material elásticolinear com rigidez constante.

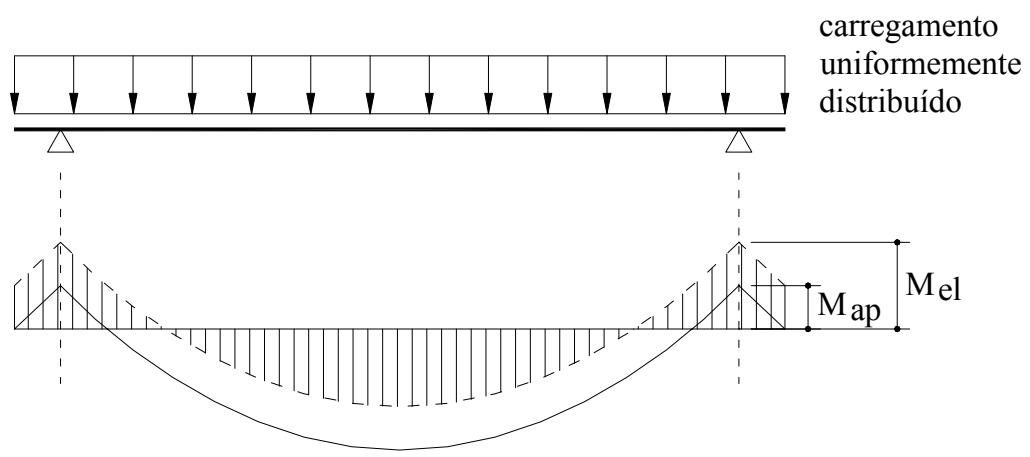

FIGURA 4.3 - Distinção entre o momento fletor considerando material elástico-linear e o momento fletor após redistribuição

O dimensionamento foi realizado considerando a atuação de ações uniformemente distribuídas ao longo do elemento unidirecional de laje com coeficiente de majoração $\gamma_{\mathrm{f}}$ de 1,4. As ações consideradas foram as seguintes:

- peso próprio do concreto: massa específica de $25 \mathrm{kN} / \mathrm{m}^{3}$; 
- peso do material de enchimento: blocos vazados de concreto com massa específica aparente de $13 \mathrm{kN} / \mathrm{m}^{3}$;

- carga permanente referente ao revestimento: $1,0 \mathrm{kN} / \mathrm{m}^{2}$;

- $\quad$ carga de utilização: $2,5 \mathrm{kN} / \mathrm{m}^{2}$.

Os valores das cargas para as lajes utilizadas estão apresentados de modo resumido na tabela 4.1 .

TABELA 4.1 - Valores das cargas para as lajes utilizadas

\begin{tabular}{|c|c|c|c|c|}
\hline & $\mathbf{g}_{\mathbf{1}}$ & $\mathbf{g}_{\mathbf{2}}$ & $\mathbf{g}_{\mathbf{3}}$ & $\mathbf{q}$ \\
\hline laje para vãos de $\mathbf{4 , 0} \mathbf{~ m}$ & 0,33 & 1,93 & 1,0 & 2,5 \\
\hline laje para vãos de $\mathbf{6 , 0} \mathbf{~ m}$ & 0,41 & 2,50 & 1,0 & 2,5 \\
\hline laje para vãos de $\mathbf{8 , 0} \mathbf{~ m}$ & 0,41 & 3,14 & 1,0 & 2,5 \\
\hline
\end{tabular}

sendo:

$\mathrm{g}_{1}$ - peso próprio da vigota protendida;

$\mathrm{g}_{2}$ - peso próprio do concreto moldado no local e peso do material de enchimento;

$\mathrm{g}_{3}$ - carga permanente relativa ao revestimento;

q - carga de utilização

$\mathrm{Na}$ figura 4.4, apresenta-se o esquema estático e o diagrama de momentos fletores para os casos com vãos duplos e vãos triplos empregados para a realização do dimensionamento da laje. 
Casos com vãos duplos

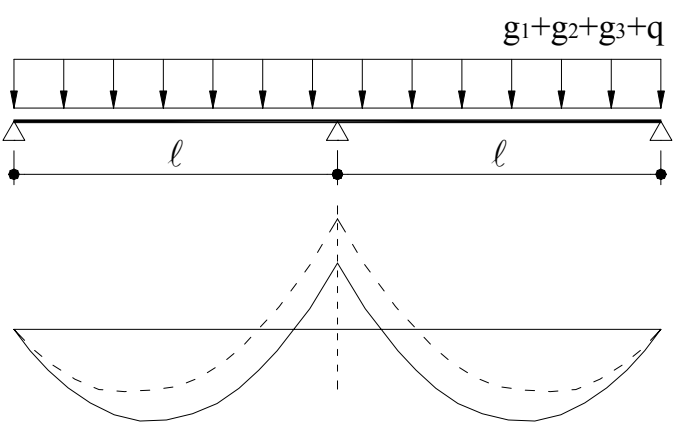

Casos com vãos triplos

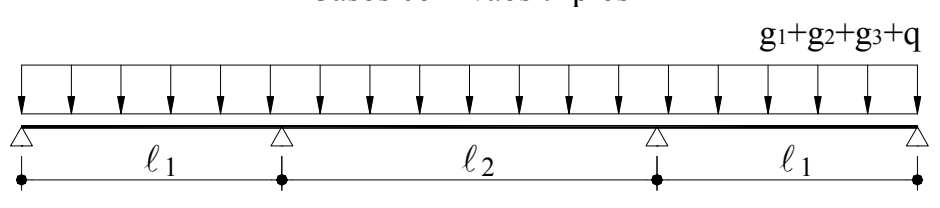

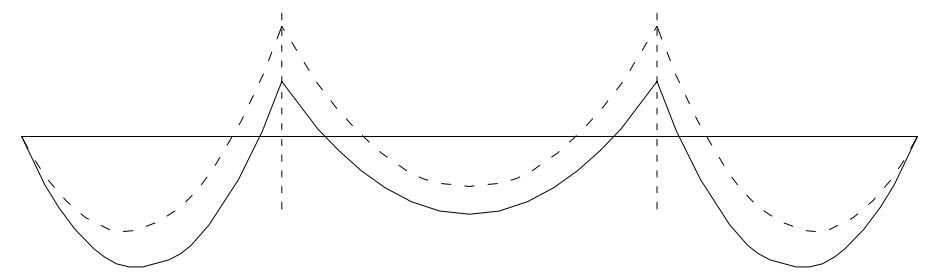

diagrama de momento fletor considerando material elástico-linear

diagrama de momento fletor após redistribuição

FIGURA 4.4 - Esquema estático e diagrama de momento fletor utilizados no dimensionamento

Portanto, como já foi comentado, foi realizado o dimensionamento utilizando vários vãos e diferentes graus de redistribuição, resultando nos casos apresentados na tabela 4.2. Nesta tabela também se apresenta a designação utilizada para cada caso, a resistência característica à compressão do concreto moldado no local e a armadura empregada no apoio (armadura de continuidade). 
TABELA 4.2 - Casos analisados

\begin{tabular}{|c|c|c|c|c|}
\hline casos & $\begin{array}{c}\text { vãos } \\
(\mathbf{m})\end{array}$ & $\begin{array}{c}\mathbf{f}_{\text {ck }} \text {-capa } \\
\mathbf{( M P a )}\end{array}$ & $\begin{array}{c}\text { grau de } \\
\text { redistribuição } \\
\eta(\%)\end{array}$ & $\begin{array}{c}\text { armadura no } \\
\text { apoio } \\
\text { (por nervura) }\end{array}$ \\
\hline $\mathrm{C} 2 / 4,0-20-0$ & $4,0-4,0$ & 20 & 0 & $4 \phi 8,0$ \\
\hline $\mathrm{C} 2 / 4,0-20-20$ & $4,0-4,0$ & 20 & 20 & $5 \phi 6,3$ \\
\hline $\mathrm{C} 2 / 4,0-20-40$ & $4,0-4,0$ & 20 & 40 & $4 \phi 6,3$ \\
\hline $\mathrm{C} 2 / 4,0-20-60$ & $4,0-4,0$ & 20 & 60 & $3 \phi 6,3$ \\
\hline $\mathrm{C} 2 / 6,0-20-0$ & $6,0-6,0$ & 20 & 0 & $5 \phi 10,0$ \\
\hline $\mathrm{C} 2 / 6,0-20-20$ & $6,0-6,0$ & 20 & 20 & $6 \phi 8,0$ \\
\hline $\mathrm{C} 2 / 6,0-20-40$ & $6,0-6,0$ & 20 & 40 & $5 \phi 8,0$ \\
\hline $\mathrm{C} 2 / 6,0-20-60$ & $6,0-6,0$ & 20 & 60 & $6 \phi 6,3$ \\
\hline $\mathrm{C} 2 / 6,0-15-20$ & $6,0-6,0$ & 15 & 20 & $6 \phi 8,0$ \\
\hline $\mathrm{C} 2 / 8,0-20-0$ & $8,0-8,0$ & 20 & 0 & $5 \phi 12,5$ \\
\hline $\mathrm{C} 2 / 8,0-20-20$ & $8,0-8,0$ & 20 & 20 & $6 \phi 10,0$ \\
\hline $\mathrm{C} 3 / 6,0-20-20$ & $6,0-6,0-6,0$ & 20 & 20 & $5 \phi 8,0$ \\
\hline $\mathrm{C} 2 / 6,0 / 8,0-20-20$ & $6,0-8,0-6,0$ & 20 & 40,0 \\
\hline
\end{tabular}

Para o caso com vãos de $8,0 \mathrm{~m}$, como pode ser visto na tabela 4.2 , foram utilizados apenas os valores de redistribuição iguais a $\eta=0$ e $\eta=20 \%$, pois graus de redistribuição acima destes fariam com que fosse ultrapassada a capacidade resistente da laje no vão, necessitando de uma laje de maior altura.

O dimensionamento da laje foi realizado considerando armadura de continuidade formada por barras de aço CA-50. O coeficiente utilizado para a minoração da resistência do aço foi de 1,15 e para o concreto pré-moldado e moldado no local foram 1,3 e 1,4, respectivamente. 


\subsection{Descrição das modelagens numéricas}

As simulações dos casos foram realizadas tomado-se partido da simetria existente (conforme figura 4.5). E em todos os casos a faixa de laje foi discretizada empregando-se elementos com comprimento de $10 \mathrm{~cm}$. Além disso, havia três tipos diferentes de seção para cada caso, conforme figura 4.5:

- seção 1: seção maciça de concreto armado, que une dois tramos consecutivos da laje;

- $\quad$ seção 2: seção composta, com armadura de continuidade;

- $\quad$ seção 3: seção composta, sem armadura de continuidade.
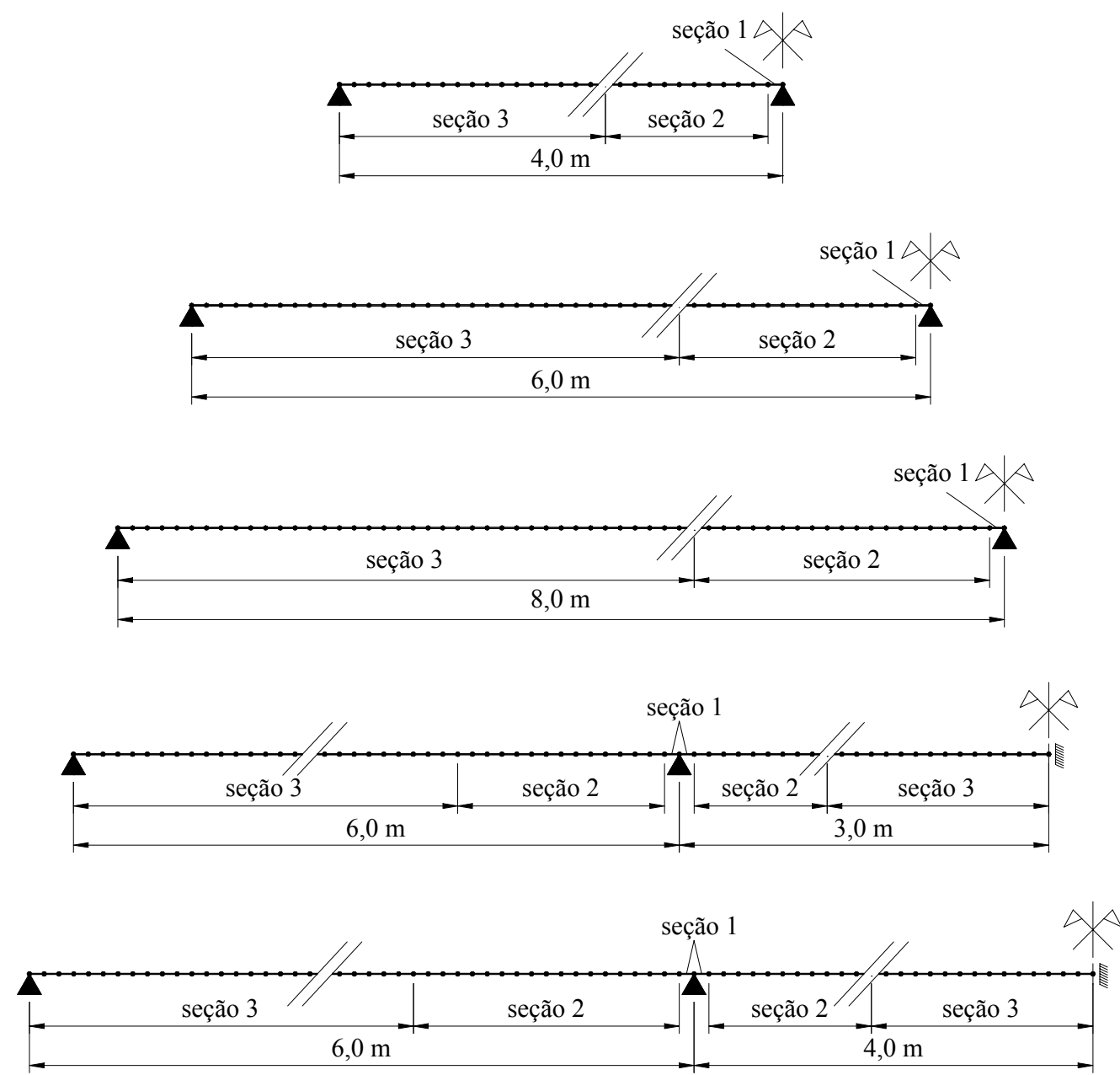

FIGURA 4.5 - Discretização dos casos analisados 
O número total de elementos de cada seção para cada caso analisado pode ser visto na tabela 4.3 .

TABELA 4.3 - Número de elementos de cada seção para os casos analisados

\begin{tabular}{|c|c|c|c|c|}
\hline \multirow{2}{*}{ casos } & \multicolumn{3}{|c|}{ número de elementos } & \multirow{2}{*}{$\begin{array}{l}\text { número total de } \\
\text { elementos }\end{array}$} \\
\hline & seção 1 & seção 2 & seção 3 & \\
\hline $\mathrm{C} 2 / 4,0-20-0$ & 1 & 14 & 25 & 40 \\
\hline $\mathrm{C} 2 / 4,0-20-20$ & 1 & 12 & 27 & 40 \\
\hline $\mathrm{C} 2 / 4,0-20-40$ & 1 & 10 & 29 & 40 \\
\hline $\mathrm{C} 2 / 4,0-20-60$ & 1 & 8 & 31 & 40 \\
\hline $\mathrm{C} 2 / 6,0-20-0$ & 1 & 19 & 40 & 60 \\
\hline $\mathrm{C} 2 / 6,0-20-20$ & 1 & 16 & 43 & 60 \\
\hline $\mathrm{C} 2 / 6,0-20-40$ & 1 & 13 & 46 & 60 \\
\hline $\mathrm{C} 2 / 6,0-20-60$ & 1 & 10 & 49 & 60 \\
\hline $\mathrm{C} 2 / 6,0-15-20$ & 1 & 16 & 43 & 60 \\
\hline $\mathrm{C} 2 / 8,0-20-0$ & 1 & 24 & 55 & 80 \\
\hline $\mathrm{C} 2 / 8,0-20-20$ & 1 & 20 & 59 & 80 \\
\hline $\mathrm{C} 3 / 6,0-20-20$ & 2 & $\begin{array}{l}14-1^{\circ} \text { tramo } \\
16-2^{\circ} \text { tramo }\end{array}$ & $\begin{array}{l}45-1^{\circ} \text { tramo } \\
13-2^{\circ} \text { tramo }\end{array}$ & 90 \\
\hline $\mathrm{C} 2 / 6,0 / 8,0-20-20$ & 2 & $\begin{array}{l}18-1^{\circ} \text { tramo } \\
16-2^{\circ} \text { tramo }\end{array}$ & $\begin{array}{l}41-1^{\circ} \text { tramo } \\
23-2^{\circ} \text { tramo }\end{array}$ & 100 \\
\hline
\end{tabular}

Os incrementos de carga considerados nas simulações foram cargas uniformemente distribuídas ao longo da faixa de laje. Isso foi feito empregando-se cargas pontuais equivalentes em cada nó discretizado.

Nas simulações numéricas foram considerados que as barras utilizadas possuíam boa aderência $\left(\beta_{1}=1,0\right)$ e a laje recebia a atuação do primeiro carregamento $\left(\beta_{2}=0,8\right)$, conduzindo ao valor do parâmetro $\beta_{\mathrm{b}}$ do CEB-90 (1991) igual a 0,8.

Em função da geometria da seção transversal, da área de aço e das propriedades dos materiais, calculou-se os parâmetros necessários para a utilização 
da relação momento $x$ curvatura. Esses parâmetros estão apresentados nas tabelas $4.4,4.5,4.6$ e 4.7 .

TABELA 4.4 - Características geométricas e mecânicas das seções para os casos com vãos de 4,0 m

\begin{tabular}{|c|c|c|c|c|c|c|c|c|c|}
\hline & & & $\begin{array}{c}I_{1} \\
\left(\mathrm{~cm}^{4}\right)\end{array}$ & $\begin{array}{c}I_{2} \\
\left(\mathrm{~cm}^{4}\right)\end{array}$ & $\begin{array}{c}\mathbf{M}_{\mathbf{r}} \\
(\mathrm{kN} \text {.cm) }\end{array}$ & $\begin{array}{c}M_{y} \\
(k N . c m)\end{array}$ & $\begin{array}{c}1 / r_{y} \\
\left(\mathrm{~cm}^{-1}\right)\end{array}$ & $\begin{array}{c}\mathbf{M}_{\mathbf{u}} \\
(\mathrm{kN} \cdot \mathrm{cm})\end{array}$ & $\begin{array}{c}1 / \mathbf{r}_{u} \\
\left(\mathrm{~cm}^{-1}\right)\end{array}$ \\
\hline \multirow{4}{*}{ 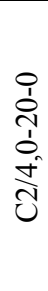 } & \multicolumn{2}{|c|}{ seção 1} & 7423,32 & 1150,89 & 418,77 & 921,55 & $3,219 \cdot 10^{-4}$ & 957,41 & $1,173 \cdot 10^{-3}$ \\
\hline & \multirow{2}{*}{ seção 2} & $M>0$ & 2549,80 & 284,45 & 587,67 & 694,50 & $2,362 \cdot 10^{-4}$ & 876,56 & $2,101 \cdot 10^{-3}$ \\
\hline & & $\mathrm{M}<0$ & 2549,80 & 733,56 & 184,90 & 782,28 & $6,176 \cdot 10^{-4}$ & 903,17 & $7,264 \cdot 10^{-4}$ \\
\hline & \multicolumn{2}{|c|}{ seção 3} & 2511,16 & 283,29 & 584,08 & 697,52 & $2,387 \cdot 10^{-4}$ & 867,94 & $2,070 \cdot 10^{-3}$ \\
\hline \multirow{4}{*}{ 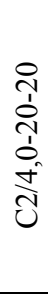 } & \multicolumn{2}{|c|}{ seção 1} & 7381,31 & 943,54 & 415,10 & 729,57 & $3,062 \cdot 10^{-4}$ & 755,98 & $1,133 \cdot 10^{-3}$ \\
\hline & \multirow{2}{*}{ seção 2} & $M>0$ & 2537,79 & 283,78 & 586,72 & 695,73 & $2,369.10^{-4}$ & 872,54 & $2,087 \cdot 10^{-3}$ \\
\hline & & $\mathrm{M}<0$ & 2537,79 & 619,25 & 184,68 & 538,00 & $6,659 \cdot 10^{-4}$ & 757,79 & $8,613 \cdot 10^{-4}$ \\
\hline & \multicolumn{2}{|c|}{ seção 3} & 2511,16 & 283,29 & 584,08 & 697,52 & $2,387 \cdot 10^{-4}$ & 867,94 & $2,070 \cdot 10^{-3}$ \\
\hline \multirow{4}{*}{ 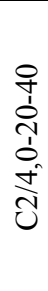 } & \multicolumn{2}{|c|}{ seção 1} & 7345,55 & 777,43 & 412,09 & 589,06 & $2,971 \cdot 10^{-4}$ & 608,78 & $1,113 \cdot 10^{-3}$ \\
\hline & \multirow{2}{*}{ seção 2} & $\mathrm{M}>0$ & 2525,96 & 283,68 & 585,47 & 696,29 & $2,377 \cdot 10^{-4}$ & 871,50 & $2,083 \cdot 10^{-3}$ \\
\hline & & $\mathrm{M}<0$ & 2525,96 & 522,29 & 183,58 & 379,44 & $6,897 \cdot 10^{-4}$ & 647,84 & $9,554 \cdot 10^{-4}$ \\
\hline & \multicolumn{2}{|c|}{ seção 3} & 2511,16 & 283,29 & 584,08 & 697,52 & $2,387 \cdot 10^{-4}$ & 867,94 & $2,070 \cdot 10^{-3}$ \\
\hline \multirow{4}{*}{ 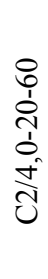 } & \multicolumn{2}{|c|}{ seção 1} & 7309,54 & 603,04 & 409,09 & 446,39 & $2,872 \cdot 10^{-4}$ & 459,72 & $1,092 \cdot 10^{-3}$ \\
\hline & \multirow{2}{*}{ seção 2} & $M>0$ & 2513,92 & 283,58 & 584,19 & 696,86 & $2,386 \cdot 10^{-4}$ & 870,58 & $2,079 \cdot 10^{-3}$ \\
\hline & & $\mathrm{M}<0$ & 2513,92 & 417,17 & 182,47 & 225,00 & $7,096 \cdot 10^{-4}$ & 535,79 & $1,049 \cdot 10^{-3}$ \\
\hline & \multicolumn{2}{|c|}{ seção 3} & 2511,16 & 283,29 & 584,08 & 697,52 & $2,387 \cdot 10^{-4}$ & 867,94 & $2,070 \cdot 10^{-3}$ \\
\hline
\end{tabular}


TABELA 4.5 - Características geométricas e mecânicas das seções para os casos com vãos de 6,0 m

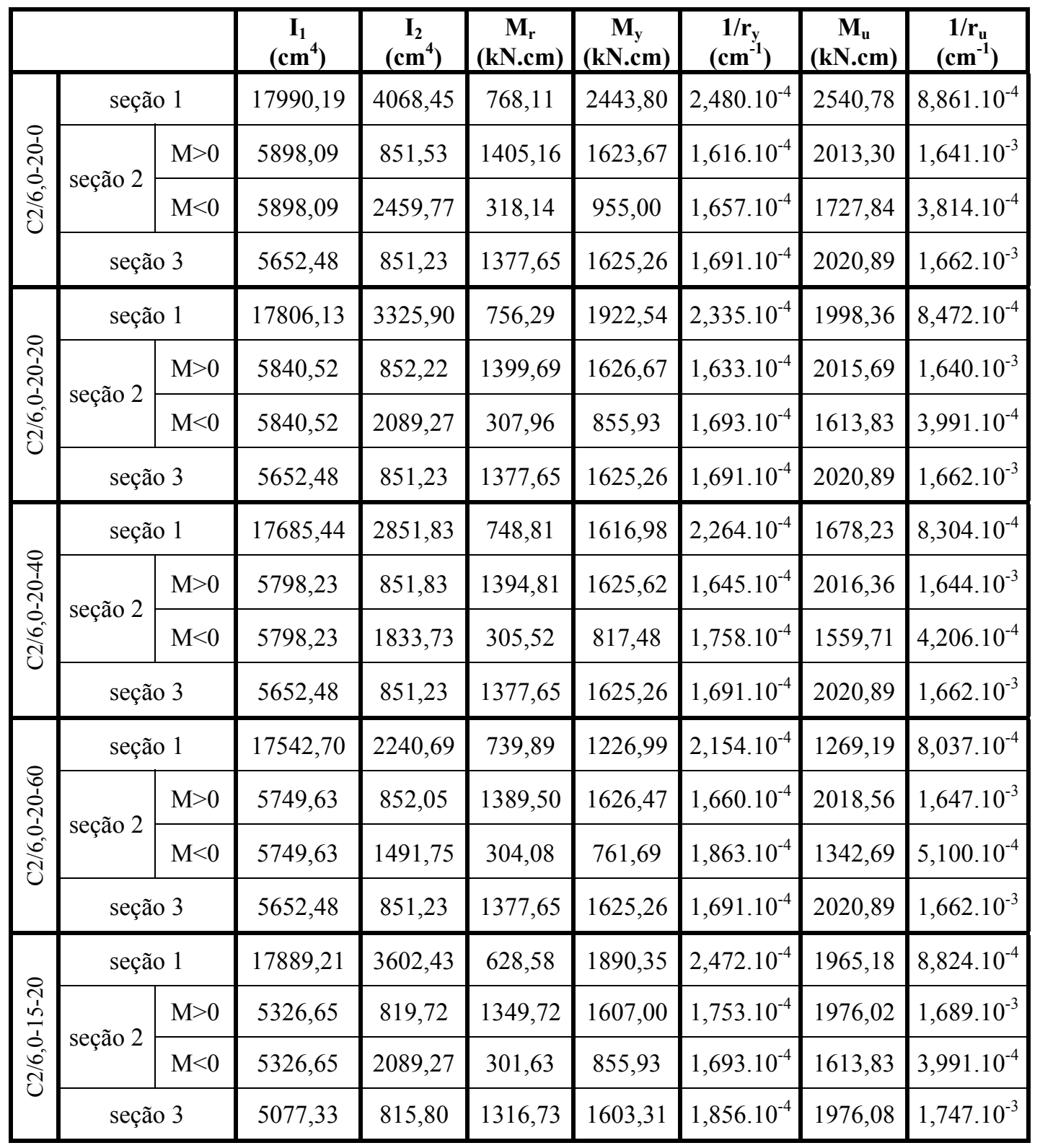


TABELA 4.6 - Características geométricas e mecânicas das seções para os casos com vãos de 8,0 m

\begin{tabular}{|c|c|c|c|c|c|c|c|c|c|}
\hline & & & $\begin{array}{c}\mathrm{I}_{1} \\
\left(\mathrm{~cm}^{4}\right)\end{array}$ & $\begin{array}{c}\mathrm{I}_{2} \\
\left(\mathrm{~cm}^{4}\right)\end{array}$ & $\begin{array}{c}\mathbf{M}_{\mathbf{r}} \\
\text { (kN.cm) }\end{array}$ & $\begin{array}{c}\mathbf{M}_{\mathbf{y}} \\
(\mathrm{kN} \cdot \mathrm{cm})\end{array}$ & $\begin{array}{c}1 / r_{y} \\
\left(\mathrm{~cm}^{-1}\right)\end{array}$ & $\begin{array}{c}\mathbf{M}_{\mathrm{u}} \\
(\mathrm{kN} \cdot \mathrm{cm})\end{array}$ & $\begin{array}{c}1 / \mathbf{r}_{\mathrm{u}} \\
\left(\mathrm{cm}^{-1}\right)\end{array}$ \\
\hline \multirow{4}{*}{ 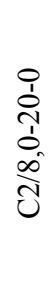 } & \multicolumn{2}{|c|}{ seção 1} & 35879,14 & 10121,01 & 1235,36 & 4846,04 & $2,017 \cdot 10^{-4}$ & 5038,00 & $9,237.10^{-4}$ \\
\hline & \multirow{2}{*}{ seção 2} & $\mathrm{M}>0$ & 11225,04 & 1749,30 & 1841,04 & 2484,75 & $1,875 \cdot 10^{-4}$ & 3001,23 & $1,085 \cdot 10^{-3}$ \\
\hline & & $\mathrm{M}<0$ & 11225,04 & 5853,04 & 427,02 & 1532,16 & $1,250 \cdot 10^{-4}$ & 2733,52 & $2,828 \cdot 10^{-4}$ \\
\hline & \multicolumn{2}{|c|}{ seção 3} & 10402,49 & 1736,08 & 1783,26 & 2484,53 & $1,967 \cdot 10^{-4}$ & 3013,87 & $1,112 \cdot 10^{-3}$ \\
\hline \multirow{4}{*}{ 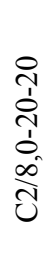 } & \multicolumn{2}{|c|}{ seção 1} & 35306,04 & 8172,73 & 1206,70 & 3786,65 & $1,901 \cdot 10^{-4}$ & 3937,80 & $6,818 \cdot 10^{-4}$ \\
\hline & \multirow{2}{*}{ seção 2} & $\mathrm{M}>0$ & 11021,11 & 1745,86 & 1827,58 & 2484,25 & $1,895 \cdot 10^{-4}$ & 3003,65 & $1,090 \cdot 10^{-3}$ \\
\hline & & $\mathrm{M}<0$ & 11021,11 & 4948,15 & 410,86 & 1443,50 & $1,328 \cdot 10^{-4}$ & 2638,41 & $3,019 \cdot 10^{-4}$ \\
\hline & \multicolumn{2}{|c|}{ seção 3} & 10402,49 & 1736,08 & 1783,26 & 2484,53 & $1,967 \cdot 10^{-4}$ & 3013,87 & $1,112 \cdot 10^{-3}$ \\
\hline
\end{tabular}

TABELA 4.7 - Características geométricas e mecânicas das seções para os casos com vãos triplos

\begin{tabular}{|c|c|c|c|c|c|c|c|c|c|}
\hline & & & $\begin{array}{c}I_{1} \\
\left(\mathrm{~cm}^{4}\right) \\
\end{array}$ & $\begin{array}{c}\mathrm{I}_{2} \\
\left(\mathrm{~cm}^{4}\right) \\
\end{array}$ & $\begin{array}{c}\mathbf{M}_{\mathrm{r}} \\
(\mathrm{kN} \cdot \mathrm{cm})\end{array}$ & $\begin{array}{c}M_{y} \\
(k N . c m) \\
\end{array}$ & $\begin{array}{c}1 / \mathbf{r}_{\mathrm{y}} \\
\left(\mathrm{cm}^{-1}\right)\end{array}$ & $\begin{array}{c}M_{u} \\
(\mathbf{k N} . c m) \\
\end{array}$ & $\begin{array}{c}1 / \mathbf{r}_{\mathrm{u}} \\
\left(\mathrm{cm}^{-1}\right)\end{array}$ \\
\hline \multirow{4}{*}{ 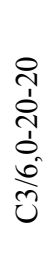 } & \multicolumn{2}{|c|}{ seção 1} & 17685,44 & 2851,83 & 748,81 & 1616,98 & $2,264.10^{-4}$ & 1678,23 & $8,304 \cdot 10^{-4}$ \\
\hline & \multirow{2}{*}{ seção 2} & $M>0$ & 5798,23 & 851,83 & 1394,81 & 1625,62 & $1,645 \cdot 10^{-4}$ & 2016,36 & $1,644 \cdot 10^{-3}$ \\
\hline & & $\mathrm{M}<0$ & 5798,23 & 1833,73 & 305,52 & 817,48 & $1,758 \cdot 10^{-4}$ & 1559,71 & $4,206 \cdot 10^{-4}$ \\
\hline & \multicolumn{2}{|c|}{ seção 3} & 5652,48 & 851,23 & 1377,65 & 1625,26 & $1,691.10^{-4}$ & 2020,89 & $1,662 \cdot 10^{-3}$ \\
\hline \multirow{4}{*}{ 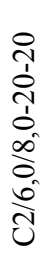 } & \multicolumn{2}{|c|}{ seção 1} & 34662,13 & 5821,87 & 1174,99 & 2579,93 & $1,767.10^{-4}$ & 2677,06 & $6,491 \cdot 10^{-4}$ \\
\hline & \multirow{2}{*}{ seção 2} & $\mathrm{M}>0$ & 10780,89 & 1741,49 & 1810,90 & 2980,99 & $4,839 \cdot 10^{-4}$ & 3006,44 & $1,097 \cdot 10^{-3}$ \\
\hline & & $\mathrm{M}<0$ & 10780,89 & 3738,20 & 392,59 & 1298,57 & $1,465.10^{-4}$ & 2359,32 & $3,593 \cdot 10^{-4}$ \\
\hline & \multicolumn{2}{|c|}{ seção 3} & 10402,49 & 1736,08 & 1783,26 & 2484,53 & $1,967 \cdot 10^{-4}$ & 3013,87 & $1,112 \cdot 10^{-3}$ \\
\hline
\end{tabular}




\subsection{Resultados obtidos nas simulações}

Neste item são apresentados os resultados obtidos nas simulações numéricas para os casos em questão.

Em todos casos analisados o processamento foi interrompido por atingir a curvatura última na seção em que se formou a rótula plástica.

\subsubsection{Casos com vãos duplos de 4,0 m}

$\mathrm{Na}$ tabela 4.8 apresenta-se um resumo do comportamento dos casos com vãos de 4,0 m. Pela tabela pode-se verificar que a fissuração no apoio para todos os casos, indiferente à taxa da armadura de continuidade, ocorreu para um mesmo nível de carga. Uma diferença ocorrida foi que para os casos C2/4,0-20-0 e C2/4,0-20-20 o escoamento da seção próxima ao apoio ocorreu depois da fissuração no vão devido à alta taxa de armadura presente no apoio para estes casos.

TABELA 4.8 - Comportamento estrutural para os casos com vãos de $4.0 \mathrm{~m}$

\begin{tabular}{|c|c|c|c|c|c|c|c|c|c|}
\hline \multirow{3}{*}{ casos } & \multicolumn{4}{|c|}{ fissuração } & \multicolumn{2}{|c|}{ escoamento } & \multicolumn{2}{|c|}{$\begin{array}{c}\text { momento } \\
\text { último }\end{array}$} & \multirow{3}{*}{$\begin{array}{l}\text { força } \\
\text { última }\end{array}$} \\
\hline & \multicolumn{2}{|c|}{ apoio } & \multicolumn{2}{|r|}{ vão } & \multirow{2}{*}{ força } & \multirow{2}{*}{$\begin{array}{c}\text { element } \\
\text { o }\end{array}$} & \multirow{2}{*}{ força } & \multirow{2}{*}{$\begin{array}{c}\text { element } \\
\text { o }\end{array}$} & \\
\hline & força & elemento & força & elemento & & & & & \\
\hline $\mathrm{C} 2 / 4,0-20-0$ & 1,80 & 39 & 7,80 & $16 / 17$ & 10,60 & $39 / 40$ & 11,0 & 40 & 11,80 \\
\hline $\mathrm{C} 2 / 4,0-20-20$ & 1,92 & 39 & 7,68 & $16 / 17$ & 8,04 & 39 & 9,60 & 40 & 11,04 \\
\hline $\mathrm{C} 2 / 4,0-20-40$ & 1,80 & 39 & 7,56 & $16 / 17$ & 6,72 & 39 & 8,64 & 40 & 10,56 \\
\hline $\mathrm{C} 2 / 4,0-20-60$ & 1,80 & 39 & 7,20 & $17 / 18$ & 3,10 & 39 & 7,60 & 40 & 10,10 \\
\hline \multicolumn{5}{|c|}{ elementos 39 e 40: } & \multicolumn{5}{|c|}{ unidade das cargas $-\mathrm{kN} / \mathrm{m}^{2}$} \\
\hline
\end{tabular}

$\mathrm{Na}$ figura 4.6 é mostrada a evolução do momento fletor negativo para a seção crítica (seção que atingiu $\mathrm{M}_{\mathrm{U}}$ ) e o máximo momento fletor positivo para os casos com vãos de 4,0 m. Pode-se observar nesta figura que há uma tendência de 
ocorrência de três trechos retos, tanto para o momento fletor positivo como para o momento fletor negativo. O primeiro trecho vai do ponto zero até o ponto em que ocorre a fissuração no apoio, o segundo trecho começa nesse ponto e vai até o instante em que ocorre a fissuração no vão da laje e o terceiro trecho acaba quando se atinge o momento último no apoio.

Pela figura 4.6 também se pode notar que os momentos fletores para todos os casos estiveram próximos entre si, começando a distanciar quando ocorre a primeira fissura no apoio e atingindo a diferença máxima durante a fissuração no vão, sendo que para um nível de carga de $7,0 \mathrm{kN} / \mathrm{m}^{2}$ a diferença entre momentos fletores positivos foi de $8,6 \%$ e de $20,3 \%$ para o momento fletor negativo.

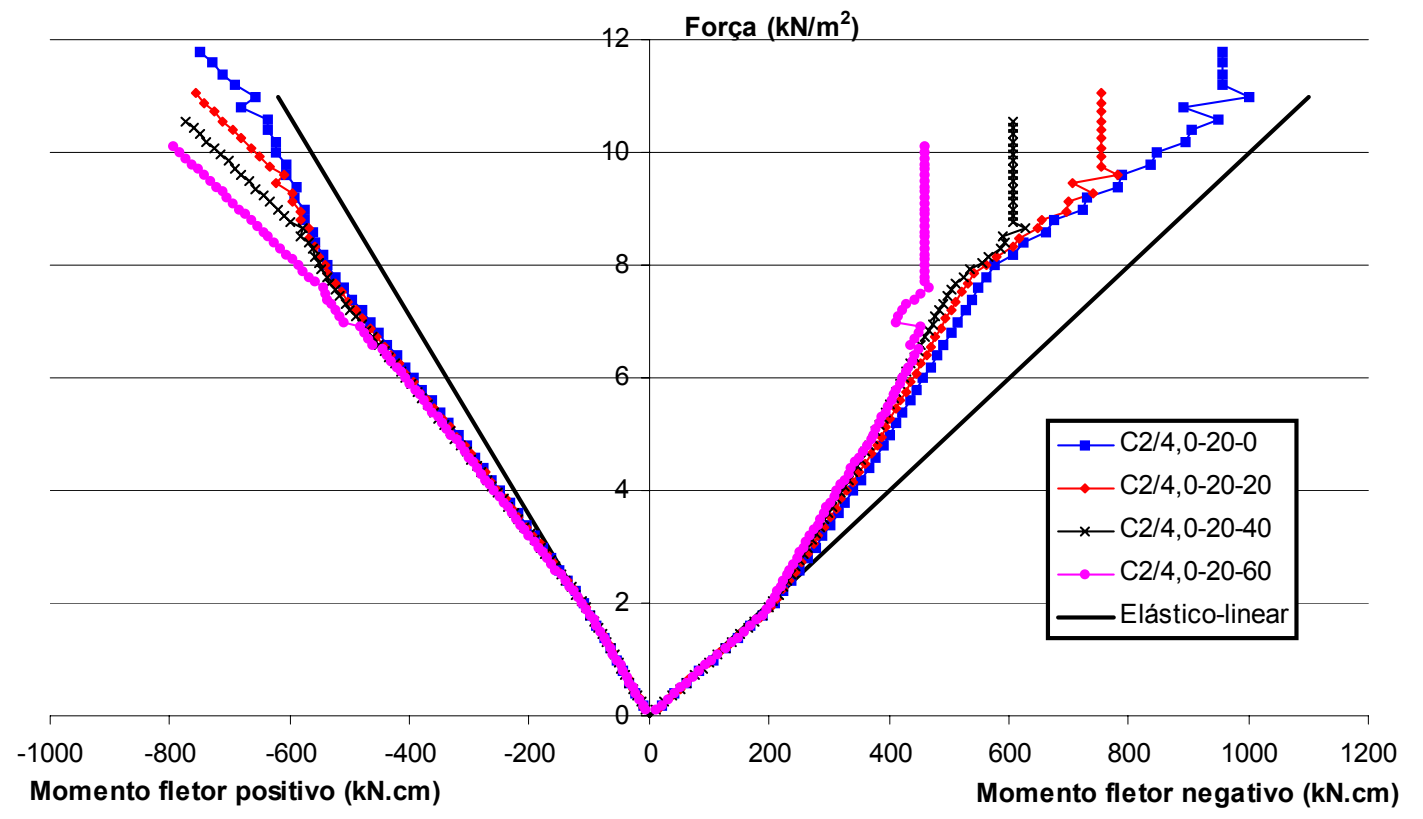

FIGURA 4.6 - Máximos momentos fletores - casos com vãos de 4,0 m

Para a força última, os valores de redistribuição dos momentos fletores no apoio foram de $18,9 \%, 31,5 \%, 42,4 \%$ e $54,5 \%$ para os casos, respectivamente, C2/4,0-20-0, C2/4,0-20-20, C2/4,0-20-40 e C2/4,0-20-60.

$\mathrm{Na}$ figura 4.7 apresenta-se a evolução dos deslocamentos máximos para os casos com vãos de 4,0 m. Por essa figura pode-se notar que até aproximadamente a carga de $6,50 \mathrm{kN} / \mathrm{m}^{2}$, incluindo a carga de serviço $\left(3,76 \mathrm{kN} / \mathrm{m}^{2}\right)$, os valores dos deslocamentos máximos para todos os casos são praticamente os mesmos, com uma 
diferença máxima de 5,5\%. Os valores começaram a distanciarem entre si no instante em que houve a fissuração no vão da laje.

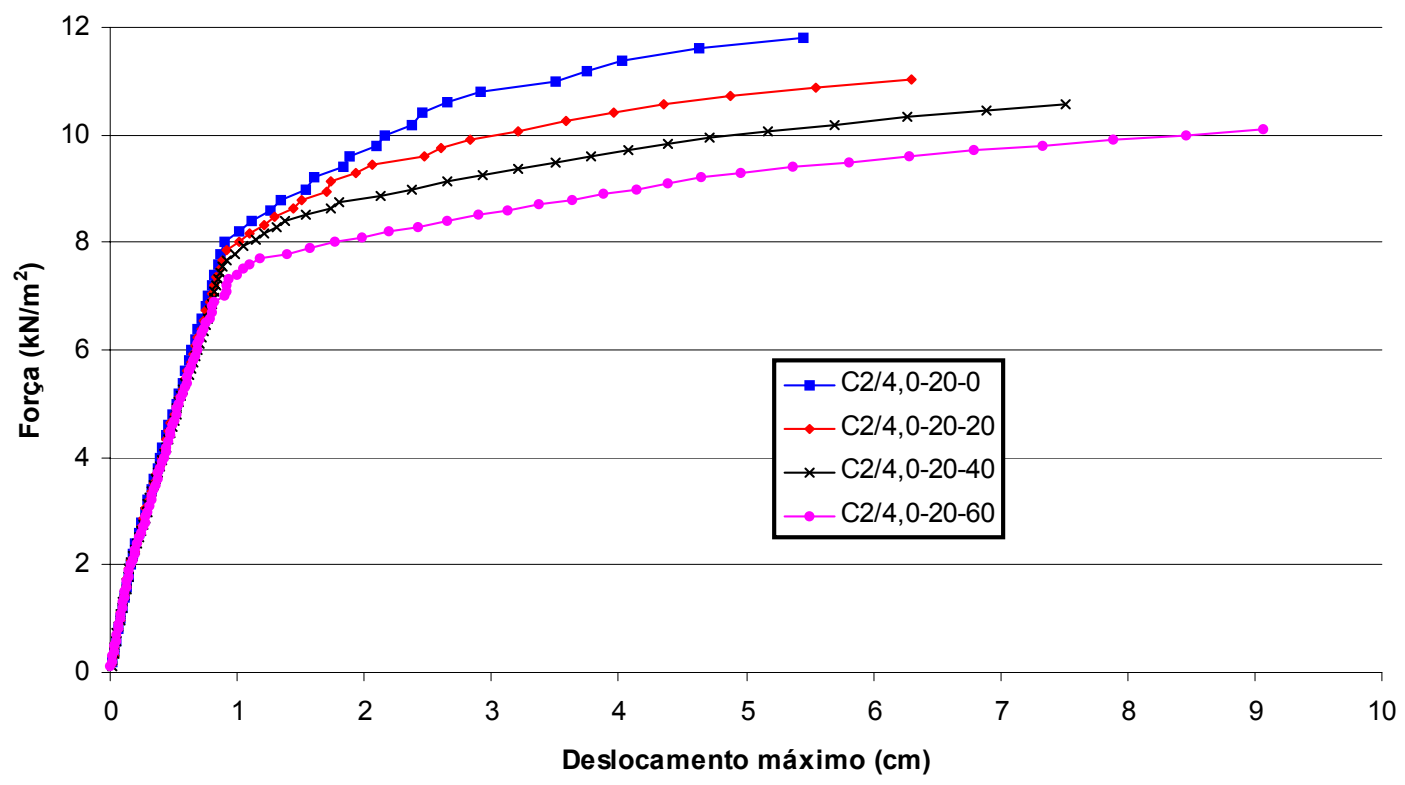

FIGURA 4.7 - Deslocamentos máximos - casos com vãos de 4,0 m

$\mathrm{Na}$ figura 4.8 são apresentados os diagramas de momento fletor para situação de carga última para os casos com vãos de $4,0 \mathrm{~m}$.

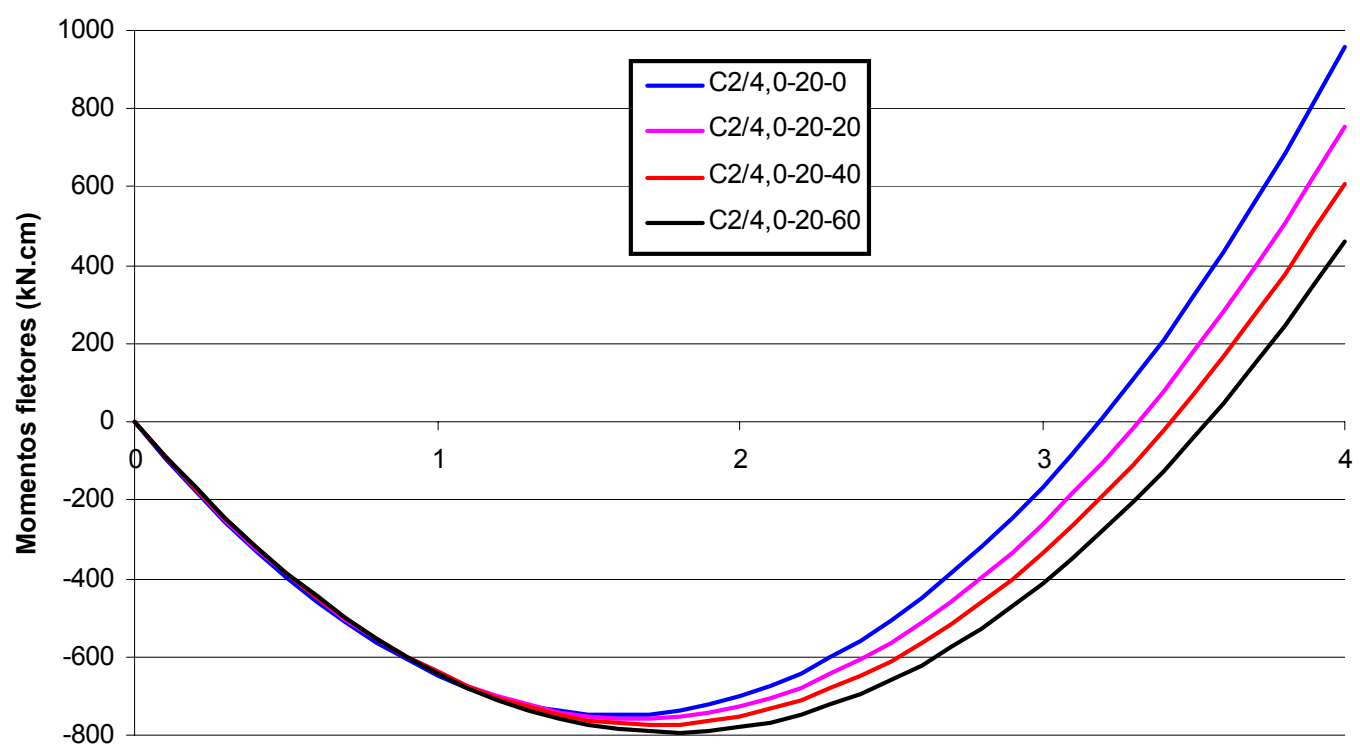

FIGURA 4.8 - Diagrama de momento fletor para carga última - casos com vãos de 4,0 m 
Pela figura 4.8 se pode verificar que o momento fletor negativo no apoio, para a carga última, apresentou um crescimento constante à medida que foi aumentada a taxa de armadura no apoio. Para o momento fletor máximo no vão, embora pequeno, também ocorreu uma variação constante com o aumento da taxa de armadura no apoio.

\subsubsection{Casos com vãos duplos de 6,0 m}

A tabela 4.9 mostra o comportamento dos casos com vãos de $6,0 \mathrm{~m}$. Pela tabela observa-se que o comportamento foi similar para todos os casos, apresentando os mesmos níveis de carga em todas as fases. Para todos esses casos, a fissuração começou na seção próxima ao apoio, seguida pelo escoamento desta seção. Logo a seguir ocorreu a físsuração no vão e em seguida a seção do apoio ou próxima a ele atingiu o momento último. O incremento de carga continuou a aumentar até que se alcançasse um dos critérios de parada, que foi para todos os casos o critério da capacidade de rotação da rótula plástica.

TABELA 4.9 - Comportamento estrutural para os casos com vãos de $6,0 \mathrm{~m}$

\begin{tabular}{|c|c|c|c|c|c|c|c|c|c|}
\hline \multirow{3}{*}{ casos } & \multicolumn{4}{|c|}{ fissuração } & \multicolumn{2}{|c|}{ escoamento } & \multicolumn{2}{|c|}{$\begin{array}{c}\text { momento } \\
\text { último }\end{array}$} & \multirow{3}{*}{$\begin{array}{l}\text { força } \\
\text { última }\end{array}$} \\
\hline & \multicolumn{2}{|c|}{ apoio } & \multicolumn{2}{|c|}{ vão } & \multirow{2}{*}{ força } & \multirow{2}{*}{$\begin{array}{c}\text { element } \\
\text { o }\end{array}$} & \multirow{2}{*}{ força } & \multirow{2}{*}{$\begin{array}{c}\text { element } \\
\text { o }\end{array}$} & \\
\hline & força & elemento & força & elemento & & & & & \\
\hline $\mathrm{C} 2 / 6,0-20-0$ & 1,40 & 59 & 8,40 & $24 / 25$ & 6,00 & 59 & 10,00 & 59 & 11,40 \\
\hline $\mathrm{C} 2 / 6,0-20-20$ & 1,44 & $59 / 60$ & 8,28 & $23-26$ & 5,58 & 59 & 9,90 & 59 & 11,34 \\
\hline $\mathrm{C} 2 / 6,0-20-40$ & 1,28 & 59 & 8,16 & $23-27$ & 5,60 & 59 & 9,76 & 60 & 11,04 \\
\hline $\mathrm{C} 2 / 6,0-20-60$ & 1,32 & 59 & 7,92 & $23-27$ & 5,52 & 59 & 8,52 & 60 & 9,96 \\
\hline $\mathrm{C} 2 / 6,0-15-20$ & 1,26 & 59 & 8,10 & $22-27$ & 5,40 & 59 & 9,54 & 59 & 11,16 \\
\hline \multicolumn{5}{|c|}{ elementos 59 e 60 : } & \multicolumn{5}{|c|}{ unidade das cargas $-\mathrm{kN} / \mathrm{m}^{2}$} \\
\hline
\end{tabular}

A evolução do momento fletor negativo para a seção crítica e para o máximo momento fletor positivo para os casos com vãos de $6,0 \mathrm{~m}$ podem ser vistos 
na figura 4.9. Também ocorreu para esses casos a tendência de três trechos retos no gráfico dos momentos fletores, sendo que o primeiro trecho foi até a fissuração no apoio, o segundo até a fissuração no vão da laje e o terceiro trecho vai até atingir o momento último no apoio.

Pela figura 4.9 pode-se verificar que os valores dos momentos fletores para esses casos foram próximos entre si, com diferença máxima ocorrida quando houve a fissuração no vão da laje. Para o valor de carga de $8,0 \mathrm{kN} / \mathrm{m}^{2}$, a diferença do momento fletor negativo foi de 7,0\% entre os casos C2/6,0-20-20 e C2/6,0-20-40 e para o momento fletor positivo máximo, a diferença foi de $6,6 \%$ entre os casos C2/6,0-20-0 e C2/6,0-20-60.

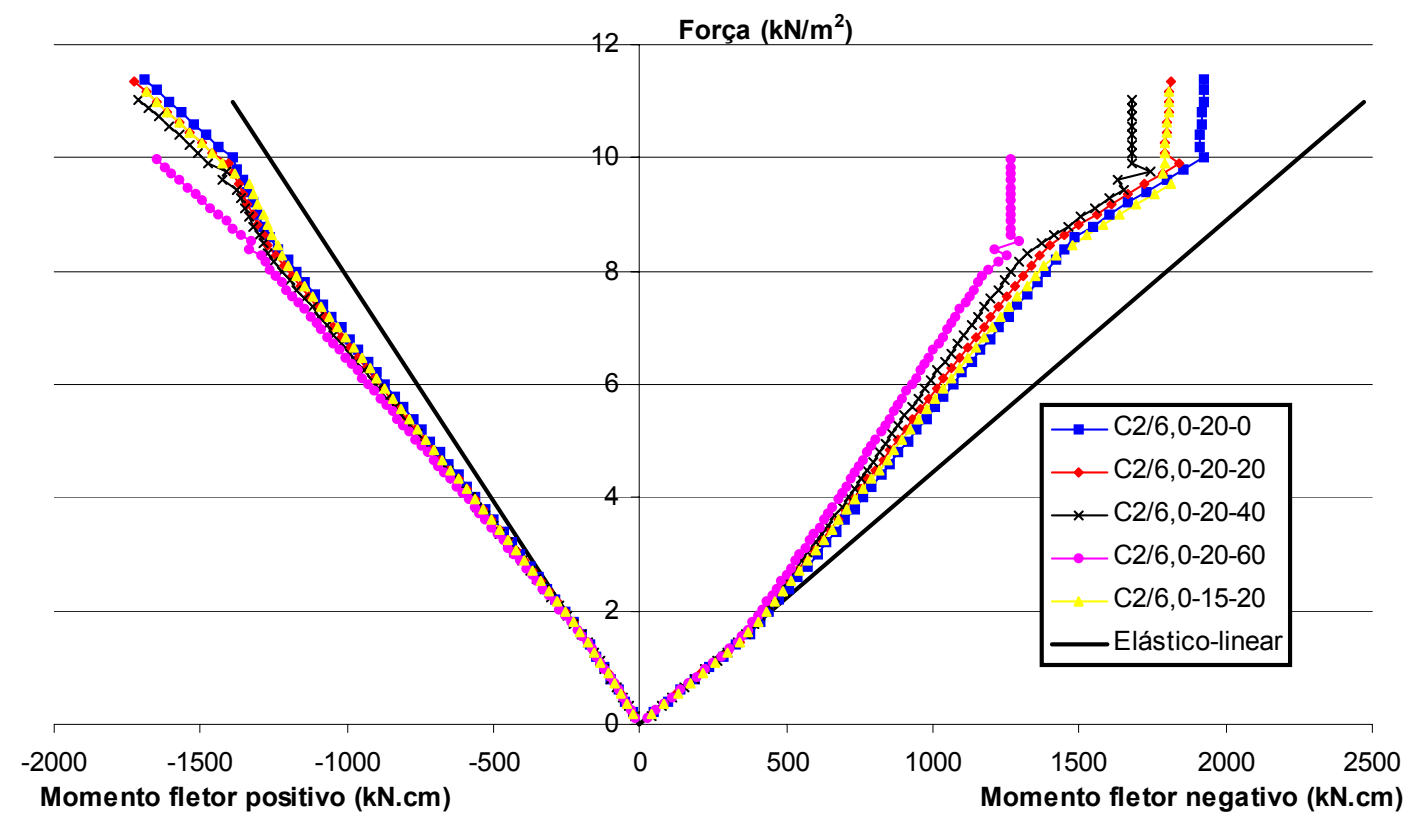

FIGURA 4.9 - Máximos momentos fletores - casos com vãos de 6,0 m

Os valores de redistribuição dos momentos fletores no apoio para a força última foram de $24,8 \%, 29,0 \%, 32,4 \%, 43,4 \%$ e $28,0 \%$ para os casos, respectivamente, $\mathrm{C} 2 / 6,0-20-0, \quad \mathrm{C} 2 / 6,0-20-20, \quad \mathrm{C} 2 / 6,0-20-40, \quad \mathrm{C} 2 / 6,0-20-60 \quad$ e C2/6,0-15-20.

Pela figura 4.10 pode-se notar que, até ocorrer a fissuração no vão, houve uma boa concordância entre os deslocamentos obtidos no vão para os casos com vãos de $6,0 \mathrm{~m}$, sendo que para a carga de serviço $\left(4,41 \mathrm{kN} / \mathrm{m}^{2}\right)$ a diferença entre os deslocamentos máximos no vão foi de $9,1 \%$ para os casos com diferentes graus de 
redistribuição (casos C2/6,0-20-0 e C2/6,0-20-60) e 9,2\% para os casos com mesmo valor adotado para o grau de redistribuição, mas resistências da capa de concreto diferentes (casos C2/6,0-15-20 e C2/6,0-20-20).

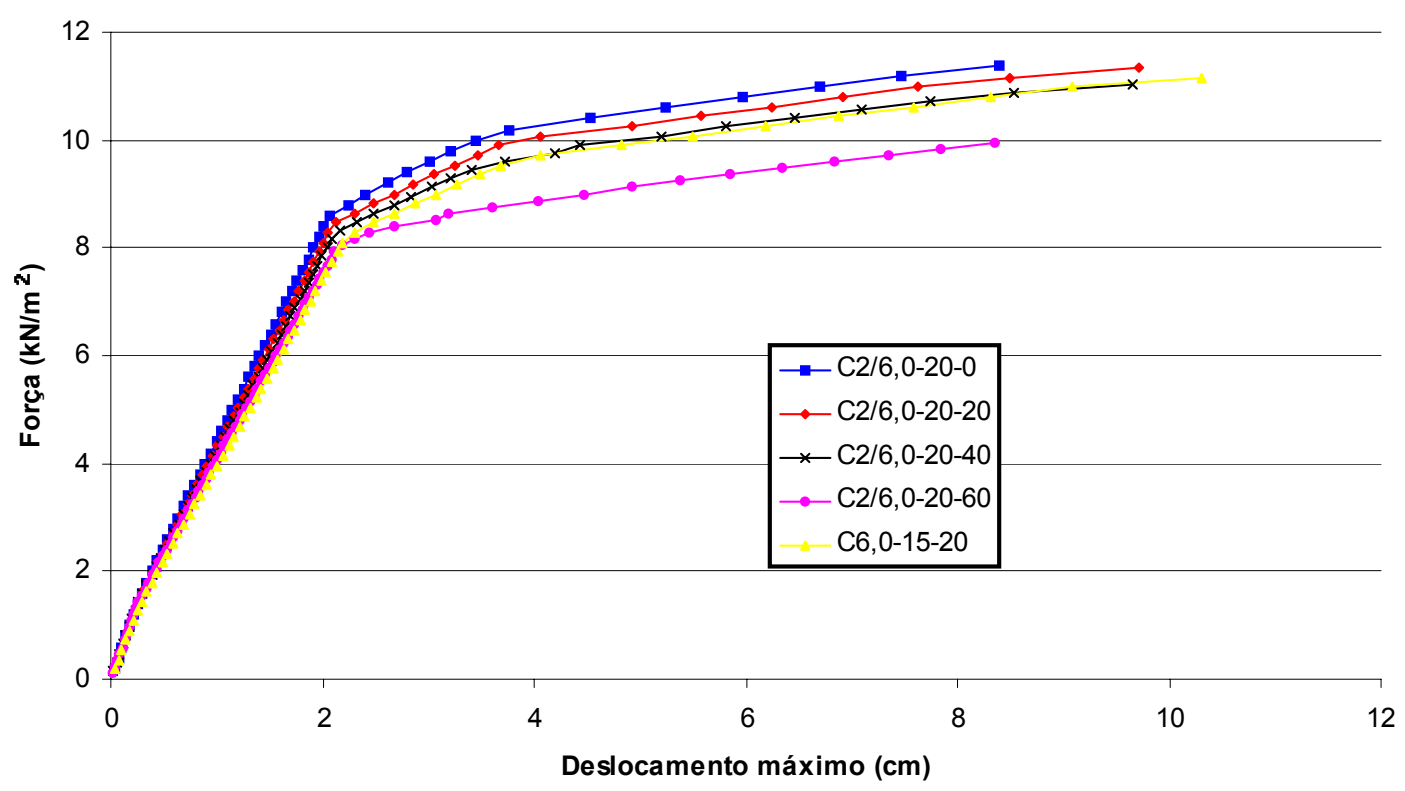

FIGURA 4.10 - Deslocamentos máximos - casos com vãos de 6,0 m

Os diagramas de momento fletor para situação de carga última para os casos com vãos de 6,0 m são apresentados na figura 4.11. Por esta figura se pode notar o crescimento do momento fletor negativo no apoio não foi uniforme com o aumento da taxa de armadura no apoio, pois houve a mudança da seção crítica do elemento 59 (seção adjacente ao apoio) para o elemento 60 (seção apoio). Isso também refletiu no crescimento do momento fletor positivo máximo no vão que também não foi constante. 


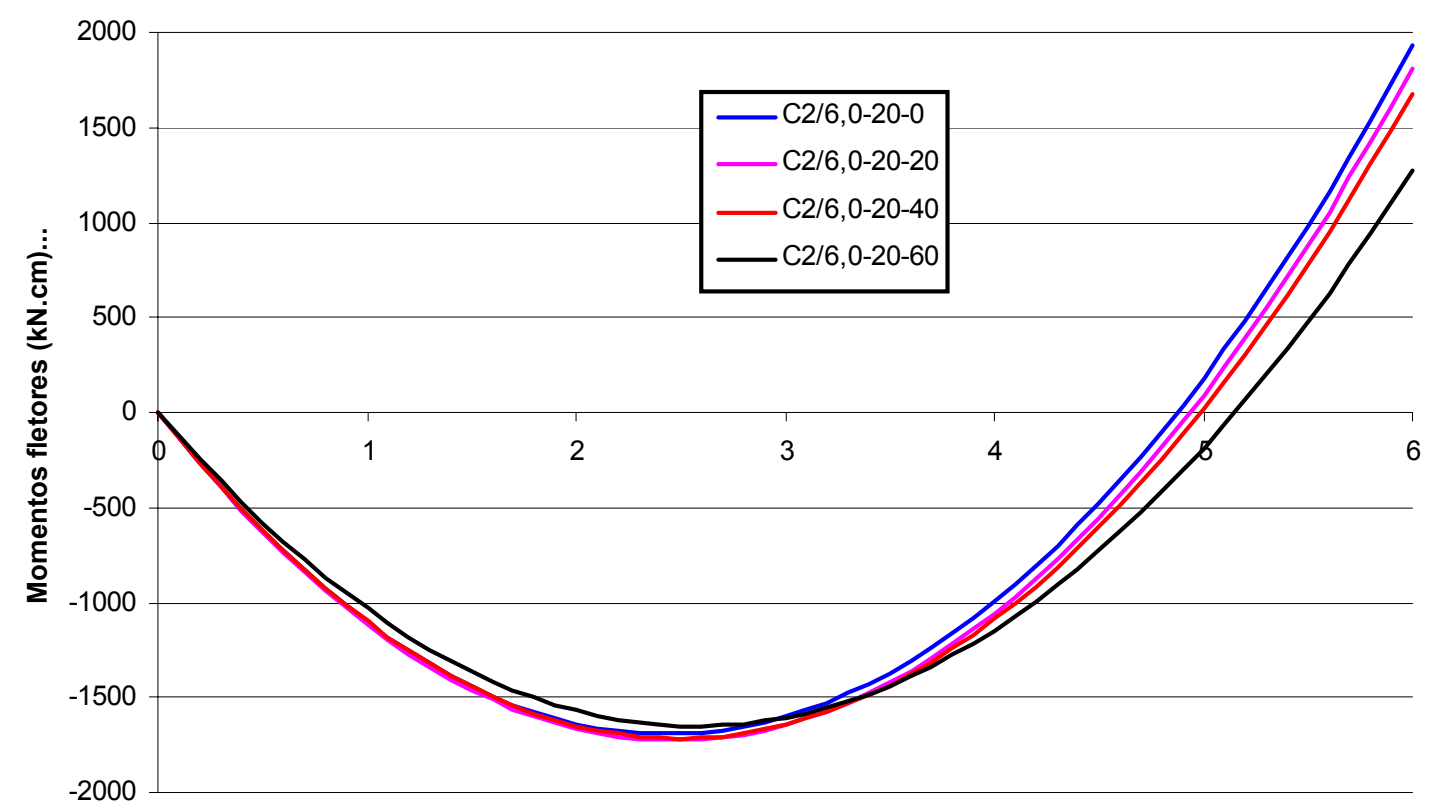

FIGURA 4.11 - Diagrama de momento fletor para carga última - casos com vãos de 6,0 m

\subsubsection{Casos com vãos duplos de 8,0 m}

O comportamento dos casos com vãos de $8,0 \mathrm{~m}$ foram resumidos na tabela 4.10. Por essa tabela pode-se notar que a mudança da armadura do apoio de um valor para atender um grau de redistribuição $0 \%$ para outro de $20 \%$ não fez diferença no comportamento da laje. A única diferença foi que a região do vão fissurada deslocou $20 \mathrm{~cm}$ na direção do apoio central para o caso C2/8,0-20-0 em relação ao caso C2/8,0-20-20 devido à maior quantidade de armadura no apoio daquele.

Um fato interessante foi que o valor da carga última para os dois casos não foi alterado com o aumento da armadura no apoio. Isso porque, para seção crítica (elemento 79), a diferença da área de armadura entre os casos foi $23,2 \%$, no entanto, a diferença do valor de momento último resistido pela seção foi apenas de 3,5\%. O valor do momento último foi um fator importante já que o processamento foi interrompido logo após atingir o momento último na seção crítica por superar a capacidade de rotação plástica da seção. 
TABELA 4.10 - Comportamento estrutural para os casos com vãos de 8,0 m

\begin{tabular}{|c|c|c|c|c|c|c|c|c|c|}
\hline \multirow{3}{*}{ Casos } & \multicolumn{4}{|c|}{ fissuração } & \multicolumn{2}{|c|}{ escoamento } & \multicolumn{2}{|c|}{$\begin{array}{c}\text { momento } \\
\text { último }\end{array}$} & \multirow{3}{*}{$\begin{array}{r}\text { força } \\
\text { última }\end{array}$} \\
\hline & \multicolumn{2}{|c|}{ apoio } & \multicolumn{2}{|c|}{ vão } & \multirow{2}{*}{ força } & \multirow{2}{*}{$\begin{array}{c}\text { element } \\
\text { o }\end{array}$} & \multirow{2}{*}{ força } & \multirow{2}{*}{$\begin{array}{c}\text { element } \\
\text { o }\end{array}$} & \\
\hline & força & elemento & força & elemento & & & & & \\
\hline $\mathrm{C} 2 / 8,0-20-0$ & 1,20 & $76-79$ & 6,60 & $26-38$ & 5,10 & 79 & 8,10 & 79 & 9,30 \\
\hline $\mathrm{C} 2 / 8,0-20-20$ & 1,20 & $76-79$ & 6,30 & $28-36$ & 5,10 & 79 & 8,10 & 79 & 9,30 \\
\hline \multicolumn{5}{|c|}{ elementos 79 e $80:$} & \multicolumn{5}{|c|}{ unidade das cargas $-\mathrm{kN} / \mathrm{m}^{2}$} \\
\hline
\end{tabular}

A evolução do momento fletor negativo para a seção crítica e para o máximo momento fletor positivo para os casos com vãos de $8,0 \mathrm{~m}$ podem ser vistos na figura 4.12. Nesta figura fica claro a existência de três trechos com os valores transição entre os trechos sendo a fissuração próxima ao apoio e a fissuração no vão. A diferença máxima dos valores do momento fletor entre os dois casos foi de $2,5 \%$ (carga de $5,4 \mathrm{kN} / \mathrm{m}^{2}$ ) para o momento fletor positivo máximo e de 5,2\% (carga de 6,3 $\mathrm{kN} / \mathrm{m}^{2}$ ) para o momento fletor negativo no apoio.

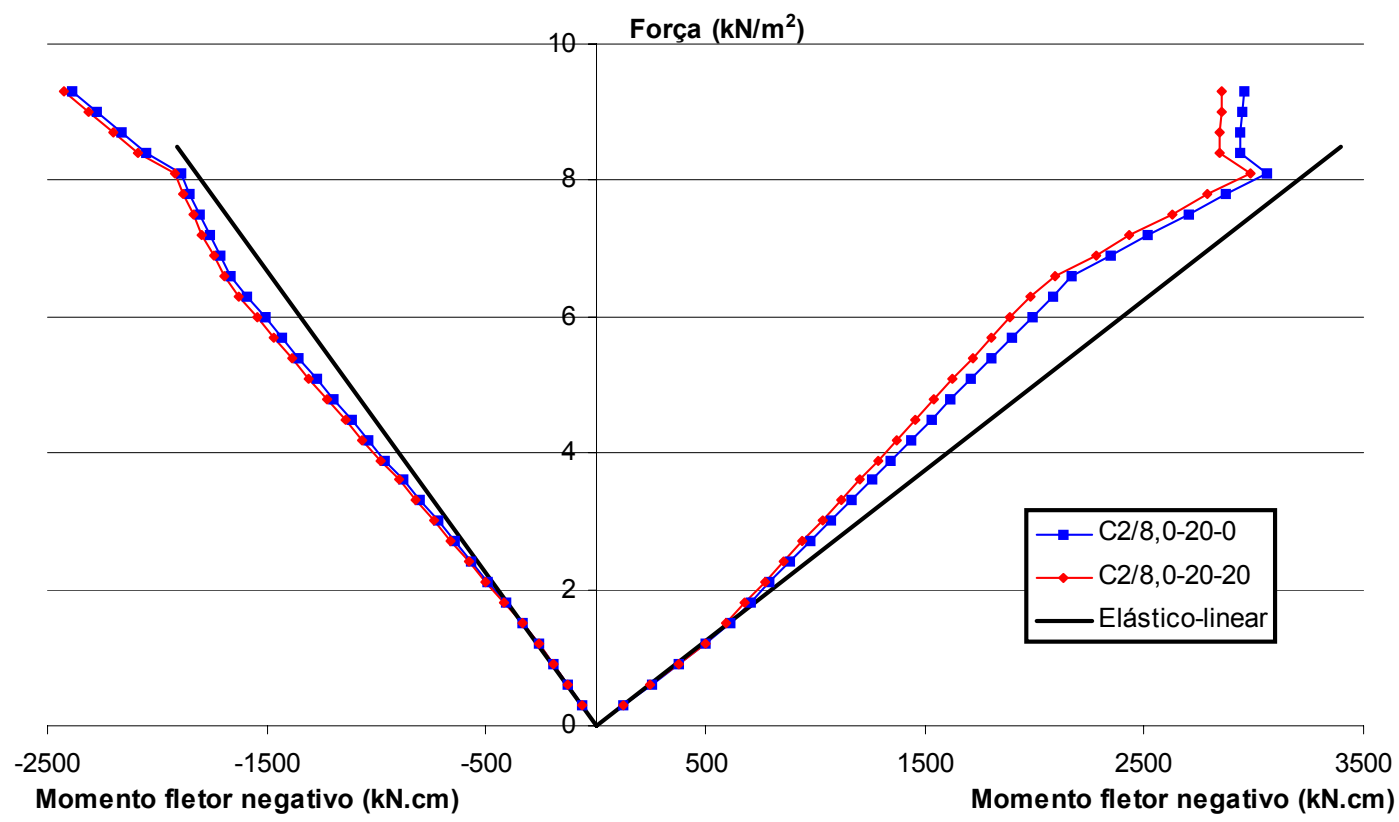

FIGURA 4.12 - Máximos momentos fletores - casos com vãos de 8,0 m 
Os valores de redistribuição dos momentos fletores no apoio para a força última foram de 20,6\% e 23,2\% para os casos, respectivamente, C2/8,0-20-0 e C2/8,0-20-20.

$\mathrm{Na}$ figura 4.13 podem ser vistos os deslocamentos máximos para os casos com vãos de $8,0 \mathrm{~m}$. Por essa figura nota-se que, para ambos os casos, o gráfico apresenta a mesma tendência, mesmo que após acorrer a fissuração no vão os valores distanciem entre si. Para a carga de serviço $\left(5,05 \mathrm{kN} / \mathrm{m}^{2}\right)$, a diferença entre os deslocamentos máximos no vão foi de $4,1 \%$.

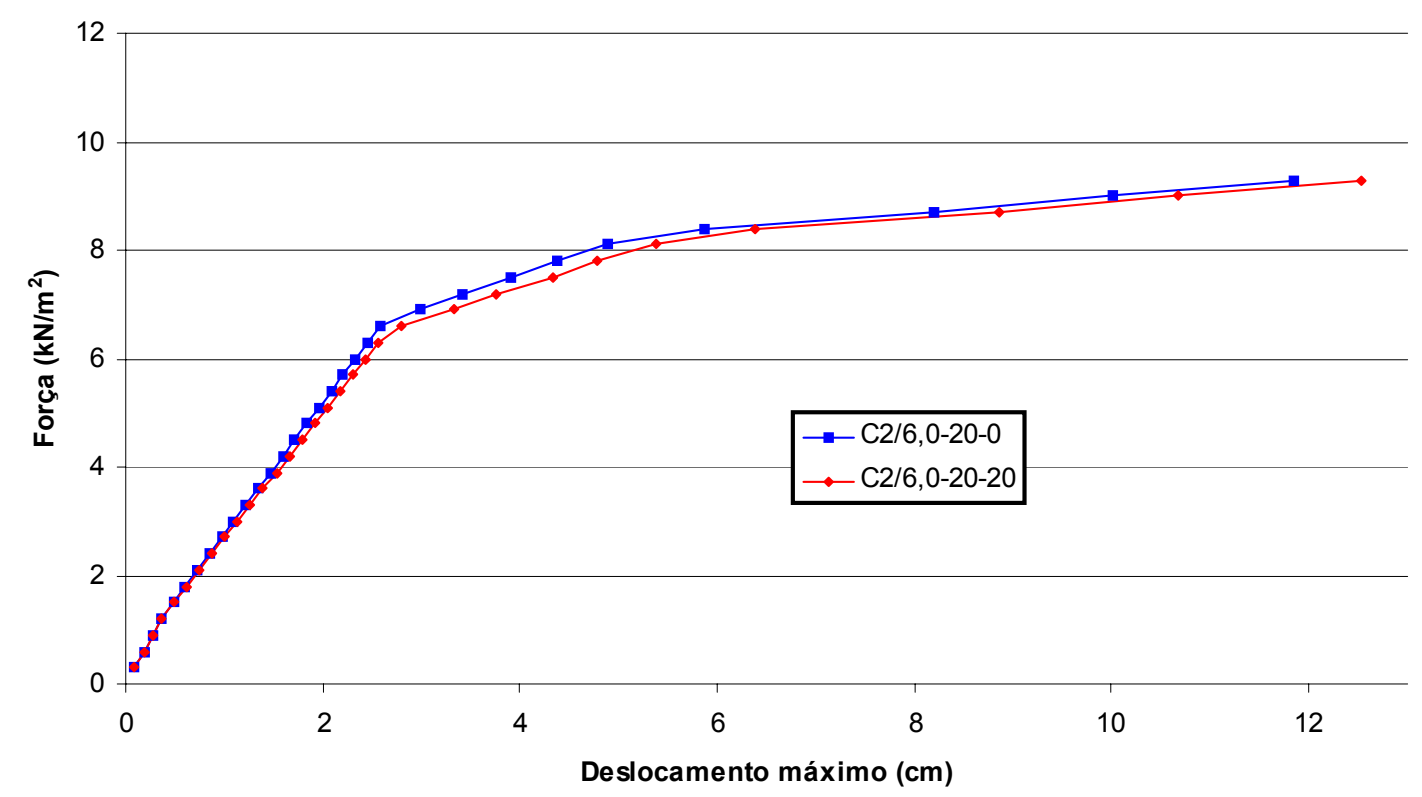

FIGURA 4.13 - Deslocamentos máximos - casos com vãos de 8,0 m

$\mathrm{Na}$ figura 4.14 são apresentados os diagramas de momento fletor para situação de carga última para os casos com vãos de $8,0 \mathrm{~m}$. Pode-se verificar que, a mudança da taxa de armadura no apoio foi muito pequena para afetar consideravelmente o comportamento entre os casos. 


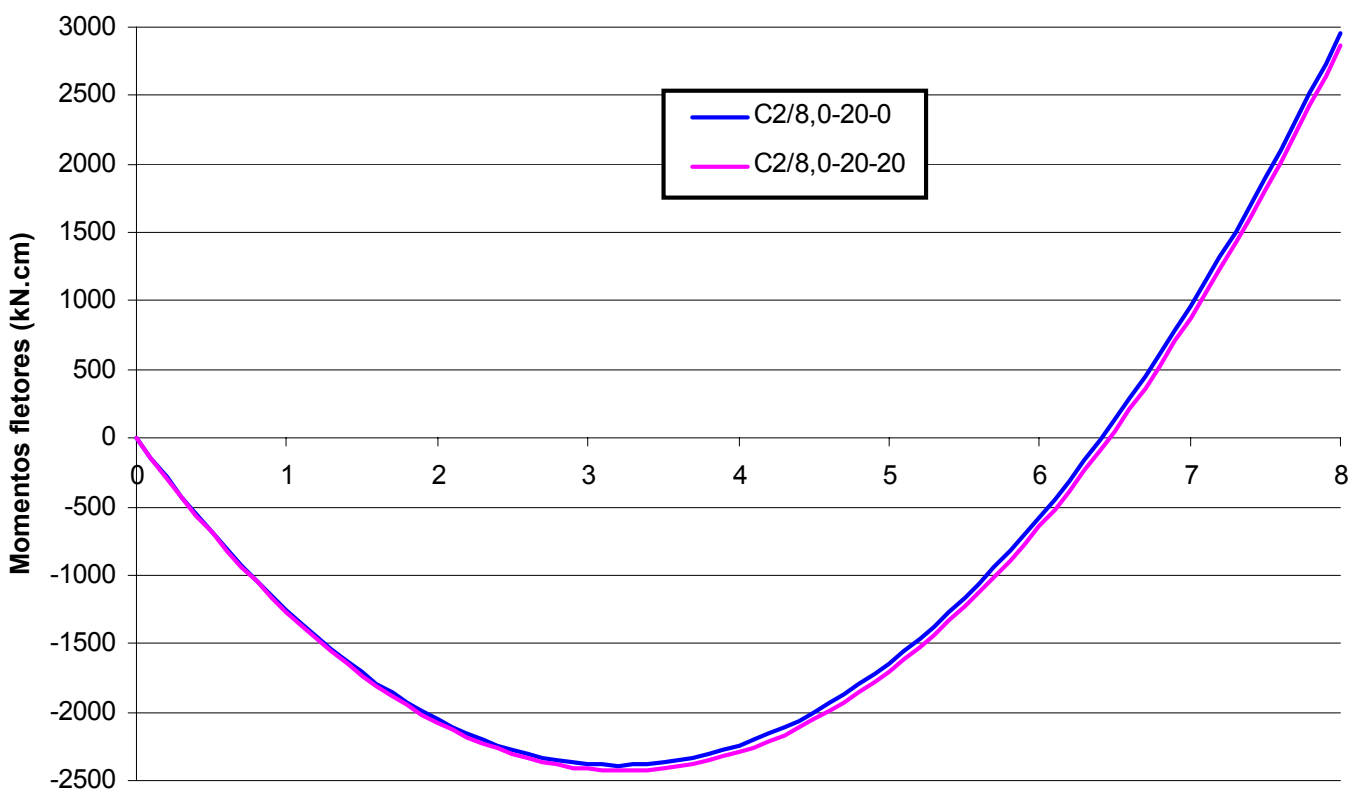

FIGURA 4.14 - Diagrama de momento fletor para carga última - casos com vãos de 8,0 m

\subsubsection{Casos com vãos triplos}

A tabela 4.11 mostra um resumo do comportamento dos casos com vãos triplos. Na tabela pode ser visto que a fissuração no vão para o caso C3/6,0-20-20 apenas ocorreu no tramo externo, enquanto que para o caso $\mathrm{C} 2 / 6,0 / 8,0-20-20$ a fissuração ocorreu no tramo interno devido à magnitude desse tramo $(8,0 \mathrm{~m})$.

TABELA 4.11 - Comportamento estrutural para os casos com vãos triplos

\begin{tabular}{|c|c|c|c|c|c|c|c|c|c|}
\hline \multirow{3}{*}{ casos } & \multicolumn{4}{|c|}{ fissuração } & \multicolumn{2}{|c|}{ escoamento } & \multicolumn{2}{|c|}{$\begin{array}{c}\text { momento } \\
\text { último }\end{array}$} & \multirow{3}{*}{$\begin{array}{r}\text { força } \\
\text { última }\end{array}$} \\
\hline & \multicolumn{2}{|c|}{ apoio } & \multicolumn{2}{|c|}{ vão } & \multirow{2}{*}{ força } & \multirow{2}{*}{$\begin{array}{c}\text { element } \\
\text { o }\end{array}$} & \multirow{2}{*}{ força } & \multirow{2}{*}{$\begin{array}{c}\text { element } \\
0\end{array}$} & \\
\hline & força & elemento & força & elemento & & & & & \\
\hline $\mathrm{C} 3 / 6,0-20-20$ & 1,62 & 59 & 7,74 & $24-27$ & 6,48 & 59 & 10,62 & 60 & 12,06 \\
\hline $\mathrm{C} 2 / 6,0 / 8,0-20-20$ & 1,60 & 62 & 7,80 & $97-100$ & 7,00 & 59 & 11,40 & 59 & 13,20 \\
\hline \multicolumn{5}{|c|}{ elementos 59, 60, 61 e 62: $\quad .59 \cdot 60{ }^{61} .62$} & \multicolumn{5}{|c|}{ unidade das cargas $-\mathrm{kN} / \mathrm{m}^{2}$} \\
\hline
\end{tabular}

Nas figuras 4.15 e 4.16 está apresentada a evolução do momento fletor negativo para a seção crítica e para o máximo momento fletor positivo para os casos com vãos triplos, respectivamente. Por essas figuras ainda se nota que os gráficos 
apresentam os três trechos retos similares aos demais casos, sendo que o terceiro trecho foi estabelecido devido à fissuração do vão crítico (vão externo para o caso C3/6,0-20-20 e vão interno para o caso C2/6,0/8,0-20-20).

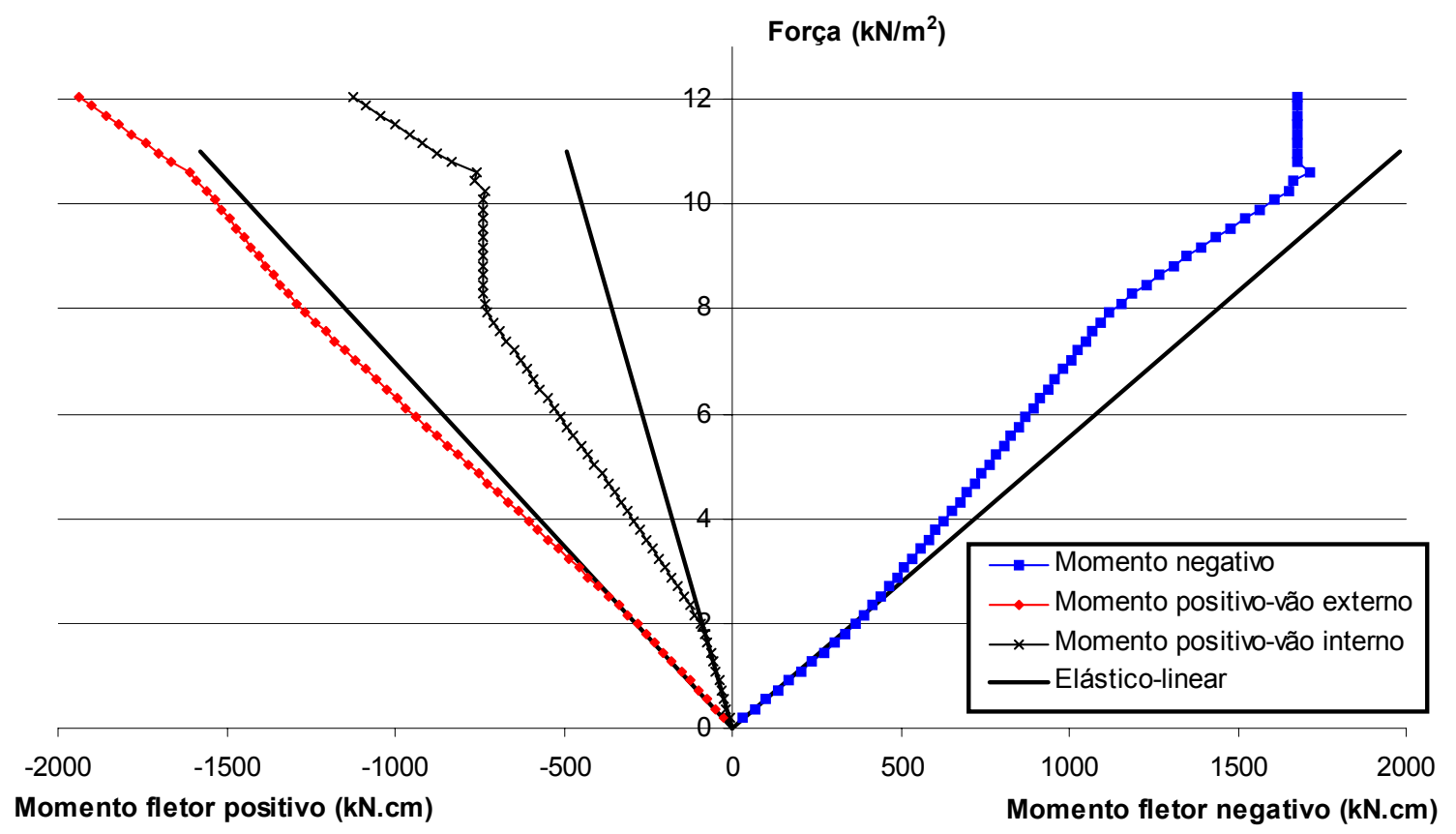

FIGURA 4.15 - Máximos momentos fletores - caso C3/6,0-20-20

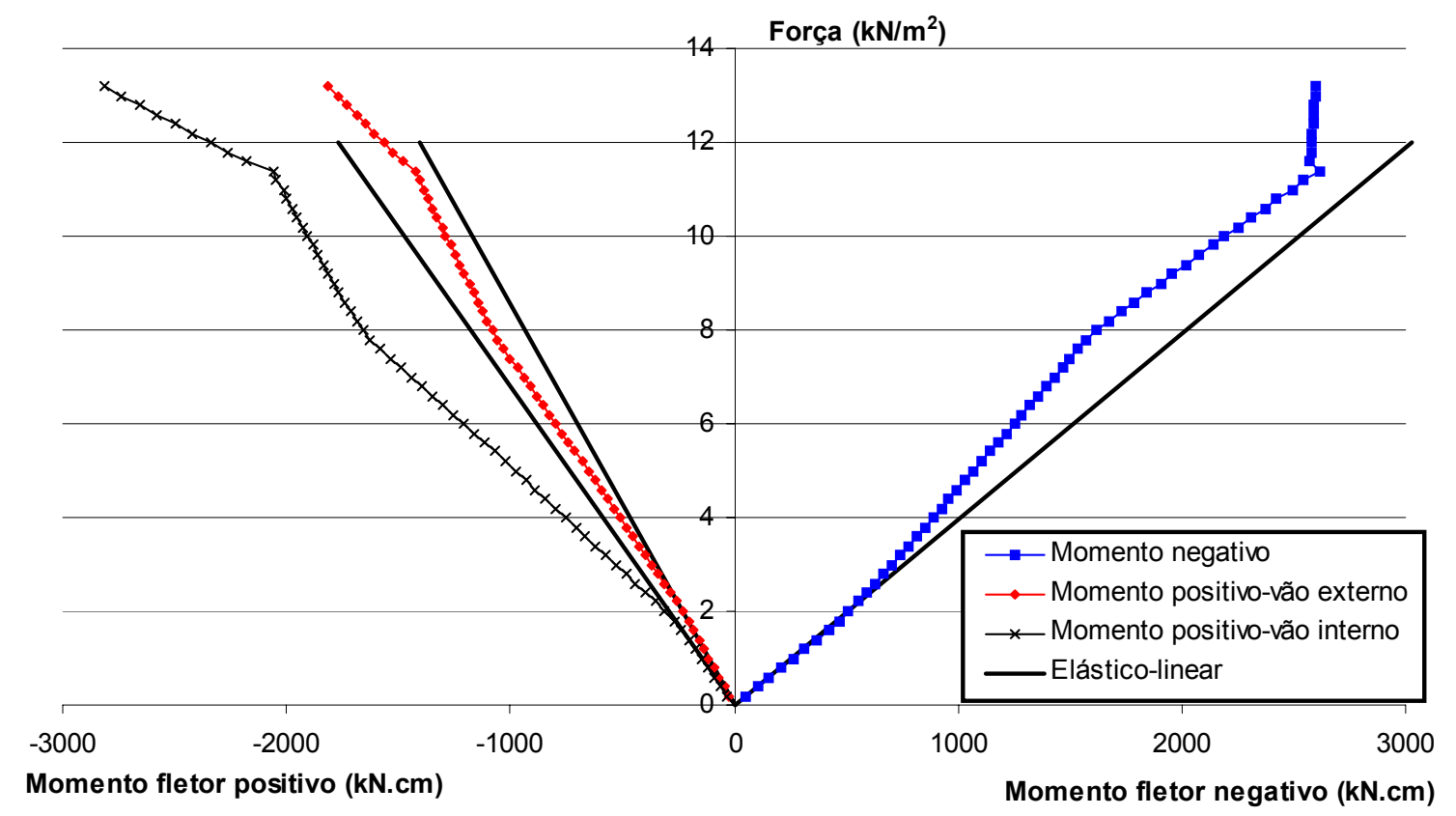

FIGURA 4.16 - Máximos momentos fletores - caso C2/6,0/8,0-20-20 
$\mathrm{Na}$ figura 4.17 podem ser vistos os deslocamentos máximos para os casos com vãos triplos. Pela figura fica claro que o vão externo foi o vão crítico para o caso C3/6,0-20-20 e para o caso C2/6,0/8,0-20-20, o vão crítico foi o interno.

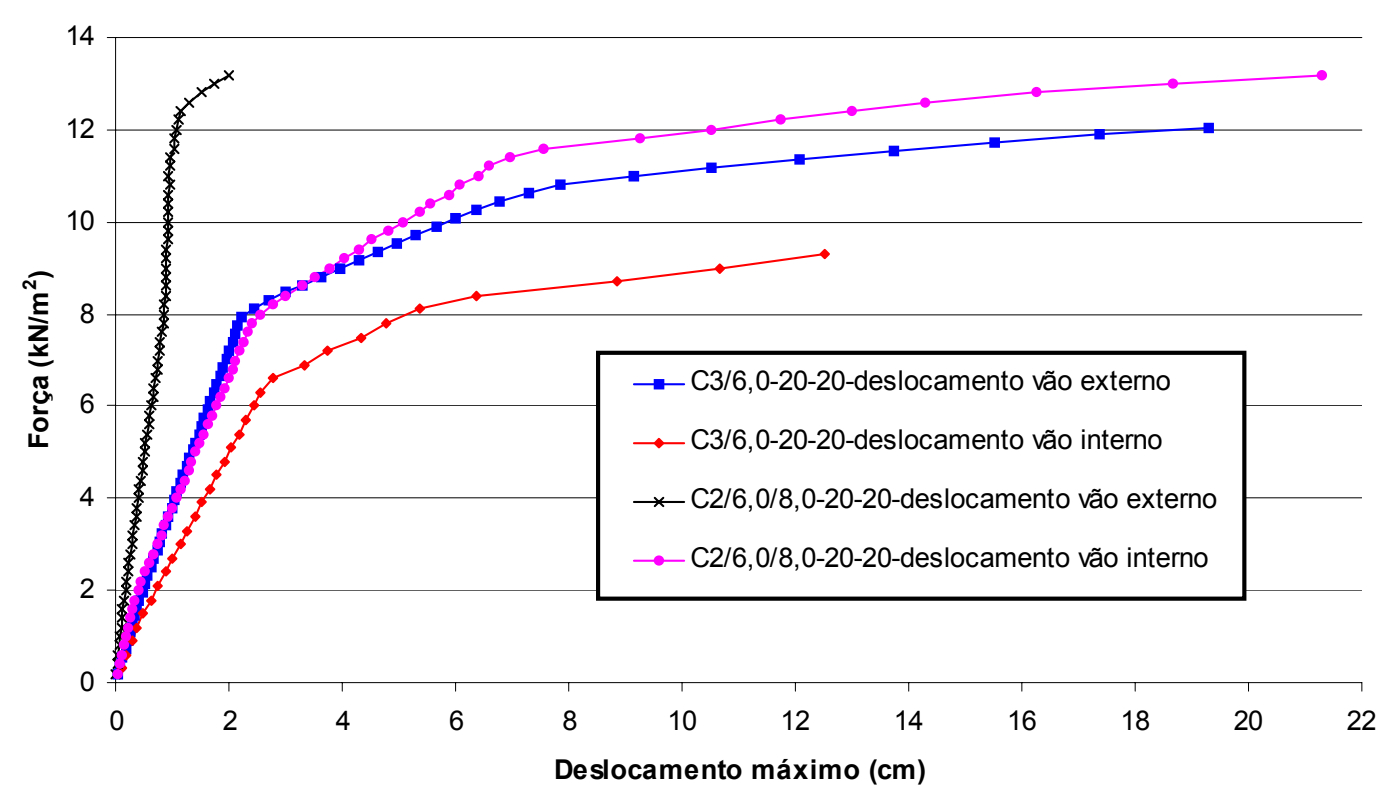

FIGURA 4.17 - Deslocamentos máximos - casos com vãos triplos

A evolução dos momentos fletores ao longo do eixo longitudinal para os casos com vãos triplos está mostrada na figura 4.18. Observa-se nesta figura que o momento negativo no apoio estabilizou no valor de momento último, enquanto que os momentos fletores positivos tiveram um crescimento uniforme no vão externo, já o vão interno teve, na fase intermediária, um trecho em que o valor do momento fletor positivo máximo praticamente não aumentou. 

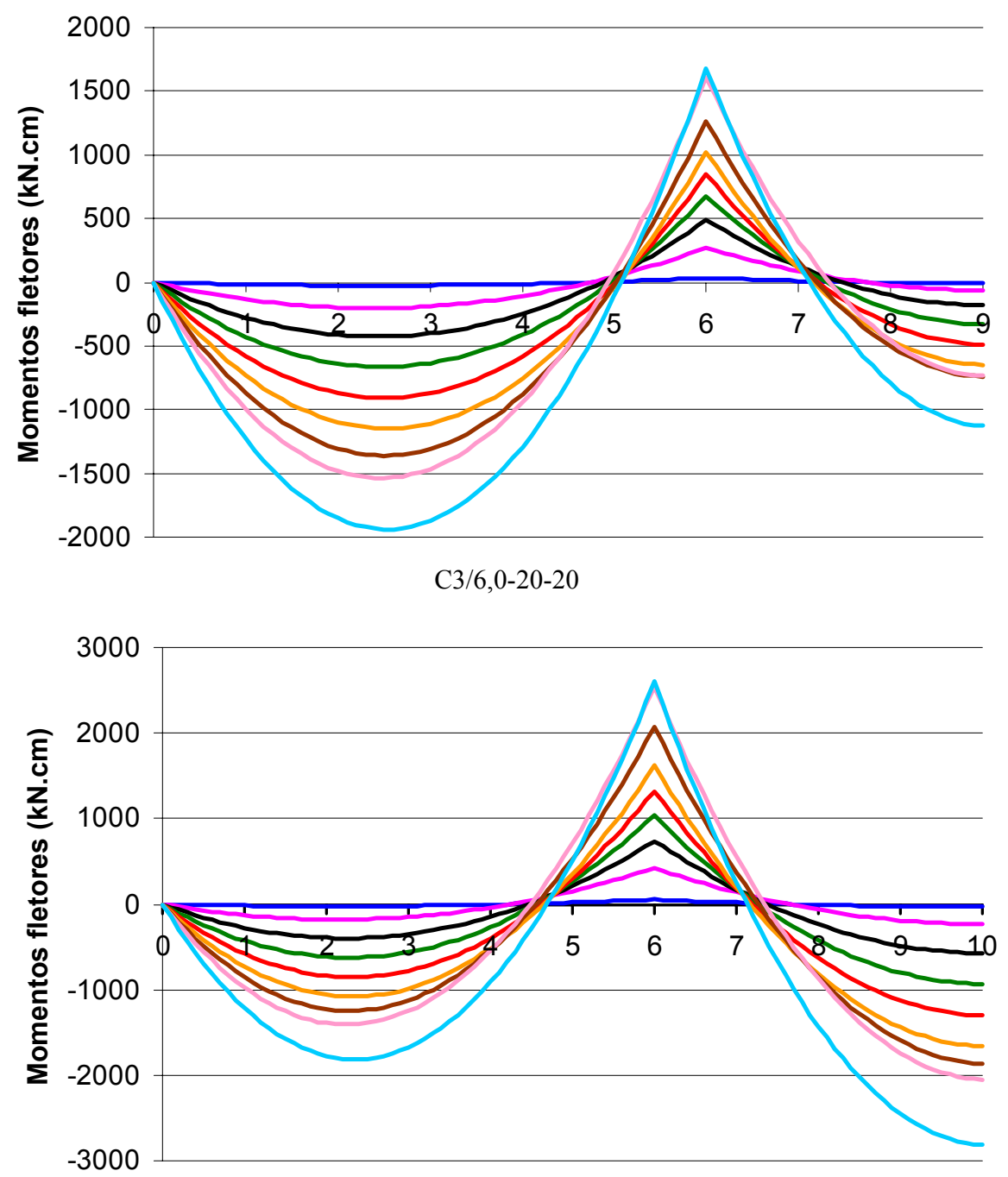

$\mathrm{C} 2 / 6,0 / 8,0-20-20$

FIGURA 4.18 - Evolução dos momentos fletores - casos com vãos triplos 


\subsection{Análise dos resultados e comentários}

O vão máximo suportável para os casos analisados, com as seções transversais adotadas, como lajes com bordas simplesmente apoiadas (biapoiadas), pode ser visto na tabela 4.12 .

TABELA 4.12 - Comparação entre vãos com continuidade e vãos biapoiados

\begin{tabular}{|c|c|c|c|}
\hline $\begin{array}{c}\text { altura da laje } \\
(\mathbf{c m})\end{array}$ & $\begin{array}{c}\text { vão contínuo utilizado } \\
(\mathbf{m})\end{array}$ & $\begin{array}{c}\text { vão biapoiado } \\
(\mathbf{m})\end{array}$ & $\begin{array}{c}\frac{\text { vão }_{\text {biap }}}{\mathbf{v a n o}_{\mathbf{c o n t}}} \\
(\mathbf{\%})\end{array}$ \\
\hline 12 & 4,0 & 3,82 & 95,5 \\
\hline 16 & 6,0 & 5,50 & 92,6 \\
\hline 20 & 8,0 & 6,43 & 80,4 \\
\hline
\end{tabular}

Pela tabela 4.12, pode-se perceber a responsabilidade da armadura de continuidade com relação à segurança global da estrutura. Nos casos com vãos de 4,0 m, essa responsabilidade é menor quando comparada com os casos com vãos de $8,0 \mathrm{~m}$, visto que para esses casos, o vão que a laje consegue vencer está muito aquém do valor utilizado (contínuo). Tanto que, o grau máximo de redistribuição que se pôde utilizar no dimensionamento desse vão $(8,0 \mathrm{~m})$, sem ultrapassar a capacidade da laje em relação ao momento fletor positivo, foi de $20 \%$ (caso $C 2 / 8,0-20-20$ ).

Optou-se por adotar uma mesma seção transversal de laje, utilizando vários graus de redistribuição dos momentos fletores negativos, sem mudança da armadura da vigota, já que a mudança na configuração das armaduras por mínima que fosse conduzia a uma sensível alteração na resistência da seção, devido à alta resistência dos fios para a armadura protendida. Além disso, a produção desse tipo de vigota não é feita para atender um vão específico, mas um intervalo, pois, se para cada vão fosse alterada a configuração de armadura, seria inviável a produção desse tipo de vigota (pré-fabricação). 
Independentemente do grau de redistribuição adotado para os momentos fletores negativos no dimensionamento, os valores dos deslocamentos máximos, para as situações de serviço, ficaram próximos para um mesmo vão, como pode ser visto na figura 4.19. A diferença encontrada entre os deslocamentos máximos foi de $6,5 \%$, $9,1 \%$ e 4,1\% para os casos com vão duplos respectivamente de 4,0, 6,0 e 8,0 m.

$\mathrm{Na}$ realidade, como foi verificado nas figuras 4.7,4.10,4.13, os deslocamentos máximos tiveram, para um mesmo vão, mas com diferentes graus de redistribuição, uma boa aproximação entre si no decorrer de todo o carregamento, começando a diferenciar quando ocorre a fissuração do vão.

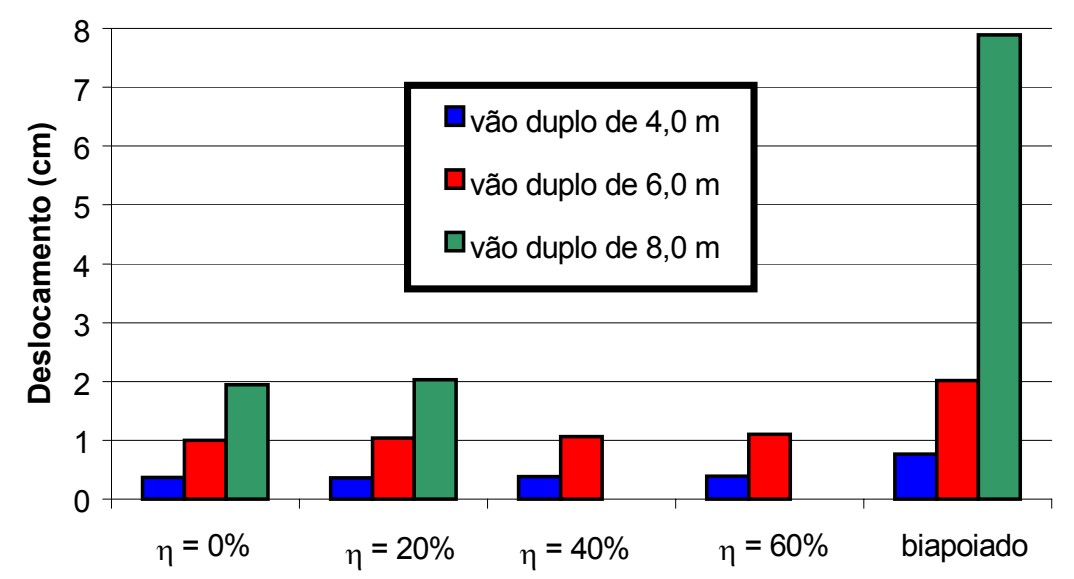

Figura 4.19 - Comparação entre os deslocamentos máximos para carga de serviço

Como já foi comentado, os casos em questão não teriam capacidade resistente para serem construídos com vão biapoiado, no entanto, foi realizado o processamento desses casos nessa situação para averiguar os benefícios da continuidade. Pela figura 4.19, pode-se notar a vantagem em se empregar a continuidade, sendo que não aproveitando a continuidade, os deslocamentos máximos na situação de serviço aumentaram 95,1\%, 83,5\% e 289,2\%, respectivamente, para os casos com vão duplos de 4,0, 6,0 e 8,0 m. 
Independentemente do grau de redistribuição adotado no dimensionamento, pôde-se verificar no item anterior que para todos os casos analisados os gráficos do momento fletor negativo para a seção crítica (seção que atingiu $\mathrm{M}_{\mathrm{U}}$ ) e do máximo momento fletor positivo apresentaram três trechos principais retos, conforme esquematizado na figura 4.20:

- trecho 1: zero até a fissuração da seção crítica próxima do apoio;

- trecho 2: fissuração da seção crítica até a fissuração no vão da laje;

- trecho 3: fissuração no vão da laje até atingir momento último da seção crítica.

Por essa figura pode-se notar que quando ocorre a fissuração da seção próxima ao apoio, aumenta a responsabilidade do vão em absorver os esforços. No entanto, quando o vão fissura, essa responsabilidade novamente é transferida para a região do apoio, até atingir o momento último.

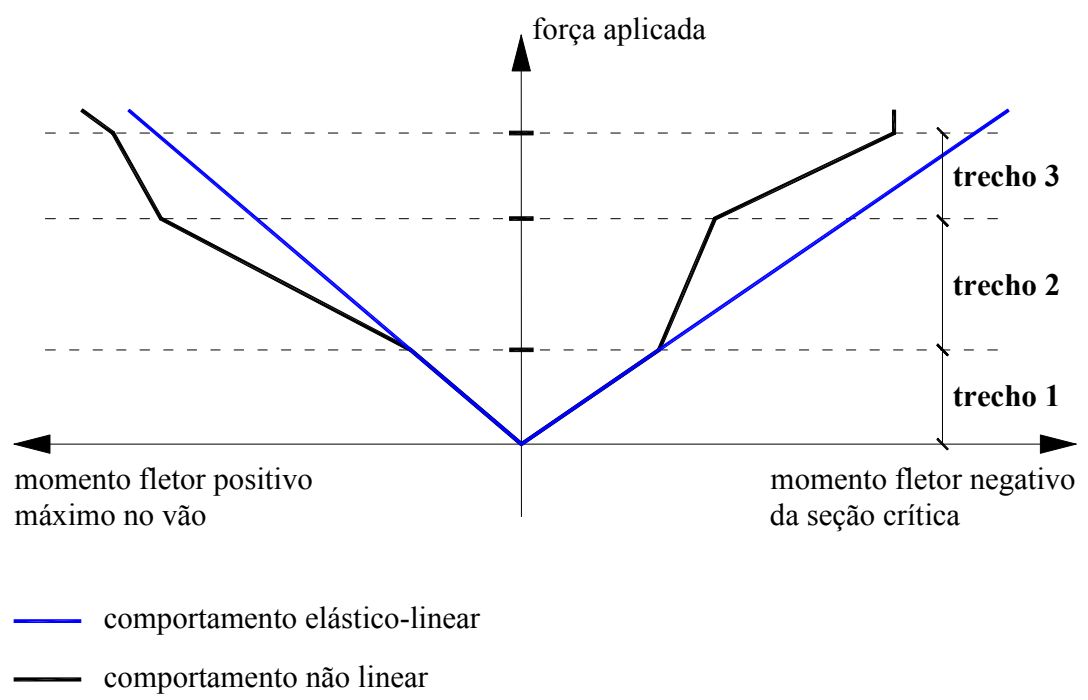

Figura 4.20 - Gráfico esquemático da evolução do máximo momento fletor para lajes formadas por vigotas protendidas

Também foi verificado no item anterior que para um mesmo vão, mas com diferentes graus de redistribuição adotados para os momentos fletores negativos no dimensionamento, os valores do momento fletor positivo máximo e momento 
fletor negativo na seção crítica apresentaram uma boa concordância entre si para um mesmo nível de carga.

O comportamento das lajes formado por vigotas pré-moldadas difere do comportamento das lajes formadas por vigotas com armação treliçada como se pode verificar pelos ensaios realizados por MAGALHÃES (2001). Esses ensaios compreenderam três modelos com vãos duplos de 4,0 m (figura 4.21) em que foi alterada a taxa de armadura no apoio de cada um deles. A taxa de armadura empregada foi igual àquelas correspondentes a um grau de redistribuição dos momentos fletores negativos de $15 \%, 40 \%$ e um modelo com apenas armadura construtiva sobre o apoio.

Os resultados obtidos nos ensaios estão apresentados nas figuras 4.22, 4.23 e 4.24. Pelas figuras pode-se verificar que não existiu um comportamento padrão entre os modelos, como foi observado nos casos analisados com vigotas protendidas. Isso foi devido ao fato que tanto o apoio quanto o vão apresentam fissuração para níveis de carga muito próximos.

Uma tentativa de entender o comportamento desse tipo de laje está mostrada na figura 4.25, sendo que para baixos valores de graus de redistribuição de momento fletor negativo adotado no dimensionamento, o momento negativo fica sempre superior ao obtido pela análise considerando material elástico-linear e o momento positivo máximo fica sempre próximo do valor elástico-linear. À medida que vai aumentando o grau de redistribuição o momento negativo começa a apresentar redistribuição e o momento positivo máximo começa a afastar do elásticolinear, ficando sempre superior a este.

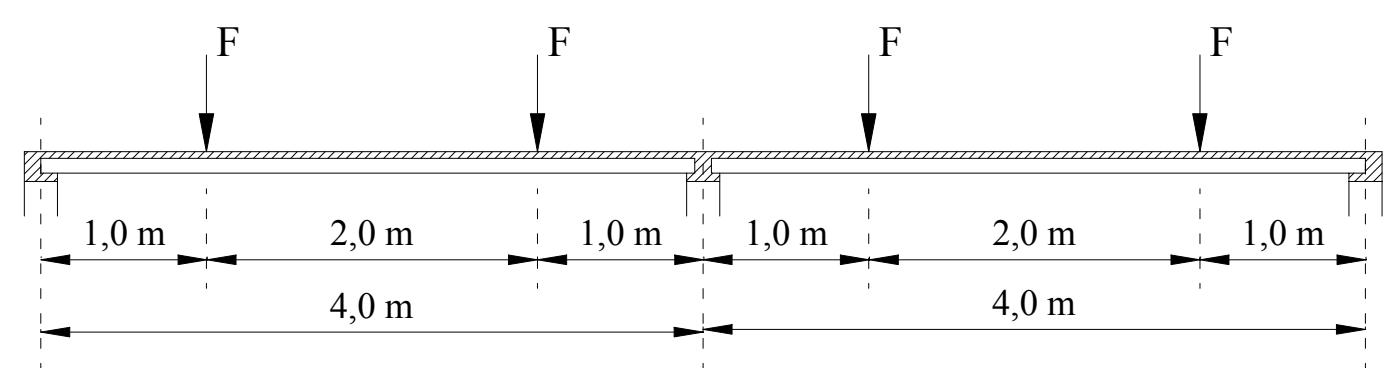

Figura 4.21 - Esquema do ensaio realizado por MAGALHÃES (2001) 


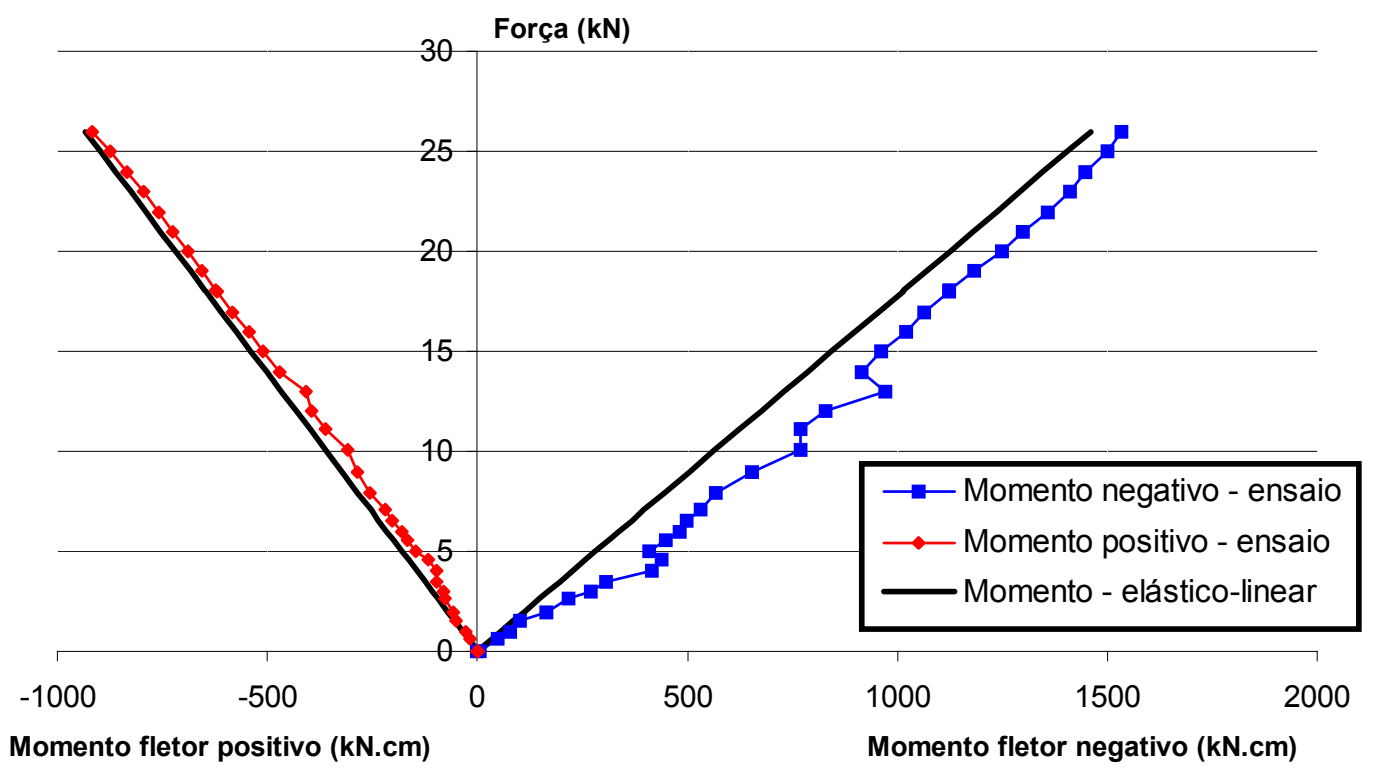

Figura 4.22 - Máximos momentos fletores para o caso com $\eta$ = 15\% [MAGALHÃES (2001)]

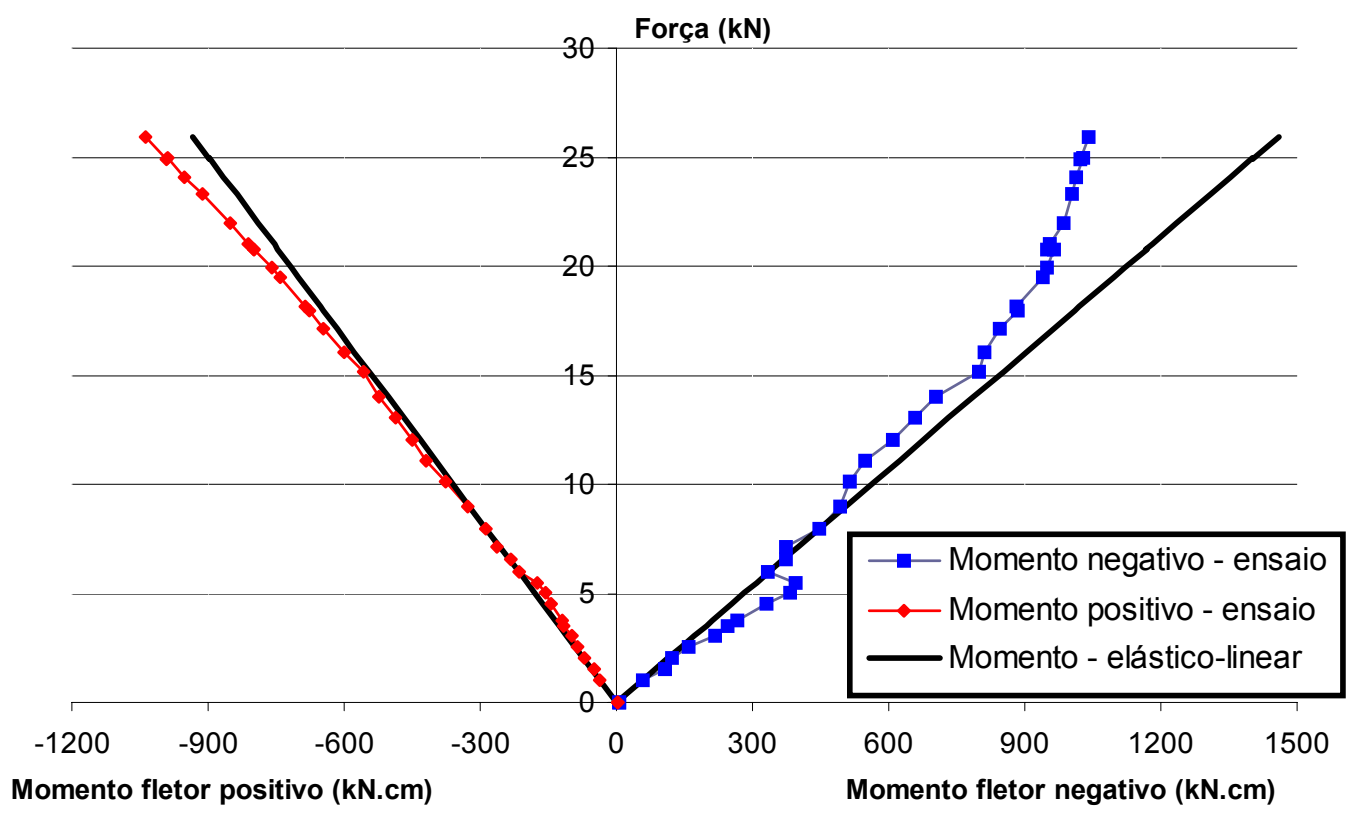

Figura 4.23 - Máximos momentos fletores para o caso com $\eta=40 \%$ [MAGALHÃES (2001)] 


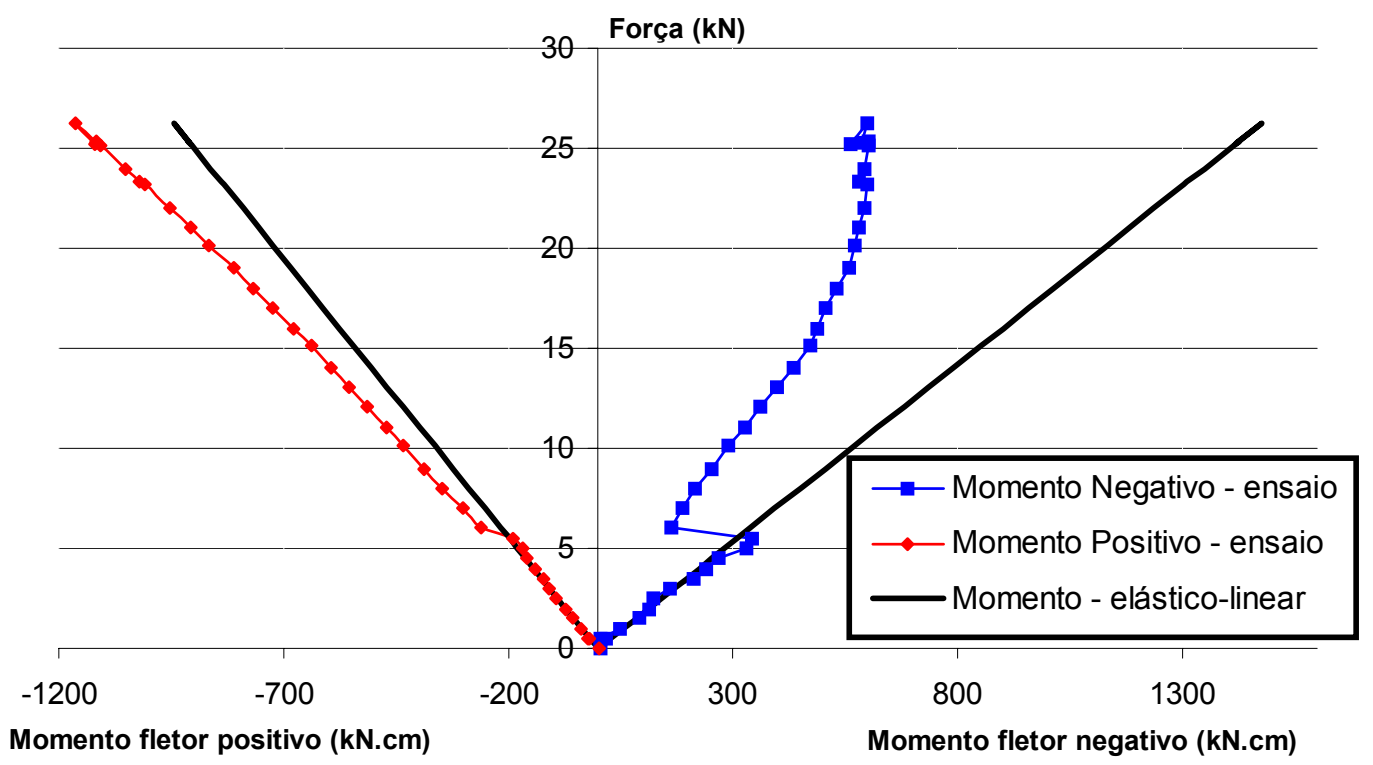

Figura 4.24 - Máximos momentos fletores para o caso com armadura construtiva sobre o apoio [MAGALHÃES (2001)]

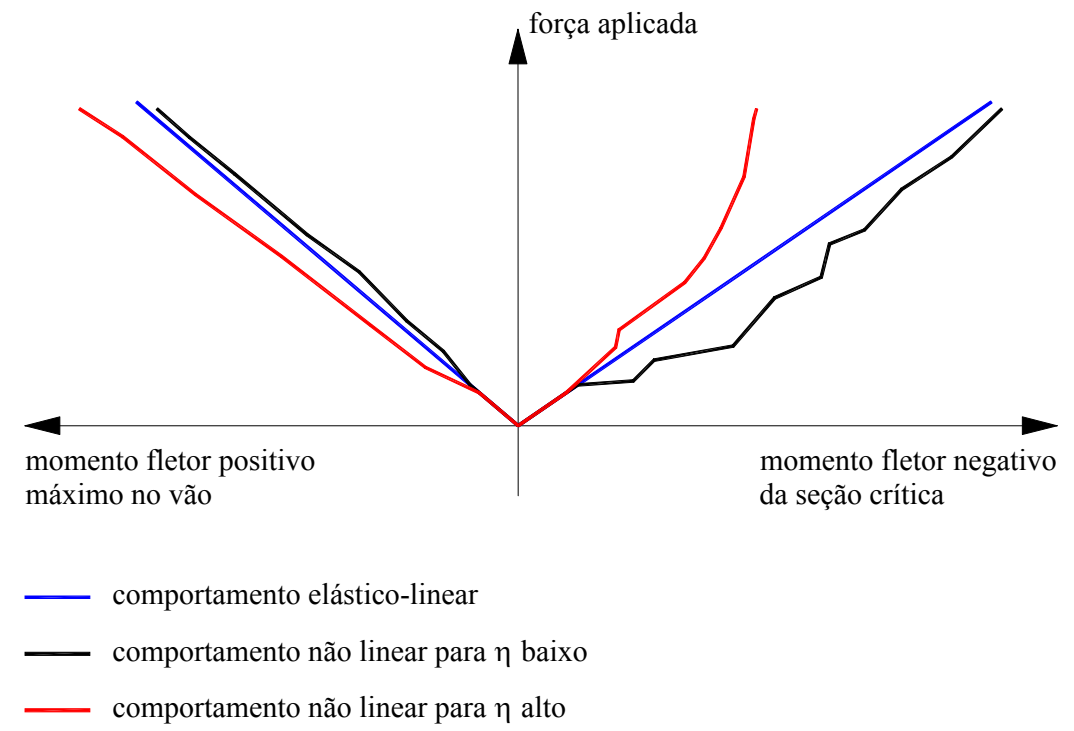

Figura 4.25 - Gráfico esquemático da evolução do máximo momento fletor para lajes formadas por vigotas com armação treliçada

Pela tabela 4.13 pode-se verificar que, para os casos analisados, houve uma discrepância entre o valor do grau de redistribuição adotado no dimensionamento e o valor encontrado no processamento. 
Tabela 4.13 - Valores do grau de redistribuição

\begin{tabular}{|c|c|c|c|}
\hline casos & $\begin{array}{c}\eta \text { adotado no } \\
\text { dimensionamento } \\
(\%)\end{array}$ & $\begin{array}{c}\eta \text { obtido na } \\
\text { simulação } \\
\text { (\%) }\end{array}$ & $\begin{array}{c}\eta \text { recomendado pela } \\
\text { CPT Planchers } \\
(\mathbf{1 9 8 0}) \\
(\%)\end{array}$ \\
\hline $\mathrm{C} 2 / 4,0-20-0$ & 0 & 18,9 & \multirow{4}{*}{$35-55$} \\
\hline $\mathrm{C} 2 / 4,0-20-20$ & 20 & 31,5 & \\
\hline $\mathrm{C} 2 / 4,0-20-40$ & 40 & 42,4 & \\
\hline $\mathrm{C} 2 / 4,0-20-60$ & 60 & 54,5 & \\
\hline $\mathrm{C} 2 / 6,0-20-0$ & 0 & 24,8 & \multirow{5}{*}{$35-55$} \\
\hline $\mathrm{C} 2 / 6,0-20-20$ & 20 & 29,0 & \\
\hline $\mathrm{C} 2 / 6,0-20-40$ & 40 & 32,4 & \\
\hline $\mathrm{C} 2 / 6,0-20-60$ & 60 & 43,4 & \\
\hline $\mathrm{C} 2 / 6,0-15-20$ & 20 & 28,0 & \\
\hline $\mathrm{C} 2 / 8,0-20-0$ & 0 & 20,6 & \multirow{2}{*}{$35-55$} \\
\hline $\mathrm{C} 2 / 8,0-20-20$ & 20 & 23,2 & \\
\hline $\mathrm{C} 3 / 6,0-20-20$ & 20 & 22,7 & $38,6-50$ \\
\hline $\mathrm{C} 2 / 6,0 / 8,0-20-20$ & 20 & 22,1 & $29,3-36,7$ \\
\hline
\end{tabular}

Pode-se notar pela tabela 4.13 que, mesmo os casos que foram dimensionados considerando como valor de momento fletor negativo no apoio aquele obtido da análise linear $(\eta=0 \%)$, apresentaram redistribuição da ordem de $20 \%$. Isso pode acarretar em um aumento do valor de momento fletor no vão, superior ao previsto no dimensionamento, estando a estrutura contra a segurança.

Os valores apresentados na tabela 4.13 estão mostrados na figura $4.26 \mathrm{em}$ forma de gráfico. Por esse gráfico, pode-se observar que os valores que melhor representa o grau de redistribuição do momento fletor negativo seriam aproximadamente $24 \%, 31 \%$ e $46 \%$, respectivamente, para os casos com vãos de 4,0, 6,0 e 8,0 m. Esses seriam valores mínimos a serem adotados para a redistribuição dos momentos fletores no apoio, de modo que a laje trabalhe na zona de segurança, não tendo risco do momento fletor resistente no vão ser ultrapassado.

Pela tabela 4.13 pode-se observar também que os graus de redistribuição recomendados pela publicação francesa CPT Plachers (1980) apresentam resultados 
razoáveis, embora uma região do intervalo proposto para o caso com vão de 4,0 m esteja contra a segurança.

Com o exposto acima se pode verificar que há poucos resultados para se propor um valor de grau de redistribuição a ser adotado no dimensionamento que se aplique para todas as situações. Isso só seria possível se fosse realizado grande quantidade de simulações variando as dimensões da laje, resistência dos materiais, número de vãos e grau de redistribuição dos momentos fletores, de modo a cobrir todas as situações possíveis.

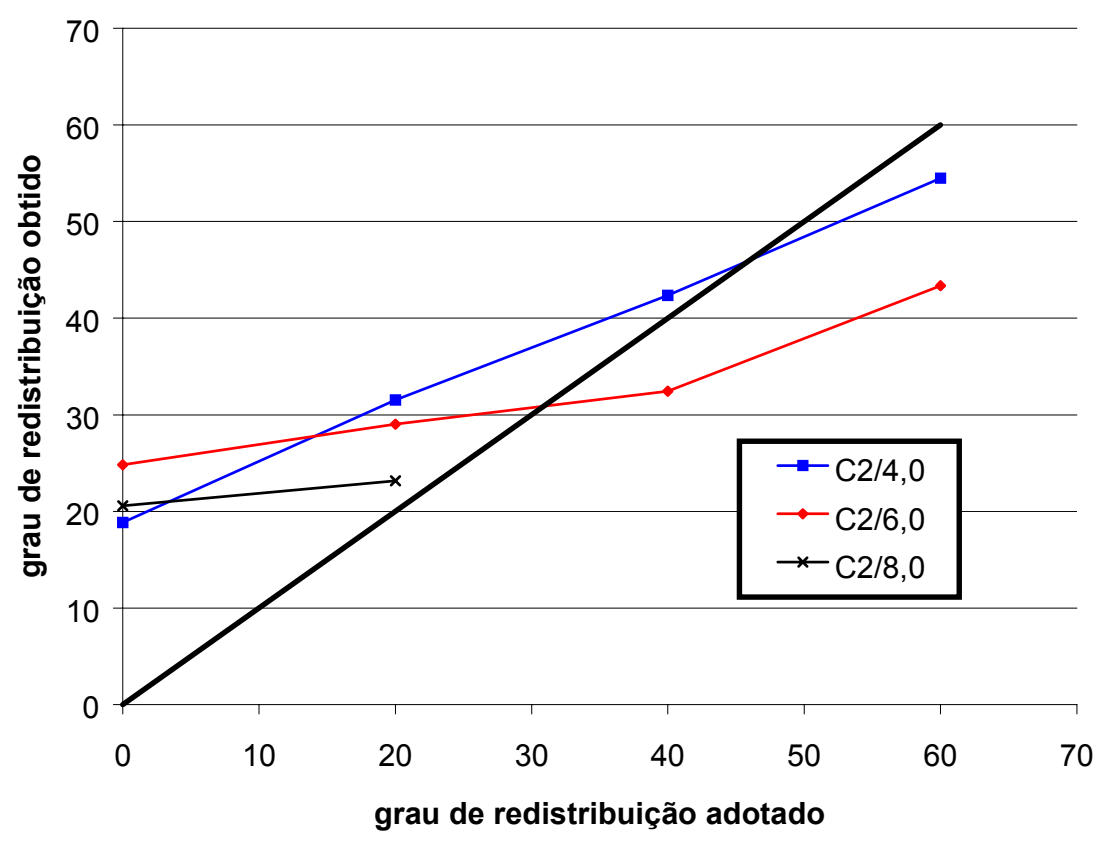

Figura 4.26 - Grau de redistribuição 


\subsection{Considerações iniciais}

Neste capítulo, apresenta-se um exemplo de cálculo de lajes formadas por elementos pré-moldados tipo vigota protendida.

Para o exemplo de cálculo foram considerados os seguintes dados:

Vão: $\ell=4,0$ m (figura 5.1)

Sobrecarga de revestimento: $\mathrm{g}_{3}=1,0 \mathrm{kN} / \mathrm{m}^{2}$

Carga de utilização: $\mathrm{q}=2,5 \mathrm{kN} / \mathrm{m}^{2}$

Com a finalidade de mostrar o que ocorre quando se passa da situação de tramo simplesmente apoiado para dois tramos contínuos, foi realizado inicialmente o cálculo para situação da laje simplesmente apoiada, em seguida foi complementado com a situação de laje contínua.

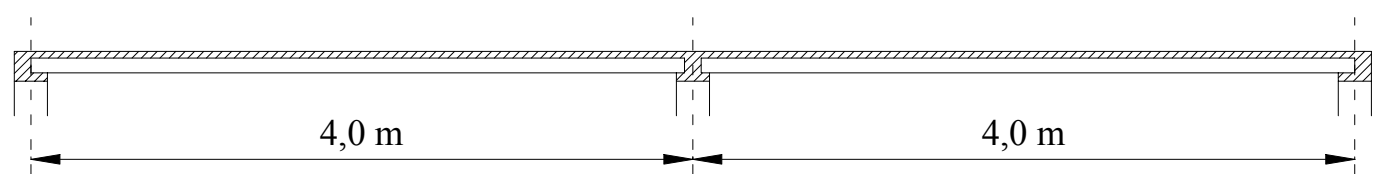

FIGURA 5.1 - Esquema da laje com vão duplo 


\subsection{Cálculos iniciais}

A vigota que foi considerada no cálculo está apresentada na figura 5.2, possuindo quatro fios de $5 \mathrm{~mm}$ de diâmetro, de aço CP160-RN, constituída por concreto de resistência característica à compressão igual $35 \mathrm{MPa}$.

A seção transversal foi completada com material de enchimento composto por blocos vazados de concreto de $8 \times 41 \mathrm{~cm}$, fazendo com que a distância entre nervuras ficasse com $50 \mathrm{~cm}$. Foi adicionada ainda uma capa de concreto, com resistência característica à compressão de $20 \mathrm{MPa}$, completando a seção final da laje com altura total de $12 \mathrm{~cm}$, conforme figura 5.3 .

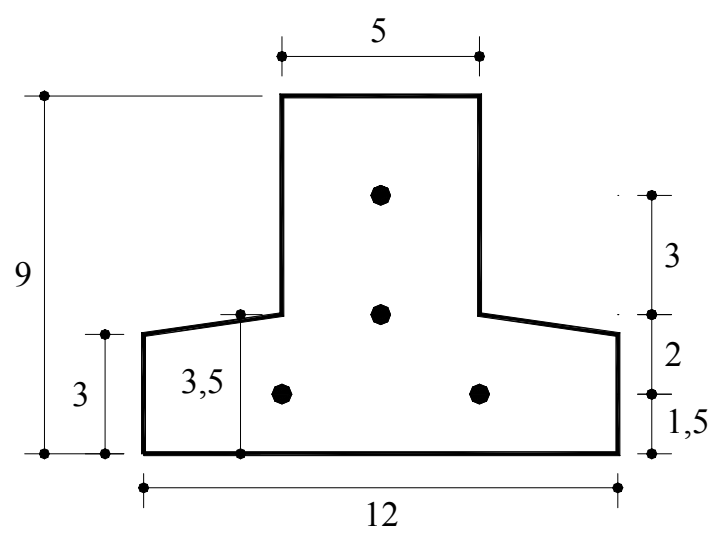

FIGURA 5.2 - Seção transversal da vigota protendida (dimensões em cm)

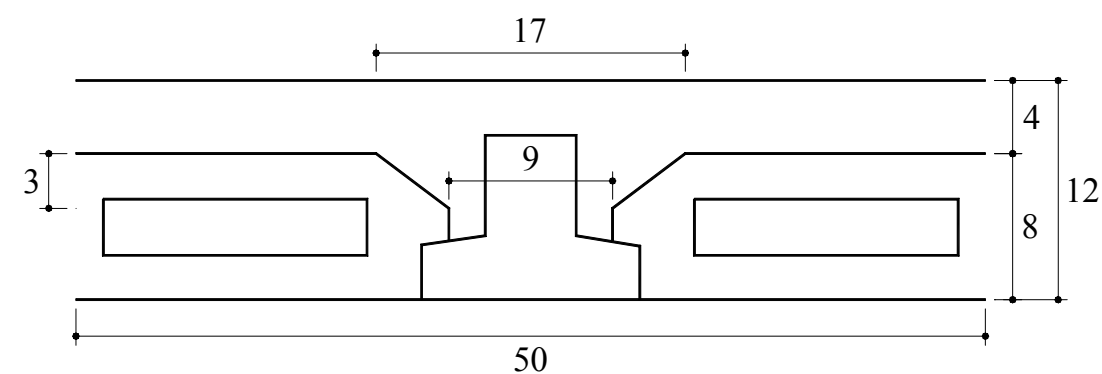

FIGURA 5.3 - Seção transversal final da laje (dimensões em cm) 


\section{a) Características geométricas da vigota}

Área:

seção transversal bruta: $A_{v}=67,75 \mathrm{~cm}^{2}$;

seção de armadura protendida: $A_{p}=0,78 \mathrm{~cm}^{2}$;

seção líquida de concreto: $\mathrm{A}_{\mathrm{c}}=\mathrm{A}_{\mathrm{v}}-\mathrm{A}_{\mathrm{p}}=66,97 \mathrm{~cm}^{2}$;

seção homogeneizada: $A_{c h}=A_{c}+\alpha_{p} \cdot A_{p}=74,77 \mathrm{~cm}^{2}\left(\operatorname{com} \alpha_{p}=10\right)$.

Centro de gravidade (com relação à borda inferior da seção):

seção transversal bruta: $Y_{1 \mathrm{v}}=3,54 \mathrm{~cm}$;

seção de armadura protendida: $\mathrm{Y}_{1 \mathrm{p}}=3,25 \mathrm{~cm}$;

seção líquida de concreto: $\mathrm{Y}_{1 \mathrm{c}}=\frac{\mathrm{Y}_{1 \mathrm{v}} \cdot \mathrm{A}_{\mathrm{v}}-\mathrm{Y}_{1 \mathrm{p}} \cdot \mathrm{A}_{\mathrm{p}}}{\mathrm{A}_{\mathrm{c}}}=3,54 \mathrm{~cm}$;

seção homogeneizada: $Y_{1 h}=\frac{Y_{1 c} \cdot A_{c}+\alpha_{p} \cdot Y_{1 p} \cdot A_{p}}{A_{c h}}=3,51 \mathrm{~cm}$.

E portanto, a excentricidade da armadura protendida em relação ao centróide da seção líquida de concreto é dada por:

$$
\begin{gathered}
\mathrm{e}_{\mathrm{p}}=\mathrm{Y}_{1 \mathrm{c}}-\mathrm{Y}_{1 \mathrm{p}}=-0,29 \mathrm{~cm} \text { ( } \\
\text { cestando a armadura protendida abaixo do seção líquida) }
\end{gathered}
$$

As características geométricas da seção líquida de concreto e da seção homogeneizada da vigota foram resumidas na figura 5.4.

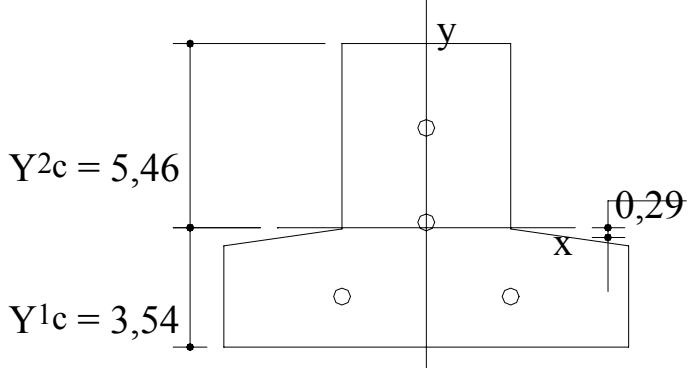

(a) Seção de concreto líquida

FIGURA 5.4 - Características geométricas da vigota (dimensões em $\mathrm{cm}$ ) 
Os momentos de inércia em relação ao eixo que passa pelo centróide da seção líquida de concreto serão:

seção transversal bruta: $\mathrm{I}_{\mathrm{v}}=448,63 \mathrm{~cm}^{4}$;

seção de armadura protendida: $I_{p}=3,33 \mathrm{~cm}^{4}$;

seção líquida de concreto: $I_{c}=I_{v}-I_{p}=445,30 \mathrm{~cm}^{4}$;

seção homogeneizada: $\mathrm{I}_{\mathrm{ch}}=478,55 \mathrm{~cm}^{4}$;

Com isso, determinam-se os módulos resistentes:

Seção líquida de concreto: $\mathrm{W}_{1}=\frac{\mathrm{I}_{\mathrm{c}}}{\mathrm{Y}_{1 \mathrm{c}}}=125,79 \mathrm{~cm}^{3}$;

$$
\mathrm{W}_{2}=\frac{\mathrm{I}_{\mathrm{c}}}{\mathrm{Y}_{2 \mathrm{c}}}=81,56 \mathrm{~cm}^{3}
$$

Seção homogeneizada: $\mathrm{W}_{1 \mathrm{~h}}=\frac{\mathrm{I}_{\mathrm{ch}}}{\mathrm{Y}_{1 \mathrm{~h}}}=136,34 \mathrm{~cm}^{3}$;

$$
\mathrm{W}_{2 \mathrm{~h}}=\frac{\mathrm{I}_{\mathrm{ch}}}{\mathrm{Y}_{2 \mathrm{~h}}}=87,17 \mathrm{~cm}^{3}
$$

\section{b) Características geométricas da laje}

Para determinar as características geométricas da laje, deve-se realizar a homogeneização da seção, conforme o exposto no capítulo 2. Para isso, multiplicamse as larguras do concreto moldado no local por:

$$
\mathrm{m}=\sqrt{\frac{\mathrm{f}_{\mathrm{ck}, 2}}{\mathrm{f}_{\mathrm{ck}, 1}}}=\sqrt{\frac{20}{35}}=0,756
$$

resultando na seção mostrada na figura 5.5. 


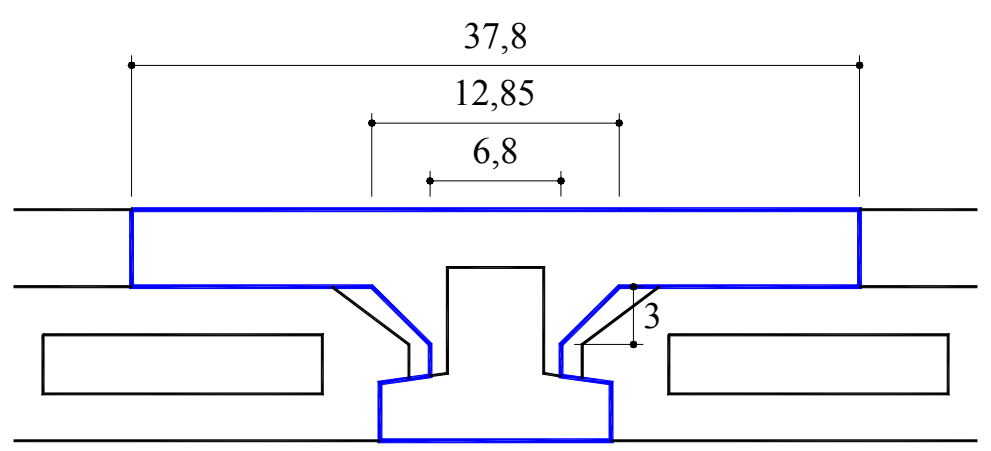

FIGURA 5.5 - Seção da laje homogeneizada (dimensões em cm)

A partir disso, pode-se determinar as características da seção da laje:

Área da seção homogeneizada: $\mathrm{A}_{\mathrm{ch}}{ }^{\prime}=238,26 \mathrm{~cm}^{2}$;

Momento de inércia: $\mathrm{I}_{\mathrm{ch}}{ }^{\prime}=2845,05 \mathrm{~cm}^{4}$;

Centro de gravidade: $\mathrm{Y}_{1 \mathrm{~h}}{ }^{\prime}=7,73 \mathrm{~cm}$ (em relação ao bordo inferior);

Módulos resistentes: $\mathrm{W}_{1 \mathrm{~h}}{ }^{\prime}=\frac{\mathrm{I}_{\mathrm{ch}}{ }^{\prime}}{\mathrm{Y}_{1 \mathrm{~h}}{ }^{\prime}}=368,05 \mathrm{~cm}^{3}$;

$$
\mathrm{W}_{2 \mathrm{~h}}{ }^{\prime}=\frac{\mathrm{I}_{\mathrm{ch}}{ }^{\prime}}{\mathrm{Y}_{2 \mathrm{~h}^{\prime}}}=666,68 \mathrm{~cm}^{3}
$$

\section{c) Definição da tensão na armadura de protensão}

Como apontado no capítulo 2, a tensão inicial $\sigma_{\mathrm{pi}}$ que a força de protensão $\mathrm{P}_{\mathrm{i}}$ introduz nas armaduras ativas, segundo a NBR-7197 (1989), na saída do aparelho de tração, deve respeitar os seguintes valores:

$$
\sigma_{\mathrm{pi}} \leq\left\{\begin{array}{l}
0,81 \cdot f_{\mathrm{ptk}} \\
0,95 \cdot \mathrm{f}_{\mathrm{pyk}}
\end{array} \quad\right. \text { (para aços da classe RN) }
$$

Para o aço CP160-RN, a NBR-7482 (1991) especifica em 160 kN/cm² e $136 \mathrm{kN} / \mathrm{cm}^{2}$, respectivamente, os valores mínimos para a resistência à tração $\mathrm{f}_{\mathrm{ptk}} \mathrm{e}$ resistência de escoamento $f_{\text {pyk }}$. Portanto:

$$
\begin{aligned}
& \sigma_{\mathrm{pi}} \leq 129,6 \mathrm{kN} / \mathrm{cm}^{2} \\
& \sigma_{\mathrm{pi}} \leq 129,2 \mathrm{kN} / \mathrm{cm}^{2}
\end{aligned}
$$


Será considerado como tensão inicial $\sigma_{\mathrm{pi}}$ na armadura protendida $\mathrm{o}$ valor de $129,2 \mathrm{kN} / \mathrm{cm}^{2}$, que cumpre as condições anteriores.

As perdas imediatas devidas ao escorregamento dos fios na ancoragem, relaxação inicial da armadura e retração inicial do concreto podem ser adotadas a grosso modo igual a 7\% para o caso de aço com relaxação normal, segundo HANAI (2001). Assim:

$$
\sigma_{\mathrm{pa}}=93 \% . \sigma_{\mathrm{pi}}
$$

A tensão inicial na armadura de protensão considerando também a perda por deformação imediata do concreto é dada por:

$$
\sigma_{\mathrm{po}}=\sigma_{\mathrm{pa}}-\alpha_{\mathrm{p}} \cdot \sigma_{\mathrm{cp}}
$$

com

$$
\sigma_{c p}=\frac{P_{a}}{A_{c h}}+\frac{P_{a} \cdot e_{p}}{I_{c h}}
$$

sendo:

$\sigma_{\mathrm{cp}}$ - tensão no concreto ao nível do baricentro da armadura de protensão, devida a força $\mathrm{P}_{\mathrm{a}}$;

$\sigma_{\mathrm{pa}}$ - tensão na armadura de protensão devida a força $\mathrm{P}_{\mathrm{a}}$;

$\mathrm{P}_{\mathrm{a}}$ - força na armadura de protensão antes da liberação dos cabos;

$\mathrm{A}_{\mathrm{ch}}$ - área da seção transversal homogeneizada da vigota;

$\mathrm{I}_{\mathrm{ch}}$ - momento de inércia da seção transversal homogeneizada da vigota;

$e_{p}$ - excentricidade da armadura protendida;

As perdas diferidas devidas à relaxação posterior da armadura, retração posterior do concreto e fluência do concreto serão estimadas em 10\%.

Portanto,

$$
\begin{aligned}
& \sigma_{\mathrm{po}}=107,1 \mathrm{kN} / \mathrm{cm}^{2} \\
& \sigma_{\mathrm{p} \infty}=94,1 \mathrm{kN} / \mathrm{cm}^{2}
\end{aligned}
$$

Com isso, pode-se determinar a força na armadura protendida: 


$$
\begin{aligned}
& \mathrm{P}_{\mathrm{o}}=\mathrm{A}_{\mathrm{p}} \cdot \sigma_{\mathrm{po}}=83,54 \mathrm{kN} \\
& \mathrm{P}_{\infty}=\mathrm{A}_{\mathrm{p}} \cdot \sigma_{\mathrm{p} \infty}=73,40 \mathrm{kN}
\end{aligned}
$$

\section{d) Verificação da vigota isolada}

Como já foi apresentado no capítulo 2, a vigota isolada deve cumprir:

$$
\begin{aligned}
& \sigma_{1}=\frac{P_{o}}{A_{c}}-\frac{P_{o} \cdot e_{p}}{W_{1}}<0,7 \cdot f_{c k j} \\
& \sigma_{2}=\frac{P_{o}}{A_{c}}+\frac{P_{o} \cdot e_{p}}{W_{2}}>0
\end{aligned}
$$

Substituindo os valores:

$$
\begin{aligned}
& \sigma_{1}=\frac{83,54}{66,97}-\frac{83,54 \cdot(-0,29)}{125,79}=1,44 \mathrm{kN} / \mathrm{cm}^{2} \\
& \sigma_{2}=\frac{83,54}{66,97}+\frac{83,54 \cdot(-0,29)}{81,56}=0,95 \mathrm{kN} / \mathrm{cm}^{2} \quad \text { (condição satisfeita) }
\end{aligned}
$$

$\mathrm{Na}$ figura 5.6 está apresentado o perfil de tensões iniciais que a vigota ficará submetida após a liberação dos cabos de protensão.

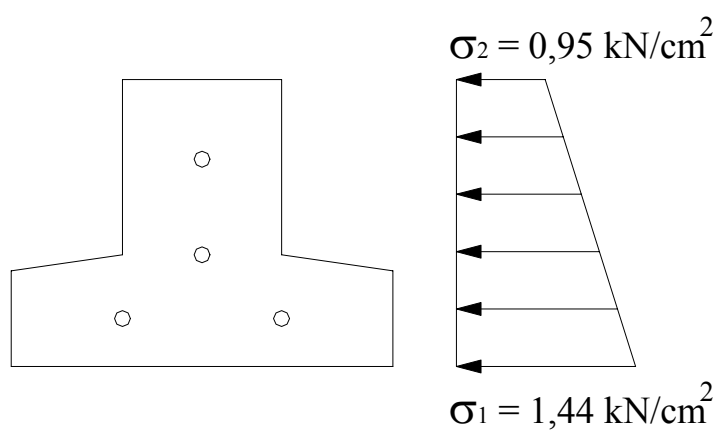

FIGURA 5.6 - Tensões iniciais na seção de concreto líquida

Portanto, deve-se ter o cuidado, durante a transferência da força de protensão, para que o concreto tenha uma resistência mínima $\left(f_{\text {ckj }}\right)$ de $2,0 \mathrm{kN} / \mathrm{cm}^{2}$ (20 MPa), satisfazendo as condições de verificação da vigota isolada. 


\section{e) Verificação da vigota na fase de construção}

Inicialmente, defini-se as cargas que atuarão sobre os elementos prémoldados durante a fase de construção da laje:

$$
\begin{array}{lr}
\text { peso próprio da vigota }\left(\mathrm{A}_{\mathrm{v}} \cdot \gamma_{\mathrm{conc}}\right) & \mathbf{g}_{\mathbf{1}}=\mathbf{1 , 6 9 . 1 0 ^ { - 3 }} \mathbf{k N} / \mathbf{c m} \\
\text { peso do concreto moldado no local }\left(\mathrm{A}_{\mathrm{CML}} \cdot \gamma_{\mathrm{conc}}\right) & 5,65.10^{-3} \mathrm{kN} / \mathrm{cm} \\
\text { peso do material do enchimento }\left(\mathrm{A}_{\mathrm{ME}} \cdot \gamma_{\mathrm{ME}}\right) & 3,98.10^{-3} \mathrm{kN} / \mathrm{cm} \\
\cline { 2 - 2 } & \mathbf{g}_{\mathbf{2}}=\mathbf{9 , 6 3 . 1 0 ^ { - 3 }} \mathbf{k N} / \mathbf{c m} \\
\text { sobrecarga de execução }\left(1,0 \mathrm{kN} / \mathrm{m}^{2}\right) & \mathbf{q}_{\mathbf{e x e}}=\mathbf{5 , 0 . 1 0 ^ { - 3 }} \mathbf{k N} / \mathbf{c m}
\end{array}
$$

Os valores das áreas e massas específicas utilizadas nos cálculos anteriores foram:

$$
\begin{array}{ll}
\mathrm{A}_{\mathrm{v}}=67,75 \mathrm{~cm}^{2} ; & \gamma_{\mathrm{conc}}=25 \mathrm{kN} / \mathrm{m}^{3} \\
\mathrm{~A}_{\mathrm{CML}}=225,78 \mathrm{~cm}^{2} ; & \gamma_{\mathrm{ME}}=13 \mathrm{kN} / \mathrm{m}^{3} \\
\mathrm{~A}_{\mathrm{ME}}=306,47 \mathrm{~cm}^{2} ; &
\end{array}
$$

Durante a fase de construção da laje, a vigota deve ser capaz de suportar seu peso próprio, trabalhando como viga simplesmente apoiada em ambos os extremos, e as demais cargas, nas mesmas condições ou como viga contínua sobre escoras quando for necessário dispor apoios intermediários.

Supondo que não utilize escoras, tem-se o diagrama de momento fletor apresentado na figura 5.7, devendo ser satisfeitas as condições:

$$
\begin{aligned}
& \sigma_{1}=\frac{P_{\infty}}{A_{c}}-\frac{P_{\infty} \cdot e_{p}}{W_{1}}-\gamma_{f} \cdot \frac{M_{g_{1}+g_{2}+q_{\text {exe }}}}{W_{1 h}}>0 \\
& \sigma_{2}=\frac{P_{\infty}}{A_{c}}+\frac{P_{\infty} \cdot e_{p}}{W_{2}}+\gamma_{f} \cdot \frac{M_{g_{1}+g_{2}+q_{e x e}}}{W_{2 h}}<0,7 . f_{c k}
\end{aligned}
$$

Substituindo os valores:

$$
\begin{aligned}
& \sigma_{1}=\frac{73,40}{66,97}-\frac{73,40 \cdot(-0,29)}{125,79}-1,20 \cdot \frac{326,40}{136,34}=-1,61 \mathrm{kN} / \mathrm{cm}^{2} \text { (ultrapassado) } \\
& \sigma_{2}=\frac{73,40}{66,97}+\frac{73,40 \cdot(-0,29)}{81,56}+1,20 \cdot \frac{326,40}{87,17}=5,33 \mathrm{kN} / \mathrm{cm}^{2} \text { (ultrapassado) }
\end{aligned}
$$




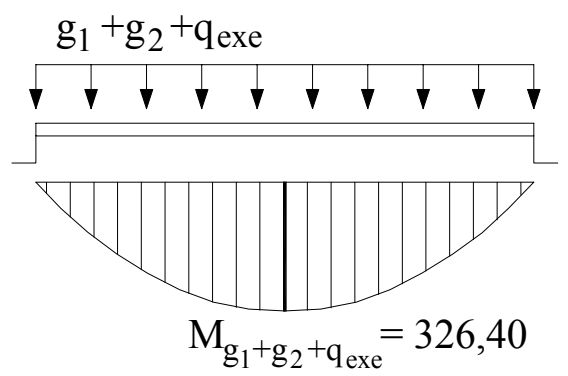

FIGURA 5.7 - Diagrama de momento fletor não utilizando escoras (valores em kN.cm)

Como os valores resultantes são superiores aos limites estabelecidos, deve-se utilizar escoras para diminuir o vão de cálculo que será utilizado na verificação das tensões. Na figura 5.8 apresenta-se o novo diagrama de momento fletor, devendo-se verificar.

Sobre as escoras:

$$
\begin{aligned}
& \sigma_{1}=\frac{P_{\infty}}{A_{c}}-\frac{P_{\infty} \cdot e_{p}}{W_{1}}+\gamma_{f} \cdot \frac{M_{g_{1}+g_{2}+q_{e x e}}}{W_{1 h}}<0,7 . f_{c k} \\
& \sigma_{2}=\frac{P_{\infty}}{A_{c}}+\frac{P_{\infty} \cdot e_{p}}{W_{2}}-\gamma_{f} \cdot \frac{M_{g_{1}+g_{2}+q_{\text {exe }}}}{W_{2 h}}>0
\end{aligned}
$$

Substituindo os valores:

$$
\begin{aligned}
& \sigma_{1}=\frac{73,40}{66,97}-\frac{73,40 \cdot(-0,29)}{125,79}+1,20 \cdot \frac{39,35}{136,34}=1,61 \mathrm{kN} / \mathrm{cm}^{2} \text { (satisfeita) } \\
& \sigma_{2}=\frac{73,40}{66,97}+\frac{73,40 \cdot(-0,29)}{81,56}-1,20 \cdot \frac{39,35}{87,17}=0,29 \mathrm{kN} / \mathrm{cm}^{2} \text { (satisfeita) }
\end{aligned}
$$

\section{No vão:}

$$
\begin{aligned}
& \sigma_{1}=\frac{P_{\infty}}{A_{c}}-\frac{P_{\infty} \cdot e_{p}}{W_{1}}-\gamma_{f} \cdot \frac{M_{g_{1}+g_{2}+q_{e x e}}}{W_{1 h}}>0 \\
& \sigma_{2}=\frac{P_{\infty}}{A_{c}}+\frac{P_{\infty} \cdot e_{p}}{W_{2}}+\gamma_{f} \cdot \frac{M_{g_{1}+g_{2}+q_{e x e}}}{W_{2 h}}<0,7 . f_{c k}
\end{aligned}
$$


Substituindo os valores:

$$
\begin{aligned}
& \sigma_{1}=\frac{73,40}{66,97}-\frac{73,40 \cdot(-0,29)}{125,79}-1,20 \cdot \frac{63,11}{136,34}=0,71 \mathrm{kN} / \mathrm{cm}^{2} \text { (satisfeita) } \\
& \sigma_{2}=\frac{73,40}{66,97}+\frac{73,40 \cdot(-0,29)}{81,56}+1,20 \cdot \frac{63,11}{87,17}=1,70 \mathrm{kN} / \mathrm{cm}^{2} \text { (satisfeita) }
\end{aligned}
$$
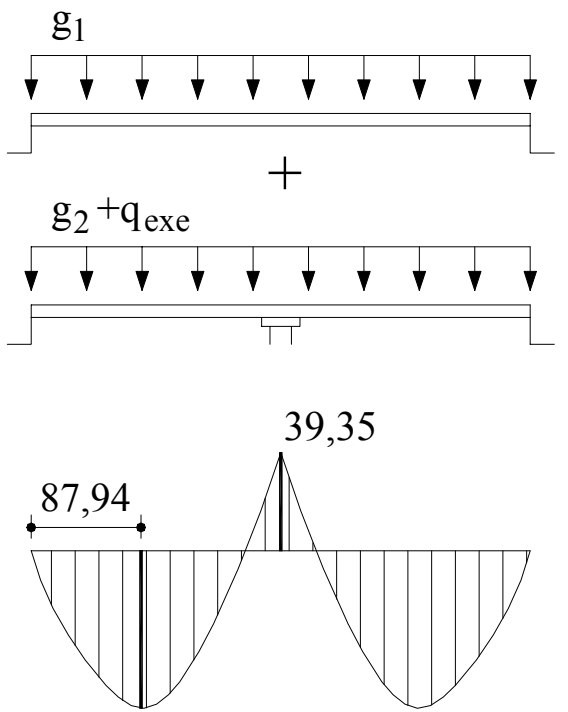

63,11

FIGURA 5.8 - Diagrama de momento fletor para a utilização de uma linha de escoras (valores em kN.cm)

As verificações para a fase de construção foram realizadas considerando $\mathrm{P}_{\infty}$ como a força atuante na vigota durante a fase de construção, sendo que o mais correto seria utilizar uma força considerando todas as perdas até a fase de execução da laje. No entanto, mesmo que fosse considerado $\mathrm{P}_{\mathrm{o}}$ como a força atuante na vigota durante a fase de construção, seriam satisfeitos os limites de tensões de tração e compressão na seção da vigota com a utilização de uma linha de escoras.

\subsection{Parte 1: laje simplesmente apoiada}

Neste item apresentam-se as verificações quanto ao estado limite último para solicitações normais e solicitações tangenciais, além do estado limite de 
fissuração e de deformação excessiva considerando a laje com tramos simplesmente apoiados.

\section{a) Determinação dos diagramas de momento fletor}

Inicialmente, atua sobre a vigota o seu peso próprio, o peso do material de enchimento e do concreto moldado no local. Após a solidarização entre o concreto da vigota e o concreto moldado no local, começa a atuar uma força equivalente devido à retirada do escoramento, além dos esforços oriundos da sobrecarga permanente e carga de utilização. Os diagramas de momento fletor dessas cargas estão apresentados na figura 5.9.

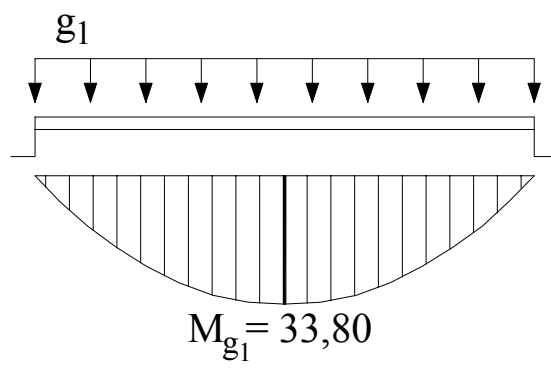

(a) peso próprio da vigota

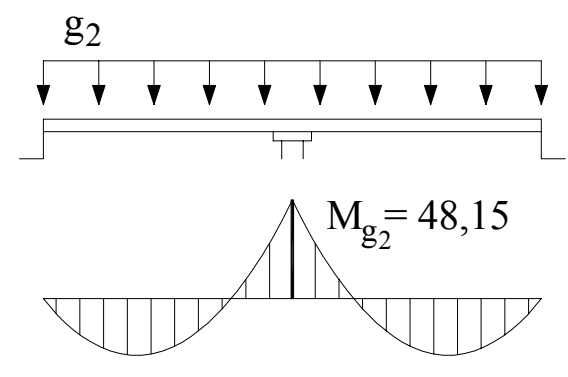

(b) peso do material de enchimento e do concreto moldado no local

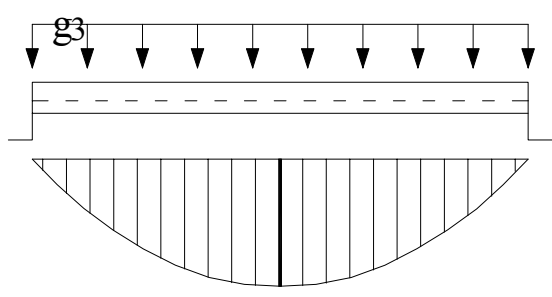

(d) sobrecarga de revestimento

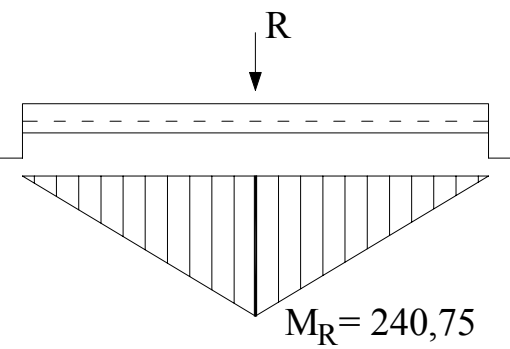

(c) reação após retirar a escora

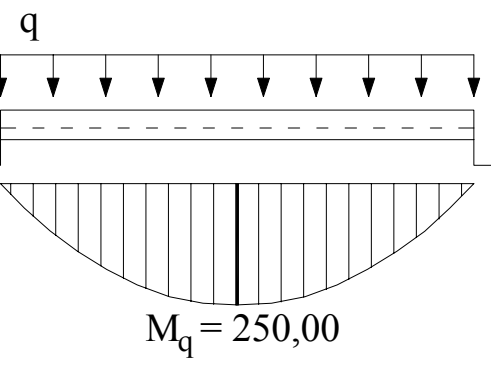

(e) carga de utilização

FIGURA 5.9 - Diagramas de momento fletor atuantes na laje (valores em kN.cm) 


\section{b) Verificação do estado limite último para solicitações normais}

Para a verificação do estado limite último para solicitações normais, inicialmente, será determinado o valor do momento último $\mathrm{M}_{\mathrm{u}}$ da seção composta. Para isso, defini-se os valores de resistência de cálculo dos materiais utilizados.

concreto pré-moldado: $\mathrm{f}_{\mathrm{cd}, 1}=\frac{\mathrm{f}_{\mathrm{ck}, 1}}{1,3} \Rightarrow \mathrm{f}_{\mathrm{cd}, 1}=2,69 \mathrm{kN} / \mathrm{cm}^{2}$

concreto moldado no local: $\mathrm{f}_{\mathrm{cd}, 2}=\frac{\mathrm{f}_{\mathrm{ck}, 2}}{1,4} \Rightarrow \mathrm{f}_{\mathrm{cd}, 2}=1,43 \mathrm{kN} / \mathrm{cm}^{2}$

armadura de protensão: $\mathrm{f}_{\text {pyd }}=\frac{\mathrm{f}_{\text {pyk }}}{1,15} \Rightarrow \mathrm{f}_{\text {pyd }}=118,26 \mathrm{kN} / \mathrm{cm}^{2}$.

Suponha-se, em princípio, que a linha neutra passe pela capa de concreto moldada no local, ou seja, $y \leq 4 \mathrm{~cm}$. Com esta hipótese, estabelecendo a equação de equilíbrio das forças atuantes na seção para $\mathrm{M}_{\mathrm{u}}$ positivo, como ilustrado na figura 5.10, tem-se:

$$
0,85 \cdot f_{\mathrm{cd}, 2} \cdot \mathrm{A}_{\mathrm{c}}{ }^{\prime}=\mathrm{A}_{\mathrm{p}} \cdot \mathrm{f}_{\mathrm{pyd}}
$$

Portanto,

$0,85 \cdot 1,43.50 \cdot y=0,78 \cdot 118,26 \Rightarrow y=1,52 \mathrm{~cm}$

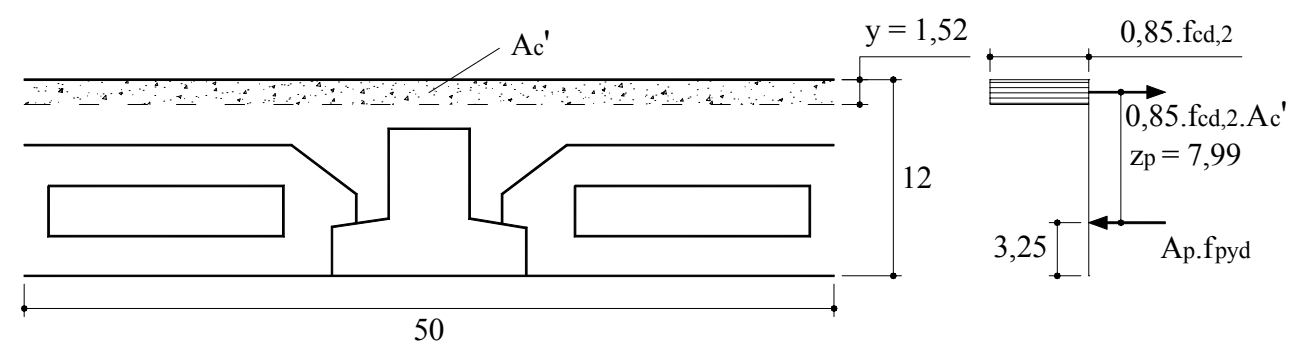

FIGURA 5.10 - Equilíbrio das forças na seção da laje para momento fletor positivo

Como a hipótese assumida é válida, deve-se verificar a validez de $\sigma_{p}=f_{\text {pyd }}$, que exige:

$$
\varepsilon_{\mathrm{pi}}+\varepsilon_{\mathrm{p}} \geq \frac{\mathrm{f}_{\mathrm{pyd}}}{\mathrm{E}_{\mathrm{p}}}
$$


sendo:

$\varepsilon_{\mathrm{pi}}$ - pré-alongamento da armadura protendida;

$\varepsilon_{\mathrm{p}}$ - alongamento da armadura devido à flexão.

O valor do pré-alongamento da armadura protendida é dado por:

$\varepsilon_{\mathrm{pi}}=\varepsilon_{\mathrm{po}}+\varepsilon_{\mathrm{cp}}$

sendo,

$$
\begin{aligned}
& \varepsilon_{\mathrm{po}}=\frac{\gamma_{\mathrm{f}} \cdot \mathrm{P}_{\infty}}{\mathrm{A}_{\mathrm{p}} \cdot \mathrm{E}_{\mathrm{p}}} \Rightarrow \varepsilon_{\mathrm{po}}=\frac{0,9 \cdot 73,40}{0,78 \cdot 20000} \Rightarrow \varepsilon_{\mathrm{po}}=0,00423 \\
& \varepsilon_{\mathrm{cp}}=\frac{\gamma_{\mathrm{f}} \cdot \mathrm{P}_{\infty}}{\mathrm{E}_{\mathrm{c}}} \cdot\left(\frac{1}{\mathrm{~A}_{\mathrm{c}}}+\frac{\mathrm{e}_{\mathrm{p}}^{2}}{\mathrm{I}_{\mathrm{c}}}\right) \Rightarrow \varepsilon_{\mathrm{cp}}=\frac{\gamma_{\mathrm{f}} \cdot \mathrm{P}_{\infty} \cdot \alpha_{\mathrm{p}}}{\mathrm{E}_{\mathrm{p}}} \cdot\left(\frac{1}{\mathrm{~A}_{\mathrm{c}}}+\frac{\mathrm{e}_{\mathrm{p}}^{2}}{\mathrm{I}_{\mathrm{c}}}\right) \\
& \Rightarrow \varepsilon_{\mathrm{cp}}=\frac{0,9 \cdot 73,40 \cdot 10}{20000} \cdot\left(\frac{1}{66,97}+\frac{0,29^{2}}{445,30}\right) \Rightarrow \varepsilon_{\mathrm{cp}}=0,00050
\end{aligned}
$$

Logo,

$\varepsilon_{\mathrm{pi}}=0,00473$

Utilizando semelhança de triângulos (figura 5.11), pode-se encontrar o valor de $\varepsilon_{\mathrm{p}}$, como mostrado a seguir.

$$
\frac{\varepsilon_{\mathrm{p}}}{\mathrm{d}-\mathrm{x}}=\frac{0,0035}{\mathrm{x}} \Rightarrow \frac{\varepsilon_{\mathrm{p}}}{8,75-1,90}=\frac{0,0035}{1,90} \Rightarrow \varepsilon_{\mathrm{p}}=0,01262
$$

Assim,

$$
\varepsilon_{\mathrm{pi}}+\varepsilon_{\mathrm{p}}=0,01735
$$

que confirmar a validez de $\sigma_{p}=f_{\text {pyd }}$, visto que $f_{\text {pyd }} / E_{p}$ é igual a 0,00591 .

Pode-se observar que $\varepsilon_{\mathrm{p}}>0,0100$ e, portanto, o esgotamento da seção se produzirá por alongamento excessivo do bordo tracionado da seção, antes que o bordo comprimido alcance o encurtamento de $\varepsilon_{\mathrm{c}}$ igual a 0,0035 . 
Pode-se corrigir o valor de $\varepsilon_{\mathrm{p}}$, de modo que a deformação $\varepsilon_{\mathrm{c}}$ fique menor que 0,0100 .

$$
\frac{\varepsilon_{\mathrm{p}}}{\mathrm{d}-\mathrm{x}}=\frac{0,0100}{\mathrm{~h}-\mathrm{x}} \Rightarrow \frac{\varepsilon_{\mathrm{p}}}{8,75-1,90}=\frac{0,0100}{12-1,9} \Rightarrow \varepsilon_{\mathrm{p}}=0,00678
$$

que ainda confirma a validez de $\sigma_{p}=f_{\text {pyd }}$.

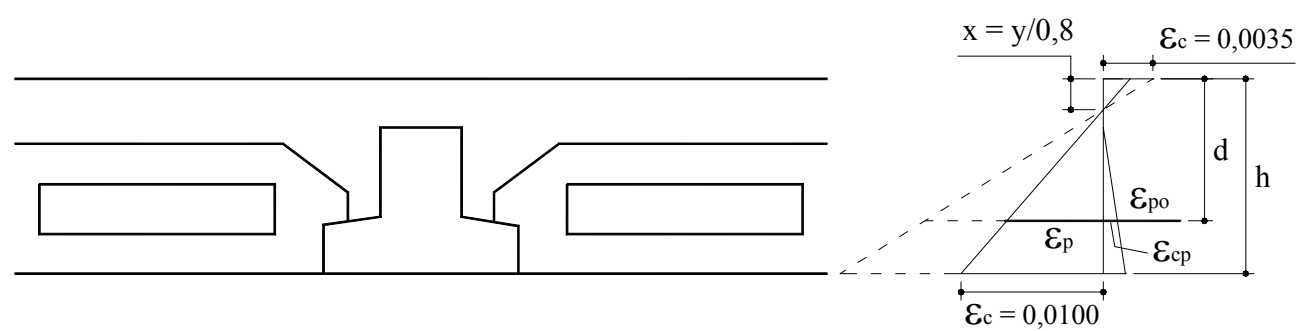

FIGURA 5.11 - Deformações da seção composta

$\mathrm{Na}$ figura 5.10, pode-se verificar que o braço de alavanca $z_{p}$ do par resistente formado pelas forças $0,85 . f_{\mathrm{cd} 2} \cdot \mathrm{A}_{\mathrm{c}}{ }^{\prime}$ e $\mathrm{A}_{\mathrm{p}} \cdot \mathrm{f}_{\mathrm{pyd}}$, vale:

$$
z_{p}=12-3,25-(1,52 / 2) \Rightarrow z_{p}=7,99 \mathrm{~cm}
$$

O momento último da seção composta é o momento resistido por tal par de forças, produto de ambas pelo seu braço. Portanto,

$$
\mathrm{M}_{\mathrm{u}}=\mathrm{A}_{\mathrm{p}} \cdot \mathrm{f}_{\mathrm{pyd}} \cdot \mathrm{z}_{\mathrm{p}} \Rightarrow \mathrm{M}_{\mathrm{u}}=0,78 \cdot 118,26 \cdot 7,99 \Rightarrow \mathrm{M}_{\mathrm{u}}=737,02 \mathrm{kN} \cdot \mathrm{cm}
$$

O valor do momento fletor solicitante máximo atuante será:

$$
\begin{aligned}
& \mathrm{M}_{\mathrm{d}}=1,4 \cdot\left(\mathrm{M}_{\mathrm{g} 1}+\mathrm{M}_{\mathrm{g} 2}+\mathrm{M}_{\mathrm{g} 3}+\mathrm{M}_{\mathrm{R}}+\mathrm{M}_{\mathrm{q}}\right) \\
& \mathrm{M}_{\mathrm{d}}=1,4 \cdot(33,80-48,15+240,75+100,00+250,00) \mathrm{kN} \cdot \mathrm{cm} \\
& \mathrm{M}_{\mathrm{d}}=806,96 \mathrm{kN} \cdot \mathrm{cm}
\end{aligned}
$$

Pode-se verificar que a seção de laje adotada não foi suficiente para absorver os esforços solicitantes normais para o nível de carga utilizado, assim para continuar com o exemplo de laje simplesmente apoiada será mudada a carga de utilização de $2,5 \mathrm{kN} / \mathrm{m}^{2}$ para $2,0 \mathrm{kN} / \mathrm{m}^{2}$, atendendo a verificação para o estado limite último para solicitações normais. 


\section{c) Verificação do estado limite último para solicitações tangenciais}

Para a verificação do estado limite último para solicitações tangenciais, deve-se utilizar a região de concreto moldado no local de $9 \mathrm{~cm}$ de largura e resistência do concreto à compressão de $20 \mathrm{MPa}$, como mostrada na figura 5.12.

Assim,

$$
\begin{aligned}
& \mathrm{V}_{\mathrm{d}} \leq 0,3 \cdot \mathrm{f}_{\mathrm{cd}} \cdot \mathrm{b}_{\mathrm{w}} \cdot \mathrm{d} \\
& \mathrm{V}_{\mathrm{d}} \leq 0,3 \cdot 20 \mathrm{MPa} \cdot 9 \mathrm{~cm} \cdot 8,75 \mathrm{~cm} \Rightarrow \mathrm{V}_{\mathrm{d}} \leq 47,3 \mathrm{kN} \\
& \mathrm{V}_{\mathrm{d}} \leq \mathrm{V}_{\mathrm{u} 2}=2 \cdot \mathrm{f}_{\mathrm{cv}} \cdot \mathrm{b}_{\mathrm{w}} \cdot \mathrm{d} \\
& \mathrm{V}_{\mathrm{d}} \leq 2 \cdot 0,16 \cdot \sqrt{20 / 1,4} \mathrm{MPa} \cdot 9 \mathrm{~cm} \cdot 8,75 \mathrm{~cm} \Rightarrow \mathrm{V}_{\mathrm{d}} \leq 9,5 \mathrm{kN}
\end{aligned}
$$

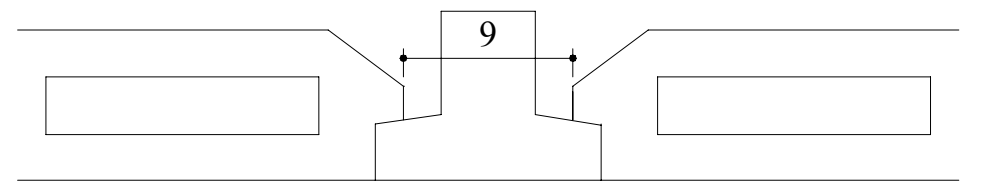

FIGURA 5.12 - Regiões para a verificação da força cortante

Além disso, para que não haja problema com o cisalhamento na interface entre os dois concretos, deve-se verificar ainda:

$$
\begin{aligned}
& \mathrm{V}_{\mathrm{d}} \leq \beta . \text { u.d. } \mathrm{f}_{\mathrm{cv}} \\
& \mathrm{V}_{\mathrm{d}} \leq 1,2.13,8 \mathrm{~cm} .8,75 \mathrm{~cm} .0,16 \cdot \sqrt{20} \mathrm{MPa} \Rightarrow \mathrm{V}_{\mathrm{d}} \leq 10,4 \mathrm{kN}
\end{aligned}
$$

O valor da força cortante máxima na nervura será:

$$
\begin{aligned}
& \mathrm{V}_{\mathrm{d}}=1,4.5,26 \mathrm{kN} \\
& \mathrm{V}_{\mathrm{d}}=7,36 \mathrm{kN}
\end{aligned}
$$

Portanto, está verificado o estado limite último para solicitações tangenciais, já que $V_{d}$ é menor que todos os valores encontrados para $V_{u}$. 


\section{d) Verificação do estado limite de fissuração}

A verificação do estado limite de fissuração será realizada em duas seções da laje:

- Seção 1: seção no meio do vão da laje;

- Seção 2: seção localizada a 93,66 cm do apoio, em que atua o maior valor de momento fletor devido às cargas $g_{1}$ e $g_{2}$. Tal momento fletor possui valor igual a $49,65 \mathrm{kN} . \mathrm{cm}$.

Relembrando do capítulo 2, tem-se:

$\sigma_{1}=\frac{P_{\infty}}{A_{c}}-\frac{P_{\infty} \cdot e_{p}}{W_{1}}-\frac{M_{1}}{W_{1 h}}-\frac{M_{2}}{W_{1 h^{\prime}}}$

sendo:

$M_{1}$ - esforços de flexão na seção antes da solidarização dos concretos;

$\mathrm{M}_{2}$ - esforços de flexão na seção após a solidarização dos concretos;

Portanto,

\section{Seção 1:}

Combinação rara:

$$
\begin{aligned}
& \sigma_{1}=\frac{73,40}{66,97}-\frac{73,40 \cdot(-0,29)}{125,79}+\frac{(-33,80+48,15)}{136,34}+\frac{(-240,75-50-200)}{368,05} \\
& \sigma_{1}=0,04 \mathrm{kN} / \mathrm{cm}^{2}(\text { ELS de Descompressão respeitado) }
\end{aligned}
$$

Combinação freqüente:

$$
\begin{aligned}
& \sigma_{1}=\frac{73,40}{66,97}-\frac{73,40 \cdot(-0,29)}{125,79}+\frac{(-33,80+48,15)}{136,34}+\frac{(-240,75-50-0,3 \cdot 200)}{368,05} \\
& \sigma_{1}=0,42 \mathrm{kN} / \mathrm{cm}^{2} \text { (ELS de Descompressão respeitado) }
\end{aligned}
$$

\section{Seção 2:}

Combinação rara:

$$
\sigma_{1}=\frac{73,40}{66,97}-\frac{73,40 \cdot(-0,29)}{125,79}+\frac{(-49,65)}{136,34}+\frac{(-112,74-71,73-143,46)}{368,05}
$$


$\sigma_{1}=0,01 \mathrm{kN} / \mathrm{cm}^{2}$ (ELS de Descompressão respeitado)

Combinação freqüente:

$$
\begin{aligned}
& \sigma_{1}=\frac{73,40}{66,97}-\frac{73,40 \cdot(-0,29)}{125,79}+\frac{(-49,65)}{136,34}+\frac{(-112,74-71,73-0,3 \cdot 143,46)}{368,05} \\
& \sigma_{1}=0,28 \mathrm{kN} / \mathrm{cm}^{2} \text { (ELS de Descompressão respeitado) }
\end{aligned}
$$

Pelos resultados pode-se verificar que a laje estará trabalhando com protensão completa, assim, a laje poderá estar localizada em um ambiente com alto nível de agressividade (muito agressivo).

\section{e) Verificação do estado limite de deformação excessiva}

Utilizando o programa computacional descrito no capítulo 3, pôde-se determinar os deslocamentos que a laje irá apresentar para a carga de serviço. A carga de serviço foi determinada utilizando a combinação quase-permanente de ações.

$$
\begin{aligned}
& \text { Ou seja, } \\
& \mathrm{F}_{\mathrm{d}, \mathrm{uti}}=\mathrm{F}_{\mathrm{g}, \mathrm{k}}+0,2 \cdot \mathrm{F}_{\mathrm{q}, \mathrm{k}} \\
& \text { com: } \mathrm{F}_{\mathrm{g}, \mathrm{k}}=\mathrm{g}_{1}+\mathrm{g}_{2}+\mathrm{g}_{3} \\
& \mathrm{~F}_{\mathrm{q}, \mathrm{k}}=\mathrm{q}
\end{aligned}
$$

Os deslocamentos ao longo do eixo longitudinal da laje podem ser vistos na figura 5.13 .

O deslocamento máximo obtido foi de $0,755 \mathrm{~cm}$. Embora não tenham sido considerados os efeitos ao longo do tempo para a determinação desse deslocamento, o valor obtido está muito aquém do limite estabelecido por norma, como pode ser verificado pelo item 2.4.4 do capítulo 2, sendo que tal deslocamento equivale a $1 / 530$ do vão $(\ell / 530)$. 


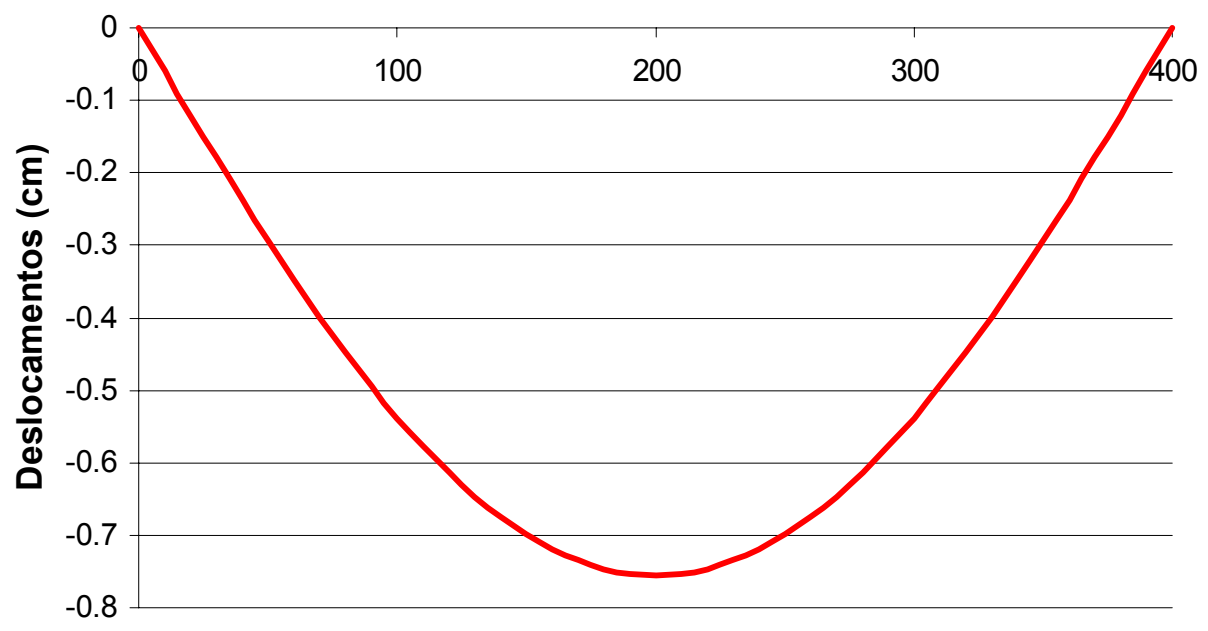

FIGURA 5.13 - Deslocamentos para a situação de serviço

$\mathrm{Na}$ figura 5.14 pode-se observar a evolução dos deslocamentos máximos ocorridos na laje biapoiada. Como se pode ver pela figura a laje não apresentará fissuras para a situação em serviço.

Pode-se determinar ainda o deslocamento da laje devido à carga acidental, que é obtido através da subtração entre o deslocamento devido à carga total e o deslocamento devido à carga permanente. Tal valor foi de $0,406 \mathrm{~cm}(1,069$ menos 0,663 ), sendo menor que o valor de $\ell / 350$ especificado pelo projeto de revisão da NBR-6118:2000 (ver tabela 2.5).

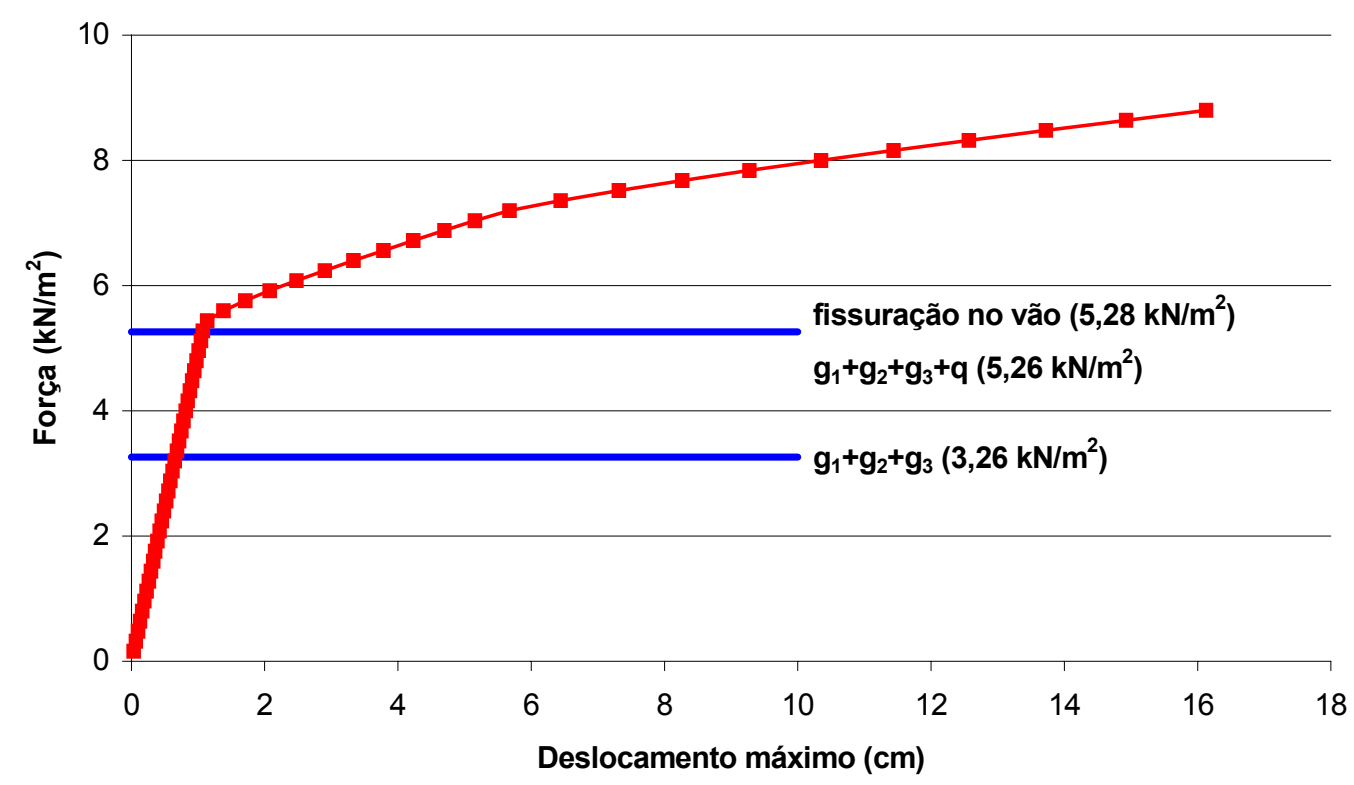

FIGURA 5.14 - Deslocamentos máximos - laje biapoiada 


\subsection{Parte 2: laje contínua}

A laje adotada não foi capaz de suportar a carga de utilização de $2,5 \mathrm{kN} / \mathrm{m}^{2}$ para a situação biapoiada, pois o máximo valor de momento fletor que essa seção suporta é de 737,02 kN.cm e, para situação biapoiada, o valor de momento fletor de cálculo seria de $806,96 \mathrm{kN}$.cm. Uma solução para esse problema seria aumentar a altura da seção transversal da seção, mas se existissem tramos consecutivos de lajes, uma melhor opção seria utilizar a continuidade no apoio, ocorrendo uma melhor distribuição dos esforços. Foi essa a solução que está sendo apresentada neste item.

Para o exemplo em questão, um valor razoável de grau de redistribuição do momento fletor no apoio a ser adotado no dimensionamento é de $40 \%$, conforme verificado no capítulo 4 (tabela 4.12). Assim, esse foi o valor utilizado para a situação de laje contínua apresentada a seguir.

\section{a) Determinação dos diagramas de esforços solicitantes}

$\mathrm{Na}$ figura 5.15, estão apresentados os diagramas de momento fletor para o tramo esquerdo do exemplo. Pela figura pode-se verificar a atuação sobre a vigota de seu peso próprio, do peso do material de enchimento e do concreto moldado no local. Após a solidarização entre os concretos, considerando redistribuição de $40 \%$ no apoio, começa a atuar uma força equivalente devido à retirada do escoramento, além dos esforços oriundos da sobrecarga permanente e carga de utilização. 


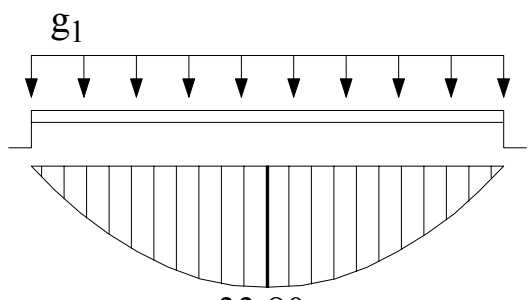

33,80

(a) peso próprio da vigota

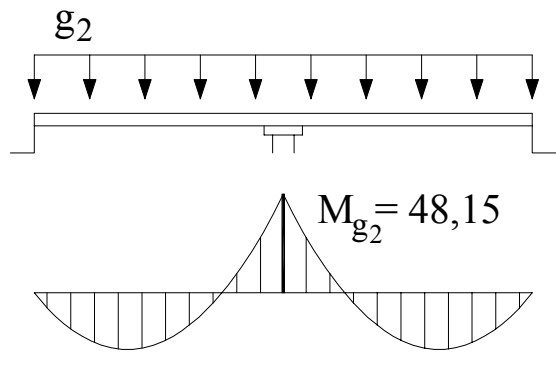

(b) peso do material de enchimento e do concreto moldado no local
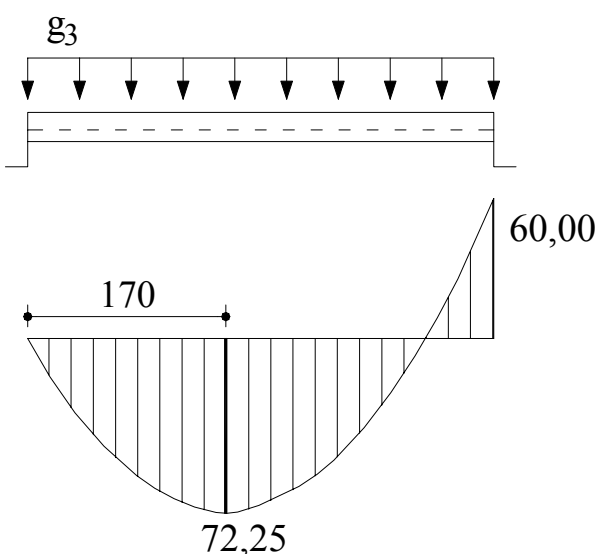

(d) sobrecarga de revestimento

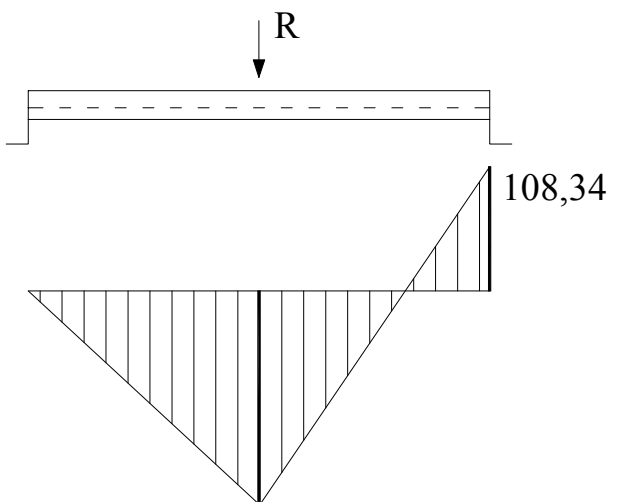

186,58

(c) reação após retirar a escora

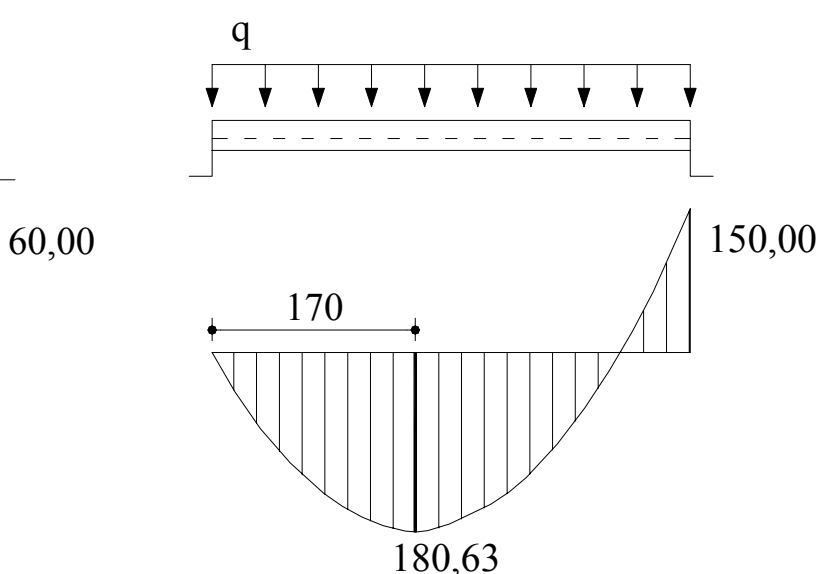

(e) carga de utilização

FIGURA 5.15 - Diagramas de momento fletor atuantes na laje (valores em kN.cm) 
Os diagramas de força cortante para o tramo esquerdo do exemplo estão apresentados na figura 5.16 .

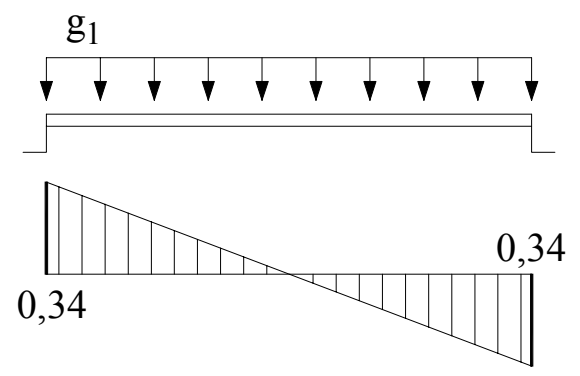

(a) peso próprio da vigota
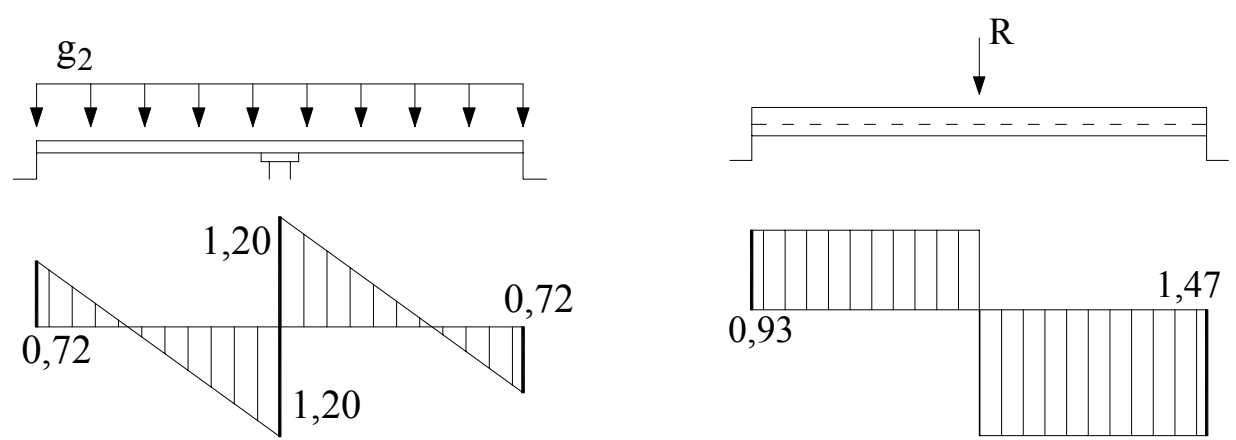

(b) peso do material de enchimento e

(c) reação após retirar a escora do concreto moldado no local
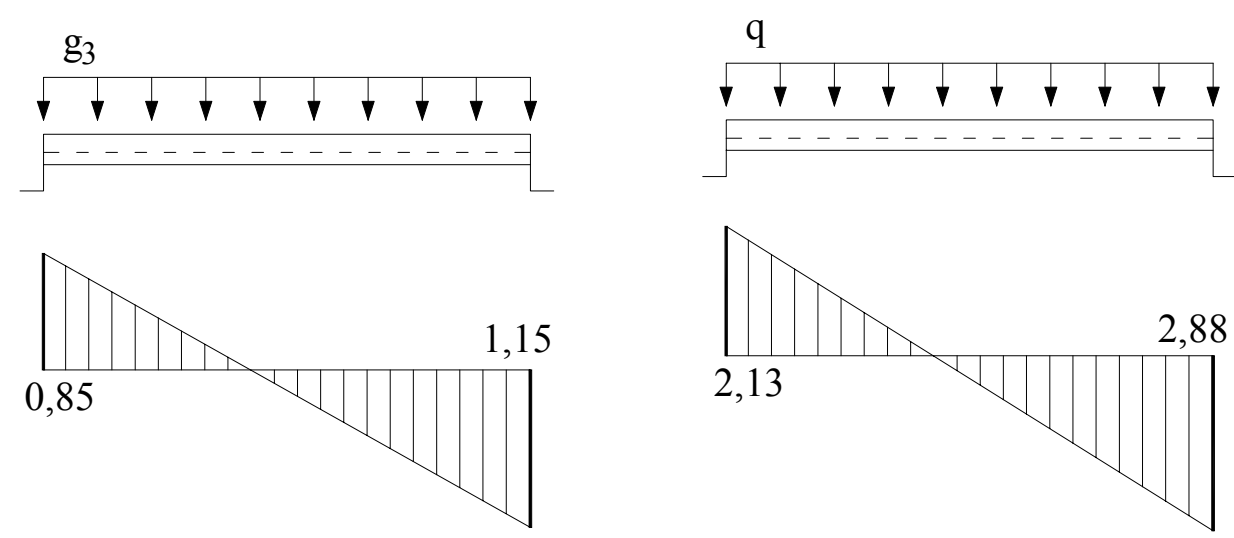

(d) sobrecarga de revestimento

(e) carga de utilização

FIGURA 5.16 - Diagramas de força cortante atuante na laje (valores em kN) 


\section{b) Verificação do estado limite último para solicitações normais}

- Verificação do momento fletor positivo máximo

O valor do momento máximo positivo de cálculo no vão está localizado a $172,39 \mathrm{~cm}$ do apoio externo com valor de 599,51 kN.cm. Esse valor está abaixo do valor último de $737,02 \mathrm{kN} . \mathrm{cm}$ resistido pela seção, calculado anteriormente e, portanto, verificando o estado limite último para solicitações normais para as seções do vão com momento fletor positivo.

- Determinação da armadura de continuidade

Pelos diagramas de momento fletor da figura 5.15, pode-se verificar que o valor do momento fletor de cálculo que atuará no apoio interno da laje será:

$$
\begin{aligned}
& M_{d}=1,4 \cdot(108,34+60,00+150,00) \mathrm{kN} \cdot \mathrm{cm} \\
& M_{d}=445,68 \mathrm{kN} \cdot \mathrm{cm}
\end{aligned}
$$

Considerando a utilização de armadura formada por aço CA-50 e utilizando 1,5 cm de cobrimento da armadura, a quantidade de armadura necessária para absorver esse momento fletor será de $4 \phi 6,3$ para cada nervura.

- Verificação do momento fletor negativo

Considerando que a laje seja apoiada em parede com largura de $20 \mathrm{~cm}$ e o material de enchimento fique $10 \mathrm{~cm}$ distante da face desta parede, tem-se o valor máximo de momento fletor negativo, atuante na seção composta da laje, localizado a $20 \mathrm{~cm}$ do apoio interno (seção B da figura 5.17).

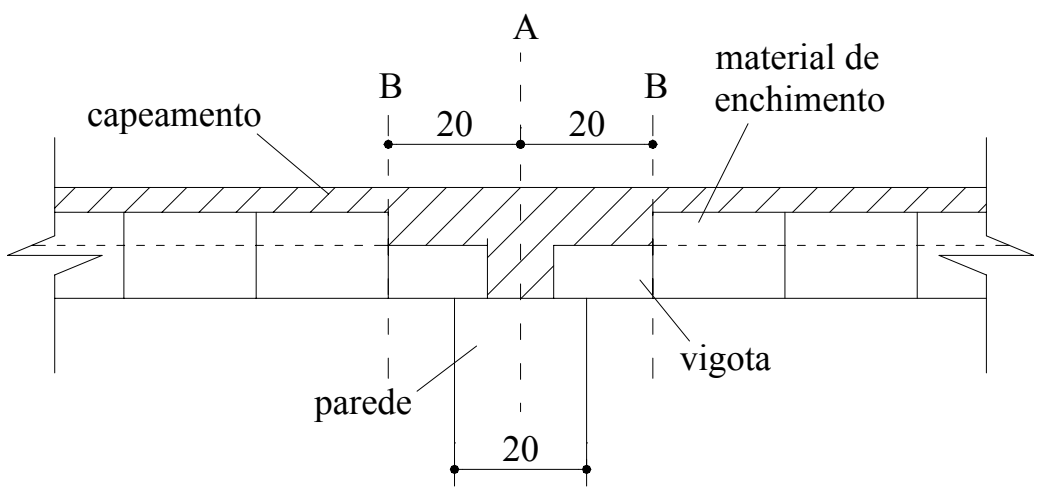

FIGURA 5.17 - Seção de verificação da laje (apoio) 
Portanto, deve-se verificar se a armadura presente no apoio será suficiente para absorver o valor máximo de momento fletor negativo atuante na seção composta da laje (seção B). Para isso, determina-se o valor do momento último $\mathrm{M}_{\mathrm{u}}$ da seção composta.

Inicialmente, serão definidos os valores de resistência de cálculo dos materiais utilizados.

concreto pré-moldado: $\mathrm{f}_{\mathrm{cd}, 1}=2,69 \mathrm{kN} / \mathrm{cm}^{2}$;

concreto moldado no local: $\mathrm{f}_{\mathrm{cd}, 2}=1,43 \mathrm{kN} / \mathrm{cm}^{2}$;

armadura: $\mathrm{f}_{\mathrm{yd}}=\frac{\mathrm{f}_{\mathrm{yk}}}{1,15} \Rightarrow \mathrm{f}_{\mathrm{yd}}=43,48 \mathrm{kN} / \mathrm{cm}^{2}$.

Suponha-se, em princípio, que a linha neutra passe pela capa de concreto moldada no local, ou seja, $y \leq 3 \mathrm{~cm}$. Com esta hipótese, estabelecendo a equação de equilíbrio das forças atuantes na seção para $\mathrm{M}_{\mathrm{u}}$ negativo, como ilustrado na figura 5.18, tem-se:

$0,85 \cdot f_{\mathrm{cd}, 1} \cdot \mathrm{A}_{\mathrm{c}}=\mathrm{A}_{\mathrm{s}} \cdot \mathrm{f}_{\mathrm{yd}}$

Portanto,

0,85.2,69.12.y $=1,25 \cdot 43,48 \Rightarrow \mathrm{y}=1,98 \mathrm{~cm}$

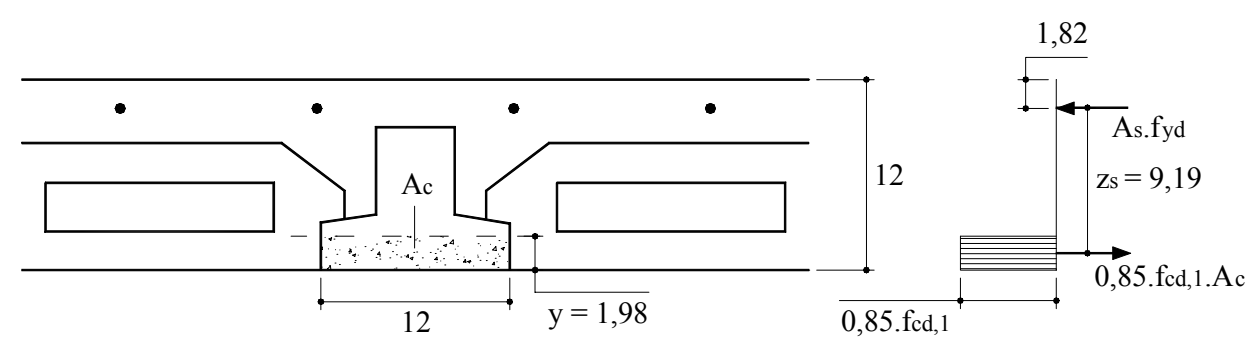

FIGURA 5.18 - Equilíbrio das forças na seção da laje para momento fletor negativo

Como a hipótese assumida é válida, deve-se verificar a validez de $\sigma_{\mathrm{s}}=\mathrm{f}_{\mathrm{yd}}$, que exige:

$$
\varepsilon_{\mathrm{s}} \geq \varepsilon_{\mathrm{yd}}
$$


Ou seja, para o estado limite último a seção deverá estar no domínio 2 ou 3. Isso será verificado, para o caso de utilização de barras CA-50, se:

$$
\begin{aligned}
& \mathrm{x} / \mathrm{d}<0,259 \Rightarrow \text { Domínio } 2 \\
& 0,259<\mathrm{x} / \mathrm{d}<0,628 \Rightarrow \text { Domínio } 3
\end{aligned}
$$

Para a caso em questão $\mathrm{x} / \mathrm{d}=0,283$. Indicando que o domínio em que a seção atingirá o estado limite último será o Domínio 3, atendendo a validez anterior.

$\mathrm{Na}$ figura 5.18, pode-se verificar ainda que o braço de alavanca $z_{\mathrm{s}}$ do par resistente formado pelas forças $0,85 \cdot f_{c d} \cdot A_{c}{ }^{\prime}$ e $A_{p} \cdot f_{p y d}$, vale:

$$
\mathrm{z}_{\mathrm{s}}=12-1,82-(1,98 / 2) \Rightarrow \mathrm{z}_{\mathrm{s}}=9,19 \mathrm{~cm}
$$

O momento último da seção composta é o momento resistido por tal par de forças, produto de ambas pelo seu braço. Portanto,

$$
\mathrm{M}_{\mathrm{u}}=\mathrm{A}_{\mathrm{s}} \cdot \mathrm{f}_{\mathrm{yd}} \cdot \mathrm{z}_{\mathrm{s}} \Rightarrow \mathrm{M}_{\mathrm{u}}=1,25 \cdot 43,48 \cdot 9,19 \Rightarrow \mathrm{M}_{\mathrm{u}}=499,48 \mathrm{kN} \cdot \mathrm{cm}
$$

O valor do momento fletor negativo máximo atuante sobre a laje será na seção B, mostrada anteriormente, com o seguinte valor:

$$
\begin{aligned}
& \mathrm{M}_{\mathrm{d}}=1,4 \cdot(78,85+38,00+95,00) \mathrm{kN} \cdot \mathrm{cm} \\
& \mathrm{M}_{\mathrm{d}}=296,59 \mathrm{kN} . \mathrm{cm}
\end{aligned}
$$

Portanto, está verificado o estado limite último para solicitações normais.

\section{c) Verificação do estado limite último para solicitações tangenciais}

O valor do esforço cortante máximo atuante na seção composta será na seção B, mostrada na figura 5.17, apresentado o seguinte valor:

$$
\begin{aligned}
& \mathrm{V}_{\mathrm{d}}=1,4 \cdot\left(\mathrm{V}_{\mathrm{g} 1}+\mathrm{V}_{\mathrm{g} 2}+\mathrm{V}_{\mathrm{R}}+\mathrm{V}_{\mathrm{g} 3}+\mathrm{V}_{\mathrm{q}}\right) \mathrm{kN} \\
& \mathrm{V}_{\mathrm{d}}=1,4 \cdot(0,31+0,53+1,47+1,05+2,63) \mathrm{kN} \\
& \mathrm{V}_{\mathrm{d}}=8,39 \mathrm{kN}
\end{aligned}
$$


O valor da força cortante máxima solicitante na seção é menor que o valor último resistido pela seção $(9,5 \mathrm{kN})$, portanto, está verificado o estado limite último para solicitações tangenciais.

\section{d) Verificação do estado limite de fissuração}

A verificação do estado limite de fissuração será realizada em duas seções da laje:

- Seção 1: seção localizada a $172,39 \mathrm{~cm}$ do apoio externo, em que atua o maior valor de momento fletor total;

- Seção 2: seção localizada a 93,66 cm do apoio, em que atua o maior valor de momento fletor devido às cargas $\mathrm{g}_{1}$ e $\mathrm{g}_{2}$, sendo esse momento igual a $49,65 \mathrm{kN} . \mathrm{cm}$.

Relembrando do capítulo 2, tem-se:

$\sigma_{1}=\frac{P_{\infty}}{A_{c}}-\frac{P_{\infty} \cdot e_{p}}{W_{1}}-\frac{M_{1}}{W_{1 h}}-\frac{M_{2}}{W_{1 h}{ }^{\prime}}$

sendo:

$M_{1}$ - esforços de flexão na seção antes da solidarização dos concretos;

$\mathrm{M}_{2}$ - esforços de flexão na seção após a solidarização dos concretos;

Portanto,

\section{Seção 1:}

Combinação rara:

$$
\begin{aligned}
& \sigma_{1}=\frac{73,40}{66,97}-\frac{73,40 \cdot(-0,29)}{125,79}+\frac{(-33,16+18,59)}{136,34}+\frac{(-160,82-72,24-180,59)}{368,05} \\
& \sigma_{1}=0,03 \mathrm{kN} / \mathrm{cm}^{2} \text { (ELS de Descompressão respeitado) }
\end{aligned}
$$

Combinação freqüente:

$$
\sigma_{1}=\frac{73,40}{66,97}-\frac{73,40 \cdot(-0,29)}{125,79}+\frac{(-33,16+18,59)}{136,34}+\frac{(-160,82-72,24-0,3 \cdot 180,59)}{368,05}
$$


$\sigma_{1}=0,38 \mathrm{kN} / \mathrm{cm}^{2}$ (ELS de Descompressão respeitado)

\section{Seção 2:}

Combinação rara:

$$
\begin{aligned}
& \sigma_{1}=\frac{73,40}{66,97}-\frac{73,40 \cdot(-0,29)}{125,79}+\frac{(-49,65)}{136,34}+\frac{(-87,38-57,68-144,20)}{368,05} \\
& \sigma_{1}=0,12 \mathrm{kN} / \mathrm{cm}^{2} \text { (ELS de Descompressão respeitado) }
\end{aligned}
$$

Combinação freqüente:

$$
\begin{aligned}
& \sigma_{1}=\frac{73,40}{66,97}-\frac{73,40 \cdot(-0,29)}{125,79}+\frac{(-49,65)}{136,34}+\frac{(-87,38-57,68-0,3 \cdot 144,20)}{368,05} \\
& \sigma_{1}=0,39 \mathrm{kN} / \mathrm{cm}^{2}(\text { ELS de Descompressão respeitado) }
\end{aligned}
$$

Pelos resultados obtidos, pode-se observar que a seção do vão não apresentará fissuras, atendendo a condição de protensão completa. No entanto, devese ressaltar que a laje irá trabalhar como elemento contínuo, assim no apoio existirá uma região de concreto armado. E como o concreto moldado no local utilizado nessa região foi C20, o projeto de revisão da NBR-6118:2000 especifica que a laje deverá estar exposta a ambientes com baixa agressividade, ou seja, ambientes internos com revestimento de argamassa e pintura.

\section{e) Verificação do estado limite de deformação excessiva}

Os deslocamentos que a laje irá apresentar para a carga de serviço foram determinados utilizando o programa computacional descrito no capítulo 3. Assim como feito para a situação simplesmente apoiada, a carga de serviço foi determinada utilizando a combinação quase-permanente de ações.

Os deslocamentos ao longo do eixo longitudinal da laje podem ser vistos na figura 5.19 .

O deslocamento máximo obtido foi de $0,385 \mathrm{~cm}$, na seção localizada a $220 \mathrm{~cm}$ do apoio interno. Tal valor corresponde a 50\% do deslocamento máximo encontrado para o caso anterior, em que a laje foi dimensionada considerando biapoiada, mesmo com o valor da carga de utilização ter aumentado $25 \%$. 
Esse valor obtido corresponde a 1/1039 do vão, ou seja, $\ell / 1039$, muito abaixo dos valores prescritos pelas normas.

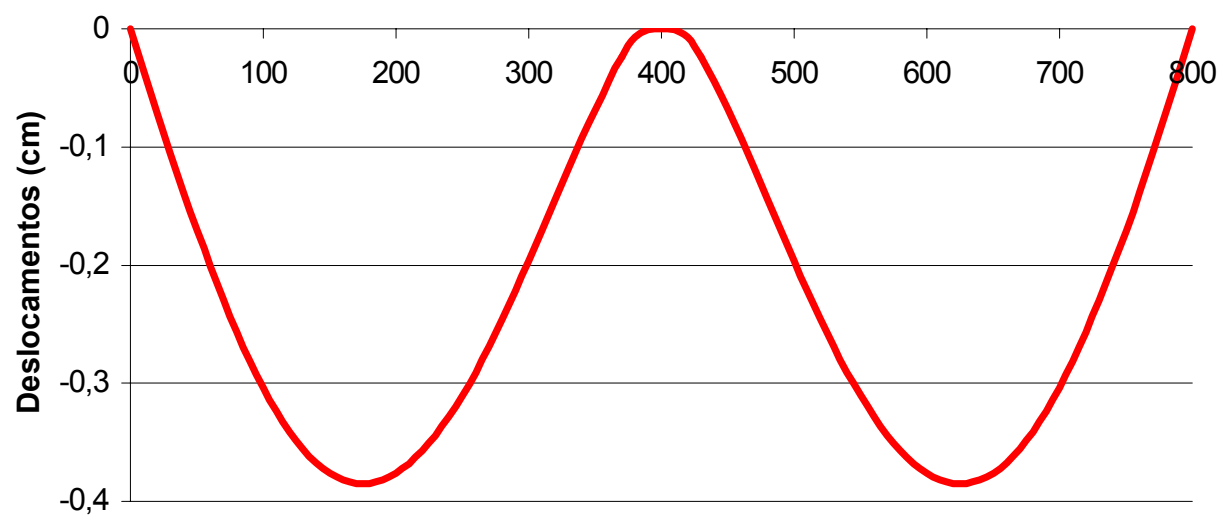

FIGURA 5.19 - Deslocamentos para a situação de serviço

Na figura 5.20 pode-se observar a evolução dos deslocamentos máximos ocorridos na laje contínua. Como se pode ver pela figura a laje não apresentará fissuras no vão para a situação em serviço.

O valor do deslocamento da laje devido à carga acidental, que é obtido através da subtração entre o deslocamento devido à carga total e o deslocamento devido à carga permanente, foi de $0,327 \mathrm{~cm}(0,647$ menos 0,320$)$, sendo menor que $\ell / 350$, especificado pelo projeto de revisão da $N B R-6118: 2000$ (ver tabela 2.5).

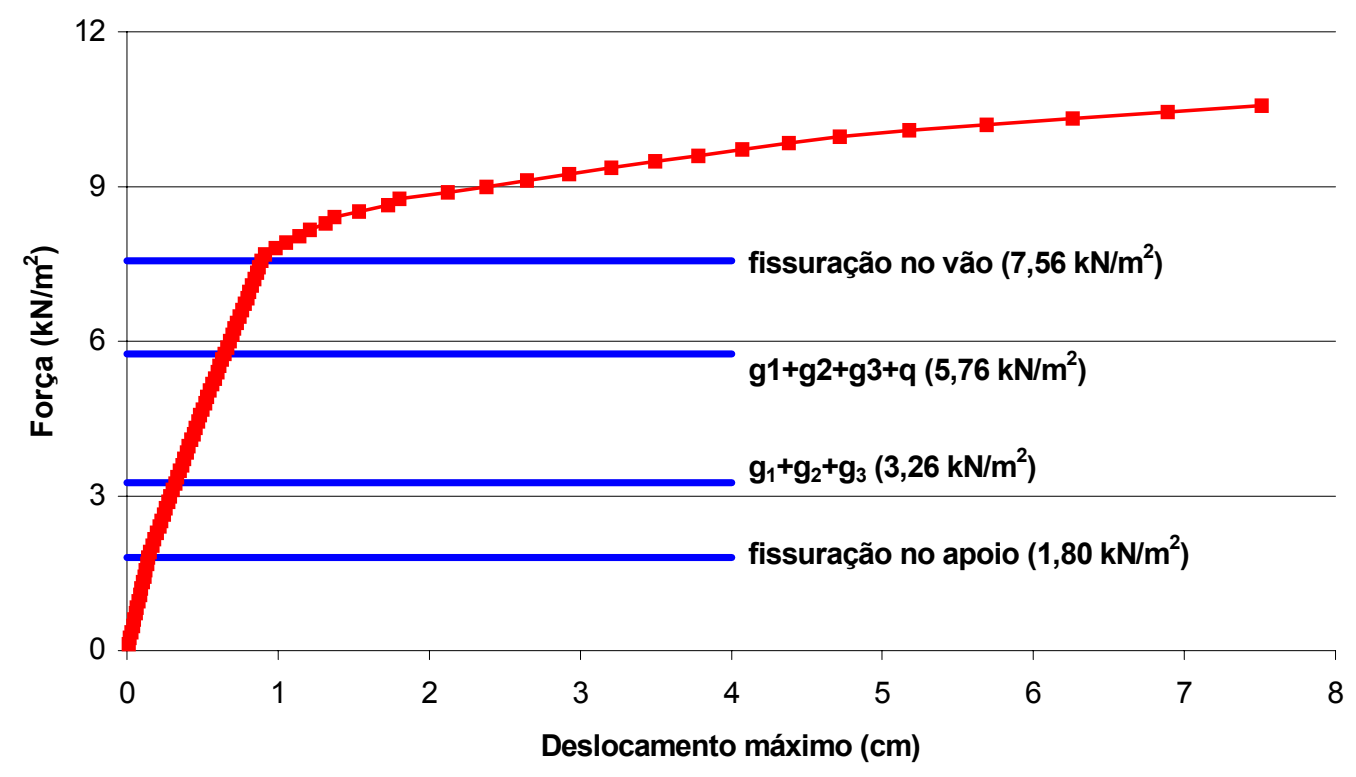

FIGURA 5.20 - Deslocamentos máximos - laje contínua 


\section{CONSIDERAÇÕES FINAIS E CONCLUSÕES}

Neste trabalho procurou-se fazer uma avaliação do comportamento estrutural de lajes formadas por elementos pré-moldados tipo nervuras protendidas, mediante estudo teórico dos momentos fletores negativos junto aos apoios de lajes unidirecionais contínuas para carregamento externo incremental. Esse estudo foi realizado através de simulações numéricas em situações representativas de projeto, através da utilização de lajes com vãos de 4,0, 6,0 e 8,0 m e vários graus de redistribuição de momento fletor no apoio.

Inicialmente o modelo teórico adotado foi avaliado através de comparações entre valores experimentais encontrados na literatura. Pelos resultados obtidos dessas comparações (capítulo 3), pôde-se verificar que a utilização da relação momento $x$ curvatura do CEB-90 (1991) em conjunto com a técnica de carregamento incremental representa satisfatoriamente o comportamento estrutural de lajes formadas por elementos pré-moldados protendidos.

A partir disso, fez-se a análise teórica dos casos representativos de projeto, chegando-se às seguintes conclusões:

a) Para todos os casos analisados o processamento foi interrompido por se atingir a curvatura última na seção que formou a rótula plástica.

b) Pôde-se verificar pelas análises teóricas que, independente do grau de redistribuição de momentos fletores negativos adotado no dimensionamento, os casos apresentaram valores de deslocamentos próximos entre si, começando a se diferenciar quando ocorreu a físsuração no vão da laje. 
c) Pelas análises, pôde-se verificar a vantagem na utilização da continuidade no apoio, sendo que, sem a consideração da continuidade os deslocamentos máximos, para a situação de serviço, aumentaram $95,1 \%, 83,5 \%$ e $289,2 \%$, respectivamente para os casos de 4,0, 6,0 e $8,0 \mathrm{~m}$ de vão. Isso também foi verificado no exemplo do capitulo 5 , em que o valor do deslocamento máximo para situação de serviço, no caso de laje contínua com redistribuição de $40 \%$ no apoio, foi aproximadamente metade do deslocamento máximo encontrado para o caso biapoiado, mesmo com a carga de utilização considerada para este ser $25 \%$ superior.

d) Pelo exemplo realizado no capítulo 5, pôde-se também verificar a principal vantagem da utilização das lajes formadas por elementos prémoldados tipo vigota protendida, que é a economia relacionada ao escoramento. No exemplo em questão, para um vão de 4,0 m houve necessidade de utilização de apenas uma linha de escoras.

e) Pôde-se verificar que para todos os casos analisados a evolução do momento fletor negativo para a seção crítica e do máximo momento fletor positivo apresentaram três trechos principais retos, sendo que o primeiro trecho vai do ponto zero até o ponto em que ocorre a fissuração no apoio, o segundo trecho começa nesse ponto e vai até o instante em que ocorre a fissuração no vão da laje e o terceiro trecho acaba quando se atinge o momento último na seção crítica.

f) Independente do grau de redistribuição de momentos fletores negativos adotado no dimensionamento houve também uma boa concordância entre os casos com relação ao nível de carga em que ocorreu a fissuração do apoio e do vão, ou seja, houve uma boa aproximação da evolução do momento fletor negativo para a seção crítica (seção que atingiu $\mathrm{M}_{\mathrm{U}}$ ) e do máximo momento fletor no vão até o ponto em que ocorreu a fissuração da seção do vão.

g) Pelos resultados obtidos da análise dos casos, pôde-se verificar que os valores que melhor representaram o grau de redistribuição do momento fletor negativo no apoio variou para cada vão analisado, assim, não foi 
possível propor um valor que se aplicasse para todas as situações. Isso só seria possível se fosse realizado grande quantidade de simulações variando as dimensões da laje, resistência dos materiais, número de vãos e grau de redistribuição dos momentos fletores, de modo a cobrir todas as situações possíveis.

h) Para os casos analisados, o valor de 15\% recomendado pela norma espanhola EF-96 (1997) para o grau de redistribuição do momento fletor negativo estaria contra a segurança, com o valor do momento fletor no vão podendo ultrapassar o previsto no dimensionamento. Já os graus de redistribuição recomendados pela publicação francesa CPT Plachers (1980) seriam mais razoáveis, pois admite valores maiores de redistribuição.

Como complementação deste trabalho de pesquisa sugere-se a realização de ensaios de lajes contínuas formadas por vigotas pré-moldadas protendidas para se ter um maior embasamento a respeito das conclusões obtidas nesse trabalho.

Sugere-se ainda a realização da análise teórico-experimental em estruturas formadas por esse tipo de elemento sujeitas à carga de longa duração, analisando os efeitos dependentes do tempo nos deslocamentos e redistribuição de momentos fletores. 


\section{BIBLIOGRAFIA}

\section{Referências Bibliográficas}

ASSOCIAÇÃO BRASILEIRA DE NORMAS TÉCNICAS. (1978). NBR 6118 -

Projeto e execução de obras de concreto armado. Rio de Janeiro.

ASSOCIAÇÃO BRASILEIRA DE NORMAS TÉCNICAS. (1984). NBR 8681 Ações e segurança nas estruturas. Rio de Janeiro.

ASSOCIAÇÃO BRASILEIRA DE NORMAS TÉCNICAS. (1989). NBR 7197 -

Projeto de estruturas em concreto protendido. Rio de Janeiro.

ASSOCIAÇÃO BRASILEIRA DE NORMAS TÉCNICAS. (2000). Projeto de revisão da NBR 6118 - Projeto e execução de obras de concreto armado. Rio de Janeiro.

ASSOCIAÇÃO BRASILEIRA DE NORMAS TÉCNICAS. (2001) Projeto de norma para Laje pré-fabricada. CE - 18:314.01. Rio de Janeiro.

CALAVERA, J. (1989). Cálculo, Construcción y Patologia de Forjados de

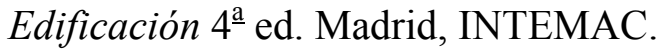

CARVALHO, R.C. (1994). Análise não-linear de Pavimentos de Concreto através da Analogia de Grelha. São Carlos. 207p. Tese (Doutorado) - Escola de Engenharia de São Carlos, Universidade de São Paulo.

CENTRE DE RECHERCHE ET D'EXPERIMENTATION SARET. (1978). Componenti in c.a.p. La Prefabbricazione ITEC/La prefabricazione. Milano.

COMITE EURO-INTERNACIONAL DU BETON (1991). CEB-FIP model code 1990. Bulletin d'Information, n. 203-205. 
COMITE EURO-INTERNACIONAL DU BETON (1998). Ductility of reinforced concrete structures. Bulletin d'Information, n. 242.

CPT Planchers - Cahiers des prescriptions techniques communes aux procédés de planchers (1980). Cahiers du centre scientifique et technique du batiment, n. 212.

DROPPA Jr., A. (1999) Análise estrutural de lajes formadas por vigotas prémoldadas com armação treliçada. São Carlos. 177p. Dissertação (Mestrado) Escola de Engenharia de São Carlos, Universidade de São Paulo.

EL DEBS, M.K. (2000). Concreto pré-moldado: fundamentos e Aplicações. São Carlos. Projeto REENGE. EESC - USP.

ESPANHA. Ministério de Fomento (1997). EF-96 - Instruccion para el proyecto y la ejecucion de forjados unidireccionales de hormigon armado o pretensado.

ESPANHA. Ministério de Fomento (1980). EP-80 - Instruccion para el proyecto y la ejecucion de obras de hormigon pretensado.

FÉDÉRATION INTERNACIONALE DU BETON (1998). Composite floor structures, guide to good practice.

FÉDÉRATION INTERNACIONALE DU BETON (1999). Structural concrete: textbook on behaviour, design and performance updated of the CEB/FIP model code 1990, fib Bulletin, v.1.

GASTAL, F.P.S.L. \& REZENDE, R.S. (1999). Análise numérica e experimental de lajes pré-moldadas protendidas com continuidade posterior por adição de sobrecamada de concreto armado. $41^{\circ}$ REIBRAC, Salvador.

GASTAL, F.P.S.L. \& SCHWINGEL, R.C. (1995). Dimensionamento automático de vigas isostáticas com protensão total ou parcial, por aderência inicial. XXVII Jornadas Sulamericanas de engenharia Estrutural, Tucumán, Argentina.

KODUR,V. \& CAMPBELL, K. (1990). Deformation controlled nonlinear analysis of prestressed concrete continuous beams. PCI Journal, v.35, n.5, p.42-55, setembro, outubro.

KODUR,V. \& CAMPBELL, K. (1996). Evaluation of moment redistribution in twospan continuous prestressed concrete beam. ACI Structural Journal, v.93, n.6, p.721-728, novembro, dezembro.

HAMBLY, E.C. (1991). Bridge deck behavior. 2.ed. London, Chapman and Hall. 
LEONHARDT, F \& MONNIG, E. (1982). Construções de concreto: princípios básicos do dimensionamento de estruturas de concreto armado. Vol. $12^{\mathrm{a}}$ ed. Rio de Janeiro, Editora Interciência.

LEONHARDT, F \& MONNIG, E.(1982). Construções de concreto: verificação da capacidade de utilização. Vol. $42^{\mathrm{a}}$ ed. Rio de Janeiro, Editora Interciência.

MAGALHÃES, F.L. (2001). Estudo dos momentos fletores negativos nos apoios de lajes formadas por elementos pré-moldados tipo nervuras com armação treliçada. São Carlos. 135p. Dissertação (Mestrado) - Escola de Engenharia de São Carlos, Universidade de São Paulo.

MULLER, J.P. (1991). Element or lattice girder floors - conventionaly reinforced and prestressed with costing examples. Betonwerk+BFT + Fertigteil Technik (Concrete Precasting Plant), 4/91 (1), 44 - 50

MUNIZ, C.E. (1991). Mais competitivas: lajes treliçadas. Revista IBRACON, v.1, n.1, p.19-21, julho, agosto.

MARCELLINO, N.A. (2001). Ligação laje-viga de estruturas pré-fabricadas de concreto. São Paulo. 221p. Tese (Doutorado) - Escola Politécnica da Universidade de São Paulo.

PRIESTLEY, M.J.N.; PARK, R.; LU, F.P.S. (1971). Moment-curvature relationships for prestressed concrete in constant-moment zones. Magazine of Concrete Research. v.23, n. 75-76, p.69-78, junho-setembro.

VASCONCELOS, A.C.; FERREIRA, M.O. (1984). Colóquio sobre concreto protendido: Cálculo atualizado de peças pré-moldadas protendidas complementadas com concreto local. São Paulo. IBRACON.

\section{Bibliografia Complementar}

ANDRADE, J.M.M. (1994). Contribuição ao cálculo dos momentos fletores dependentes do tempo em vigas de pontes pré-moldadas protendidas com a continuidade estabelecida no local. São Carlos. 161p. Dissertação (Mestrado) Escola de Engenharia de São Carlos, Universidade de São Paulo.

ASSOCIAÇÃO BRASILEIRA DE NORMAS TÉCNICAS. (1980). NBR 6120 Cargas para o cálculo de estruturas de edificações. Rio de Janeiro. 
ASSOCIAÇÃO BRASILEIRA DE NORMAS TÉCNICAS. (1985). NBR 7480 Barras e fios destinados a armaduras para concreto armado-Especificação. Rio de Janeiro.

ASSOCIAÇÃO BRASILEIRA DE NORMAS TÉCNICAS. (1990). NBR 7481 Telas de aço soldadas para armadura de concreto - Especificação. Rio de Janeiro.

ASSOCIAÇÃO BRASILEIRA DE NORMAS TÉCNICAS. (1991). NBR 7482 Fios de aço para concreto protendido - Especificação. Rio de Janeiro.

BARBOZA, A.S.R. (1992). Contribuição à análise estrutural de sistemas lajes-vigas de concreto armado mediante analogia de grelha. São Carlos. 129p. Dissertação (Mestrado) - Escola de Engenharia de São Carlos, Universidade de São Paulo.

BORGES, J. (1997). Critérios de projeto de lajes nervuradas com vigotas prémoldadas. São Paulo. 116p. Dissertação (Mestrado) - Escola Politécnica da Universidade de São Paulo.

BOCHI Jr., C.F. (1995). Lajes nervuradas de concreto armado: projeto e execução. São Carlos. 183p. Dissertação (Mestrado) - Escola de Engenharia de São Carlos, Universidade de São Paulo.

DINIZ, H. (1988). Lajes com armação em treliça. 2 ed. São Paulo, Vieira Campos.

DI PIETRO, J.E. (1993) Projeto, execução e produção de lajes com vigotas prémoldadas de concreto. Florianópolis. 99p. Dissertação (Mestrado) - Universidade Federal de Santa Catarina.

FRANCA, A.B.M.; FUSCO, P.B (1997). As lajes nervuradas na moderna construção de edifícios. São Paulo, AFALA/ABRAPEX.

HANAI, J.B. (2001). Fundamentos do concreto protendido. São Carlos, Notas de aula.

LIMA, J.C.O. (1993). Sistema treliçado global. 4.ed. Campinas, Mediterrânea. (Boletim técnico).

MENDES, J.A. (1993). Cálculo Automático de perdas progressivas em peças de concreto protendido. São Carlos. 196p. Tese (Doutorado) - Escola de Engenharia de São Carlos, Universidade de São Paulo.

MERLIN, A.J. (1999) Lajes pré-moldadas de concreto: a consideração da plastificação nos valores dos momentos negativos em elementos hiperestáticos e 
seus efeitos no dimensionamento do pavimento. Trabalho de iniciação científica. Universidade Federal de São Carlos.

OESTERLE, R.G.; GLIKIN, J.D.; LARSON, S.C. (1989). Design of precast prestressed bridge girders made continuous. National Cooperative Highway Research Program, TRD, n. 322, novembro.

SOUZA, V.C.M, et al. (1983) Lajes em concreto armado e protendido. Niterói, EDDUFF. Universidade Federal Fluminense Niterói.

TAN, K.H.; ZHENG, L.X.; PARAMASIVAM, P. (1996). Designing hollow-core slabs for continuity. PCI Journal, v.41, n.1, p.82-91, janeiro, fevereiro. 